\title{
SEX AND BORDERS: \\ GENDER, NATIONAL IDENTITY AND PROSTITUTION POLICY IN THAILAND
}

\section{LESLIE ANN JEFFREY}

A thesis submitted to the Faculty of Graduate Studies in partial fulfilment of the requirements for the degree of Doctor of Philosophy.

Graduate Programme in Political Science

York University

North York, Ontario

May 1999 
National Library

of Canada

Acquisitions and Bibliographic Services

395 Wellington Street Ottawa ON K1A ON4 Canada
Bibliothèque nationale du Canada

Acquisitions et services bibliographiques

395, rue Wellington Ottawa ON KIA ON4 Canada
The author has granted a nonexclusive licence allowing the National Library of Canada to reproduce, loan, distribute or sell copies of this thesis in microform, paper or electronic formats.

The author retains ownership of the copyright in this thesis. Neither the thesis nor substantial extracts from it may be printed or otherwise reproduced without the author's permission.
L'auteur a accordé une licence non exclusive permettant à la Bibliothèque nationale du Canada de reproduire, prêter, distribuer ou vendre des copies de cette thèse sous la forme de microfiche/film, de reproduction sur papier ou sur format électronique.

L'auteur conserve la propriété du droit d'auteur qui protège cette thèse. $\mathrm{Ni}$ la thèse ni des extraits substantiels de celle-ci ne doivent être imprimés ou autrement reproduits sans son autorisation. 
Sex and Borders: Gender, National Identity and Prostitution Policy in Thailand

by

Leslie Ann Jeffrey

a dissertation submitted to the Faculty of Graduate Studies of York University in partial fulfillment of the requirements for the degree of

\section{DOCTOA OF PHILOSOPHY}

(c)

Permission has been granted to the LIBRARY OF YORK UNIVERSITY to lend or sell copies of this dissertation, to the NATIONAL LIBRARY OF CANADA to microfilm this dissertation and to lend or sell copies of the film, and to UNIVERSITY MICROFILMS to publish an abstract of this dissertation. The author reserves other publication rights, and neither the dissertation nor extensive extracts from it may be printed or otherwise reproduced without the author's written permission. 


\section{Abstract}

This dissertation examines prostitution policy in Thailand as a product of debates over gender and national identity in the context of Western global hegemony. It moves beyond studies of prostitution policy as a product of state capitalism and patriarchy to examine how the 'prostitution problem' is conceptualized. It argues that because of the importance of the female body to the production and maintenance of national identity, prostitution policy - as a disciplinary mechanism over female sexual behaviour - is a fundamental site of the creation and policing of national identity. The thesis traces the development of prostitution policy and the construction of 'The Prostitute' in different historical periods in relation to the changing concepts of gender and national identity.

The dissertation begins with a discussion of the importance of gender and perceived sexual behaviour in the establishment of the identities of 'civilized' and 'uncivilized' nations during the semi-colonial period in Thailand and how this in turn influenced the gradual criminalization of prostitution as a way of demonstrating adherence to the 'international standards of civilization' and Thailand's identity as a 'civilized nation'. It next examines the shift from elite defined notions of nation identity to middle-class imaginings that rested on the notion of the peasant as symbolic of 'true Thai identity.' The growing involvement of peasant women in prostitution beginning in the 1960s with the arrival of American air-force personnel was, therefore, interpreted as symbolic of the decline of national culture and the need for elite guidance over peasant women's behaviour. Finally it examines how elite women were able to use their roles as 
defenders of national identity to legitimize criticism and discipline of male sexual and familial behaviour in the 1990 s but at the price of intensified pressure for women, particularly prostitute women, to be disciplined into 'correct cultural behaviour' rather than recognizing prostitute women's own demands as workers and political agents in their own right. 


\section{Acknowledgments}

First and foremost I would like to thank the many people who took the time to be interviewed for this thesis and provided information and guidance while I conducted field work in Thailand. For funding and support I would like to thank the Government of the Netherlands, York University Faculty of Graduate Studies, the Canada-ASEAN Centre, the Joint-Centre for Asia Pacific Studies, the Institute for International and Strategic Studies at Chulalongkorn University, the Atlantic Human Rights Centre, and the University of New Brunswick - Saint John. Many thanks go to my committee - Sandra Whitworth, Penny van Esterik and Shannon Bell - for guidance and encouragement. Finally, of course, thanks to friends and family who supported me during the writing of this thesis particularly Greg Cook, Elizabeth Philipose, Feng Xu, Yumiko lida, Mary Young and Joanna Everitt (for holding UNBSJ Political Science together while I completed the dissertation).

Interviewees and helpful people: Dr. Supang Chantavanich, Dr. Kritaya Archavanitkul,

Dr. Suteera Thomson, Christine Beddoe (ECPAT), Wanee B. Thitiprasert (FOW), Jenny Visessiri, Dr. Chalermsook Boonthai (NCWT), Jasmine Caye (CPCR), Mary Packard Winkler, Suchit Tripitak (NCWA), Khunying Chandhanee Santaputra, Therese Caouette, Sanitsuda Ekachai, Dr. Saisuree Chutikul, Sriwatana Chulajata (NCWA), Thanphuying Dittikarn Bahkdi, Sukanya Hantrakul, Siriporn Skrobanek, Khunying Kanitta Wicharoen, Dr. Darunee Tantiwiramanond, Suphalak Booranin, Dr. Pasuk Pongpaichit, Khunying 
Ambhorn Meesook, Chantawipa Apisook (EMPOWER), Rangsima Limpisawas(FFW),

Dr. Napat Sirisambhand, Dr. Prathumpoon, Dr. Amara Phongsaiphit, Ranee

Hassarungsee (FOW), Beth Greeney (EMPOWER) 


\section{Table of Contents}

Introduction

$\begin{array}{ll}\text { Gender and the Nation } & 7\end{array}$

The Prostitution Debate 13

Feminism, Post-colonialism and Prostitution 22

$\begin{array}{ll}\text { A Note on Method and Terms } & 28\end{array}$

$\begin{array}{ll}\text { Chapter Outlines } & 33\end{array}$

Chapter 1: Theories of Politics and the Politics of Theory:

Theorizing Prostitution Policy 38

The State of Thai Studies 43

$\begin{array}{ll}\text { Prostitution in Thailand } & 48\end{array}$

International Relations, Culture and National Identity 62

The Construction of National Identity $\quad 68$

Gender, Sexuality and National Identity $\quad 74$

Political Agency, Gender and National Identity $\quad 81$

Chapter 2: Chapter 2: 1850-1960: Imperialism, Gender and Sexuality 86

Sex, Gender and the Boundaries of the Early Modern Siamese State $\quad 87$

Imperial Desire: Gender and the Iconography of Rule 97

The Imperial Presence in Siam and the Critique of Polygamy 104 
The White Slave Trade and the Internationalizing of the Imperial Gender Order

Conclusion

Chapter 3: The Criminalization of Prostitution

Post-Revolutionary Prostitution Law, 1932-1966

Phibun and the New (Inter)Nationalism

Prostitution Policy in an International Era

Thailand under Sarit

Conclusion

Chapter 4: Peasants, Prostitutes and Thai National Identity, 1960-1980

Politics in the 1960 s and 1970 s

The Growth of the Prostitution Industry

Rural Resistance

Students, Elites and the Threat of Cultural Decline

University Women's Groups

Conclusion

Chapter 5: Elite Women and the Reconstruction of Thai Identity

Crackdown and Reconstruction: Re-configuring Thai Identity

Elite women and National Identity

Prostitution and the Elite 
The Progressive Elite and Premocracy 265

$\begin{array}{ll}\text { Conclusion } & 276\end{array}$

Chapter 6: The New Non-governmental Movement and the

Prostitution Question, Prostitution Law under Premocracy 277

$\begin{array}{ll}\text { Premocracy, Politics and Growth } & 278\end{array}$

The Prostitution-tourism Industry 283

New Women's Organizations and the Sex-exploitation of Women 288

$\begin{array}{ll}\text { Official Response } & 304\end{array}$

$\begin{array}{ll}\text { Conclusion } & 315\end{array}$

Chapter 7: Prostitution and the New Man,

Prostitution Policy in the 1990s $\quad 317$

Prostitution and the 'Image Problem' 319

The New Middle Class, Government Capacity and Local Notables

International Image and the New Man 336

Prostitution Policy in the 1990s: Disciplining Men 345

$\begin{array}{ll}\text { Conclusion } & 361\end{array}$

Chapter 8: The Middle-class and the Material Girl 362

Peasant Parents and the 1996 Bill 363

The Continued Criminalization of Prostitution 372

NGOs and Prostitution in the 1990s:

Towards a Politics of Work 
The Middle Class and the Material Girl

The Growth of the Middle Class

Conclusion

Chapter 9: Conclusion

The International and the National: Global Politics of Representation

Sex and Borders: Gender and the Nation 


\section{List of Tables}

Table I: Prostitution Policy, $1909-1928 \quad 132$

$\begin{array}{ll}\text { Table II: Prostitution Policy 1932-1966 } & 179\end{array}$ 


\section{Introduction}

There is no such thing as The Prostitute; there are only competing versions of prostitution. The Prostitute is an invention of policy-makers, researchers, moral crusaders, and political activists.... The Prostitute functions as a 'magic sign' whose meaning always exceeds its definition.

Wendy Chapkis, Live Sex Acts, 211.

'The Prostitute' has made frequent appearances on the world stage over the course of the last century and a half. International discussions of the 'sexual degeneracy' of 'uncivilized' nations, for example, or the 'economic backwardness' of the 'underdeveloped world', or the world-wide oppression of women under patriarchy, have drawn on the symbolic force of The Prostitute. It is these discussions that have drawn my attention to the discursive construction of prostitution as part of the international politics of representation. In particular, it has been the raised voices of women from non-Western ${ }^{1}$ nations asking for attention to be paid to the ways in which non-Western women are represented - not merely as an issue of 'image', but as a fundamental issue of power. Underlying international discussions of the 'prostitution problem' is a plea for an understanding of how important Western discursive dominance is in shaping politics in non-Western countries. Prostitution is a particularly sensitive area of discussion in this regard, because of the way gender and sexuality have been invoked in both imperialist and nationalist constructions of cultural

\footnotetext{
' The terms 'Western' and 'non-Western' are, like the terms 'First World' and 'Third World', problematic in their seeming characterization of overlapping and complex realities in different parts of the world as monolithic and mutually exclusive. I use the terms here as a shorthand for global relations of power that have, since the age of imperialism, typically involved the predominance of Euro-American countries (in all their complexities) and of a Euro-centric point-of-view.
} 
identities. In this thesis I examine prostitution policy in Thailand as the product of debates over gender and national identity in a context of Western hegemony.

Prostitution in Thailand has garnered international attention over the past two decades with the seeming explosion of sex-related industries in that country after the Vietnam war. The sex-tourism industry has most recently been eclipsed in the international spotlight by the growing awareness of the numbers of women (from Thailand as well as other poor countries) working in the prostitution industries of Europe, North America and Japan. Pundits point to the 'Asian cultural tradition' of dutiful daughters to explain the phenomenon, rarely questioning either the developed world's own complicity in the political economy of the region or Western men's demand for cheap, exotic sexual pleasure. Prostitute women appear either as 'innocent victims' of a cruel cultural tradition or heartless 'gold-diggers' - in a repetition of the West's cultural stereotypes of prostitute women. These representations of Thai women and Thai culture have raised numerous protestations from both the Thai government and Thai citizens who recognize in these characterizations the familiar strains of cultural imperialism - the differentiation and hierarchization of cultures that enables political and economic dominance - portraying Thailand as 'backward', 'debauched' and 'primitive', and incapable of Western 'civilization'.

Similarly, there have been numerous studies of prostitution in Thailand in recent years. Most have emphasized the interests of the Thai state and capitalist class in maintaining prostitution, particularly tourism-oriented prostitution, as a profitable enterprise for men and for capital. Alternatively, prostitution has been viewed as the product of an unchanging 
culture based on Buddhism, which relegates women to a secondary status. Women, according to Buddhism, lack merit and are a source of pollution, even as they are deemed responsible for the maintenance of the family. On the whole, these studies view the Thai state and culture as unchanging entities and the interests of capital as unchallenged. Such studies fail to capture the changes and challenges to prostitution policy, and gender relations generally, over the years. The result has been a growing resentment in Thailand of the failure of - particularly foreign - academics and media to portray "what we're doing about it." 2 The complaint echoes post-colonial critiques of the portrayals of the 'third world' as inert and unchanging (without an infusion of Western impetus) and as less developed and less capable than Western states. Chandra Mohanty's classic study "Under Western Eyes” has clearly outlined the ways in which Western studies of third world women tend to essentialize third world women in a way that deprives them of agency in the eyes of the West, and reasserts Western 'superiority'.

This debate leads us to recognize the fundamental importance of representation as part of the international power struggle between what are tellingly called 'First' and 'Third' worlds. Three of the most important lessons that I learned in carrying out field research for this project were learn, listen and link - that it is the responsibility of Western researchers to

2 This point was emphasized to me over and over again in interviews with both government and non-government representatives in Thailand in 1996.

${ }^{3}$ See Chandra Mohanty, "Under Western Eyes: Feminist Scholarship and Colonial Discourses," Third World Women and the Politics of Feminism, eds., Chandra Mohanty, Ann Russo, Lourdes Torres (Bloomington: Indiana University Press, 1991). 
learn about issues that are of concern to those outside the West, that we need to learn about them by listening to non-Western voices and finally, that if we do these two things we will have to always make the link from problems in specific countries to the wider, global environment in which they occur. After spending six months in Thailand listening to the voices of those who were organizing, or speaking out, on the issue of prostitution, it became apparent that the link to Western power that had been ignored in analyses of Thai prostitution was the issue of Western discursive power in representing the Third World. It was also clear that this power was very salient in the daily politics of countries such as Thailand. How Thailand was represented on the world stage was an issue of everyday discussion that played out in national politics, particularly around the issue of prostitution, influencing the reformulation of gender and national identity. This realization led me to look at the debates around prostitution policy as a forum for the construction of national identity in the face of Western cultural imperialism.

This thesis addresses the issue of prostitution in Thailand not as a study of the whys and hows of the prostitution industry that has made Thailand (in)famous as 'the world's biggest brothel' but as a study of the political discussion of and response to prostitution as a window onto the linkage between gender and national identity. That is, rather than looking at how economics, gender relations or culture have contributed to the growth in prostitution over the years, I look at how the prostitution problem is conceptualized and how that conception is linked to notions of gender and national identity in a globalized world. In this 
way I seek to understand how prostitution policy has been shaped over the years by concerns to construct and maintain national identity.

I explore how the debate over prostitution policy in Thailand is a debate over women's bodies as markers of national boundaries to be controlled by the state. In today's Thailand, the debate over prostitution is a struggle over modernity and tradition, over masculinity and femininity, over the role of the state and the identity of the nation. In this era of globalization, as in the era of imperialism, states have responded with both resistance and acquiescence to global pressures and influences. These global pressures have not simply been economic or military but also discursive. In order to understand policy making in so-called third world countries we need to recognize the important place of the international politics of representation, of Western representational power and of resistance to it, in non-Western countries. Prostitution policy, as the site of the creation of gender and sexual identities, which undergird national identity, is shaped by the concern to respond to Western representational power. Today, for instance, prostitution policy is guided by the desire of the Thai middleclass for Thailand to be both a modern state as represented by the masculinity of the men that govern it - on par with the Western world - and a traditional nation - a distinct national identity as represented by Thai women. That is, prostitution policy seeks to discipline women, to regulate women's bodies, into their 'correct' cultural roles as, for example, mothers to the nation. In the particular history of the formation of Thai national identity, prostitute women have come to be interpreted as unable to control their own futures. In the discourse of the Thai middle-class, prostitute women are icons of the decline of tradition and 
the (negative) result of a rush to modernity without the proper guidance of the elite. In this way prostitutes' own voices and demands have been drowned out in the modern Thai polity and they have become the objects of policy rather than the subjects of politics.

In this thesis I argue first for a social constructionist approach to prostitution. By viewing The Prostitute, as well as gender and culture, as constructed categories, we begin to open up the possibilities of agency - of resistance and challenge. In this way we also begin to understand the ways those possibilities are made invisible by particular discursive renderings of identities. That is, rather than assuming that prostitute women are silent, or victims, or greedy consumers we must assume that there is nothing essential about them at all, and that the identities and modifiers given to them are, in fact, constructions imposed through power. Second, I argue that in order to understand how The Prostitute is constructed we need to examine the "universe of political discourse" in Thailand that produces The Prostitute. I view that universe as an arena of 'sense making' in which various discourses are taken up by political actors that contend for hegemonic appeal. Third, I argue that in Thailand that universe is fundamentally shaped by the struggle between international/Western representations and Thailand's self-construction of national identity. And, fourth, because of the links between constructions of national identity, gender identity and sexual behaviour, I argue that constructions of 'The Prostitute and, by extension, prostitution policy, are fundamentally shaped by these discourses over national and gender identity.

Thus, I examine prostitution policy as a discursive terrain, one in which gender and national identities are produced and regulated. I argue that prostitution policy in Thailand is 
fundamentally shaped by concerns over gender and national identity. That is, I look at culture as continually constructed through operations of power rather than a given. In particular, I look at that aspect of culture which is national identity as being constructed in contention with imperialist representations of other cultures. Similarly, Ilook at gender as a construction imposed on the fluctuating realities of sexed bodies - a construction that is interdependent with that of national identity. That is, constructions of gender have been central mechanisms of constructing national and imperialist identities. The Prostitute, therefore, is a particular form of gender construction - a category with no inherent meaning but with a great deal of discursive power in the modern world because it is the dividing line between good and proper - that is, acceptable - women, and bad, unacceptable women.

\section{Gender and the Nation}

The construction and maintenance of borders is a complicated business. 'Borders' must be mapped not simply on geographic terrain but in the minds and on the bodies of the inhabitants of that geography. Without this deeper inscription, a line on a map is meaningless. 'Nations', therefore, rest on the construction of national identities. The regulation of women's bodies, in particular, is an integral part of inscribing national/ethnic identities because of women's reproductive role. As both the literal and figurative reproducers of the race (through biological reproduction and cultural reproduction), women and the control of their sexuality are key to the national(ist) project. The image of the prostitute, for instance, works to regulate women's sexual activity by confining women's 
proper sexual role to reproduction. Women who 'squander' their sexuality (i.e. by engaging in sexual relations outside the confines of marriage or by engaging in sexual relations with more than one man) cannot be mothers to the nation. Such women, 'whores', are duly confined to the margins of society as both punishment and warning. The construction of national identity, therefore, is closely linked to the construction of gender identity and the regulation of sexual behaviour.

Prostitution is a particularly rich ground for the investigation of the linkages between gender and national identity because of the centrality of women's sexuality in establishing and maintaining these identities. The classification of prostitution involves a process of identifying correct and incorrect sexual behaviour on the part of women, and of distinguishing between good and bad women. Women's correct sexual behaviour - usually within the bonds of marriage and family - grounds the categories of gender (what men and women should be and do). It simultaneously undergirds the categories of class (which men and women properly understand and apply these categories) and national identity (which women are the mothers to our nation - the ones that populate the motherland that the manly state seeks to protect). Women's stepping outside the boundaries of proper sexual behaviour destabilizes these very categories. The invocation of prostitution (understood to be a shameful and unacceptable sexual behaviour) serves to discipline women's behaviour into accepted modes and, therefore, to stabilize these other categories. In this understanding, I look at gender as a social relation of power, as a process of imposing certain hierarchical identities of masculine or feminine that are then read as natural and unchanging. Gender, 
rather than a pre-given identity emanating from sexed bodies, is constructed through operations of power. The construction of gender carries particular power because its constructedness (and therefore the operation of power) is so easily hidden in the apparently natural division between male and female bodies.

National identity is a similarly constructed category, invoked to unite certain peoples against an outside 'other' and to legitimize state authority over a particular territory. Feminist theorists of nationalism have pointed out that the nation is fundamentally gendered. Women stand in different relation to the nation than men. Some theorists of nationalism and gender, like Kumari Jayawardena, argue that moves to establish a sovereign nation - as opposed to clans or kin groups - also open space for women's citizenship rights by dissolving old kin based loyalties. ${ }^{4}$ Others point out, however, that the control of women and women's sexuality remains central to ideas of national identity. Floya Anthias' and Nira Yuval-Davis' now classic study, Woman-Nation-State, outlines five ways in which women have tended to:

participate in ethnic and national processes and in relation to state practices: as biological reproducers of members of ethnic collectivities; as reproducers of the boundaries of ethnic/national groups; as participating centrally in the ideological reproduction of the collectivity and as transmitters of its culture; as signifiers of ethnic/national differences - as a focus and symbol in ideological discourses used in the construction, reproduction and transformation of

\footnotetext{
${ }^{4}$ Kumari Jayawardena, Feminism and Nationalism in the Third World (London: Zed, 1986).
} 
ethnic/national categories; as participants in national, economic, political and military struggles. ${ }^{5}$

It is women's symbolic role that is most central to my discussion here, since it is women's symbolic role as mothers and biological and cultural reproducers that are central to discourses of national identity. The material effect of these roles is the control of women's sexuality as central to maintaining national identity. This centrality leads to an "intense preoccupation with women's appropriate sexual conduct," which "often constitutes the crucial distinction between the nation and its 'others'."6 Women's sexuality, therefore, can mark the very borders of the nation-state - its purity, the purity of the nation; its defilement, the defilement of the nation. The prostitute, therefore, appears as a liminal figure in relation to the mother, as she marks the borderlands of female sexuality. She is the internal 'other' that threatens the purity of the nation. The rise of the prostitute, in this formulation, signals the loss of control over female sexuality and, therefore, is a harbinger of the disintegration of national culture and identity. Most threatening of all, the prostitute - seen as one who uses her own sexuality for profit - is a subversive figure. While all women's sexuality can be viewed as at risk of 'foreign invasion' - the prostitute appears to seek out such an invasion. She is a potential fifth column within the nation anchored by female purity. (Indeed, that the

${ }^{5}$ Floya Anthias and Nira Yuval-Davis, Woman-Nation-State (New York: St. Martin's Press, 1989) 7.

${ }^{6}$ Deniz Kandiyoti, "Identity and its Discontents: Women and the Nation," in Patrick Williams and Laura Chrisman, eds., Colonial Discourse and Post-Colonial Theory: A Reader (New York: Columbia UP, 1994) 377. 
prostitute figures regularly as a 'spy' in various literatures and histories comes as no surprise here.) Other accounts of prostitution as sexual labour, or as the operation of male sexual privilege, must always vie with this powerful symbolism of the prostitute. At most, these accounts may argue for a more sympathetic understanding of the prostitute as a victim of larger forces (a symbolic rape victim). In the context of concern over defending and maintaining national identity (as in this period of globalization), however, the perpetrators will appear as foreign (foreign militaries, rapid modernization/Westernization).

As symbols, prostitute and non-prostitute women, are denied national agency. Anne McClintock has argued that women's symbolic relation to the nation denies them active citizenship: "excluded from direct action as national citizens, women are subsumed symbolically into the national body politics as its boundary and metaphoric limit: 'Singapore girl, you're a great way to fly'. Women are typically construed as the symbolic bearer of the nation, but are denied any direct relation to national agency." Indeed, the centrality of the symbol of women has rarely translated into full citizenship, although some women have been able to trade on their cultural role in order to gain social power. As with women more generally, therefore, the agency of the prostitute is always problematic. Seen as an agent, she is an accomplice in the destruction of national identity. Seen as a victim, she is sympathetic but also powerless. These portrayals encourage patronizing and stifling reactions.

${ }^{7}$ Anne McClintock, "Family Feuds: Gender, Nationalism and the Family," Feminist Review 44 (Summer 1993): 62. 
With the rise of Western colonialism this symbolic national discourse was internationalized. The regulation of racial/sexual boundaries was central to the colonial project. Women's bodies were again important 'boundary markers' in this process. The colonial community was consolidated through the call to protect white womanhood (pure, virtuous and 'civilizing') from the colonial 'other' figured as a sexual threat. Colonized women came to be read as sexually voracious (i.e. prostitutes), or as unwilling victims of oversexed local males, which required the intervention of the colonial power in order to 'rescue' them. White prostitute women, meantime, were re-presented as victims of an international ring of white slave traders. It was this process that underlay early international intervention in the field of prostitution - through international conventions on the white slave trade at the turn of the 20th century. In this way a particular discourse of gender was internationalized.

The designation of bad girls and good girls, of proper gender identity and sexual behaviour, therefore, has long been a part of international politics. ${ }^{8}$ It is a process which deserves closer investigation because it helps to shed light on modern day problems such as the sex-trade in Thailand. In the present day debate over the sex-trade in Thailand, the prostitute's constructed status is often forgotten. A full understanding of the current situation requires that we recognize that prostitution is a symbolic terrain deeply embedded in gender and national constructions at precisely the point where the two identities intersect. How such

${ }^{8}$ See also, for example, Cynthia Weber, Faking It: US Hegemony in a Post-phallic Era ( Minnesota: University of Minnesota Press, 1999). 
constructions have worked to shape our understandings of the modern-day sex-industry in Thailand is an important matter of investigation. Certainly, popular representations of Thailand as the 'brothel of Asia' owe much to colonial practices of characterizing the 'other' as feminine, debauched and primitive.

\section{The Prostitution Debate}

The constructed nature of the category prostitute or prostitution has been made clear in feminist debates over prostitution as well as in the history of the term itself. Prostitution is a highly elastic category. For this reason, debates among social scientists about what actually constitutes prostitution continue. Even the vague definition of prostitution as "the exchange of sexual services for material gain" is easily challenged, for instance, when actresses in 17th century England were considered whores; or when courts in Toronto in 1998 are preoccupied by the question of whether "spanking is sex" when a dominatrix is charged with keeping a bawdy house. Similarly, in studying Thailand, Eric Cohen questions whether women who act as girlfriends to tourists during their stay in return for 'gifts' can be included under the rubric of prostitution; others problematize the categorization of 'hired wives' during the Vietnam war. ${ }^{9}$ In most countries the definitional niceties (or lack thereof) are left to the police who use their 'common sense' to determine who is or is not a prostitute. They also decide at what particular moment and in what particular place a woman becomes

${ }^{9}$ See Eric Cohen, "Thai Girls and Farang Men: The Edge of Ambiguity," Annals of Tourism Research 9 (1982): 403-428. 
a prostitute. The very flexibility of the category prostitution should alert us to the tenuousness of the link between 'reality' and 'representation'. Indeed, the feminist attempt to challenge masculinist representations of prostitution (as, for example, functional to male sexual needs) by presenting a 'truth' founded on women's experience of prostitution (as, most importantly, exploitation) foundered in their inability to uncover a common experience. Prostitutes' rights activists have argued that prostitution is 'just another job', while others, including former prostitutes, have organized against prostitution as a 'degrading and dehumanizing' experience.

At the theoretical level, the difficulties of radical feminist readings of prostitution came from their essentialist understanding of 'woman'. In the 1970s, radical feminists sought to uncover the 'truth' of prostitution. Kathleen Barry's work on "female sexual slavery" dismissed the notion of women's agency or choice in prostitution. She focussed instead on prostitution solely as sexual oppression and slavery. Barry argued that women were duped and forced into prostitution in order to serve men's sexual drive. In her 1995 book, after nearly 20 years of organizing and researching on prostitution and "female sexual slavery", she explains how, before she undertook this research, she "did not fully grasp how utterly without value female life is under male domination. Women as expendables. Women as throwaways. Prostitution - the cornerstone of all sexual exploitation."10 For Barry, prostitution is clearly a product of women's status as objects of male sexual power. Thus,

${ }^{10}$ Kathleen Barry, The Prostitution of Sexuality: The Global Exploitation of Women (New York: New York UP, 1995) 9. 
along with Catharine MacKinnon, Barry views sexual exploitation as the basis of women's subordination, which is epitomized in prostitution. Barry views power in simple one-sided terms - men have it, women do not - and sex is the basis of that power. Indeed, if sex is nothing but male domination and exploitation of women then prostitution, by definition, is also exploitation.

Barry's analysis is subject to all the usual critiques of radical feminism. Its singular notion of power precludes any possibility of change. As Thanh-dam Truong points out, while criticizing the functionalism of sociobiological approaches to prostitution, analyses like Barry's merely substitute "functional for male biology" with "functional for male social power." "Like any functional analysis, the focus is on system maintenance and reproduction rather than possibilities for change.

In Barry's analysis it appears that only women who do not engage in prostitution have any social power. Prostitute women are by definition powerless. In her later book it seems that all women who engage in heterosexual sex are by definition exploited because sex itself is a "violation of women, whether or not there is consent, as there is usually presumed to be in prostitution." 12 Male sexual power is total and all-encompassing. The line between sex, sexual exploitation and sexual abuse is erased in Barry's account, which dismisses feminists

\footnotetext{
"Thanh-dam Truong, Sex, Money and Morality: Prostitution and Tourism in South-East Asia (London: Zed, 1990) 46.

12 Barry, 278.
} 
who defend prostitution and/or pornography as victims of childhood sexual abuse. ${ }^{13}$ With MacKinnon, Barry accepts the ideology of male power as reality. As Joan Cocks argues, this understanding of sex as power/domination collapses the two into one as if there can be no sex without domination. ${ }^{14}$

Further still, the analysis both essentializes and universalizes male and female natures (men as sex-monsters; women as victims). In doing so, Barry repeats the very representation of women that she argues underlies male domination. As Shannon Bell has pointed out, in radical feminist analyses of prostitution, "Woman is nothing but a prostitute, and the prostitute is nothing but a hole, a passive object of the omnipotent phallus." ${ }^{15}$ Women are everywhere and always victims; the system of patriarchy, therefore, is unchanging and unchangeable.

The implications of this approach were felt in the practical politics of feminist organizing. While radical feminists argued that heterosexual sex was universally oppressive to women and that women were universally victimized by the male sex drive, women working in the sex-trade, in contrast, argued against these assumptions, by emphasizing

${ }^{13}$ Barry, 279.

${ }^{14}$ Joan Cocks, The Oppositional Imagination: Feminism, Critique and Political Theory (London: Routledge, 1989) 158.

${ }^{15}$ Shannon Bell, Reading. Writing and Rewriting the Prostitute Body (Bloomington: Indiana UP, 1994) 86. 
women's choice and control in the sexual transaction within prostitution. ${ }^{16} \mathrm{~A}$ singular and generalizable experience of prostitution was not to be found as both sides produced spokeswomen of the 'actual' experience of prostitution in the debate over responses to prostitution. The organization of Whores' Congresses in the 1980s - to argue for women's right to choose prostitution as a legitimate career - rejected the anti-sexual exploitation (and anti-sex) campaigns of Kathleen Barry, Catharine MacKinnon and Andrea Dworkin. Prostitute advocates argued instead that it was the attitude held towards sex-workers both by society and in the law - the "Whore Stigma"- that resulted in the violence and abuse often suffered by women in prostitution, rather than anything inherent about prostitution itself. ${ }^{17}$ The high-handedness of Barry's and others' dismissal of those who viewed prostitution differently - particularly prostitute women themselves - created a critical dilemma for a feminist movement dedicated to the 'truth of experience'. This dilemma continues to confront women organizing on the prostitution question today, as various factions push for new international legislation to address prostitution. While Barry campaigns for a law that would see prostitution defined as exploitation, others (including some prostitute advocates and feminists from Thailand) argue that only instances of force and abuse in prostitution should be criminally sanctioned.

${ }^{16}$ See Wendy Chapkis, Live Sex Acts (New York, Routledge, 1997) Chapter 1, for a discussion of the variations in the radical feminist position between anti-sex and pro-positive sex feminists.

${ }^{17}$ See Gail Pheterson's discussion of the "Whore Stigma" in Gail Pheterson, ed. $\underline{A}$ Vindication of the Rights of Whores (Seattle: Seal Press, 1989). 
In this thesis I consider there to be neither any singular or generalizable experience of prostitution nor any singular 'prostitute'. Rather I view 'the prostitute' as a subjectposition constructed in discourse and imposed on a shifting reality. I consider it important to approach the issue from this angle in order to address prostitute women's own concerns. In using this approach I draw on the work of social constructionist feminists who question the standpoint epistemology of some strains of feminism. The recovery of women's history, women's experience and women's point-of-view, seen as the central project of early feminist theorizing, has been fundamentally challenged by the different experiences of, for example, women of colour, lesbian women and prostitute women. Certainly, the life stories of women in prostitution in Thailand indicate that their experiences of selling sex vary widely among different women, as well as for individual women across time (for instance, their experience of entry into prostitution, and their experience as a seasoned sex-worker). ${ }^{18}$ This is not to say that there is no lived experience, no actual feelings of pain or pleasure, but that to mistake experience for analysis and as a foundation of theory is problematic. As Joan Scott argues:

When experience is taken as the origin of knowledge, the vision of the individual subject... becomes the bedrock of evidence upon which explanation is built. Questions about the constructed nature of experience, about how subjects are constituted as different in the first place, about how one's

${ }^{18}$ See, inter alia, the interviews with prostitute women in Dave Walker and Richard S. Ehrlich, "Hello My Big Big Honey": Love Letters to Bangkok Bar Girls and Their Revealing Interviews (Bangkok: Dragon Dance Publications, 1992); Sukanya Hantrakul, "The Spirit of a Fighter: Women and Prostitution in Thailand," Manushi. 18 (Oct-Nov. 1983); Pasuk Phongpaichit, From Peasant Girls to Bangkok Masseuses (Geneva: International Labour Office, 1982). 
vision is structured - about language (or discourse) and history - are left aside. The evidence of experience then becomes evidence for the fact of difference, rather than a way of exploring how difference is established, how it operates, how and in what ways it constitutes subjects who see and act in the world. ${ }^{19}$

That is, expanding the category woman or prostitute to women or prostitutes who have different experiences of the world around them based, for instance, on their race or class or sexuality, is not sufficient to interrogate the operation of power. Rather, such a move merely affirms and revalues the differences among these groups. For post-structural theorists, simply uncovering the experiences of women or prostitutes repeats the assumption that there is indeed a group of people who are different from an assumed norm (whether 'men' or 'good women'). Such an assumption precludes that the fact these are very complex and complicated individual human beings, who are categorized in a particular way by discourses of power in order to impose controls and discipline and to establish positions of power.

Post-structural feminist theorists critique the notion of the stable subject woman/ women as a modernist concept of the subject as something given, outside the operation of power and, therefore, outside of politics. For post-structural theorists building on the work of Foucault, the idea of a stable subject is constituted through the very conceptual apparatus that seeks to discover it. Knowledge, for Foucault, is power. That is, to seek to define a subject is to immediately delimit the unlimitable. In the case of gender definition, it is to "tie

\footnotetext{
${ }^{19}$ Joan Scott, “"Experience'," Feminists Theorize the Political, eds. Judith Butler and Joan W. Scott (New York: Routledge, 1992) 25.
} 
an individual to her sex." ${ }^{20}$ Indeed, according to Derrida, the process of definition involves differentiation from a pre-given norm and hence, hierarchy and exclusion. Thus 'woman' is constructed as different from, indeed opposite to, and lesser than 'man'. 'The Prostitute' is the negative opposite of the 'Good Woman as Wife and Mother'. It is for this reason that some theorists argue that to define 'woman' is to invoke the very power mechanism(s) which are responsible for the oppression of the sexed bodies called women.

For post-structuralists, social reality is not pre-given, rather it is constructed through discursive processes. Power, therefore, is productive. To understand and resist power we need to deconstruct it - make the constructive process visible and uncover the ways in which certain sexed bodies are interpolated as women and therefore viewed or treated in particular ways. Thus, as Scott argues further, "making visible the experience of a different group exposes the existence of repressive mechanisms, but not their inner workings or logics. For that we need to attend to the historical processes that, through discourse, position subjects and produce their experiences."2l That is, it is most important not to theorize about the oppression of a pre-constituted group 'women', but to examine the constitution of gender identity through discourses which establish that reality. By looking at gender as a constructed category, rather than a pre-given entity, post-structural theorists are able to recognize the differential construction and meaning of gender categories in different times and places and

\footnotetext{
${ }^{20}$ Denise Riley, "Am I That Name?" Feminism and the Category of "Woman" in History (Minneapolis: University of Minnesota, 1988).

${ }^{21}$ Scott, 25.
} 
among different women. And, instead of searching for an essential core of 'womanhood' that binds us all together (particularly an essential victimhood as Barry would have it), poststructuralist theorists uncover the ways in which female bodies are interpolated as 'women' including, for example, as 'victims' or 'whores'.

Thus, it is the construction of the category 'prostitute' that shapes the lives and experiences of women, by delineating the boundaries of proper and improper female behaviour and seeking to penalize and/or regulate those who fall into the category of improper. The regulatory function of the category prostitute makes the actual content highly variable rather than a simple correspondence between an embodied activity and an abstract label. As Wendy Chapkis has argued:

There is no such thing as The Prostitute; there are only competing versions of prostitution. The Prostitute is an invention of policy-makers, researchers, moral crusaders, and political activists.... The Prostitute functions as a 'magic sign' whose meaning always exceeds its definition. ${ }^{22}$

Again, this is not to say that there are no 'women selling sex', no actual women engaged in the commercial-sex business. Rather it is to argue against any assumption of necessary experience or reality arising from this activity and to focus our attention on the ways in which, to paraphrase Denise Riley, actual women working in the industry are positioned as prostitutes. ${ }^{23}$ Law and policy, I argue throughout this thesis, are determined by, and

\footnotetext{
22 Wendy Chapkis, Live Sex Acts (New York: Routledge, 1997) 211.

${ }^{23}$ Riley, 3.
} 
reproduce, how prostitutes are seen and understood, that is, how they are positioned. Thus, we need to ask how prostitute women in Thailand come to be positioned as 'victims of a foreign invasion' or 'consumers' or 'backward peasants' and what the implications of such positionings are.

\section{Feminism, Post-colonialism and Prostitution}

Having recognized the power of knowledge itself and the discursive construction of woman/women as an operation of power, a further challenge to feminist theorizing about women came from post-colonial feminists who pointed to the essentialist representations of Third World women as imperializing. Western theorists, post-colonialists argued, needed to recognize the power of Western discourses in constructing the 'Third World', as well as 'Third World women', in ways that reproduced and legitimated a hierarchy between 'First' and 'Third' worlds. Indeed, what post-colonial analysts have uncovered is the way in which particular representations - or, more properly, constructions - of 'the other' enabled the operation of political and economic imperialism.

Chandra Mohanty's ground-breaking article, “Under Western Eyes: Feminist Scholarship and Colonial Discourses," has drawn attention to the issue of power and representation in feminist theorizing. Mohanty argues:

Western feminist scholarship cannot avoid the challenge of situating itself and examining its role in [an imperialist] global economic and political framework. To do any less would be to ignore the complex interconnections between 
first and third world economies and the profound effect of this on the lives of women in all countries. ${ }^{24}$

Mohanty points to the global hegemony of Western scholarship and its role in the reproduction of Western political hegemony. Specifically, Mohanty follows the understanding of 'contemporary imperialism' put forward by Anouas Abdel-Malek as a struggle for "control over the orientation, regulation and decision of the process of world development on the basis of the advanced sector's monopoly of scientific knowledge and idea creativity." That is, Western(centric) discourse attempts to delimit the political possibilities for the globe, for example, the correct 'path towards development' or the content of 'modernity'. Western knowledges and ideas, therefore, have a political power which must be "defined and named."25 Naming the power of knowledge, Mohanty stresses, is essential if feminists are to forge international links on women's struggles. Western representations of a singular and monolithic 'Third World Woman' are viewed as imperialistic and imperializing by many women in the Third World. ${ }^{26}$ Third World feminists, therefore, call for a feminism that makes the links between first and third worlds, takes the time to learn

${ }^{24}$ Chandra Mohanty, "Under Western Eyes: Feminist Scholarship and Colonial Discourses," Third World Women and the Politics of Feminism, eds. Chandra Mohanty, Ann Russo, Lourdes Torres (Bloomington: Indiana UP, 1991) 54.

${ }^{25}$ Mohanty, 54. Mohanty here points out that this critique is not simply aimed at "Western feminists" but at anyone who uses the techniques that she criticizes.

${ }^{26}$ Mohanty, $54 \& 63$. See also note 7. 
about the different configurations of gender and power, and experiences thereof in different societies, as well as listens to the voices of those experiencing it.

It is these concerns, therefore, that underlie Third World feminists' challenge to Western feminist representations of the situation of prostitute women in developing countries. First, in the debate over prostitution, feminists from Third World countries have been at pains to emphasize the role of the American military and the global economy in the spread of prostitution. Radical feminists' focus on the operation of sexual power alone was quickly challenged by those feminists, particularly Third World feminists, who felt that the operations of power were not simply based in gender or sexuality. The overwhelming focus on sexual domination erases not only modes of opposition and resistance, but of other forms of power as well. Women from Thailand who were working on the issue of prostitution argued that understanding prostitution required understanding the international operation of the capitalist economy in prostitution. Women were not simply victims of an international patriarchy but also of a capitalist system that positioned them as cheap sexual labour. ${ }^{27}$ Thanh-dam Truong's analysis of the Thai sex industry countered Barry's presentation of the same in terms merely of male sex right by analysing the global capitalist institutions - hotels, airlines, tour operators - that provided the infrastructure, and demand, for the trade. ${ }^{28}$

${ }^{27}$ See, for example, Siriporn Skrobanek, The Transnational Sex-exploitation of Thai Women, Master's research paper, Institute of Social Studies, The Hague, March 1983.

${ }^{28}$ Truong, 46. 
First World feminists' ignoring of issues that are considered important by Third World feminists is a product of the social power of First World analysts. As activists from non-Western countries soon began to point out, Barry's analysis reproduces colonizing representations of Third World women that position them as 'always already victims' and the Third World man as sexually rapacious. These are the kinds of representations that give evidence of the First World's assumption of the right to speak for the Third World and that underwrite the First World's assumed right to act upon the Third World. As Aiwha Ong has argued, "when feminists look overseas, they frequently seek to establish their authority on the backs of non-Western women, determining for them the meanings and goals of their lives." ${ }^{29}$ Barry's silencing of other possibilities of interpretation as 'false consciousness', grants agency and, therefore, power only to herself and those who think similarly. Only these women are able to understand the 'true' meaning of prostitution. Drawing on an epistemology of ascribed standpoint, where only women who have raised their consciousness through feminism are capable of seeing the truth, Barry takes upon herself the task of correct interpretation of reality, and in that repeats the operation of power in First World/ Third World relations, where the First World establishes 'true meaning'.

Indeed, it is this assumption of a shared victimhood of women that makes Thai feminists organizing on the issue of prostitution uneasy - recognizing in Barry's assumptions the essentialized construction of 'The Third World Woman' as 'passive victim' without the

${ }^{29}$ Aihwa Ong, "Colonialism and Modernity: Feminist Re-presentations of Women in Non-Western Societies,” Inscriptions 3.4 (1988) 80. 
modern agency of her First World sisters and, therefore, in need of their aid and direction. Indeed, there is a frightening echo of the very language used by sex-tourists themselves in the representation of Asian women as passive. Siriporn Skrobanek, for one, in her analysis of the "international sex-exploitation of Thai women" has always been careful to point out the efforts of women in the international marriage and prostitution trades to resist modes of power and to act on their own behalf (although not under conditions of their own choosing). ${ }^{30}$ Sukanya Hantrakul, as well, has drawn attention to the "spirit of a fighter" that is in many Thai prostitute women and argued that it is instead the institutions of penal reform that attempt to discipline women into "acceptable behaviour" that are problematic."

Underlying this position, but seldom discussed, is the crucial issue of the representation of 'Thai culture' and 'Thai women'. Feminists from Thailand have been very sensitive to the need to both recognize Thai women's weak position in the global economy and to not present Thai women in prostitution as mere victims of larger processes. Similarly, there has been a sensitivity by both state and non-state Thai representatives to the representations of Thai culture in the international media as the underlying cause of the booming sex-industry. These protestations draw our attention to an under-explored aspect of both international politics and international feminist politics - the politics of representation. This underlying struggle is about the colonizing moves of those who would

\footnotetext{
${ }^{30}$ Siriporn..

${ }^{31}$ Sukanya Hantrakul, "Spirit of a Fighter," Manushi.18 (1983).
} 
assume to speak for 'women of the world', who represent women as victims in much the same way as colonizing powers have always represented the 'other' as victimized, backwards and traditional. It is part of the continued debate at the United Nations over new instruments to address the prostitution trade - as exploitation by definition or as part of the survival strategy of powerful women in limited circumstances. In this sense, the contention over how to approach the prostitution issue at a global level is itself part of the international politics of representation - of the contest over the construction of identities - of the 'West' versus the 'rest', of the colonized and the colonizer.

What these debates make very clear is that the politics of representation, the concern of the essentialized construction of identities, is not merely a theoretical point of interest, rather it is part of the everyday political struggle and the operation of power that has historical consequence. That is, it is a vitally important part of international (and, as we shall see, national) politics and power that has been virtually ignored by political scientists.

These concerns can best be addressed, as I argue in the next chapter through a social constructionist understanding of politics in Thailand - an understanding that takes neither Thai culture or Thai women as given, but one that views that as constructed in historical time and space and through the operation of power. Further, the above debate has brought into stark relief for me the importance of viewing Thai politics in the framework of the international struggle over representation. In particular, I focus on the struggle over national identity in the face of Western imperialism and neo-imperialism and its link to gender 
constructs in order to present a different understanding of prostitution policy as a terrain of contested identity construction.

\section{A Note on Method and Terms}

This dissertation is based on documentary research as well as six months of field work in Thailand, which included interviews with key 'opinion makers' and activists on prostitution issues. As a discussion on the discourses that shape prostitution policy I have necessarily focussed on middle-class and elite voices, which have had the most direct influence on government policy. My conversations with prostitute women were only casual. Although it is indeed prostitute women's voices that need to be heard, this should be accomplished first by creating space for those voices. That is, rather than seeking out a more 'true' voice of prostitution in prostitute women - hoping that it alone would challenge current understandings of prostitution - I have instead concentrated on explaining why it is such a voice has not been heard. The works of Pasuk Phongpaichit, Siriporn Skrobanek, Sukanya Hantrakul, Cleo Odzer, Lenore Manderson and Chris Lyttleton have all uncovered prostitutes' various interpretations of their own lives - particularly as wage earners (Pasuk, Siripom) but also as 'gender renegades' (Sukanya, Manderson, Odzer). These interpretations, however, have been suppressed in hegemonic consuructions of the prostitution problem. Future research that builds on these insights and provides further access to the rich, conflictual voices of prostitute women is important. We need first, however, to understand how hegemonic constructions that erase these self-interpretations come to be dominant. To 
do this, I have focussed in this dissertation on the voices of the elites in Thailand who have been most influential in shaping current understandings of the prostitution problem. It is these voices that show us how prostitution, gender and the nation are viewed by policymakers at both national and international levels.

In addition, my training as a political scientist, rather than an anthropologist, has prepared my best for analysing those who are closest to the centres of power. Gradually, excellent anthropological work that attempts to foreground the voices and selfunderstandings of prostitute women is becoming available. My task, however, was to uncover elite and middle-class constructions of gender, national identity and prostitution in order to understand how particular interpretations come to be imposed and what their implications are.

During my time in Thailand I conducted in-depth interviews with some twenty five key activists, directors of women's organizations, academic researchers, journalists and bureaucrats. Although I had achieved a basic level of (Central) Thai before beginning my research, the interviews were mainly conducted in English with an interpreter present for those interviews where both languages were used. The interviews were open-ended and lasted anywhere between one half hour and two full hours.

Documentary research was conducted at the offices of the main feminist organizations in Thailand, particularly the offices of the Foundation for Women and the Friends of Women, as well as several excellent research libraries in Bangkok and Chiang Mai. Those included the Siam Society, the Thailand Information Centre, the Women's 
Studies Centre at Chiang Mai University, the United Nations offices in Bangkok and the various libraries of Chulalongkorn University. Some original and reprinted historical documents were used for the historical sections of the dissertation, particularly some of the travel journals of Western diplomats in 1800 s Siam. I also closely tracked opinion and events through the two English-language papers in Thailand, The Nation and The Bangkok Post, from July 1996 through to July 1997 . While the language of publication necessarily limited what insights I could gather, my purpose again was not to uncover 'Thai opinion' but to trace the representation of 'Thai identity' to the West. Additionally, these two papers are recognized as key mediums of educated, 'Westernized' middle-class and elite opinion making and therefore, provided me with insights into how these classes in particular sought to represent and construct themselves and others.

Further to the issue of language, throughout the dissertation I have relied on the Thai transcription system of the Royal Institute, based on phonetic transcription without tonal marks, except where common usage or the source being quoted dictated otherwise. I use Siam for Thailand before 1939 and Thailand after that date (despite the more complicated history and politics surrounding the change in name). For Thai names I have tried to follow the transcription used by the persons themselves or traditional transcriptions for historical personages. In line with Thai usage, Thai people are referred to throughout by their given names, rather than their surnames, and entered in the bibliography according to given names. Titles are used where required, particularly where they are important to denote class status. The terms "M.R." (maum ratchawong) and "M.L." (maum luang) for minor royalty and 
“Thanphuying/Khunying" for grades of 'ladyship' granted by the king appear throughout [with the exception of Lady (Khunying) Laiad who is most commonly referred to in the English language historical literature by the English term]. "Phra” for monks of the Buddhist order (the Sangha) and "Ajaan" for professor are also used, again to denote the social elevation indicated by such titles.

This classification system brings us to a discussion of certain aspects of Thai social hierarchy and social system that require clarification. Before 1932 the monarchy was the core of political power. I have used the term 'absolute monarchy' loosely here to refer to the monarchical system between the early $15^{\text {th }}$ century (the Ayuthayan empire) and 1932, in which ultimate decision-making authority rested with the king. It must be pointed out, however that some, like John Girling, would argue that the "absolutist theory of an allpowerful god-king (chao chivit 'lord of life') contrasts with the reality of a balance of power among king, princes, and nobility." 32 Indeed, an extensive feudal elite, denoted by a system of "dignity marks" - the sakdina system, literally "power of the land" - worked to administer the kingdom's affairs. The sakdina system ranked each and every member of the kingdom, from royalty through slaves. The higher the rating of a noble, the more land and, more importantly, more labour (serfs or phrai) controlled by the noble. ${ }^{33}$

\footnotetext{
32 John Girling, Thailand: Society and Politics (Ithaca: Cornell University Press, 1981) 21.

${ }^{33}$ Girling, 21-29. See also Truong, 142-146.
} 
The place of the monarchy in Thailand remains (or, more appropriately has been made) central in many ways even though it is no longer absolute. In the post-1932 era, the monarchy is technically a figurehead, who is subject to the rule of law through the constitution, but who continues to have a great deal of moral and symbolic influence (as I shall discuss in later chapters). The monarchy as a source of legitimacy and influence is central to my understanding of class divisions in Thailand today.

Reflecting the difficulties of applying what are generally Western, male and economically defined notions of class to Thailand I have used the terms 'elite', 'middleclass' and 'peasant' quite broadly. My definitions of 'elite' and 'middle-class' are meant to denote a simplified version of the complex and overlapping class divisions in Thai society. I use 'elites' to refer to those with links to the 'more traditional' centres of power in the monarchy and upper echelons of government. For example, the "khunyings" are women who have been recognized by the monarchy for their service and dedication to the nation. Elites and elite women also generally come from wealthy families but it is important to distinguish them from the "nouveaux riches" of the post 1970 s period. Today, "elite' women also tend to be an age cohort that is somewhere over fifty (i.e. in their thirties or older during the 19731976 democracy period) although this is not necessarily the case. This distinguishes them from the generation of student activists in the 1970s who are now, approximately, in their forties. The term the 'new middle class', which I will discuss in more detail in Chapter 8, refers to the new class of post-secondary educated, often urbanized, individuals who work in particular sectors of the economy e.g. managerial and professional sectors. For the rural 
class that continues to rely, at least in part, on the land for survival I have used the generic term 'peasantry' to distinguish them from the urban working class and rural elites.

\section{Chapter Outlines}

Chapter 1 examines the recent literature on prostitution in Thailand and politics in Thailand and argues for a post-colonial and social constructionist approach to understanding prostitution policy in Thailand. Such an approach allows us to see how prostitution policy is part of the discursive construction of gender and national identity.

Chapter 2 gives an overview of the early history of Thai-Western relations and the centrality of gender identities and sexual practices to establishing identity and difference between the colonizing West and Siam/Thailand. In particular, Siam was construed as lacking in the masculine attributes of good governance as evidenced, for example, by what Westerners considered 'improper' and 'excessive' sexuality in the institution of the harem. In the relations between the West and Siam, gender and sexuality became important grounds for establishing identity and difference.

In Chapter 3 I examine the reconstruction of Thai national identity after the overthrow of the absolute monarchy in 1932. In attempting to throw off the unequal treaties of the colonial era the new government sought to prove its 'modernity', particularly through the manipulation of gender to show that Thai women were 'modern yet traditional'. This new discourse of femininity opened a path for elite women to political and professional influence. In the same vein, the government slowly adopted the standards of prostitution policy being 
advocated by the United Nations. However, these new standards did not resonate outside the state. Elite men, including Prime Minister Sarit, continued to draw on older modes of gender identity to legitimize his rule. In 1966, therefore, new laws that effectively served to regulate the prostitution industry were put into place.

Chapter 4 looks at the 'boom period' of prostitution in Thailand during the Vietnam war when American troops were stationed throughout the country. The chapter illustrates how, in this period, peasant women's bodies became emblematic of the Thai national body. The entry of thousands of peasant women into the sex-trade around the American airbases was used as a symbol of the process of 'Westernization' and the loss of 'Thai culture' by the middle-class student movement, which sought to overthrow the old elite military order. Such a representation of women in prostitution, however, erased any sense of independence or agency on the part of the women themselves, and instead presented them as victims of larger forces in need of aid and direction.

Chapter 5 examines the immediate post-revolutionary period as the 'enlightened' forces within the military and the elite worked to stabilize Thai identity. In an attempt to include the peasantry within the ideology of the nation, peasants were constructed as the 'backbone of the Thai nation'. Peasant agency and struggle was erased by representations that emphasized their 'happy and contented' lifestyle, which grounded Thai culture. The 'reeducation' of peasant women - particularly prostitute women - into their 'proper' role as mothers of the nation, and symbols of national identity, became an important task of the reconstructed Thai state. This process also opened a path for elite women to claim a social 
and political role in disciplining peasant women into their proper roles and to ground their legitimacy in criticizing male sexual and social behaviour.

Chapter 6 looks at the implications of this particular construction of prostitute women as icons of cultural decline for organizing to protect prostitute women. As new women's organizations formed in the 1980 s they sought to have the economic exploitation of women in the 'newly industrializing' Thailand, recognized. While prostitute women themselves sought to organize for better working conditions, the new women's groups tended to focus on the abolition of prostitution because it was seen as a form of exploitation of women. Such a focus, however, failed to challenge the over-riding elite emphasis on re-enculturating prostitute women into their 'proper' roles as peasant women. It also contributed to government responses that continued to restrict prostitute women's self-determination.

Chapter 7 discusses the growth of a new ideology of masculinity with the rise of the middle-class. Middle-class men were reconstituted as symbols of modernity and progress in the face of 'old', elite forms of masculinity that were now no longer seen as capable of 'good governance'. The chapter examines the new Act for the Suppression of Prostitution, the first prostitution legislation passed after thirty years of struggle. For the first time, the legislation targeted clients (of underage girls), undermining the claim to male sexual privilege that had maintained the prostitution industry. Elite women were able to make use of their role as interpreters of tradition and modernity as well as the hegemonic masculinity of Western modes of governance to criticize male prerogatives in Thailand. As in the 
colonial era Thai male sexual behaviour - particularly in polygamy - was linked to an inability to govern rationally and competently.

Chapter 8 follows the parallel construction of womanhood by the new middle class, in particular the continued endowment of peasant women with the responsibility for the maintenance of Thai culture. The post-1970s period was one of rapid economic growth in Thailand, which led to the formation of an urban middle-class that, while partaking from the benefits of 'modernity', felt itself cut off from 'tradition'. Thus, while new feminist organizations attempted to emphasize the economic exploitation inherent in prostitution, the now hegemonic middle-class continued to interpret prostitution as a threat to the traditional identity of the nation and viewed prostitute women in particular as greedy consumers - who, unlike the middle-class and their progressive elite allies, did not understand how to engage with modernity while preserving national identity and tradition. In particular, the middleclass had come to distrust and distance itself from the peasantry, which was viewed as blocking middle-class aspirations for democratic governance by their corruption and by backing the military structure. Prostitutes, as peasant women who should be upholding Thai identity and tradition for the middle class, were clear examples of modernity run amuck. Prostitutes' own efforts to organize were dismissed, and prostitutes were constructed as in need of the aid of elite women to guide them into their proper roles. Thus, the price of disciplining male behaviour was the continued disciplining of peasant and prostitute women to adhere to the 'traditional' identity mapped out for them by the elite. Prostitute women, 
therefore, rather than being recognized as self-interpreting agents, remained objects of disciplinary policy 'for their own good'.

In the following chapter I will examine the politics of power in the construction of meaning, in particular, in the construction of gender and national identity in a globalized world. This theoretical discussion will provide the framework for the historical analysis of prostitution policy in the following chapters. 
Chapter 1: Theories of Politics and the Politics of Theory. Theorizing Prostitution Policy

"You don't see what we're doing about it," is a phrase that has rung in my ears since spending six months in Thailand talking to people about the prostitution problem. Western inability to 'see what's happening' in Thai politics - the struggles, conflicts and changes - is a product, not of a simple ignorance, but of the ways in which Western representations have produced Thailand as a stable, cultural whole, different from - and lesser than - the West. This is a fundamental operation of cultural imperialism and one of which many Thais have long been aware.

In this chapter I examine the ways in which Thai politics have been viewed in traditional studies of both politics generally, and prostitution more specifically. In particular, I examine the reliance on an essentialized and ahistoric notion of political culture as an explanatory variable. The reliance on an essentialized political culture has resulted in studies that have failed to show the dynamism and struggle in Thai politics, most importantly, over culture itself. As well, I argue that the production of Thailand and Thai politics in this political culture vein is, in fact, an operation of power. This power is a central part of international politics - the politics of representation - and one that fundamentally shapes Thai politics, as political forces in Thailand respond to imperializing representations through the construction of national identity. My own understanding of prostitution policy in Thailand draws on social constructionist approaches that examine state policies as a reflection of a struggle over meaning and the constitution of identities that confer legitimacy on particular actors while delegitimizing others. In particular, I argue that prostitution policy reflects 
debates over the construction of gender identity and national identity in response to Western (discursive) imperialism.

Having established in the introductory chapter that prostitution itself has no essential meaning, we need to ask how and why prostitution comes to be seen in a certain way in any particular historical location. We must then examine what the implications are of prostitution and prostitutes being seen in this particular way. This thesis, therefore, examines the political struggle over meaning and it views the state as a powerful site of the inscription and institutionalization of meaning. I argue that the meaning attached to prostitution is established in particular historical locations as the product of larger political debates over culture (examined here as national identity), gender, and sexuality. These meanings and identities are then inscribed in state policies concerning prostitution. While the occurrence of large-scale and organized prostitution in Thailand cannot be seen outside the structures of economic and gender inequality, the policies and politics surrounding prostitution need to be investigated beyond the mere assumption that these policies are functional to the maintenance of political or economic power. Nor can they be seen as a response to a particular reality of prostitution. Such assumptions discount the importance of politics itself. They ignore agency, struggle, and the construction of meaning.

My rendering of political struggle is a particularly discursive one. People are meaning creators, as well as consumers. They are interpretive agents who act, not simply on the basis of pre-given interests (hunger, greed, sexual drive, survival, power), but in terms of the meaning given to these interests. This meaning is not inherent, but constructed in a social 
context, and politics is the process of constructing and contesting meanings. In this thesis, I draw on Derrida's notion that, in the post-Enlightenment era, meaning is structured in binary oppositions, so that a fluid social reality is violently rendered into oppositional categories, which are hierarchically positioned so that one term is given precedence over the other. In formulations of identity such dualism and hierarchization are the key processes which render certain actors legitimate and powerful while silencing others, such as in the opposition and hierarchization of male/female, colonizer/colonized. Although this process is a particular product of the Western past, it has become hegemonic in the international realm through Western imperialism and neo-imperialism. As Robert Cox has pointed out, international hegemony rests not only on a preponderance of material capabilities but on predominance of certain intersubjective meanings. ${ }^{1}$ Non-Western societies, therefore, are faced with operating in a globalized world in which the terms of reference have been set by the West. While Western economic power has been widely recognized, few note the importance of Western discursive power in international politics.

Looking at the construction, and contestation, of meaning as an act of power begins to explain why one of the central issues of international discussions of the prostitution problem in Thailand is precisely how Thailand and Thai women are represented in these discussions. The imposition of meaning is itself an act of power. It creates the social reality

${ }^{1}$ Robert Cox, "Social Forces, States and World Orders: Beyond International Relations Theory," Neo-Realism and its Critics, ed. Robert O. Keohane (New York: Columbia University Press, 1986) 218. 
in which we act. At the international level, imperialism has worked through the creation of the 'oriental other' in a way which "elevates and normalizes the Occident while demonizing the Orient."

I argue that politics is structured through discourse, and that particular meanings and identities become hegemonic and form the framework of political debate. Political actors who wish to make their voices heard on the political stage must, in order to be successful, appeal in some way to this larger discourse - even if to undermine it. In Thailand, this larger framework has been fundamentally shaped by (neo)imperialism and resistance to it. As this chapter will show, gender is an important component of national identity construction. Gender both shapes, and is shaped by, national identity. Gendered issues such as prostitution are, in Thailand, debated in the context of national identity construction. An investigation into prostitution policy, therefore, requires an inquiry into the meaning given to prostitution itself an examination of how this meaning is constructed.

In this chapter, I first examine how previous discussions of both politics and prostitution in Thailand have failed to fully account for prostitution policy because of the essentialism and/or latent structural functionalism of their analyses. These essentializing analyses have reproduced colonizing constructions of Thai culture, and Thai women, and they have obscured political action and change. They fail to fully explain, or explore, the constitution of prostitution policy. For example, some feminist studies account for the

${ }^{2}$ Edward Said, Orientalism (New York: Vintage, 1979). 
tolerance and, in fact, encouragement of prostitution by certain state institutions. These same studies, however, fail to explain why prostitution has been criminalized by the Thai state even though the industry has been an extremely profitable one for both the state and the capitalist class. It is the criminalization of prostitution that women working in the industry themselves see as the most problematic issue. The earlier feminist approaches reflect general political studies of Thailand that have emphasized an unchanging and 'traditional' political culture as the underlying explanatory factor for Thai political development, thereby dismissing the fact, and importance, of political struggle. Political studies of Thailand have tended to view culture as a given entity, rather than as a constructed identity that is debated, contested, and structured through the operation of power. These mainly Western studies fail to see their own power position in reproducing colonizing representations of Thailand.

In contrast, I argue for: 1) a social constructionist approach to both gender and culture (in terms of national identity), in order to understand the operation of power in the constitution of these identities; and 2) a post-colonial approach, in order to highlight how national identity and gender are constructed in an international context of imperialism, or, more recently, Western hegemony. I draw on recent anti-essentialist studies of national identity to explain the constructed and historical nature of the nation, and post-colonial studies of national identity to highlight the international context of these constructions. Further, I turn to recent feminist theorizing on the interrelation of constructions of the nation and constructions of gender, in order to bring us full circle to the place of prostitution policy in Thai society as a key site of the creation of these identities. 


\section{The State of Thai Studies}

Traditional political science approaches to the study of Thai politics have focussed on stability rather than change. They point to an ahistorical and essentialist 'culture' that supports a military-bureaucratic dominance. Such a focus blinds us to the changes occurring within Thai society, and it leaves us unprepared for such events as the 1973 student uprising or the 1992 democracy protests. Further, it leaves uninvestigated the operation of power.

Ken Young contends that political science studies on Southeast Asia have tended to view culture in "essentialist, ahistorical and simplistic" terms because of the continued influence of Parsonian structural-functionalism. Young points out that anthropological studies, working within the same structural-functionalist framework, were an essential basis for much early political science work in the area. In Thai studies, Embree's "loose-structure" theory on rural Thailand formed the basis of Fred Riggs' classic 1966 "Thailand: The Modernization of a Bureaucratic Polity." Embree presented Thai society as individualistic and lacking in "regularity, discipline, and regimentation" - that is, Thai society lacked the "duty and obligations" of Japanese or Chinese society. ${ }^{3}$ The concept of a "looselystructured" society steered research away from questions of social stratification, including

${ }^{3}$ Ken Young, "Political Science and Southeast Asia: The Neglect of Gender," Why Gender Matters in Southeast Asian Politics, ed. Maila Stivens, Monash Papers on Southeast Asia, No. 23 (Clayton, Victoria: Monash University, Centre for Southeast Asian Studies, 1991) 98. See also John F. Embree, Loosely Stmuctured Social Systems: Thailand in Comparative Perspective (New Haven, Yale University Southeast Asia Studies, 1969); Fred Riggs, Thailand: The Modernization of a Bureaucratic Polity (Honolulu: University of Honolulu Press, 1966); Jack M. Potter, Thai Peasant Social Structure (Chicago: University of Chicago Press, 1976). 
gender and class. Riggs' analysis emphasized the Thai values, personality and patronage which supported the "bureaucratic polity." Like many political culture analyses that followed in the structural-functional tradition, then, Riggs' analysis re-inscribed the notion of an unchanging 'traditional' culture that supported a 'backward' political system and that lacked the dynamism of 'modern' Western democracies.

In the wake of the 1973 student uprising, political scientists turned to the problem of democratization, or the lack thereof, in Thailand. David Morell and Chai-Anan Samudavanija examined the failure of democracy efforts in terms of the strength of "traditional Thai institutions," such as the monarchy, the military and the bureaucracy, that again leaned on cultural explanations that tended "to ossify elite definitions of Thai culture," according to William Callahan. ${ }^{4}$ While later Marxist approaches to Thailand introduced a more conflictual and less functional political analysis, the problem of cultural essentialism continued to appear. Culture was no longer viewed as a determining factor, but it was seen as a kind of residual category that explained away any lacunae in the analysis. Young quotes from John Girling's study of Thailand, which - although it stressed that Thailand is now a "political-cultural order undergoing change brought about by 'modernisation"” - continued to speak about Thailand in terms that echoed Riggs:

Most of modern Thai history has been fashioned around consensus, based on traditional Thai values, patterns of

${ }^{4}$ William Callahan, Imagining Democracy: reading "the Events of May" in Thailand (Singapore: ISEAS, 1998) 5. The weight of 'traditional attitudes' as the major barrier to democratization remains predominant in Thai analysis of the political system. 
behaviour, and institutions... [this] consensus is expressed through personality, patronage, customary values, and - the embodiment of all three - the bureaucracy. The values sustaining the 'bureaucratic polity' are those of a status society...5

Other neo-Marxist analysts, like Kevin Hewison, viewed culture as 'super-structural', a byproduct of the structural base of material conditions. Hewison argued: "I would not suggest that the analysis of culture and ideology is irrelevant, but I would emphasize that they should be seen for what they are, as reflections, albeit poor and partial, of the real base of society." 6 Hewison's analysis - which was highly critical of earlier structural-functional analyses of Thai politics - focussed on the development of Thai capitalism (rather than "comprador" capitalist dependency or 'traditional' political culture) as the central determinant of Thai state policy. ${ }^{7}$

While Hewison's conflict-oriented approach moved studies of Thai politics away from assumptions of stability and towards change, such an approach continued the tendency to leave unquestioned the construction and maintenance of particular cultural values, values that are of obvious benefit to those who rule. As Ken Young has pointed out, political studies have tended to reproduce the world view of the power elite themselves. Such studies obscure

${ }^{5}$ Girling c.f. Young, 98.

${ }^{6}$ Hewison c.f. Callahan, 28-29 note 16.

${ }^{7}$ See Kevin Hewison, Bankers and Bureaucrats: Capital and the Role of the State in Thailand, Monography Series 34, Yale University Southeast Asia Studies (New Haven: Yale Center for International and Area Studies, 1989). 
the "creation, symbolisation and maintenance of many forms of social cultural identity [which] cannot be left to chance by those in power." The powerful "have an interest in the formation and propagation of these forms of social and personal identity." ${ }^{88}$ Studies that fail to investigate the construction of these identities, therefore, fail to fully investigate the operation of power.

These same traditional political science studies also failed to investigate gender structures, in part because of their assumption of the naturalness of gender relations. That is, gender - like culture - in traditional analyses, is seen as outside of politics and the operation of power. Indeed, gender is itself seen as part of culture. As Young notes:

The processes of gendering, too, are part of this culturalpolitical complex, but little recognition is extended to the role that gender identification and gender ascription have in the real and ideological struggles for control of social institutions.... Gender... is a part of the cultural complex which can too easily be passed over as something given and outside the domain of political contestation. ${ }^{9}$

Of course, as Young points out, it is not only this cultural determinism which leads to the ignoring of gender as a political issue. Political science is notorious for failing to investigate gender power as a result of the gender biases embedded in political science inquiry, including the separation of 'public' from 'private' spheres and the designation of the 'public' sphere

\footnotetext{
${ }^{8}$ Young, 95.

${ }^{9}$ Young, 96.
} 
as the proper focus of study. ${ }^{10}$ In Southeast Asia, however, as Maila Stivens points out, the contention that women have been relegated to the 'private sphere', and therefore overlooked by masculinist political science, is difficult to sustain. Women have been for some time the central workforce in the service and manufacturing industries of these Newly Industrializing Countries. Such blindness to their presence is possible only by the operation of power through particular gender constructs. State policies in the region, for example, have portrayed women primarily as mothers. ${ }^{11}$ Clearly, the social construction of gender, like culture, requires close analysis as an operation of power.

Further still, traditional analyses of Thai politics have failed to study their own power position in reproducing colonizing constructions of 'Thailand', 'Thai politics' and 'Thai culture' as backward, traditional and unchanging. That is, academic analyses are themselves political. As powerful sites of the creation of 'knowledge' and 'truth', they produce the social 'reality' they then presume to study. They essentialize and bifurcate overlapping and contested identities into distinct and opposite units. In particular, by constructing Thailand as traditional and unchanging, such studies, by implication, present the West as modern, progressive, and therefore, better. These studies are part and parcel of international relations themselves. They are part of the construction of identities of 'us' and 'them', and 'East' and

\footnotetext{
${ }^{10}$ For a further critique of the 'radical deafness' of political science to feminist inquiry see Kathy E. Ferguson, "Male-Ordered Politics: Feminism and Political Science," Idioms of Inquiry, ed. Terence Ball, (New York: State University of New York Press, 1987).

${ }^{11}$ Stivens, 16-17.
} 
'West' where one identity takes precedence over the other and can lay claim, therefore, to international authority and legitimacy. It is precisely this sort of process that produces resistance and spurs the process of national identity construction in the 'other' country, such as Thailand.

Overall, Thai studies have tended to take the existence of a Thai nation-state for granted, unproblematically reproducing imperialist representations of culture and national identity constructed by the ruling elite, and therefore ignoring a central operation of power. This assumption has most recently been challenged by studies of national identity, which from their inception, have had to contend with the invented character of such identity. Further still, political studies of Thailand have failed to investigate their own position of power, of inventing 'Thailand' for Western consumption. They also have failed to see the national political process of inventing Thailand to resist imperialist constructions. I draw on the post-colonial versions of national identity studies to examine the construction and maintenance of Thai national identity.

\section{Prostitution in Thailand}

The study of the growing prostitution industry in Asia drew attention to the specificities of prostitution in that region in the 20th century. Of particular concern was the role of the military (including, most importantly, the American military) in organizing and encouraging the spread of prostitution services. As well, analysts examined the role of the economy of the region, specifically the importance of the service and tourism industries. 
Overall, it was clear that women's poverty was the central motivating factor in entering into prostitution in Thailand. Not all poor countries, however, had such a large prostitution industry as Thailand. Analysts looked to the cultural specifics of Thailand itself to explain this difference.

In her 1980 study, Khin Thitsa pointed to the "traditional attitudes" towards women in Theravada Buddhism, the dominant religion in Thailand, that reinforced women's low status in the national and international economies. Buddhism's relegation of women to a lower status in the socio-religious order underwrote, according to Thitsa, women's "secondclass status" in Thai society and opened the way into prostitution. As Thitsa argues:

I believe that prostitution is where women most fulfill their role expectations, that being woman's image as lustful, seductive, corrupting, greedy. We have seen how it is economic necessity which motivates women to resort to this sphere of activity. With the low value attached to the female body and the female spirit by Buddhism, she has been sufficiently degraded already to enter prostitution. If historically woman has served man, helping him as wife, minor wife or mistress, it is not such a big step to become an actual prostitute. ${ }^{12}$

Thai women's entry into prostitution, therefore, was a function of her "degraded status" in Thai Buddhism.

Thitsa's blanket condemnation of Thai Buddhism was challenged by Charles Keyes, who argued that a closer analysis of Buddhist texts would reveal a number of images of

${ }^{12}$ Khin Thitsa, Providence and Prostitution: Image and Reality for Women in Buddhist Thailand (London: Change International, 1980) 23. 
women. In particular, women appeared predominantly as "mother-nurturer" rather than as simply a "source of pollution" as Thitsa would have it. ${ }^{13}$ Further, Keyes pointed out the selfprofessed importance of the image of "mother-nurturer" in the lives of women in the sexindustry. Similarly, Pasuk Pongpaichit's research on the sex-industry documented women's own sense of themselves as family wage-earners. ${ }^{14}$ Thai feminists resented Thitsa's 'blaming Buddhism' for the growth of prostitution and thereby dismissing its importance in the lives of many Thai women, prostitute and non. From Thitsa's analysis, Thai women who follow Buddhism suffer from 'false consciousness'. Indeed, Buddhism today has become a site of political resistance for many women, including young middle-class women who are going to 'spiritual retreats' or who are taking up the nun-hood in the face of Westernization, and the international sexualization of Thai women. Women in prostitution similarly value their religious beliefs, using their income to give donations to the temples and make merit for themselves, as well as enriching the coffers of the temples. ${ }^{15}$ The difference between official

${ }^{13}$ Charles F. Keyes, "Mother or Mistress but never a Monk, Buddhist Notions of Female Gender in Rural Thailand," American Ethnologist 11.2 (1984): 223-241. See also Thomas Kirsch, "Text and Context: Buddhist Sex Roles/Culture of Gender Revisited" American Ethnologist 12.2 (1985): 302-320.

${ }^{14}$ This was not universal, however, women from the North of Thailand were more likely to express this view than other women. Chris Lyttleton's research has shown that northeastern women in prostitution have much less sense of responsibility to the family. See Chris Lyttleton, "The Good People of Isan: Commercial Sex in Northeast Thailand," The Australian Journal of Anthropology 5.3 (1994): 275.

${ }^{15}$ For a different analysis of Buddhism and women see Chatsumarn Kabilsingh, Thai Women in Buddhism, (Berkeley: Parallax Press, 1991). Chatsumarn argues that the negative influences of Chinese and Indian patriarchal societies are the source of inequality in 
Thai Buddhism - organized and regulated by the state itself, often in ways that promote state interests $^{16}$ - and Buddhism as it is practised in daily lives, must be taken into account in any analysis of the role of religion in determining women's lives. Peter Jackson's account of reformist Buddhism and the middle class shows how new reformist interpretations of Buddhism emphasize the individual's capacity to attain religious and political liberation rather than being condemned by their dharma to live out a particular life. ${ }^{17}$ Women's 'low value', therefore, is challenged and challengeable.

Thitsa's analysis also makes one of the colonizing moves, outlined by Chandra Mohanty in feminist theorizing about the lives of 'third world women', by confusing 'discourses of representation' with 'material realities' ${ }^{18}$ The extent to which women internalize the dictates of religion - which are not by any means singular or necessarily coherent - is a matter of investigation, with an ear open for the possibilities of both internalization and resistance. ${ }^{19}$ The ahistorical rendering of Buddhism, furthermore, presents Thai women as 'frozen in time', and 'mired in tradition', rather than revealing how

Buddhism rather than being inherent in the religion itself.

${ }^{16}$ See the accounts of the political role of Buddhism in Peter Jackson, Buddhism. Legitimation and Conflict: The Political Functions of Urban Thai Buddhism (Singapore, Institute of Southeast Asia Studies, 1989).

${ }^{17}$ Peter Jackson, "Thai-Buddhist Identity: Debates of the Traiphuum Phra Ruang," in National Identity and Its Defenders, ed. Craig J. Reynolds (Chiang Mai: Silkworm Books, 1991) 195.

${ }^{18}$ Mohanty, 69.

${ }^{19}$ See Mohanty, 62. 
tradition is constantly re-constructed in the face of historical change. Indeed, women often live in a situation of a "deeply felt tension between tradition and modernity."20 As I argue in this thesis, that tension is often mediated precisely through the categories of gender and class.

Anthropological studies of gender have moved beyond macro-level arguments about the role of Buddhism in determining the nature of women's lives to micro-level studies of local areas and groups of women to more specifically account for the operation of power in women's lives. ${ }^{21}$ The overarching cultural argument, however, continues to live on in accounts of prostitution. This includes the discussion of the often ignored issue of the behaviour of men. Chris Lyttleton has argued that much less attention has been paid to men's decision to go to prostitutes, because there is an overarching cultural argument that such behaviour is culturally acceptable and expected. However, when, where and under what

${ }^{20}$ Aihwa Ong, "Colonialism and Modernity: Feminist Re-presentations of Women in Non-Western Societies" Inscriptions 3/4 (1988): 86. The opposite contention - that prostitute women in Thailand have 'thrown off' the shackles of 'tradition' and become, therefore, more liberated than their sisters (see Cleo Odzer's claim that prostitutes are "pioneers in advancing women's autonomy by breaking from the mould of suppressed and passive females." Cleo Odzer, Patpong Sisters: An American Woman's view of the Bangkok Sex-trade (New York: Blue Moon Books, 1994) 309) repeats the same dichotomization of tradition and modernity, failing to note the constructed, rather than essential, nature of both. Thai feminists protested the characterization of Thai women and resisted advocating sexual liberation for Thai women as a path to liberation generally. See Chilla Bulbeck, Re-Orienting Western Feminisms (Cambridge: Cambridge UP, 1998) 184.

${ }^{21}$ See, for example, the studies in Nancy Eberthardt's collection Gender, Power, and the Construction of the Moral Order: Studies from the Thai Periphery (Madison: University of Wisconsin-Madison, Center for Southeast Asian Studies, 1988). 
specific historical circumstances this takes place is not investigated. Questions about those men who do not go, and why they abstain, are simply not asked. The monolithic assumptions about Thai men, Lyttleton argues, are "predicated on images of unrestrained male libidinousness and sexual profligacy is considered a national character trait."22

Furthermore, the failure to explore beyond the functionalist assumption that economic need leads to women entering prostitution has failed to account for different patterns of entry to the profession. The fact that women from the poorest province of Isaan enter at a lower rate than women from the better-off North should give pause. ${ }^{23}$ Lyttleton argues for much more detailed and finely-tuned accounts of prostitution in Thailand by pointing out that "the ideologies enlisted above [by Thitsa and Kirsch] have a directive force in the lives of all Thai Buddhists but they cannot simply be pinned together with monolithic assumptions of economic functionalism if we are to appreciate the vast array of forms in which prostitution is found. ${ }^{24}$ Lyttleton found that:

there is no doubt young women learn that prostitution is an ever present recourse to make money and young men grow up aware that sexual outlet may be had through visiting prostitutes. The point that must be kept at the forefront is that men, and in many instances, CSWs [commercial sex workers] exercise some degree of choice as to the specific form and frequency of commercial sex in which they involve themselves. These choices are not only pragmatic in the sense

\footnotetext{
${ }^{22}$ Lyttleton, "The Good People of Isan," 265.

${ }^{23}$ Lyttleton, 266.

${ }^{24}$ Lyttleton, 264.
} 
of economics or logistics but are formed around expectations of the style of interaction found in different locales. ${ }^{25}$

He also found that women in commercial sex work were often aware of the shifting nature of force and choice in their lives. ${ }^{26}$ As Lyttleton relates, many women working in the industry express both a sense of fierce independence as well as a sense of accomplishment and satisfaction in their work. At the same time, they complain of loneliness and a sense of unease about themselves and the work. ${ }^{27}$

Another major study of the prostitution industry in Thailand was produced in the early 1980 s by Pasuk Phongpaichit, now a leading Thai political economist. Pasuk's work, still relatively singular in the field, examined the entry into prostitution of fifty Bangkok masseuses. Pasuk emphasized choice rather than force in her study. While taking account of the "limited choices" faced by young, rural Thai women traditionally responsible for the maintenance of the family in a country reliant on cheap primary production and labour, Pasuk drew attention to the women's own interpretation of their lives as family wage earners. She concluded that the women were "engaging in an entrepreneurial move designed to sustain the family units of a rural economy which was coming under increasing pressure." 28 The

\footnotetext{
${ }^{25}$ Lyttleton, 266.

${ }^{26}$ Lyttleton, 272.

${ }^{27}$ Lyttleton, 272.

${ }^{28}$ Pasuk Phongpaichit, From Peasant Girls to Bangkok Masseuses (Geneva: ILO, 1982) 74.
} 
relative benefits of the sex-trade meant that "no amount of agitation is likely to change things while the cost incentives remain the same, and the opportunities for alternative employment are so limited."29 Pasuk's contribution to the wider understanding of prostitute women's own views of their lives remains an important contribution in the field, although some scholars were critical of the lack of emphasis on the structural determinants and state/capitalist responsibility. Thanh-dam Truong, for one, argued that studies must recognize and analyse the industries and social relations that support the work, rather than just examining the conditions under which the work is taken up. ${ }^{30}$

Thahn-dam Truong's comprehensive analysis of the prostitution industry in Thailand draws on post-structural analyses of gender and on neo-Marxist analyses of capital. Truong argued that analyses which focussed on sex alone, such as Barry's, ignored the issues important to Third World women working in the sex-industry and the complex social processes that constitute the social reality of Third World women. Truong argued that:

For many of these women [Third World women in prostitution in the tourist and informal sectors], the issue is not just sexual freedom or oppression but concerns deeplyrooted dimensions of social inequality exacerbated by social change such as agrarian change, urbanization, foreign currency crisis, international labour mobility, and militarization. ${ }^{31}$

\footnotetext{
${ }^{29}$ Pasuk, "From Peasant Girls," 76.

${ }^{30}$ Thanhn-dam Truong, Sex, Money and Morality (London: Zed, 1990) 49.

${ }^{31}$ Truong, 55.
} 
In particular, Truong argued that prostitution in the Third World "cannot be limited to questions pertaining to the male-female relationship alone, but must take into account the process of internationalization of production in the area of leisure and entertainment facilitated by state and capital intervention. ${ }^{32}$ Truong argued for an understanding of prostitution as sexual labour, as it is organized by relations of production.

Truong's analysis of the sex-trade in Thailand provides a richly detailed analysis of the economics of the international tourism industry in Thailand as well as the construction of gender and sexuality in Thai culture. She argued that the particular construction of gender and sexuality under Buddhism "became interwoven with state structure, law and relations of production" and the state's facilitation of the process of surplus extraction. ${ }^{33}$ Thus, "productive services in prostitution create surpluses that can be extracted by economic agents as well as by the state." ${ }^{34}$ The moral and legal condemnation of prostitution permits further intensification of this surplus extraction by reinforcing "the relation of domination and dependency between [women in prostitution] and their employers" and by undercutting the possibility of resistance by prostitute women. ${ }^{35}$ This extraction process has been internationalized with the building of the tourist industry and the globalization of the Thai economy.

\footnotetext{
${ }^{32}$ Truong, 55.

${ }^{33}$ Truong, 195.

${ }^{34}$ Truong, 197.

${ }^{35}$ Truong, 197.
} 
For Truong, then, the actions of the Thai state can be understood in terms of its role in maintaining capitalist accumulation - organizing the means of production and disorganizing resistance to capital accumulation. Such a deterministic model, however, leaves little room to understand tensions and contradictions in Thai politics and the spaces for resistance. In particular, it ignores women's own organizing around the issue of prostitution. While Truong views gender and sexuality as historically constructed, she sees them as constructed within an (unchallenged) national cultural frame (Buddhism). She does not see how national culture is itself a discursive construct which is constructed through gender as we will discuss below. It is the interaction between, and tension among, discourses of gender, national culture, and class - to name a few that are central to my analysis - that opens spaces for political contestation. In particular, the state is imbued in processes not only of capital accumulation, but of the reproduction of national identity. Hence state interests can be contradictory and competitive - as they are, for instance, in an age of globalization in which national identity appears to be under threat by globalizing cultural forces. The state operates in concert with globalizing capital while it seeks to retain its sphere of power in the 'national'. It therefore resists, to some degree, the forces of globalizing culture. Gender simultaneously constructs and is constructed by these competing discourses, which opens space for opposition and resistance. As Aihwa Ong's work in Malaysia shows, the meanings 
attached to women's absorption into the industrial labour force are multiple (indeed, "inflationary"). They are contested rather than singular and purposeful. ${ }^{36}$

Even more recent analyses of the sex-industry in Thailand, which focus on the cultural representation of the industry, also tend to view culture in deterministic terms. Ryan Bishop and Liilian Robinson's Night Market: Sexual Cultures and the Thai Economic Miracle examines the discursive construction of the Thai sex-industry, investigating the ways both Thailand and Thai women are represented in international discourses to produce the colonial other, and the ways that internal discussion of the sex-industry is suppressed. Even in this discursive account, Thailand again appears as unchanging and unchangeable. For example, in documenting the "unspeakability" of the sex-trade within the borders of Thailand as a "cultural aphasia," Bishop and Robinson correctly argue that the state relegates any external mention of the sex industry to the "unspeakable." Their thesis is that only the move from unspeakability to speakability "makes exploitative situations more difficult to perpetuate." 37 Bishop and Robinson, however, seem to assume a nearly unchallenged, and unchallengable, state power. They quote Eve Sedgwick to argue that "in the theatrical display of an already institutionalized ignorance no transformative potential is to be looked for."38 The authors cite two examples of attempts to render the sex-trade "speakable" - Sanitsuda

${ }^{36}$ See Aiwha Ong, Spirits of Resistance and Capitalist Discipline: Factory Women in Malaysia (New York: State University of New York, 1987).

${ }^{37}$ Bishop and Robinson, 215.

${ }^{38}$ Eve Sedgwick c.f. Bishop and Robinson, 203. 
Ekachai's investigative journalism in the 1990 book "Behind the Smile" and Kanha Watanaphat's (a.k.a. K.Surangkhanang's) 1930s novel "The Prostitute" - but stress the limited impact of these counter-discursive contributions. ${ }^{39}$ They argue that:

The rhetoric of inquiry and critique has often been unspeakable in the development of the Thai nation-state as a modern entity. The gossip of these two texts offers alternatives to the public discourse of modernity that has historically led, in Thailand, to a crushing cultural aphasia about the lived realities of modernization and the sex industry. ${ }^{40}$

In this interpretation, however, Bishop and Robinson ignore one of Foucault's central arguments of the operation of power in the rendering of a subject as "speakable." They appear to argue instead, that the simple uncovering of an 'unspeakable truth' will (eventually) lead to the emancipation of the women in the industry. From the perspective of the production of discourse as power, however, I would argue first, that prostitution, in terms of gender relations, sexuality, economics, has always been speakable only in very particular way; secondly, those particular ways of discursively constructing the industry have always been challenged, more or less successfully, as part of the political struggle over the constitution of identities; and finally, each of the different ways of constructing the "problem of prostitution' engage different relations of power. The 'speakability' rendered in Sanitsuda Ekachai's journalism, therefore, may invoke discourses of nation, class and gender that

\footnotetext{
${ }^{39}$ Bishop and Robinson, 208-216.

${ }^{40}$ Bishop and Robinson, 217.
} 
inscribe middle-class discourses of identity which subjugate peasant renditions. Bishop and Robinson's account leads us to believe that there is nothing further to investigate within these very 'counter-discourses.' I argue, however, that politics is always the struggle between discourses which invoke their own relations of power. As Penny van Esterik has pointed out, there are a wide variety of voices on the 'prostitution problem' in Thailand, the least audible being the voices of prostitutes themselves. ${ }^{41}$ Otherwise, Thailand and Thai politics again appear uncontested and immutable. Thailand appears as the stable, ahistorical 'other' whose path is determined. The struggle of many Thai women to 'do something' about prostitution in Thailand is erased in such an approach.

Feminist studies of prostitution in Thailand, therefore, have generally examined the causes and consequences of the prostitution industry by focussing on the role of patriarchy, capital and the state in their maintenance of these two modes of power. The tendency of even feminist studies of politics to view the state as a "unitary, monolithic subject" that is effective “in securing the social conditions of reproduction and thereby women's subordination" fails, according to Maila Stivens, to deal adequately with the role of the state in Southeast Asia, which is best seen "as a complex of relations, the site of class struggle." insights into the state are needed, "the functionalism, instrumentalism and ethnocentrism of

\footnotetext{
${ }^{41}$ Penny van Esterik, "Thai Prostitution and the Medical Gaze," Gender and Development in Southeast Asia, eds. Penny van Esterik and John van Esterik (Montreal: Canadian Asian Studies Association, 1992) 135.

${ }^{42}$ Stivens, 18.
} 
much western theorising will all cause difficulties. We shall need more subtle analyses of how gender relates to the complex of relations forming the state in the various countries of the region. ${ }^{, 43}$ Such a subtle analysis, I argue, requires a better understanding of the role of meaning in the workings of the state. In particular, it requires an understanding of the international construction of meaning, the construction of which Western feminist analyses are a part, and the impact this process has on non-Western states.

Indeed, feminist theorizing about prostitution in Thailand has itself tended to repeat colonizing representations of Thai women, Thai culture and the Thai state. Such representations fail to acknowledge the diversity and contestation surrounding these very categories. These representations, furthermore, are themselves part of the international politics of representation. This is the discursive construction of 'other' cultures/nations in ways that present cultures as "bounded wholes" and that implicitly or explicitly valorize one's own culture and delegitimize others. The blindness to this process evident in much feminist theorizing in prostitution has been a source of its inability to see one of the central political processes in the formation of prostitution policy - that is, the construction of national cultural and gender identities in resistance to Western hegemony. This constructive process has both opened up, and closed down, spaces for political struggle. By looking at the state as a site of discursive struggle over identity construction we can begin to see how

${ }^{43}$ Stivens, 20. 
political actors, including women, engage with the state in order to 'do something' about prostitution.

This tendency to take culture and gender as given has also been marked in political science analyses of Thai politics which have failed to see the full scope of political struggle and the operation of power - particularly their own power to produce and represent Thailand in a way that silences these struggles and presents Thailand as backward or traditional and unchanging. I draw on Edward Said's approach to cultural imperialism to show how imperialism is fundamentally a discursive phenomenon that enables economic or military domination. I also incorporate post-colonial approaches to examine national identity. as a constructive process, one that occurs in the context of resistance to cultural imperialism. Finally, I draw on feminist post-colonial accounts of how gender is central to the construction of national identity.

\section{International Relations, Culture and National Identity}

While International Relations ${ }^{44}$ and Comparative Politics have taken the nation-state as their foundational unit of analysis for many years, recent theoretical developments have opened up the question of the social and political construction of nation-states themselves. Critical theorists examine the nation-state not as a pre-given and essential entity but as a constructed, and contested, symbolic terrain. Post-structuralist scholars, following Foucault,

\footnotetext{
${ }^{44}$ I use 'International Relations' here to mean the discipline of the study of real world 'international relations'.
} 
argue that power operates in the very construction of such categories as 'nation-state' by freezing the vagaries of social life into a particular 'reality' and by 'forgetting' the process of constructing that reality. Instead this construction is presented as pre-existing truth, which is outside the operation of power. ${ }^{45}$ In a related conceptual move, International Relations and Comparative Politics schools have tended to treat 'culture' as an unproblematic category, where it is often rescripted as national identity and viewed as a distinct and self-contained entity. Comparative Politics at least has had the advantage of a long history of study of nationalism and national identity, which, from the beginning, had to admit to the imagined property of the phenomenon. ${ }^{46}$ International Relations, on the other hand, which viewed itself as the study of the interaction of pre-constituted nation-states often failed (until very recently) to investigate the question of nation-ness. Instead, national identity was dismissed as a matter of 'internal' rather than 'external' politics. This assumption of preconstituted cultural entities has underlain some seemingly irresolvable debates over universality and cultural relativism. Debates over the applicability of international human rights standards, for example, often have foundered on the question of universality versus cultural relativism.

${ }^{45}$ R.B.J. Walker, "Sovereign Identities and the Politics of Forgetting," Inside/Outside: International Relations as Political Theory (New York: Cambridge University Press, 1993) 159-183.

${ }^{46}$ See, for example, Ernst Renan, "What Is a Nation?" Becoming National: A Reader, eds. Geoff Eley and Ronald Grigor Suny (New York: Oxford University Press, 1996). Original lecture delivered in 1882 at the Sorbonne. 
Alternatively, the question of culture, in political science, has been dismissed under the rubric of 'ideology' or it has been ignored altogether in favour of 'state interests' or 'economics' (of either Marxist or liberal varieties). As Rob Walker has argued, 'culture' in International Relations was a victim first, of the accepted foundational ontological division between idea and matter (addressed in part by Gramscian notions of hegemonic practices)and second, the conflict of universalism and pluralism articulated as national identity and assigned to the discipline of anthropology. ${ }^{47}$

A fundamental challenge to International Relations' conception of, or ignoring of, culture came in the form of post-colonial critiques. Most notable of these was Edward Said's Orientalism, which exposed the construction of the culture of the colonized 'other' (through literature and the nascent social sciences as well as official rhetoric) as a (if not the) central mode of operation of imperialism. While Orientalism has been heavily criticized for its overestimation of Western power, the book remains most important, as Frederick Buell has expressed it, for its "demystification of the notion of the local production of culture and its revelation of how individual cultures, along with the idea of 'culture', have been produced

${ }^{47}$ R.B.J. Walker, "The Concept of Culture in the Theory of International Relations," Culture and International Relations, ed. Jongsuk Chay (New York: Praeger, 1990) 5-6. The strict maintenance of disciplinary boundaries between political science (particularly International Relations) and anthropology has meant that few in political science have drawn upon the long history of theorization of and investigation into culture that the field of anthropology provides. 
as part of the construction of geopolitical relationships. ${ }^{, 48}$ That is, the construction of cultural difference is, in fact, part of the international operation of power. Despite the potentially revolutionary impact of such an insight into the role of culture in international relations, discussions of culture and national identity remain on the fringes of International Relations inquiry. ${ }^{49}$

This decided disinterest in nation and culture is a function of the Western-centrism of International Relations theory production. Only those in a culturally hegemonic position could afford to assume that culture is immaterial. ${ }^{50} \mathrm{It}$ is also a function of the a-philosophical turn in American International Relations theorizing, so that the 'ideational' realm - that is, culture in the sense of a web of social meaning - was dismissed as 'idealist. ${ }^{51}$ Where culture has begun to creep into the school of International Relations it has been in the form of concern over threats to 'Western civilization' as in Huntington's "Clash of Civilizations"

${ }^{48}$ Frederick Buell, National Culture and the New Global System (Baltimore: Johns Hopkins UP, 1994) 37. Buell quotes Masao Miyoshi's argument that the impact of Said's book in 1978 was indeed surprising given that similar ideas had been expressed in anticolonial liberation ideologies since 1945 and the civil rights movement since the $1960 \mathrm{~s}$. See Masao Miyoshi, Off Center: Power and Culture Relations between Japan and the United States (Cambridge, Mass, Harvard UP, 1991).

${ }^{49}$ See Walker, "The Concept of Culture," 7-8.

${ }^{50}$ Immaterial here is given the full meaning of the word, that is culture is both 'not important' and, second and relatedly, it is 'not material' i.e. 'not real' in the sense that money or power is real but it is a 'cover' for more 'real/material' interests.

${ }^{51}$ Walker, "The Concept of Culture," 7. 
and, again, fears over cultural relativism. ${ }^{52}$ In both these cases, however, culture is again seen as a bounded entity rather than a constitutive process. From a non-hegemonic perspective as we shall see in this thesis - it is quite clear that the construction and representation of cultural/national identity is in fact a central part of international relations of power and should, therefore, be a part of International Relations inquiry.

A most notable exception to this silence in International Relations is David Campbell's work on American foreign policy and the constitution of the American self..$^{53}$ Campbell's insistence on the importance attached to the construction of national identity by foreign policy makers through the opposition of the national self to less desirable 'others', hints at what post-colonial thinkers like Said have been arguing: the construction of identity is a material part of global power relations.

The interdisciplinary study of globalization has proved more open to this concept. While, at first, studies of globalization focussed on the 'new' phenomenon of the rapidly giobal spread of cultural influences breaking down 'old' national cultures, analysts gradually came to contest the concept that cultures were ever closed, hermetically (or hermeneutically) sealed wholes. Robert Cox's reintroduction of Gramscian ideas into International Relations theorizing has also brought intersubjective meanings and ideas back into the theorization of

\footnotetext{
${ }^{52}$ See Samuel Huntington, “The Clash of Civilizations?" Foreign Affairs (Summer 1993): 22-49.

${ }^{53}$ See David Campbell, Writing Security: United States Foreign Policy and the Politics of Identity (Minneapolis: University of Minnesota Press, 1992).
} 
international order as part of the triumvirate of material capabilities, institutions and ideas which constitute the 'historical structures' of social forces, states and world orders. International hegemony, therefore, rests not only on a preponderance of material capabilities but on reinforcing norms or images of world order and their institutionalization. ${ }^{54}$ While Cox's Gramscian notion of hegemony opened up the space for theorizing about the place of meaning in international relations, it did not include the actual constitution of social entities as an operation of power. However, Cox's model does show that hegemony is more than economic/material power and that shifts in inter-subjective meanings can alter material relations and institutions and vice versa. And, as Mark Neufeld has argued, a small but growing number of post-modern, feminist and critical theorists have begun to explore the intersubjective meanings that constitute global orders, challenging the dominance of positivist orientations in the field. ${ }^{55}$

However, the creation of cultural difference between, rather than within, nations is an under-explored aspect of international relations. Said's work, for example, has made it apparent that this aspect of global power relations requires further analysis. I argue in this thesis, that national identity is, in fact, constructed in this international interaction. This process began in the age of imperialism. Imperialist representations of other cultures were

\footnotetext{
${ }^{54}$ Robert Cox, "Social Forces, States and World Orders," Neo-Realism and its Critics, ed. Robert Keohane (New York: Columbia University Press, 1986) 204-254.

55 Mark Neufeld, The Restructuring of International Relations Theory (Cambridge: Cambridge University Press, 1995) 91-94.
} 
both drawn upon and resisted by the objects of these representations as part of a global struggle over representation and construction of identities. The importance of the global in the construction of local or national identities is taken up by post-colonial theorists of national identity.

\section{The Construction of National Identity}

In my approach to 'national identity' in Thailand I draw on the work of postcolonialists, such as Partha Chatterjee and Thongchai Winichakul, who emphasize the constructed nature of 'the nation' and the global interactions that shape that construction. The idea that nations are constructed entities, however, already has a respected place in comparative studies.

The new classics of nationalism studies by Ben Anderson, Eric Hobsbawm and Ernst Gellner emphasized the 'creation' and 'imagining' of national identities rather than trying to uncover a primordial source of nationalist identification. Gellner has argued: "Nationalism is not the awakening of nations to self-consciousness: it invents nations where they do not exist." 56 Anderson, however, argued that Gellner "is so anxious to show that nationalism masquerades under false pretences that he assimilates 'invention' to 'fabrication' and 'falsity', rather than to 'imagining' and 'creation'." Where, for Anderson, “communities are to be distinguished, not by their falsity/genuineness, but by the style in which they are

\footnotetext{
${ }^{56}$ Ernst Gellner, c.f. Benedict Anderson, Imagined Communities (New York: Verso, 1991) 6 .
} 
imagined." 57 According to Anderson, the nation is fundamentally imagined "because the members of even the smallest nation will never know most of their fellow-members, meet them, or even hear of them, yet in the minds of each lives the image of the communion." Anderson's Imagined Communities, according to Geoff Eley and Ronald Suny, marked "the moment of transition in the literature from structural and materialist analyses of nationalism to an approach stressing the meanings and effects of a 'sense of nationality'." 59 This transition also opened up the way for studying the construction and maintenance of national identity as an operation of power.

Eric Hobsbawm uncovered the process by which the state became a central agent in the creation of national identity with the transformations in state forms to the post-French revolution modern state, "defined as a (preferably continuous and unbroken) territory over all of whose inhabitants it ruled, and separated by clearly distinct frontiers or borders from other such territories" with unprecedented reach into the farthest corners of this territory. ${ }^{60}$ National identity became a way for these states to bind their citizenry to them, to secure their loyalty, particularly in war. While Hobsbawm carefully notes that these were not mere exercises of "manipulation from above" but built on other non-state based nationalisms, the

\footnotetext{
${ }^{57}$ Anderson, "Imagined Communities," 6.

${ }^{58}$ Anderson, "Imagined Communities," 6.

${ }^{59}$ Geoff Eley and Ronald Girgor Suny, eds. "Introduction," Becoming National: A Reader (New York: Oxford UP, 1996) 24.

${ }^{60}$ E.J. Hobsbawm, Nations and Nationalism since 1780 (London: Cambridge UP, 1992) 80 .
} 
state itself was clearly indebted to the creation and maintenance of national identity writ large in order to build and maintain its own legitimacy. ${ }^{6 \mathrm{I}}$ That is, there were no "more primordial" and smaller "nationalisms" on which the state built. Rather, nationalism built on some previously constructed aspect of social reality that constituted 'group-ness' for a variety of people and therefore resonated with the populace to some degree. Further, the success of this state enterprise rested on the ability to 'forget' this process of national imagining and rather to present it as a 'natural' phenomenon. Nonetheless, Hobsbawn makes clear the importance of the construction of 'national identity' to the survival of the state itself.

While Western analyses of national identity have clearly illustrated the imagined and constructed nature of the nation, it has been the task of post-colonial theorists to point to the global nature of identity construction - of nationalism as resistance to imperialism - while at the same time drawing attention to the role of national political elites in constructing particular national identities. ${ }^{62}$ Thongchai Winichakul's exploration of the construction of the Thai nation emphasized the degree to which the elite invented Thailand in a way that supported its hegemony. ${ }^{63}$ Thailand, he argued, was not a pre-given entity, defended from the

\section{${ }^{61}$ Hobsbawm, 91-92.}

${ }^{62}$ Indeed, it has been the task of post-colonial theorists to point to the unique nature of national identity construction in the South, refuting Hobsbawm's dismissal of Third World nationalism as a 'derivative discourse.' See Partha Chatterjee, Nationalist Thought and the Colonial World: A Derivative Discourse? (London: Zed Books, 1986).

${ }^{63}$ Benedict Anderson, "Radicalism after Communism in Thailand and Indonesia," New Left Review 202 (November-December 1993) 13. 
ravages of colonialism by a wise monarchy and carefully brought into modernity with its identity intact. Thailand, "was a discursive construct. The Thai monarchs were merely the instrument of the new discourse. And Thainess was nothing but a construct of humble origin." Building from Anderson's analysis, Thongchai examined the practice of geography (mapping and surveying) as another 'technology' - other than language - through which the nation was imagined and made real. Through the technology of mapping, a "we-self" distinct from the "enemy-other" was constructed and manipulated by elites. By pointing to the constructed nature of the Thai nation, Thongchai sought to open the way for "counterhegemonic" constructions of the nation in service to progressive politics. ${ }^{65}$

Thongchai criticized Anderson's failure to recognize the importance of 'the other' in the imagining of the nation. As post-colonial theorists point out, national identity is not simply based on imaginings of 'internal' samenesses but also of 'external' differences. The age of colonialism marked the heights of national romanticism in Europe and consolidation of imperial/national identity in its 'difference' from the colonial 'other' - a difference which is always constructed in hierarchical terms which always underwrote the imperial exercise of power over the 'lesser peoples' of the colonies. Said's latest book, Culture and Imperialism, back-pedals on the Western-determinism of Orientalism and allows that "it was

\footnotetext{
${ }^{64}$ Thongchai Winichakul, Siam Mapped (Chiang Mai: Silkworm Books, 1994) 12.

${ }^{65}$ Anderson, 'Radicalism', 13.
} 
the case nearly everywhere in the non-European world that the coming of the white man brought forth some sort of resistance," particularly, nationalist movements. ${ }^{66}$

What remains most important, however, is that Said brought to our attention that imperialism was, first and foremost, discursive. It created the Orient as an object suited to in fact, which demanded - imperial authority. ${ }^{67}$ As Said reminds us, furthermore, "the enterprise of empire depends upon the idea of having an empire." ${ }^{.68}$ As he argued in Orientalism, this goes beyond seeing orientalism - the discursive creation of the Orient - as justification of empire, rather orientalism came before empire, it made empire possible. It was enabling, therefore, rather than justificatory. ${ }^{69}$

It is a central point of this thesis that the colonized were well aware of the discursive nature of this process, of the importance of representation and identity construction to the imperial project. The response, therefore, was to construct one's own identity as a nation. For colonized states the process of national identity construction was marked by the need to address both the colonial powers and local inhabitants by proving oneself a national state, now established as the only legitimate form of state, and a civilized state and, at the same time, producing an identity distinct from Western colonial identity. Thus colonized states both resisted and acquiesced to colonialism's constructions.

\footnotetext{
${ }^{66}$ Edward Said, Culture and Imperialism, (New York: Alfred A. Knopf, 1993) xii.

${ }^{67}$ Said, Culture, 9.

${ }^{68}$ Said, Culture, 11.

${ }^{69}$ See Said, Orientalism, 39-40.
} 
Partha Chatterjee's account of anti-colonial nationalism argued that rather than being a copy of European forms of nationalism, as Anderson argued, anti-colonial nationalism marked out a territory of acquiescence in the material realm (the economy, statecraft, science and technology) "a domain where the West had proved its superiority and the East had succumbed. In this domain, then, Western superiority had to be acknowledged and its accomplishments carefully studied and replicated." 70 But nationalism also marked out a domain of resistance, an "inner" "spiritual" realm which bore "the 'essential' marks of cultural identity." Chatterjee wrote: "The greater one's success in imitating Western skills in the material domain, therefore, the greater the need to preserve the distinctness of one's spiritual culture."7l Importantly, these realms were gendered. The inner realm constituted the realm of the family, and of women. This was precisely the realm that European criticism of 'Indian tradition' had focussed on by arguing, for instance, that the treatment of women in Indian tradition was "barbaric. ${ }^{72}$ And, while Chatterjee does not explicitly state this, the outer realm is presumably the realm of men, whose modernity would not be threatening to the nation and indeed, good for the state.

Thus, post-colonial theorists made it clear that the construction of national identity and difference occurs in a global context of struggle over representation and identity. Further,

\footnotetext{
${ }^{70}$ Partha Chatterjee, The Nation and Its Fragments: Colonial and Postcolonial Histories (Princeton: Princeton UP, 1993) 6.

${ }^{71}$ Chatterjee, The Nation, 6.

${ }^{72}$ Chatterjee, The Nation, 6.
} 
Chatterjee's analysis shows that gender plays a key role in the establishment of identity and difference, that the identity of women was central to grounding national identity. In this thesis I argue that gender and sexual behaviour were, in fact, key in undergirding constructions of national identity and difference. Further, it is for this reason that prostitution policy is centrally shaped by these concerns. To underline this argument I draw on the feminist analysts of national identity, who have drawn out the role of gender in national identity.

\section{Gender, Sexuality and National Identity}

Feminist analysts have begun to draw attention to how constructions of 'the nation' have shaped and been shaped by notions of gender. The gendered nature of the nation is clear to Anne McClintock who has argued that "nations have historically amounted to the sanctioned institutionalization of gender difference."73 Thus, particular formulations of national identity encompass, and depend upon, particular "gender regimes," as R. W. Connell deems them. Acknowledging this link, Deniz Kandiyoti argued that "nationalist histories of states and their politics of national identity can shed considerable light on the nature and transformation of gender regimes." 74 In the next section I outline the ways in which

${ }^{73}$ Anne McClintock, "Family Feuds: Gender, Nationalism and the Family," Feminist Review 44 (1993): 61.

${ }^{74}$ Deniz Kandiyoti, "Identity and its Discontents: Women and the Nation," in Colonial Discourse and Post-Colonial Theory: A Reader, eds. Patrick Williams and Laura Chrisman (New York: Columbia UP, 1994) 378. 
constructions of gender and sexuality are interdependent with constructions of 'the nation' and the implications this interdependence has for the study of prostitution policy.

Like Chatterjee, Anne McClintock points to the ways in which gender is used to resolve the tensions within nationalism. Gender, according to McClintock, can resolve the "Janus-faced" nature of national historical time (because it appeals as both a modernizing force and a preserver of tradition) by figuring women as:

the atavistic and authentic 'body' of national tradition (inert, backward-looking, and natural), embodying nationalism's conservative principle of continuity. Men, by contrast, represent the progressive agent of national modernity (forward-thrusting, potent and historic), embodying nationalism's progressive, or revolutionary principle of discontinuity. Nationalism's anomalous relation to time is thus managed as a natural relation to gender $^{75}$

The importance of national identity for the post-colonial state cannot be overemphasized. And the implication of the importance attached to this identity is most marked for female bodies. As Aihwa Ong and Michael Peletz point out:

the post-colonial state, in its varied tasks of building a national identity, meeting challenges from communally-based interest groups, and representing itself as a modern nation, is continuously engaged in defining the composition and form of political society. This making and patrolling of the body politic is an ongoing struggle that often entails the inscription of state power on women's (and to a lesser extent, men's) bodies. $^{76}$

${ }^{75}$ McClintock, 66.

${ }^{76}$ Aihwa Ong and Michael G. Peletz, "Introduction," Bewitching Women and Pious Men: Gender and Body Politics in Southeast Asia, eds. Aiwha Ong and Michael G. Peletz, 
While the importance of the link between gender and national identity has often been ignored by male scholars of national identity, as well as by Western feminist scholars, it has become an issue of increasing concern for post-colonial feminists.

Women's particular relation to the nation is a product of the literal and figurative roles that women's bodies play in the reproduction of the nation. Nira Yuval-Davis and Floya Anthias have laid out the various ways that women can be implicated in national processes and state practices:

as biological reproducers of members of ethnic collectivities; as reproducers of the boundaries of ethnic/national groups; as participating centrally in the ideological reproduction of the collectivity and as transmitters of its culture; as signifiers of ethnic/national differences - as a focus and symbol in ideological discourses used in the construction, reproduction and transformation of ethnic/national categories; as participants in national, economic, political and military struggles. 7

Thus, the control of women's bodies and sexual behaviour are central to these processes of building and maintaining national identity.

In particular, it is women's sexual bodies that figure prominently in the nationalist imaginary. As biological and cultural reproducers of the nation, women's bodies are significant 'boundary markers' of the nation. Jan Pettman has argued 'the use of women as boundary markers suggests why the control of women and especially their sexuality is

(Berkeley: University of California Press, 1995) 6.

${ }^{77}$ Floya Anthias and Nira Yuval-Davis, Woman-Nation-State (New York: St. Martin's Press, 1989) 7. 
strategic in the maintenance and reproduction of identity and difference, and so of 'the community'." ${ }^{78}$ The importance of women's reproductive role and the avoidance of miscegenation is most clear in ethnic nationalisms, but the maintenance of women's honour as the honour of the nation is also part of the symbolism of what Yuval-Davis has called "cultural nationalisms," which are based on distinctive cultural as opposed to ethnic identities. ${ }^{79}$ The symbolism of 'woman as nation' to be protected by the manly state resonates with many instances of modern nationalism. Importantly, Deniz Kandiyoti has pointed out that the centrality of women to the nation is constantly reaffirmed in the "intense preoccupation-with women's appropriate sexual conduct. The latter often constitutes the crucial distinction between the nation and its 'others." women's appropriate sexual conduct is key to the survival of the (imagined) nation. Thus, as Kandiyoti argued, "women's bodies in particular are commonly used to symbolize and threaten transgressions of social boundaries." They therefore require close control by the state that seeks to stabilize national identity. ${ }^{81}$

Sexuality is clearly central in the construction of imperialist identities. It is no coincidence that sexuality became a central concern of the European state during the Imperial

\footnotetext{
${ }^{78}$ Jan Jindy Pettman, Worlding Women: A Feminist International Politics (New York: Routledge, 1996) 59.

${ }^{79}$ Nira Yuval-Davis, Gender and Nation (London: Sage, 1997) 45.

${ }^{80}$ Kandiyoti, 377.

${ }^{81}$ Ong and Peletz, 6.
} 
era, which was also the era of the formation of the middle class. In Europe, it was 'respectability' on which the newly formed middle class based its identity, differing itself from both the 'uncouth' lower class and the 'decadent' upper class, according to George Mosse. ${ }^{82}$ Nationalism, Mosse argues, "absorbed and sanctioned middle class morals and played a crucial part in spreading respectability to all classes of the population." 83 Respectability became, therefore, the basis of nationhood. This was made clear in the discourse of 'civilization' and 'civilized' behaviour based on the control of 'passions,' which differentiated Europe from other cultures considered depraved. ${ }^{84}$ This differentiation also rested on gendered distinctions - where European civilizations were considered manly in their bearing and non-European civilizations feminine in their passivity. Colonized men were considered not 'properly' masculine because of their inability to 'control their passions'.

For the colonized, colonialism was often understood as a loss of masculinity. Postcolonial theorists such as Ashis Nandy and Franz Fanon have equated colonization with feminization. ${ }^{85}$ Cynthia Enloe has pointed to the ways that anti-colonial nationalism "typically has sprung from masculinized memory, masculinized humiliation and masculinized hope. Anger at being 'emasculated' - or turned into a 'nation of busboys' - has

\footnotetext{
${ }^{82}$ George Mosse, Nationalism and Sexuality (New York: Howard Ferrig, 1985) 9.

${ }^{83}$ Mosse, 9.

${ }^{84}$ Mosse, 17.

${ }^{85}$ Yuval-Davis, 53.
} 
been presumed to be the natural fuel for igniting a nationalist movement." often been a process of 'hypermasculinization' in national movements - a re-masculinization through the glorification of "aggression, achievement, control, competition and power" according to Nandy. ${ }^{87}$ Particularly important was the control of women. Lily Ling has pointed to the process of "hypermasculine developmentalism" in East Asia, including support for the sex industry, as a reaction to the "feminizing" of Asian societies by the West. In a militarized setting, women's bodies can be particularly restricted. Joanne Sharpe has argued that "prevention of foreign penetration of the motherland - and women's bodies as symbols of it - is at the very heart of national-state security. The female is a prominent symbol of nationalism and honour. But this is a symbol to be protected by masculine agency." ${ }^{88}$ At the same time, militarized societies may promote sexual service industries for their 'own boys', at which time it becomes (some) women's national duty to service the nation's manhood. Women's sexual self-determination, on the other hand, is threatening to the national order.

\footnotetext{
${ }^{86}$ Cynthia Enloe, Bananas, Beaches and Bases (Berkeley: University of California Press, 1989) 44.

87 Nandy c.f. L.H.M.Ling "The Other Side of Globalization: Hypermasculine Developmentalism in East Asia," paper presented at the International Studies Association meeting 18-22 March 1997, Toronto. 10.

88 Joanne Sharpe, "Gendering Nationhood: A Feminist Engagement with National Identity," Body Space, ed. Nancy Duncan, (New York: Routledge, 1996) 100.
} 
The centrality of gender and sexuality to constructions of national identity certainly cast issues of prostitution policy in a light other than that of simple economic or 'patriarchal' considerations. Given the importance of national identity to post-colonial societies, we must take account of this important discourse in shaping the policies which affect women's lives. Certainly, policies designed to address prostitution, whether to encourage or discourage it, are directed at disciplining particular masculine and feminine identities and sexual behaviours - behaviours and identities that undergird the 'national body.'

\section{Political Agency, Gender and National Identity}

The importance of sexuality and the control of women's bodies to the nationalist project, however, does not predetermine women's situation. As Anthias and Yuval-Davis have pointed out, the roles that women play in national identity formation will be differently constructed in different historical contexts and the importance of each will vary. ${ }^{89}$ Indeed, the implications of the importance of women's roles will differ according to the political struggles within a particular historical location. On the one hand, for instance, nationalist movements have been well known to restrict women's roles in social and political life in the name of preserving the purity of the nation. Women's bodies also become the site of national resistance to colonialism, which, as Chatterjee demonstrated, often targeted the family and the treatment of women as evidence of the need for colonial intervention. On the other hand,

\footnotetext{
${ }^{89}$ Anthias and Yuval-Davis, 7.
} 
national movements have provided an opportunity for women to participate in political processes and to push for a re-shaping of the gender order by taking up their roles as mothers of the nation, for instance, to demand changes in the gender and sexual order. Kumari Jayawardena has also shown us how feminist movements have often arisen in tandem with nationalist movements. ${ }^{90}$

Further, differences among women put them in varying positions vis à vis the dominant constructions of national identity. Differences in class are particularly central, in this study, in the ways in which women interact with the discourse of national identity. Deniz Kandiyoti has pointed out that, far from being a determinate discourse, the Janus-faced nature of national identity generates "highly fluid and ambivalent field of meanings which can be reactivated, reinterpreted and often reinvented at critical junctures of the histories of nation-states." Those meanings, therefore, are open to intervention and subversion by political actors.

These constructions, then, of gender, nation, sexuality and class are mutually determining rather than predetermined. Their interdependencies and tensions mean they are contested and shifting over time and in different contexts. The state can attempt to manage these shifting categories. Indeed, the state becomes hegemonic when a particular set of meanings which legitimize the state's power are stabilized. But these meanings are always open to challenge, and politics is the process of challenging them. Rather than there being

\footnotetext{
${ }^{90}$ Kumari Jayawardena, Feminism and Nationalism in the Third World (London: Zed Books, 1986).
} 
one singular discourse of gender determining women's lives or shaping policy concerning women, there are always other discourses which overlap and create tensions in and struggles over the way women are constructed. The outcomes of these struggles cannot be predetermined, and there are often unexpected outcomes that counter powerful interests.

Thus while one's subject position as, for instance, a 'woman' or a 'prostitute' may be determined by larger social forces, this position may be taken up and challenged or subverted by political agents in the course of political struggle. This thesis, therefore, follows a historical chronology because of the importance of the weight of the past in shaping the political possibilities in the present. Iexamine what subject positions have been created - that is, how 'the prostitute' or 'women' have been constructed - and what the implications of those particular constructions are. In particular, I look at how certain constructions open up or close down possibilities for certain voices to be heard in politics.

It is in this way that I see actors as both constituted by and constitutive of discourses. As Ernesto Laclau and Chantal Mouffe have argued, identities need to be articulated in discourse. ${ }^{91}$ Such articulation creates places from which actors can speak and be heard. But, as Derrida has made clear, those identities are always articulated in a manner that establishes hierarchy, valuing one identity over another - male over female, national over foreign; good woman over bad. Thus, within any dualist construction, one identity provides a more immediately legitimate place from which to speak. That is, as meaning creators, actors

\footnotetext{
${ }^{91}$ See Ernesto Laclau and Chantale Mouffe, Hegemony and Socialist Strategy (New York: Verso, 1985).
} 
engage with and make use of discourses in order to make themselves heard within what Jane Jenson has called the "universe of political discourse"-the field of hegemonic meanings that structure dominant political understandings. Actors that can take up the 'valued' positions created within that universe will be most successful in making themselves heard in the political arena. In Thailand, where the universe of political discourse has been centrally structured around concerns about national identity, those who appeal to these concerns will garner political influence.

While we can abstractly designate the state's interest in, for instance, controlling women's sexuality and maintaining the conditions of capitalist accumulation, the actual ways in which these interests are worked out and struggled over are a matter of historical investigation. ${ }^{92}$ Robert Connell has argued, for example, that the state is not inherently patriarchal. Rather, it is historically constructed as patriarchal in a "political process whose outcome is open." ${ }^{.93}$ Connell explained that the state is "at the centre of a reverberating set of power relations and political processes in which patriarchy is both constructed and contested." However, the state does play a vital role in constituting social categories and therefore, the interests at play in sexual politics. ${ }^{94}$ In turn, these interests and identities

\footnotetext{
${ }^{92}$ See Jane Jenson, "Gender and Reproduction: Or, Babies and the State," Studies in Political Economy 20 (Summer 1986) 10 for her critique of functionalist accounts of the state and patriarchy on these grounds.

${ }^{93}$ R.W. Connell, Gender and Power: Society, the Person and Sexual Politics (Cambridge: Polity Press, 1987) 129.

${ }^{94}$ Connell, 130
} 
constructed by the state may be able to take up their (negatively or positively) legitimated identity to make demands on the state. Thus, women who are interpolated as mothers of the nation may use this position to gain political influence. As Pringle and Watson have argued: "It is in the process of engagement with the arenas of the state that interests are constructed. Through creating a framework of meanings, through the use of particular languages or discourses, certain possibilities for change emerge." An approach which examines the constitution of these identities, therefore, also allows us to see how these identities are taken up and/or resisted in political struggle and how some voices come to be legitimized and others delegitimized.

In this thesis I argue for a more sophisticated understanding of the role of the state as a site of struggle over meaning and the eventual institutionalization of meaning. In particular, in order to understand the Thai state's response to prostitution we need to understand the symbolic role of gender and sexed bodies in the establishment of national identity. I look at prostitution policy as productive of identities (rather than merely acting upon pre-given identities). These identities include gender and national identities. Prostitution policy is central in creating the prostitute as well as the ideal Thai woman and the ideal Thai man. Such an approach - which focuses on the politics of meaning around

${ }^{95}$ Rosemary Pringle and Sophie Watson, “'Women's Interests' and the Post-Structuralist State," Destabilizing Theory: Contemporary Feminist Debates, eds. Michele Barrett and Anne Phillips, (Stanford: Stanford University Press, 1992) 69. 
prostitution - allows us to see the political struggles of groups within Thailand, particularly women, to shape prostitution policy.

Thus, I look at prostitution and the prostitute as a subject position created through the overlapping discourses on gender, national identity and class, rather than viewing prostitution as an objective activity or the prostitute as a stabilized subject involved in that activity. This is not to say there are no actual women working in the industry of prostitution. There most definitely are. The meaning of that activity, however, is not inherent. Rather it is historically and politically determined. One's experience, therefore, is, in part, shaped by that meaning; and certainly, state policies are shaped by the hegemonic meanings given to prostitution. These meanings, however, are constantly struggled over and challenged. They are constituted in conjunction with the meanings of gender, class and national identity. As Shannon Bell has pointed out, the prostitute body is the terrain of the inscription of identity and otherness, which is produced essentially as "a negative identity by the bourgeois subject, an empty symbol filled from the outside with the debris of the modern body/body politic, a sign to women to sublimate their libidinal body in their reproductive body." 96 The prostitute therefore, serves as a very powerful symbol for the creation of class, gender and national identities. I examine prostitution policy in Thailand as a- site of the production of and contestation over these identities.

96 Shannon Bell, Reading, Writing and Rewriting the Prostitute Body (Bloomington: Indiana UP, 1994) 72. 


\section{Chapter 2: Imperialism, Gender and Sexuality}

Women's importance to the 'Thai nation' is historically specific. Indeed, the concept of a Thai nation itself is a historical construct. As Thongchai Winichakul points out, history is written in a way that "presupposes the definite presence of a political or socioeconomic 'thing', a kingdom or a state since time immemorial." Traditional histories recount the intelligence of the Thai monarchs in protecting the state from colonisation and transforming traditional 'Siam' into the modern nation of 'Thailand', while preserving what are deemed to be the essential characteristics of Thai culture, particularly Buddhism and the monarchy. Rather, Thongchai insists that the nation must be regarded as a discursive construct, carefully constructed over time and space, and always in relation to an 'other', a negative identity.

This chapter examines how gender and sexuality became central markers of national identity and difference between the 'civilized' West and 'uncivilized' Siam in the 1800s and early 1900s. In particular it explores how the Siamese state was constructed as 'feminine' and Siamese gender relations as 'uncivilized' by visiting Westerners. Secondly, it shows how Siamese policies on polygamy and, eventually, prostitution were shaped by the tension between appearing as 'civilized' to the imperial powers, while at the same time, resisting imperial authority through the assertion of male sexual prerogative in polygamy and prostitution.

I Thongchai Winichakul, Siam Mapped: A History of a Geo-body of a Nation (Chiang Mai: Silkworm Books, 1994) 12. 
As Thongchai has pointed out in his history of the creation of Thai identity, the coming of the Europeans in the mid-1800s marked an opposition of two distinct conceptions of statehood - one the European nation-state of contiguous borders and presumably identifiable citizenry; the other the overlapping sovereignties and tributary systems of Asia. In Siam, the idea of a nation-state had to be introduced and made real - in part through the mapping of boundaries which had never previously existed - in order to resist the encroachment of the imperial powers. The inculcation of a national identity was a major concern of the governments of the period, beginning particularly with King Vijiravudh. These "official nationalisms" - as Benedict Anderson has called them - were instruments of the state rather than popular movements. ${ }^{21}$ But while their effects are limited on the populace, the changes under these nationalistic programs inscribed new gender ideals among the elite. Elite women made use of their new position as icons of Thailand's modernity to agitate for change - first to end polygamy and then to rewrite prostitution legislation into the international language of social welfare.

Sex, Gender and the Boundaries of the Early Modern Siamese State

State concern over the control of women's bodies changed dramatically over the course of the "early modern" period (1500-1800) of Siamese history. ${ }^{3}$ While non-elite

${ }^{2}$ See Benedict Anderson, Imagined Communities (New York: Verso, 1991) 99-101.

${ }^{3}$ This designation of "early modern" comes from Anthony Reid, ed. Southeast Asia in the Early Modern Era: Trade, Power and Belief (Ithaca, NY: Cornell UP, 1993). 
women's sexual behaviour was of little concern to the state in the 1500 s and local custom did not stigmatize the exchange of sex for material gain, after the arrival of Westerners beginning in the mid-1500s - these realities slowly began to change.

Thongchai's study is particularly instructive for the purposes of this chapter in pointing out that the spatial conception of the Siamese nation was entirely different from the Western notion of contiguous boundaries and was instead based on "sacred topography" the spiritual realm of a king's sovereignty. ${ }^{4}$ Rather than borders of defended territory then, sovereignties were overlapping spheres of influence (conceived in a spiritual rather than a territorial sense) and relations between spheres managed through tributary relations of gift giving. In many ways, then, the king himself embodied 'the nation' as well as the state. Women played an important role in the harem as consorts and wives of the king, who produced both heirs to the throne and staff for the state. As well, elite women provided a bond between rulers and between rulers and nobles in a state and inter-state system based on tribute and alliances. Gifts of women as wives from nobles to the king, and vice versa, cemented ties of loyalty and service as between rulers of different spheres of influence. The sexual behaviour of elite women, particularly those within the king's harem, was closely guarded as their bodies marked the boundaries of the state. Thus, control of women's bodies increased with their closeness to the centre of influence, the king himself. One of the earliest available historical sources - the account of a French nobleman, Simon de la Loubere, in

${ }^{4}$ See Thongchai, Chapter 1. 
1697 - tells us that elite women were severely punished for adultery and promiscuity. The king's wives were most strictly guarded, being housed in the Inner Palace - a palace entirely of women presided over by the Queen or principle wife of the king, and guarded by female guards. The penalty for promiscuity on the part of a member of the king's harem was sometimes death. ${ }^{5}$

The punishment for promiscuous elite wives and daughters was to be sold to a particular noble who ran a brothel, the proceeds of which were taxed by the king. ${ }^{6}$ The ideology of the importance of women to the state is summed up in what was told to la Loubere by members of the Siamese court - "there is not a vertuous Woman in Asia, who in time of war chuses not rather that her Husband should kill her, than that he should suffer her to fall under the power of the Enemies [sic]." Clearly elite women's bodies were viewed as of national importance and the threats of 'whoredom' and death worked to circumscribe women's bodily freedom particularly among elite women.

Among commoner women, however, there was less sexual restriction. Divorce and remarriage were a matter of relative ease. La Loubere remarks with some amazement that women were allowed to remarry "the very day of the Divorce, they not troubling themselves

${ }^{5}$ Simon de la Loubere, The Kingdom of Siam (1697; New York: Oxford in Asia Historical Reprints, Oxford UP, 1969) 74.

${ }^{6}$ la Loubere, 74.

${ }^{7}$ la Loubere, 74. 
with the Doubt, that may thence arise touching the Father of the first Child, that may be born after the second Marriage."

Temporary marriages were often contracted with visiting traders. European men arriving on ships in Southeast Asia were, in the 1500s and early 1600s, often met by offers of a woman's companionship and services for a negotiated fee. ${ }^{9}$ While European men interpreted these offers as evidence of the promiscuity of native women, villagers viewed the exchange of sexual and domestic services for gifts, trading rights and the prestige linked to Europeans as part of the cycle of gift giving and support. ${ }^{10}$ Temporary husbands were expected to abide by the marriage arrangement and infidelity was not tolerated. The closeness of a woman's relatives and the status granted to women as family supporters meant there was swift retribution for the abuse of native wives. ${ }^{\text {I }}$ The arrangement was terminated with the end of the man's stay and the provision of pecuniary compensation. As a Dutch visitor in 1604 commented "so they leave each other in friendship, and she may then look for another man as she wishes, in all propriety, without scandal." ${ }^{12}$ Indeed, a woman's status after a

${ }^{8}$ la Loubere, 53.

${ }^{9}$ See the accounts in Anthony Reid, Southeast Asia in the Age of Commerce: Volume I: The Land below the Winds (New Haven: Yale UP, 1988) 49 \& 155.

${ }^{10}$ See Barbara Watson Andaya, "From Temporary Wife to Prostitute: Sexuality and Economic Change in Early Modern Southeast Asia," Journal of Women's History 9.4 (Winter 1998): 13-14.

"Andaya, 15. Andaya quotes a Northern Thai law that argues that parents would be 'distressed' at the physical abuse of their daughter.

${ }^{12}$ c.f. Reid, Vol. I, 155. 
marriage with a foreigner was often heightened, as she was viewed as enriched in both goods and knowledge. ${ }^{13}$

The temporary marriage arrangements offered distinct advantages for both parties, particularly when trade relations were involved, because women controlled much of the market activity in most parts of Southeast Asia. Liaisons between native wives and foreign husbands could provide the ground for economic and political power for the wives. In Siam in the 1640s a woman of Peguan (Burmese) descent - Osoet Pegu - who was the trading and sexual partner of several successive Dutch traders, was able to dominate Dutch-Siamese trade and wield a good deal of influence at the Siamese court. ${ }^{14}$ The husbands gained as well; as a 13th century Chinese visitor pointed out, the wives sold their husbands' goods "to a much better account than they could be sold for by wholesale."15 They also obviously benefited from the cultural passport that native wives provided, both in terms of language skills and cultural information. Women were not unknown in the region in diplomatic or emissary roles because of these connections and language skills. ${ }^{16}$ These abilities, then, provided social mobility and influence for women.

However, as feminist analysts of women's history in Siam/Thailand point out, while women's status differed widely according to their class status, they still occupied a secondary

\footnotetext{
${ }^{13}$ Andaya, 16.

${ }^{14}$ Reid, Vol. I, 165.

${ }^{15}$ Chou Ta-kuan, c.f. Reid, Vol.I, 155.

${ }^{16}$ Reid, Vol. I, 166.
} 
position to men. According to the ancient law, women had no civil status on their own but were merely the "chattels of men," who could be sold by their fathers or husbands. ${ }^{17} \mathrm{~A}$ woman without a father or husband had no right to lodge a legal complaint against a man who had molested her. ${ }^{18}$ Thus, while common women may have been able to choose their husbands and gain economic power and importance, they remained limited by their legal and class status, by the glorification of the role of motherhood and by being barred from full religious service as monks - a role that gave men social mobility and respect. ${ }^{19}$ While elite women served an important ambassadorial role, it was "diluted by heavy endorsement of

\footnotetext{
${ }^{17}$ Darunee Tantiwiramanond and Shashi Pandey, "The Status and Role of Thai Women in the Pre-Modern Period: A Historical and Cultural Perspective," Sojourn 2.1 (1987) 133.

${ }^{18}$ Sukanya Hantrakul, "Prostitution in Thailand," Development and Displacement: Women in Southeast Asia, eds. Glen Chandler, Norma Sullivan and Jan Branson (Clayton, Australia: Centre of Southeast Asian Studies, Monash University, 1988) 116.
}

${ }^{19}$ Women were only allowed to become mae chii, nuns who were and are treated more as servants to the monks than as religious figures in their own right. While this interpretation of Buddhism is historically specific - Sulak Sivaraksa argues that women were admitted into the Holy Order (Sangha) in Buddha's time and up until the 10th century AD when the fortunes of Buddhism became linked to royal houses - it has had profound effect on women's position in contemporary Thailand, since daughters cannot earn the merit associated with entering the monkhood that sons can. See Sulak Sivaraksa, "Buddhist Women: Past and Present," Siamese Resurgence (Bangkok: Asian Cultural Forum on Development, 1985) 52-59. Others, such as Chatsumarn Kabilsingh point to Brahminical influences from India in the Ayutthayan era (1350-1767) reinforcing the king's status and power and diminishing women's status by restricting them to the domestic sphere, subordinating them to male power and authority and denying them access to education. See Chatsumarn Kabilsingh, Thai Women in Buddhism (Berkeley: Parallax Press, 1991) 4-7. Women are also viewed as a sexual threat to the purity of the Sangha - hence monks are forbidden to come into physical contact with women. 
female passivity and adoration of female physical attractiveness, as revealed in classical Thai literature," which emphasized women's toleration of their husband's polygamy. ${ }^{20}$

As Europeans' true interest in the area became clearer over the course of the 1600 s, however, restrictions were placed on intermarriage with foreigners. By the mid- 1600 s it was already becoming clear that the intentions of Europeans in Southeast Asia went beyond simple trade. Beginning in 1657 a law prohibiting the marriage of Siamese women to foreigners was proclaimed. George Smith argues that the law was the result of the dispute over the religious teaching of children of 'mixed marriages'. European men had in 1641 obtained the reversal of the policy prohibiting the children of these marriages from leaving Siam in order to receive a Christian education. Osoet Pegu, however, successfully petitioned the king to keep her three daughters from her marriage to Dutch factor van Vliet in Siam. The 1657 law, Smith suspects, was designed to prevent Siamese subjects from allowing their daughters to marry foreign merchants "since this would entice them to accept a foreign religion."2I The prospect of religious take-over loomed even larger in the late 1600 s, with the French missions sent by Louis XIV. Indeed, la Loubere himself was part of a French mission

${ }^{20}$ Darunee and Pandey, 139, 135.

${ }^{21}$ George Vinal Smith, The Dutch in 17th Century Thailand (Northern Illinois University, Centre for Southeast Asian Studies, Special Report \#16, 1977) 102. It is also possible, however, that the king sought to increase his control over trading activities by eliminating female competition: at the time of la Loubere's visit, one princess was embroiled in a dispute with the king over his annulment of her trading rights. La Loubere, 101 . 
which hoped to convert the king (and, therefore, his followers) to Catholicism and anchor French influence in the country by stationing troops very near to the capitol, Ayuthaya. ${ }^{22}$

The differing attitudes of European and Chinese men towards temporary marriage, however, had also begun to undermine the status of local women. Port prostitution began to appear in the late 1500 s because of the "different expectations" of European and Chinese men, according to Anthony Reid. However, it mainly involved the slave women of noblemen. ${ }^{23}$ Women who were captured in war became absolute slaves (as opposed to ascribed or debtor slaves) often forced into prostitution in brothels or bought by noblemen to entertain visiting guests as a matter of hospitality. ${ }^{24}$ Barbara Andaya also points out that the association of the prestige of a man with the number of women he possessed also placed

22 David Wyatt, "Introduction" in Simon de la Loubere, The Kingdom of Siam (1697; New York: Oxford in Asia Historical Reprints, Oxford UP, 1969) vi-vii.

${ }^{23}$ On slavery in Southeast Asia see Anthony Reid, "Introduction: Slavery and Bondage in Southeast Asian History," Slavery, Bondage and Dependency, ed. Anthony Reid (St. Lucia: University of Queensland Press, 1983).

${ }^{24}$ Sukanya, 117. In the system of slavery in Southeast Asia, war slaves were on the bottom rung - the 'absolute' slaves rather than the debtor slaves who sometimes sold themselves into bondage to pay off a debt, or to avoid corvee labour, and who could buy themselves out again - being able to work or trade for their own benefit outside their labour as a slave. According to Jit Poumisak, old Ayutthayan documents refer to a prostitute section of the city as "Sampheng", from the Khmer word for flower. Craig Reynolds, Thai Radical Discourse: The Real Face of Thai Feudalism Today (Ithaca: Cornell UP, 1987) 134. The women were, at least at some point, most likely Cambodian war prisoners from the wars with Siam throughout Ayutthayan era. Indeed, in late 1500s there were a series of conquests over Cambodia eventually resulting in a Cambodian Prince being taken captive in the Siamese court. Anthony Reid, Southeast Asia in the Age of Commerce: Volume II: Expansion and Crisis (New Haven: Yale UP, 1993) 188. 
financial strains on noble households with the monetization of the economy beginning in the late 1500 s. At the same time there was a growing number of European men in port-cities, who viewed the sex for money exchange as a temporary transaction, creating a demand for sexual services outside the 'cycle of gift giving' which created responsibilities and obligations. The exchange of sex for money by slave-wives, in turn, contributed to the maintenance of the household. ${ }^{25}$

While temporary marriage continued to be practised, European disregard for its strictures of fidelity and support was rapidly undermining local practices and beliefs, and with them, women's status. Increasingly, liaisons were contracted between European men and marginalised women who were far from the protections of home, such as slaves, exslaves and foreigners. ${ }^{26}$ By the time of la Loubere's arrival in 1697 it had been established that only Peguan (Burmese) women contracted temporary marriages with foreigners. La Loubere had the impression that "the Siamese are naturally too proud to give themselves to Foreigners, or at least to invite them."27 Peguan women were accordingly characterized as being "of a more amorous Complexion than the Siamese: they have at least more spirit and briskness. 'Tis an established opinion in the Indies, that the people have more or less vigor and spirit, according as they are nearer, or remoter from Pegu." 28 The demarcation between

\footnotetext{
${ }^{25}$ Andaya, 17 - 19.

${ }^{26}$ Andaya, 23.

${ }^{27}$ la Loubere, 53.

${ }^{28}$ la Loubere, 53.
} 
the 'amorous' Peguans and the 'proud' Siamese indicates a closing in of Siamese society and increased regulation of elite Siamese women's sexuality.

Indeed, soon after la Loubere and his retinue left Siam, the powerful, Greek advisor to the King, Constantine Phaulkon, was killed by the anti-foreign faction in court as the king lay dying. After the king's death, a new era in Siamese history was ushered in as the country closed itself off from European influence. An intriguing royal decree near the end of the Siamese empire of Ayuthaya in the mid-1700s forbade the ethnic groups of Thai (Siamese), Mon and Lao

... to have sexual intercourse in secret with Indians, French, English, Kula(?) and Malays - who are heathens - in order to protect the people from misfortune... If anyone fails to heed this and secretly has sexual intercourse with heathens she is to be arrested, interrogated, and punished at the maximum by execution. Parents and kinfolk, near and far, who fail to make her obey and prevent this are to be punished. ${ }^{29}$

While the Thai Marxist theorist Jit Poumisak and others read the intent of this law as containing prostitution within brothels in order to ensure taxes were collected on all transactions, it is important that the decree pertains only to sexual intercourse with certain foreigners and fails to mention the exchange of money. ${ }^{30}$ Women's sexual relations with 'heathens' were seen as a potential threat to the religious identity of Siam. In these various

${ }^{29}$ Craig Reynolds, Thai Radical Discourse: the Real Face of Thai Feudalism Today (Ithaca: Cornell Southeast Asia Program, 1987) 134.

${ }^{30}$ Reynolds, 134; Thanh-dam Truong, Sex-Money-Morality (London: Zed, 1990) 150. 
laws Siam had recognized the importance of demarcating its national/cultural space through the regulation of women's bodies.

Imperial Desire: Gender and the Iconography of Rule

The importance of gender and sexuality in marking the difference between national 'self and 'other', and the power of particular gender constructs in establishing global authority, was made very clear in the imperial era. The establishment of Western authority rested heavily on colonial discourses that marked the differences between the Siamese and Westerners in sexualized and gendered terms. Siam was represented as feminine or improperly masculine, evidenced by practices of polygamy and prostration (the lowering of the body in front of royalty) and therefore naturally subordinate to the 'manly' Western states. The accounts of British and American missionaries and diplomats in 19th century Siam make it clear how maintaining their imperial status rested on the manipulation of categories of gender and sexuality that established Western powers as legitimate and lasting states - associated with masculinity and sexual restraint: and the Siamese state as illegitimate and collapsing - associated with femininity and sexual excess. Westerners pointed to Siamese gender and sexual practices, therefore, as evidence of the barbarity of the Siamese. To Westerners, the Siamese failed to display the proper gendered order that underlay Western civilization and superiority. This understanding legitimized Western imperial status and threatened the sovereignty of the Siamese state. 
These characterizations and associations are particularly evident in the obsessive discussion of polygamy and prostration in the journals of visiting diplomats and missionaries. Gender and sexuality became central discourses of national identity and difference in this period for both the colonizing forces and the resistant elements within the Siamese state. Although the monarchs and nobles made nods in the direction of abolishing polygamy by instituting gradual liberalizations in women's position in Siam, they resisted formal abolition until after the overthrow of the absolute monarchy in 1932.

While the issue of polygamy had been of some fascination to the European visitors of the 16th and 17th centuries, the practice was understood in terms of the practices of the absolutist state. La Loubere explained to the French court that polygamy was not a matter of debauchery but of "Pomp and Grandeur."31 Such pomp and grandeur were understood at the court of Louis the XIV - the Sun King. Indeed, gender roles in Europe had not yet been restricted to a dualistic opposition of male and female and still allowed for some ambiguity in gender definition. Indeed, the second in command on the mission of which la Loubere was a part was the cross-dressing Abbé de Choisy who appeared at the Siamese court "gorgeously arrayed in a feminine evening gown, make-up and jewellery."32

${ }^{31}$ la Loubere, 52.

32 Marjorie Garber, "The Occidental Tourist: M. Butterfly and the Scandal of Transvestism," Nationalisms and Sexualities, eds. Andrew Parker, et. al. (New York: Routledge, 1992) 140. 
By the middle of the 18 th century, however, effeminate aristocrats were being excluded from political power across Europe. ${ }^{33}$ The establishment of Enlightenment thought brought profound changes in the conceptualization of gender and, with it, the conceptualization of proper political rule. The changes that swept across Europe in the 18 th century created an association of absolutism, sexual debauchery and 'the feminine'. Restrained sexuality, 'manliness' defined as the natural opposite of 'femininity' and proper rule were the. order of the day. With the development of Enlightenment science, the conceptualization of 'the feminine' shifted along with the reconceptualization of nature. Susan Hekman argues that nature as feminine in the form of "nuturing mother or wild, insatiable Fortuna" was replaced with nature as feminine in its passivity and subjection to domination and control by the (male) scientist: "A new image of the female emerged in the modern world, a female to be controlled and dissected. This image legitimated not only the domination of nature but that of women as well." ${ }^{34}$ Control of female sexuality - through the differentiation of private and public spheres, and women's confinement to the former - was a central part of French revolutionary and Napoleonic legislation, for example. ${ }^{35}$ European

${ }^{33}$ Randolph Trumbach, "Sex, Gender, and Sexual Identity in Modern Culture: Male Sodomy and Female Prostitution in Enlightenment London," Forbidden History: The State, Society and the Regulation of Sexuality in Modern History, ed. John C. Fout (Chicago: University of Chicago Press, 1992) 91.

${ }^{34}$ Susan Hekman, Gender and Knowledge: Elements of a Postmodern Feminism (Boston: Northeastern UP, 1990) 114-116.

${ }^{35}$ Jeffrey Merrick, “ Forbidden History: The State, Society and the Regulation of Sexuality in Modern History, ed. John C. Fout (Chicago: University of Chicago Press, 
literature moved from the celebration of openly sexual heroines like Moll Flanders to the sexually repressed heroines of Victorian novels. Gradually, the division of the sexes into two distinct and opposite categories came to be viewed as natural and unchanging.

Masculine political rule was constructed and justified in terms of masculine rationality and control - in opposition to feminine disorderliness and emotionality. Conceptions of masculinity, like femininity, had gone through revolutionary changes in the Enlightenment era. Masculinity was established as the clear-cut opposite of femininity, and heterosexuality became the compulsory norm. R.W. Connell points out that "the requirement that one must have a personal identity as a man or a woman, rather than simply a location in the social order as a person with a male or female (or hermaphroditic) body, gradually hardened in European culture. ${ }^{36}$ Gendered character became the understood basis for the nature and actions of individuals. Masculine character was most specifically marked by rationality and governance was re-written as requiring such rational control. 'Excessiveness', and lack of restraint in either sexual or political affairs - now characterized as 'feminine' were expunged from the new ideology of masculinity. The new state in the West, therefore, established itself as 'manly' in a particular sense - heterosexual, rational and restrained. And, as Connell argues, "with masculinity defined as a character structure marked by rationality, and Western civilization defined as the bearer of reason to a benighted world, a cultural link

1992) 187.

${ }^{36}$ R.W. Connell, Masculinities (Berkeley: University of California Press, 1995) 188. 
between the legitimation of patriarchy and the legitimation of empire was forged." 37 Indeed, gender underwrote the establishment of Empire. The 'natural' rule of male over female was extended to the rule over racial 'others', characterized as feminine or, alternatively, as hypermasculine, lacking the self-restraint of civilized manliness.

Further, as Michel Foucault has made clear, control of sexuality became key in the Victorian period to inducing the self-discipline that marked the Victorian construction of civilization. Rather than being repressed, sexuality was discussed obsessively in order to construct and, therefore, regulate and control individual bodies and the body politic. ${ }^{38}$ The discourse of national identity and its extension into 'civilization' drew on constructions of proper and improper sexual behaviour to anchor its claims to superiority. Imperial desire was 'restrained' - citizens of the 'civilized' West were expected to adhere to the codes of Victorian sexuality. Sexual self-control was metonymic for imperial control. The colonial 'other' was oppositionally depicted as over-sexed and therefore incapable of self-rule (both personally and politically). The celebration of restrained sexual behaviour resonated with and reinforced the construction of the 'gentleman', the icon of civilized rule, who treated women with courteous, if patronizing, respect. Gender and sexuality, therefore, became important grounds on which imperialism was legitimized and contested.

${ }^{37}$ Connell, 186-187.

${ }^{38}$ See Michel Foucault, The History of Sexuality: An Introduction, Vol. I (New York: Vintage, 1990). 
Indeed, in the era of renewed contact between Siam and the Western powers in the mid-1800s, the ideology of the masculine/sexually restrained and legitimate Western state was supported through the regulation of the desire and sexual behaviour of the representatives of the West in Siam. Sexual restraint was the measure of acceptability for Western diplomats. Numerous American diplomats were rejected for their inappropriate behaviour. US Consul Aaron Westervelt, in particular, was vilified for his deportment. The US consulate during his tenure was characterized as being as "bad as a house of prostitution." Another potential consul was ejected from the post before even leaving the US on the grounds that he had "very indiscreetly cohabited" with a "disreputable woman" in his youth. ${ }^{39}$ Stories like the one following, related by missionary Dan Bradley on the consequences of sexual excesses, were instructive. Bradley maintained that Westervelt had "tried to entice away" a young convert girl from Bradley's mission and while Westervelt failed, his business partner, Allen, succeeded. The girl:

... then went to live with Allen and his other mistress.... Allen died of consumption a few years later, a thoroughly wicked and unrepentant man to the very end. And Mr. Westervelt's daughter, by a woman with whom he had lived in an earlier time, became a concubine in the palace of the Second King. ${ }^{40}$

${ }^{39}$ Benjamin Batson, "The First American Diplomats in Siam," Thai-American Relations in Contemporary Affairs (Singapore: Executive Publications, 1982) 10.

${ }^{40}$ Bradley, 11-12. 
Thus, not only are the wages of sin death, but the lack of sexual control on the part of Westervelt leads to the servitude of his offspring to the colonized - symbolic of a loss of imperial power.

The proper sexual and gender orientations are made abidingly clear by F.A. Neale's account. Neale was one of the British functionaries who advised the Siamese government in the mid-1800s. In one of his popular accounts of "life among the Siamese" Neale wrote of the possibility of cultural "disorientation" - as is "the case with those whose long absence from their native country makes them almost incredulous in their own senses" - and how he found himself beginning to admire the faces of women in Malaysia. He reassured his audience, and himself:

...that so surely as I returned to England and gazed upon our native belles, when I saw that in addition to the most perfect symmetry of features, there was the stamp of understanding upon their lovely faces, that affection beamed in each eye, and warmth of feeling oozed out from betwixt their rosy lips; that education, and innocence, and moral refinement, dwelt like a bright cloud of light refulgent in their faces, then was I compelled to avow, as I now most steadfastly do, that there is no country like Great Britain in the world for beauty, wit, and wisdom. ${ }^{41}$

'Beauty' clearly rested on the principles of the imperial mother country, so visible in British women and so lacking in Asian women - education, intelligence, affection, innocence and moral refinement. Western men's sexuality was properly 'oriented' around this construction

${ }^{41}$ F.A. Neale, Residence in Siam at the Capital of the Kingdom of Siam (1850) (London: Office of the National Illustrated Library, 1852; reprinted, Bangkok: White Lotus, n.d.) 77-78. 
- beauty and desirability only in the lofty ideals of the motherland as personified by her women. Western male desire, therefore, was not of a base sexual nature but of a 'civilized' character. The state, gender and sexuality were bound together into a reinforcing discourse of masculine nationalism and the desirability of imperial authority.

The Imperial Presence in Siam and the Critique of Polygamy

In the mid-1800s, after a century and a half of isolation from the Western world, Siam had once again opened up to foreign emissaries from Europe and the United States. The Siamese had little choice in the matter, given the inroads being rapidly made by the French in Vietnam and the British in Malaysia and Burma. 'Unequal treaties', which imposed extraterritorial provisions and restricted import tariffs, had already been imposed on Japan and China, the dominant regional powers. When King Mongkut ascended to the Siamese throne in 1851 he knew that negotiation with the Western powers was inevitable. Missionaries and diplomats had begun to appear with alarming regularity in Bangkok some years earlier.

Missionaries from the United States and Britain came to Siam in the 1830s seeking to convert a nation of Buddhists to Christianity. Official representatives were also sent specifically to negotiate trade treaties. The 'semi-colonial era' in Siam is marked by the signing of a treaty between Britain and Siam through Sir John Bowring, which established immunity from Siamese law for British subjects and their full rights to residence and purchase of property in Siam. A similar deal was signed with the US in 1856, and several 
European powers thereafter. Although the treaties did not establish formal colonial rule, their provisions clearly established the distinctive and higher status of Europeans and Americans as opposed to the Siamese, and the right of the Western powers to abrogate Siamese sovereignty. Both of these provisions were hallmarks of imperial authority. ${ }^{42}$

Polygamy loomed large in the eyes of the Westerners who dealt with the elite in Siam. The harems of notables were a matter of much concern (and titillation) for missionaries and diplomats alike. ${ }^{43}$ The British envoy, Sir John Bowring, held numerous discussions with King Mongkut - while negotiating the famous trade treaty - on the practice that Westerners found "exotic, self-indulgent, and uncivilized." ${ }^{24}$ Dr. Dan Bradley, the most prominent American missionary in Bangkok, who had a close relationship with King

${ }^{42}$ The definition of imperialism is of course a matter of some debate and my inclusion of the United States as a holder of imperial authority may strike some as incorrect. However, aside from the clear evidence of American involvement in cultural imperialism as described in this chapter, the US was also imperialistic in its approach to Southeast Asia before the takeover of the Philippines in $\mathbf{1 8 9 8}$ through its treaty practices, as in Siam, and its willingness to use force ( as in 'gunboat diplomacy') in order to achieve its goals in the region. See James W. Gould, "American Imperialism in Southeast Asia Before 1898" Journal of Southeast Asian Studies 3.2 (Sept. 1972): 306-314.

${ }^{43}$ Malek Alloula has argued that the harems of Eastern countries, with their cloistered (and sometimes veiled) women, were a site of frustrated Western desire - the desire to know and therefore to exercise power. See Alloula Malek, The Colonial Harem (Minneapolis: University of Minnesota Press, 1986).

${ }^{44}$ Craig Reynolds, "A Nineteenth Century Thai Buddhist Defense of Polygamy and some Remarks on the Social History of Women in Thailand," (Paper Prepared for the Seventh Conference of the International Association of Historians of Asia, Bangkok, 22-26 August 1977) 16. 
Mongkut, admonished the king in the Bangkok Calendar - an expatriate paper published by Bradley - saying "virtue can never have much sway in Siam, nor any true prosperity, until polygamy is made a crime by the Government." ${ }^{45}$ The enormously popular (in the West) accounts of life in the Inner Palace penned by Anna Leonowens in the 1850s, often characterized the despair and cruelty of life "locked away" in the harem. ${ }^{46}$ The tyrannical treatment of women that polygamy was presumed to involve indicated to Westerners a lack of the kind of (gentle)manly virtues of Western governance. Such representations of native practices where commonplace throughout the Empire, legitimizing the imperial mission by presenting white men as saving "brown women from brown men" in Gayatri Spivak's. terms. ${ }^{47}$

Polygamy, to Western observers, evidenced the lack of sexual control among the Siamese (men) and, therefore, in the imperialist ideology, the Siamese lack of the 'moral character' which underwrote the imperial right to rule. Western visitors and residents in Siam constantly referred to the 'excessive' numbers of wives maintained by the King. These numbers gave evidence of the King's (and other Siamese's) lack of sexual control and his

${ }^{45}$ Abbot Low Moffat, Mongkut. The King of Siam (Ithaca: Cornell UP, 1961) 135.

${ }^{46}$ Interestingly, Leonowens' representation of the members of the harem as powerless pawns differs greatly from Western men's accounts of that institution as a hotbed of political manipulation of the king. The difference, perhaps, reflects Leonowens' understanding of women's lack of political power.

${ }^{47}$ Gayatri Spivak, "Can the Subaltern Speak?"Colonial Discourse and Post-Colonial Theory: A Reader, eds. Patrick Williams and Laura Chrisman (New York: Columbia University Press, 1994) 93. 
inability to rule. British advisor F.A. Neale quoted a number of some 1,500 in Mongkut's predecessor's harem and Bowring estimated 600 for Mongkut himself. ${ }^{48}$ In his journal, Bowring noted his disgust with the 'excess' of the King's harem, relating an incident in which the King joked with an American dignitary that his wife could dance as well as any of the King's own wives and why not send her hither? Bowring remarked with disdain that "one would think that he would be satisfied with 600 and not require the 601 st."49 So disturbed was Mongkut by Bradley's accounting of his wives that the King published in the Bangkok Calendar his own calculation of his wives and concubines - 27 royal mothers, 34 concubines and " 74 daughters of noblemen who have been presented to the King by their fathers, with the view to serve as maids of honor...." ${ }^{50}$ The difference in numbers was in part based on a different or (mis)understanding of the roles of women within the Inner Palace not all of whom were actual concubines or wives. Many members of the Inner Palace were servants and staff, as well as young women sent to be trained in the arts by their parents and thus to catch the eye of a nobleman, if not the king himself, for marriage. Indeed, some of the Inner Palace were renowned poets and musicians. Others were the daughters and wives of previous kings and some forbidden to marry at all. ${ }^{51}$

\footnotetext{
${ }^{48}$ Neale101.
}

${ }^{49}$ Sir John Bowring, The Kingdom and People of Siam, Vol.II (London: John. W. Parker and Son, 1857) 320.

${ }^{50}$ Moffat, 134-135.

${ }^{51}$ Reid, Vol. I, 169; Darunee and Pandey, 136; Reynolds, 10-11. 
Nonetheless, the sexual excess that was assumed to be represented by polygamy, was thought to bring about physical exhaustion and the degeneration of moral and physical character and, therefore, an inability to govern. A memorandum from a British official in Siam in the late 1800 s worried about the likelihood of a French take-over of Siam and remarked: "the King, who is honest, after a period of dangerous physical weakness, has regained strength, but is quite incapable mentally, exhausted by women, anxiety and opiates. ${ }^{52}$ Such dissolute behaviour rendered rational, scientific and morally upright rule impossible, and instead, lead to absolutist excesses of cruelty. Joseph Balestier, an American diplomat in Siam in the mid-1800s, brought these themes of excessiveness and inability to rule together when he remarked in his report to the Secretary of State:

The present King of Siam is a sensualist having no less than a thousand women in his harem and a devotee of Buddhism with a retinue of forty thousand priests and forty wats or temples... Upon these he spends the entire income of the kingdom. But though he reigns he does not govern the State, the administration of which is in the hands of rapacious and arbitrary lords who, by a heartless and relentless course towards their vassals and serfs and the Chinese are fast bringing about the utter ruin of the country. ${ }^{53}$

According to this understanding then, only the self-controlled behaviour of Western men could produce "governance." Siamese masculinity, on the other hand, led to absolutism.

\footnotetext{
${ }^{52}$ Brailey, 37.

${ }^{53}$ c.f. Spector, 301. Emphasis added.
} 
The contemporary Western accounts of the period also make frequent mention of the "disgusting" practice of prostration as indicative of the 'unmanliness' of both sovereign and subjects. Sir Bowring stated that "the groundwork of all Siamese institutions and habits is a reverence for authority. This principle is pushed to forms of the most extravagant excess; on the one side of assumption and on the other of prostration." 54 The usually unflappable George Finlayson, scientific observer with the first diplomatic mission from England, exclaimed, upon observing the "beast-like" attitude of servants in the houses of important ministers of state, "How abominable, how revolting this assumption of despotic power!" 55 Western diplomats and missionaries resisted the practice of prostration with all their might. Their own exclusion from the practice was insufficient and missionaries "sought nothing less than the total elimination of such an undemocratic procedure." ${ }^{" 56}$ Mongkut was so concerned to demonstrate his good will to Bowring that he began to eliminate the practice among his ministers - eventually having them sit on chairs for trade negotiations. Bowring's views were made clear in his journal entries where he wrote of the "barbaric grandeur", "subject state" and "crawling obeisance" of the Siamese state. He remarked in his journals: "The abject state

\section{${ }^{54}$ Bowring, Vol. II, 281.}

${ }^{55}$ George Finlayson, The Mission to Siam and Hue: 1821-1822 (Bangkok: The Siam Society, 1988) 126-127.

${ }^{56}$ Bruce Reynolds, "American Missionaries in Nineteenth-Century Thailand," Thai-American Relations in Contemporary Affairs, ed. Hans H. Indorf (Singapore: Executive Publications, 1982) 34. 
of every individual exceeds belief." ${ }^{\text {"T }}$ Clearly marking the differentiation between 'rational' Western governance and Oriental despotism, Bowring noted that the King was unlikely to even understand the principles of "political science." 58

In front of royalty, full bodily prostration was the expected mode of interaction. Everyone was to maintain a lower bodily position than the king while in his presence. In a study of the Chinese version of prostration, the koutou, James Hevia has argued that rather than indicating servility - as it was read by the West - the koutou was part of a ritualized empowerment process in which a ruler empowers inferior rulers to command their own space. It is a transferral or conferring of power rather than a giving up of power..$^{59}$ Bodily prostration in Siam carried a similar meaning. Westerners, however, interpreted the practice only in terms of servility and slavery on the one hand, and excessiveness on the other. Both of these aspects marked the failure of properly masculine behaviour on the part of the Siamese. The Western view of such practices is illustrated by Bradley's approval of the US Consul's refusal to prostrate himself in front of the King and instead to execute a "graceful bow." Bradley advised his readers: "It will be interesting and profitable to observe for a moment how different was this manly bearing of the Consul from the customs of the Siamese courtiers."

\footnotetext{
${ }^{57}$ Bowring, Vol. II, 270.

${ }^{58}$ Bowring, Vol. II, 281.

${ }^{59}$ Hevia, 193.

${ }^{60}$ Bradley, 114. Emphasis added.
} 
Western visitors to Siam (particularly those on state or church business) were careful to display behaviour which underlined their 'civilized' status. An ideology of desire as correctly oriented towards the homeland rather than the colonial other served to regulate this behaviour. This desire was based on the proper gender identities and relations of the imperial powers - the ideal woman, educated, refined and godly, in a companionate marriage to a rational and fatherly man. True love and proper heterosexual desire, however, are only possible among the civilized Westerners. Indeed, the Siamese, according to the Westerners, were ugly, undesirable and undistinguishable in gender. Many of the Western accounts of the period remark - unfavourably - on the masculine appearance of Siamese women. Bradley noted "it was remarkable how masculine the women appeared. Their dress differed little if any from that of males.... Their hair was cut short.... They were nearly as large and muscular as the males." ${ }^{\prime \prime}$ Bowring had also commented on the effeminate appearance of the men: "Siamese men seldom have beards, the hair is plucked out by the roots... This gives them an effeminate appearance."62 British envoy Crawfurd's assistant George Finlayson wrote that women's blacking of teeth "together with the coarse red painting of the mouth and lips, which they derive from the constant eating of betel, catechu, and lime together, gives to them a disgusting appearance. ${ }^{\text {63 }}$ His description is matched by a later British observer, F.A. Neale,
${ }^{61}$ Bradley, 4.
${ }^{62}$ Bowring, Vol. I, 135.
${ }^{63}$ Finlayson, 108. 
whose ironic account of a Siamese wedding harps on the "ugliness" of the bride. Neale declares that "the Siamese ladies may without the smallest fear of competition proclaim themselves to be the ugliest race of females upon the face of the globe." "undesirable in the extreme because of their masculine appearance." 65 To make matters worse, observers noted, the women were rarely shy and retiring in proper feminine fashion in their encounters with Western men. ${ }^{66}$ Polygamy, to Westerners, appeared in direct contrast to their ideals of love, marriage and proper gender relations. The Siamese were deemed incapable of true love as defined by Western ideals and sanctioned by the Western state. Neale argued that:

Siamese husbands and wives, and parents and children, possess only a kind of animal instinct, or magnetism, which creates a sensation towards each other almost amounting to friendship, but that holy thing, love, is unknown amongst them; as well it may be, for how could so much impurity be caged up with so fair and spotless an emotion? ${ }^{67}$

Missionaries were keen to demonstrate proper relations between the sexes "à la Americain"companionate, heterosexual interaction - for example, by walking arm in arm upon leaving the palace. Bradley opined: "The sight of a man and his wife walking together and, much

${ }^{64}$ Neale, 153.

${ }^{65}$ Neale, 153.

${ }^{66}$ Andrew Turton, 'The Ethnography of Embassy," paper presented at the Sixth International Thai Studies Conference, Chiang Mai, 14-17 October 1996; Finlayson, 107.

${ }^{67}$ Neale, 159. 
more, arm in arru was something they had never before seen, and it was to them most strangely diverse from Siamese custom." Western 'civilization' are highlighted in accounts such as these in such a way as to emphasize the need for Western instruction and guidance - in both personal and political affairs.

While the critique of polygamy appeared, at least, to have at its heart the treatment of women, the focus of critiques of indigenous practices, like polygamy, throughout the colonial world was not the status of women. Rather, as Lati Mani has argued in the Indian case, "women [were] the site on which tradition was debated and reformulated. What was at stake was not women but tradition." ${ }^{\circ 9}$ That is, the critics of polygamy were most concerned to assert the barbarity of indigenous culture and the superiority of imperial civilization. ${ }^{70}$ Thus, as Margaret Strobel has noted in relation to the practice of sati in India "women were the terrain, but the struggle was over something else - the conception of Indian tradition, or Indian moral readiness of self-rule." Indeed, when polygamy was finally rendered illegal in Thailand in 1936 through the rewriting of the marriage provisions in the Civil Code under British legal advice, men were given the right to divorce their wives for infidelity but wives

\footnotetext{
${ }^{68}$ Bradley, 31.
}

${ }^{69}$ c.f. Margaret Strobel, Gender, Sex and Empire (Washington DC: American Historical Association, 1993) 13.

${ }^{70}$ See Strobel for a discussion of these concepts in relation to the British critique of the practice of sati in India. Strobel, 12.

${ }^{71}$ Strobel, 16. 
were denied the same right. ${ }^{72}$ The focus of these reforms, therefore, was clearly not on providing women with more fair and equitable treatment in marriage customs. Polygamy in Siam, as constructed and represented by Westerners, evidenced Siamese inability to rule in their lack of proper masculine behaviour and sexual control. Ending the practice of polygamy, therefore, was one of the conditions of Siam's entry into the company of 'civilized' nations. By targeting gender and sexual practices such as polygamy as representative of the essential barbarity of Siamese culture, however, the imperial powers also made gender and sexuality the key terrain on which the nature of the Siamese culture was debated by both Siamese and Western elites.

\section{Gender, Polygamy and Siamese National Identity}

The Siamese monarchs in the age of imperialism operated under the constant threat of colonization or protectorship. Siam was in some ways protected by its geographical position - as a buffer zone between the two imperial powers of Britain and France. However, incidents like the 1893 Paknam Incident in which French gunboats sailed into Bangkok and the French government demanded far-reaching territorial concessions and spoke of establishing a French protectorate, made Siam's tenuous position as the last independent kingdom in Southeast Asia very clear. ${ }^{73}$ The need to respond to the European powers on their

\footnotetext{
${ }^{72}$ Suwadee, 23; Omvedt, 44.
}

${ }^{73}$ Nigel Brailey, 1. Gerrit Gong also points out that the 'buffer state' thesis needs to be carefully qualified by the fact that a great deal of Siamese 'territory' (or, more properly, 
own terms was equally clear and the governments under Kings Mongkut, Chulalongkorn and Vijiravuth struggled to maintain independence by proving themselves leaders of a 'modern' and 'civilized' nation - the standards for which had been clearly set by the Western powers. As Gerrit Gong argues, these 'standards of civilization' became increasingly juridical in character in the late 1800s and early 1900s: "International legal rights and capacities became contingent on fulfilment of the standard's requirements; so did recognition of full ('civilized') legal personality and admittance into the Family of Nations."74 Aside from governmental practices (the guarantee of basic rights to citizens, an organized and efficient bureaucracy, adherence to international law) certain social practices, or more precisely, the abandonment of certain practices such as suttee, slavery and polygamy, were a central part of these standards. ${ }^{75}$ Gender practices, therefore, were deeply imbricated in the debate over what constituted traditional values and what needed to be modernized.

During Mongkut's reign, members of the nobility defended the role of polygamy in Buddhist culture. They even went so far as to publish a written defence in English to explain the cultural roots of the practice to foreigners. Nonetheless, the pressure of criticism was so great that Mongkut's advisors floated the possibility of monogamy for the monarch being

areas that Siam considered part of its realm) was given up to the European powers during this period and further, that Siam lost political control over half of its remaining territory "after adopting the 'buffer state' role." Gong, 216.

\footnotetext{
${ }^{74}$ Gong, 4.

${ }^{75}$ Gong, 14-15.
} 
written into the 1856 trade treaty with America. The King also issued edicts in 1854 allowing women to resign from the Inner Palace to please foreign powers. ${ }^{76}$ In 1868 Mongkut issued a decree proclaiming that wives and children could no longer be sold by their husbands or parents. ${ }^{\pi}$

While Craig Reynolds argues that Mongkut adjusted marital practices because of "his own innate sense of justice informed by the increasingly powerful example of Western culture," it was also clear that the Europeans viewed such practices as grounds for colonisation and that the Siamese monarchy understood this threat. Mongkut, and his successor Chulalongkorn, therefore, carefully negotiated changes in gender practices in order to maintain their at least formally sovereign status. At the same time, the state and elites constructed what was 'essential tradition' to Siamese identity and culture and therefore unchangeable ${ }^{78}$ That is, polygamy was defended not as a state practice but as a cultural practice - in line with the tenets of Buddhism. It was viewed, by Siamese elites, therefore, as part of Siamese identity and not amenable to European interference. "A Buddhist Defense of Polygamy" argued that polygamy was not a violation of the prohibition of sexual misconduct in Buddhism and that it "accommodates the differences in man's and woman's nature," where men have the sexual prerogative because they are less inclined to jealousy and

${ }^{76}$ Reynolds, 17.

${ }^{77}$ Reynolds, 20.

${ }^{78}$ Reynolds, 21. 
more compassionate than women. If a woman should have more than one husband, on the other hand, she would be likely to kill those she no longer loved. ${ }^{79}$ The author explained that this difference in male and female natures was something recognized in Siamese culture, unlike European culture which viewed male and female natures as the same. ${ }^{80}$

King Chulaiongkorn, while engaging in a series of reforms during the "Chakri Reformation" (1890-1910) to modernize the state according to Western standards, vigorously refused to abandon the polygamous system. Chulalongkorn's son, Virijavudh, who saw himself as a modernizing king, at first promised to remain monogamous. However, he abandoned this pledge when his first marriage failed to produce an heir. ${ }^{81}$ The practice of polygamy took on an importance and certain intractability, particularly for the defenders of the monarchy as part of this newly formed 'national identity'.

Indeed, the monarchy found itself embattled from all angles with the powerful weapon of the anti-polygamy critique. In recognition of the symbolic importance of polygamy to the monarchists, the critique of polygamy was taken up by a growing group of elites who sought to reform governmental practices in Siam. Chulalongkorn's reforms of the state and the consequent growth of the bureaucracy created new factions among elites (now

\footnotetext{
${ }^{79}$ Reynolds, 27-28, and Appendix II.

${ }^{80}$ Reynolds, Appendix II.

${ }^{81}$ Vella, 154.
} 
including both commoners and aristocrats) who were in potential conflict with the throne. ${ }^{82}$ These modernizing elites resented the influence that could be had through the royal harem and they drew on Western fears of unruly and excessive female power to draw British attention to the weakness of the absolutist state, hoping to gain British backing for the overthrow of the old system. The elites complained of the inordinate power of members of the harem who curried favour with the king for members of their family - thus hampering effective rule of the country by allowing these families complete protection from discipline: "Unless a man is of high moral principle, if he happens to be closely related to the favourite wives of the King, he is apt to be most arrogant and despotic and would commit crimes and oppression with immunity." ${ }^{83}$ According to these critics, it was not only the King who was ruled by his wives, but his courtiers were as well:

It is a matter of every day's conversation amongst the Princes that this Prince or that noble 'succeeds very well now that his wife has got an entrance into the grace of this and that Queen and succeeded in pleasing one and given no offence to the other'.... No man can hope to succeed very well unless backed up by this influence, and those who have succeeded never know when they might fall out of favour, because it all depends upon their wives' or relatives' skill and cleverness to maintain the favour or influence of one favourite of the King without offending others.... ${ }^{84}$

${ }^{82}$ See Chaiyan Rajchagool, The Rise and Fall of the Thai Absolute Monarchy (Bangkok: White Lotus Press, 1994) 155-158.

${ }^{83}$ Nigel J. Brailey, Two Views of Siam on the Eve of the Chakri Reformation (Whiting Bay: Scotland: Kiscadale Publications, 1989) 57.

${ }^{84}$ Prince Pritsdang to Mr Swettenham, c.f. Brailey, 76-77. 
Chulalongkom, however, continued to defend the polygamous system, strongly upbraiding a young prince who dared to criticise the system. ${ }^{85}$ Some analysts argue, that the practice of polygamy became even more important at this time because of the integrative function it had among elites, by keeping a large number of important families and local leaders attached to the monarchy in Bangkok through their connections to the harem. ${ }^{86}$ Thus, while Chulalongkorn went so far as to abolish the system of slavery that the Western powers found so 'uncivilized', he was unmoved by arguments against polygamy, or prostitution - which increased rapidly with the abolition of slavery and the institution of military conscription.

\section{The White Slave Trade and the Internationalizing of the Imperial Gender Order}

While polygamy had been the subject of constant Western condemnation from the early 1800 s, firmly establishing sexual behaviour and gender roles as grounds for differentiating superior and inferior cultures, prostitution was the subject of much less attention. $^{87}$ In part, this reflected the colonial powers' own awkward position vis-à-vis prostitution, which was generally viewed as a 'necessary evil' and in Britain in the mid-

${ }^{85}$ Brailey, 18.

${ }^{86}$ See Susan Morgan, "Introduction," The Romance of the Harem, by Anna Leonowens, ed. Susan Morgan (Charlottesville: University Press of Virginia, 1991) xxviii-xxix.

${ }^{87}$ While prostitution received occasional mention in visitors' accounts as an example of the disregard for sexual propriety among the 'natives', or of the cruelty of slavery (most prostitute women were bonded slaves) it had none of the symbolic import of polygamy. 
1800s had been regulated through the Contagious Diseases Acts and in France through licensed brothels. The growing political salience of the first wave of feminism and the social purity movement of the late Victorian era in Europe and North America soon put the 'prostitution problem' on the international agenda.

The Contagious Diseases Acts had touched off a storm of controversy in Britain, where Josephine Butler and the Ladies' National Association had protested the treatment of working class women and the assumption of male sexual prerogative under the Acts. The Acts were designed to ensure soldier's sexual health by subjecting women, particularly those suspected of prostitution, to examinations for venereal diseases. The campaign gained the support of the religious moral reform movement and managed to bring about the rescinding of the Acts by the $1880 \mathrm{~s}$ in Britain. Regulated brothels, which the social reformers linked to the international 'traffic in women' (the forcing or enticement of women into brothels), remained in place in Malaysia and India as a convenient way to service male British nationals while avoiding interracial marriage and concubinage. The continuing campaign against prostitution, however, eventually resulted in international agreements to suppress the traffic in women.

In the larger political discourse of the time, however, the issue of traffic in women was soon translated into the 'white slavery panic', which built on stories of innocent (white) women and girls abducted into the trade by evil (often foreign) traffickers. ${ }^{88}$ In response to

${ }^{88}$ For accounts of the movement to repeal the Contagious Diseases Acts in England see Judith Walkowitz, Prostitution and Victorian Society: Women. Class and the State 
the panic, a number of international treaties to ban the traffic in women and children were signed in the early 1900 s. According to Deborah Steinstra, the conventions "consolidated many of the gendered assumptions of the time, both about the role of women and men in society as well as about the role of the state in sexual relations." ${ }^{89}$ Women were seen as passive victims who required protection from the (paternal) state rather than as social and sexual agents. Accordingly, the conventions criminalized procurement even where it occurred with the woman's consent. 90 The result was the regulation of the travel of women and of "the migration of women for employment purposes by gathering information about why they would leave their country and ensuring they received protection if they appeared vulnerable to or were victims of procurers." $91 \mathrm{Men}$, on the other hand, appeared either as procurers and pimps or as protectors, the client being conspicuously absent in the agreements and the discussions around them. ${ }^{22}$ The thrust of these provisions, therefore, was not to provide women with social and sexual independence, but rather to reform women into their

(New York: Cambridge University Press, 1980); on the white-slavery panic see Deborah Gorham, "The 'Maiden Tribute of Modern Babylon' Re-Examined: Child Prostitution and the Idea of Childhood in Late-Victorian England," Victorian Studies 21.3 (Spring 1978) 353-380.

${ }^{89}$ Deborah Steinstra, "Madonna/Whore, Pimp/Protector: International Law and Organization Related to Prostitution," Studies in Political Economy 51 (Fall 1996): 191.

\footnotetext{
${ }^{90}$ Steinstra, 195.

9I Steinstra, 192.

92 Steinstra, 192.
} 
proper gender roles as wives and mothers. At the same time, they left men's sexual prerogatives intact.

These agreements, which were formalized in the wake of the First World War with the establishment of the League of Nations, were part of the growing web of international community. In insisting on international adherence to this gender code, the Western powers were seeking to impose not a more equitable gender arrangement, but merely a gender code that reflected Western understandings of 'civilized' gender behaviour.

With the growth of prostitution in the early 1900 s in Siam, the Siamese government's response reflected the predominate bias towards regulating prostitution. Indeed, it was the government's concern to eliminate slavery in line with Western standards while failing to reintegrate slave women into society through the education and training given to men, that may have led to a direct increase in the number of women entering into prostitution as a way to provide for themselves. Along with polygamy, the practice of slavery had been a continual target of criticism by Westerners with their particular understanding of slavery based on the absolute enslavement of Africans by Europeans and Americans. In Southeast Asia, meanwhile, the practice was very different. People could sell themselves into and buy their way out of slavery. King Chulalongkom was very sensitive to the European strictures of 'civilization', which excluded the practice of slavery. After several attempts in the late 1800 s, slavery was finally abolished in law in 1905. Its abolition meant that a large pool of labour was suddenly freed from its traditional means of subsistence. While men were at least 
in part reabsorbed through the institution of mandatory military service and education towards wage-earning work, women were not as 'fortunate'.

There were those among the elite and aristocracy that campaigned for women's education in the aftermath of the abolition of slavery. Some officials in the government, particularly in the Department of Education, along with Chulalongkom's chief wife, Queen Soawapha, argued that as traditional providers for families, women would have to be prepared for new careers. The Minister of Education and the Director General of the Department of Education wrote to the Queen that "women's education is a contemporary necessity. After the abolition of slavery, these educated women will be able to earn their own living., ${ }^{, 93}$ King Chulalongkorn, along with his sons, championed a new form of Thai society based on male military conscription (instead of the old corvée system) which was, therefore, focussed on the training of the male citizenry. This, too, was part of the "standards of civilization" - the existence of an organized national military able to defend a given territory. The king argued that, given the strictures under which the government's budget was placed by the Bowring Treaty, emphasis should be put on the education of boys. ${ }^{94}$

The abolition of slavery did indeed have profound effects on non-elite women. As Suwadee Patana argues "in [the] early period women were able to earn some money for their families by simply selling themselves into slavery. The process of abolishing slavery in the

\footnotetext{
${ }^{93}$ Chaophraya Phatsakorawong and Prince Kitiyakorn, July 1897, c.f. Suwadee, 13.

${ }^{94}$ Suwadee, $12-13$.
} 
late nineteenth century made such things more difficult." ${ }^{, 95}$ Sukanya Hantrakul surmises that a large number of women - now no longer the slave-wives of individual men or slave-women who had provided sexual service to visiting guests of their master - drifted into prostitution as a means of maintaining themselves and their families in the post-slavery era. ${ }^{96}$ While slave status may have been officially eradicated, the practice of debt slavery, in other forms, remained alive and well among the general populace. Women were sold, or sold themselves, into brothel service for an advance. Often they insisted that the debt to the madams be paid off, even when they were 'liberated' through marriage.

The government's view of (at least, commoner) women's role in the new nation during the final years of Chulalongkorn's reign was made clear with the passing of the Venereal Diseases Act in 1909. To ensure the collection of taxes on this activity and control for venereal disease in an era of now continuous military training, the Venereal Diseases Act required that anyone wanting to operate a prostitution business or wanting to work as a prostitute had to secure a license from the government, which was to be renewed every three months. ${ }^{98}$ For women to obtain and renew their licenses they must prove themselves free of

${ }^{95}$ Suwadee, 13.

${ }^{96}$ Sukanya Hantrakul, "Prostitutes and Human Rights in Thailand," (n.p., 1982) 7.

${ }^{97}$ League of Nations Commission of Enquiry into Traffic in Women and Children in the Far East, "Siam: Internal Conditions Relating to Traffic," Report to the Council (New York: League of Nations, 1933) 313-314.

${ }^{98}$ Social hygiene had already become a matter of some concern since the last decade of the 1800 s. Cleanliness in order to avoid epidemics was encouraged in the growing city of Bangkok which experienced outbreaks of cholera in 1906 and 1911. Suwadee, 9. 
venereal disease and freely willing to engage in prostitution. Operators, for their part, were to ensure that the area used was clean and out of public view and that no prostitute was confined or under fifteen years of age. Nor was the operator to accuse prostitutes of theft for losing things given to them by the operator - a common technique of indebting prostitutes at the time. ${ }^{99}$ Clearly, the government sought to establish that prostitutes were operating freely and not in any way enslaved - in line with the anti-slavery reforms - but prostitution itself was not viewed as incompatible with choice. That is, women were not assumed to be enslaved through prostitution, but provisions were required to ensure no-one was forced into or forced to stay in prostitution. Indeed, the penal code, which went into operation that same year, also provided anti-trafficking measures, but, in the case of adult women, defined trafficking as only occurring in those cases where the woman was deceived or threatened by violence. $^{100}$

Thus, while the registration act shows that the government did not share the increasingly predominant Western assumption that women did not have sexual or social agency, and that it viewed women in prostitution as carrying on the tradition of female service to the family; it also shows that there was less concern for (especially common) women's health or independence than men's. While registration did not subject women to the same kind of reform attempts that were occurring in Europe and North America, it did

99 "Summary of the Control and Prevention of Venereal Disease Act R.S. 127, 1909, in Fox, Exhibit A, 147-148.

${ }^{100}$ S.276, Penal Code of 1908, in League of Nations Commission of Enquiry, 311. 
subject them to increased segregation from the community at large and increased control from state apparatus and brothel owners. ${ }^{101}$ At the same time, the government under Chulalongkorn clearly put emphasis on protecting male health, male education and male sexual access over and above women's health, education and training. The control of women's bodies in order to provide 'risk-free' sexual access for men, and therefore a healthy army, indicates that the monarchy's priorities were the formation and strengthening of the male national body.

The state reforms undertaken by Chulalongkorn enabled his successor, Vijiravudh, to press for greater international recognition and the end of the unequal treaties. The main goal of Siamese foreign policy in the first decades of the 20th century "was to extend and develop completely an international awareness of Thailand's increasing stature within the system of nation-states." ${ }^{102}$ By demonstrating its adherence to Western standards of 'civilization' the Siamese government sought to support its right to more equal treaty agreements. It was, according to Peter Oblas, "the policy of the Siamese government to

${ }^{101}$ By regulating brothels the government made it illegal for women to operate independently in prostitution and to move in and out of the trade. While there is little information on how the trade operated at this time in history evidence from other countries has shown how licensing regulations have usually worked to decrease women's independence and to delimit a particular identity as 'prostitute', rather than its being viewed as a sometime occupation or occasional exchange. See Judith Walkowtiz, Prostitution and Victorian Society (New York: Cambridge University Press, 1980).

${ }^{102}$ David Wilson c.f. Gong, 230. 
appeal to the West on its own terms and in its own language." ${ }^{103}$ Accordingly, Siam joined the League of Nations at its inception - the only Southeast Asian nation to do so - having taken part in World War Ion the side of the Allies with an eye to ridding itself of the unequal treaties under which it still laboured.

In its attempt to become part of the international society of civilized states, the Siamese government also became party to the social conventions on trafficking that had become such a key part of international society's gender standards. Siam was party to the 1904 International Agreement for the Suppression of the White Slave Traffic, which focussed on the protection of women and girls, and to the International Convention for the Suppression of the White Slave Traffic of 1910 , which made procurement a punishable offence. ${ }^{104}$ In 1921 Siam signed the League of Nations' International Convention for the Suppression of the Traffic in Women and Children. ${ }^{105}$

Siam's international good behaviour did yield results. At Versailles, Siam shed its unequal treaty with Germany. In 1920, the United States relinquished both its fiscal and extraterritorial rights. At the same time, new treaties with Japan and France were underway. The British, however, remained reluctant, especially in regards to relinquishing extraterritorial rights. Britain objected to the 'improper' administration of the Siamese

\footnotetext{
${ }^{103}$ c.f. Gong, 231.

${ }^{104}$ Truong, 155; Steinstra, 192.

${ }^{105}$ League of Nations Commission of Enquiry, 308.
} 
juridical system. Chulalongkorn's successor, Vijiravudh, advocated a policy of doing everything possible to please the British, but it was only through the appointment of Francis B. Sayre of Harvard Law School as go-between with Britain and other European states that new treaties were finally signed by 1926 , and only as late as 1939 that extraterritoriality was fully extinguished. ${ }^{106}$ The new treaties, which still retained some conditions to protect European nationals from the 'not quite yet up to standard' Siamese judicial system, were to remain in force for ten years - awaiting the finalization of the codification of Siamese law. ${ }^{107}$

It was in this context of trying to convince the European powers of the soundness of the Siamese legal system and its adherence to the "standards of civilization" that Siam signed the 1921 Convention, even as legalized brothels remained in place. Then, in 1928 , under King Prajhadipok, Siam instituted its own anti-trafficking legislation. The Siamese antitrafficking act reflected European influences. It empowered officials "to examine all women and girls coming into or departing from Siam" and, should there be a "reasonable suspicion" that the woman had been brought in or attempted to be taken out of Siam for the purpose of prostitution, the woman would be detained for investigation and returned to her country of origin if the case was proven. ${ }^{108}$ That the conventions on trafficking had some effect in at

106 Walter F. Vella, Chaivo! King Viiiravudh and the Development of Thai Nationalism (Honolulu: University of Hawaii Press, 1978) 122-124; Gong, 231-237.

${ }^{107}$ Gong, 236-237.

${ }^{108}$ League of Nations' Commission of Enquiry, Annex II "Extracts from the Traffic in Women and Girls Act, B.E. 2471 (1928) 325. 
least keeping white women from entering prostitution in other countries appears to be borne out by the disappearance of Russian, British, American and French prostitutes in Bangkok by the late 1920 s. $^{109}$

Along with Siam, France and the United States (and their colonies) maintained a system of licensed brothels arguing that they were an internal rather than an international affair, and more humane and 'civilized' than abolitionism. ${ }^{\text {II0 }}$ On the other hand, the French considered the traffic in women a product of Asiatic culture, which could be modified through the influence of French culture "so respectful of the rights of women and children."

The Siamese government was able both to take advantage of the separation of national and international affairs as it pertained to licensed brothels and to distance itself from 'uncivilized behaviour' by treating the issue of prostitution as largely one of Chinese immigration and Chinese cultural practice. Vijiravudh's sinophobia has been well noted by chroniclers of his time. While Vijiravudh modelled himself the first nationalist in Siam, "the target of this nationalism, however, was neither the United Kingdom, which controlled ninety per cent of Siam's trade, nor France, which had recently made- off with easterly segments of

${ }^{109}$ League of Nations Commission of Enquiry, 316.

${ }^{110}$ Thanh-dam Truong, Sex. Money and Morality: Prostitution and Tourism in Southeast Asia (London: Zed, 1990) 83-85.

${ }^{111}$ Saigon Court of Appeal, c.f. Truong, 85. 
the old realm: it was the Chinese whom his father had so recently and blithely imported."12 Walter Vella argues that this distinction was not only a product of Vijiravudh's brand of Thai nationalism, which sought to distinguish a Thai nation from other Asian nations, but also from an increasing sense of Chinese identity even among the diaspora after the 1911 revolution and the Sun-yat Sen government's appeals to Chinese everywhere to support the political changes in China. ${ }^{113}$ The threat of republicanism represented by the Chinese community was taken very seriously by the Siamese monarchy. The monarchy and the Chinese community in Siam were also increasingly competitive in the growing capitalist economy as the Chinese business community's profit from the export trade expanded. ${ }^{114}$

The Chinese were, in any case, a convenient and acceptable target at the time. Vijiravudh's most sinophobic writings, which called the Chinese the "Jews of the Orient," arose in part from a desire to please the Europeans and drew on anti-Chinese European writings, according to Vella. ${ }^{115}$ Indeed, the League of Nations Enquiry documents - reflecting the racial concerns underlying the anti-trafficking movement - leaned heavily on racial categories and take up the focus on Chinese prostitution unproblematically. The fear of communism also fed the sinophobia of the period, particularly in the 1930s. Kenneth Landon, a US envoy reporting to the State Department on the likelihood of communist

II2 Benedict Anderson, Imagined Communities (New York: Verso, 1991) 100.

${ }^{113}$ Vella, 187-188.

${ }^{114}$ Chaiyan, 153-154.

${ }^{115}$ Vella, 193-194. 
influence in Siam in this period, argued that the crackdown on immigration was a response to the growing 'insularity' of the Chinese community with the arrival of Chinese women. ${ }^{\text {I6 }}$ In the social hygiene language of the time the Chinese were suspected of a moral turpitude that was understood to lead to communism. The Chinese were often characterized as a threat to public morals, with their 'vices' of gambling, prostitution and opium-smoking. Kenneth Landon, writing reports on the Chinese in Thailand for the US State Department in the 1930s mainly to assess the likelihood of their becoming communists, examined the "habits or vices which continue to modify the general trend toward sensible and modern ideas on health." ${ }^{17}$ He wrote:

Gambling, opium smoking and prostitution form the vice pattern or ill-health activity of the Chinese in Thailand as well as British Malaya. Thailand has a large floating population of Chinese coolies who work in rice mills, in tin mines, and as freight coolies. They find their pleasure largely in gambling, opium, or with prostitutes. The stable Chinese population also supports all three of these questionable luxuries. Homosexuality is common, especially among the floating population. ${ }^{118}$

${ }^{116}$ Kenneth Perry Landon, The Chinese in Thailand (New York: Russell and Russell, 1977) 205. Kenneth Landon and Victor Purcell, (The Chinese in Southeast Asia, 2nd edition (Kuala Lampur: Oxford UP, 1965)) both emphasized an increasing insularity and increasing attachment to China among the Chinese in Siam in the post-revolutionary era. However, it must be noted that both were writing in an effort to measure the potential for the Chinese diaspora to support a Communist insurgency in Southeast Asia.

${ }^{117}$ Landon, 88.

${ }^{118}$ Landon, 89. 
Landon's concern with the "Chinese vices" of opium, gambling and prostitution reflected the Western beliefs of the period that linked the lack of 'social hygiene' to the growth of communism. Landon wrote: "Many Chinese young men have admitted to the writer that the evil influences which brought about final moral breakdown, usually accompanied by disease, was traceable to prostitutes in the market place." 19

\section{Table I: Prostitution Policy, $1909-1928$}

1904 Siam signs International Agreement for the Suppression of the White Slave Traffic.

1909 Siamese government passes Venereal Disease Control Act.

1910 Siam signs International Convention for the Suppression of the White Slave Traffic.

1921 Siam signs the League of Nations' International Convention for the Suppression of the Traffic in Women and Children

1928 Siamese government passes Anti-Trafficking Act.

The 1928 anti-trafficking act came into effect at a time when prostitution numbers and the immigration of Chinese women appeared to be steadily increasing. Between 1919 and 1929 the female Chinese population increased by 140 percent. However, it still remained well below the male Chinese population. ${ }^{120}$ Registered Chinese brothels greatly outnumbered

${ }^{119}$ Landon, 98.

${ }^{120}$ League of Nations Commission of Enquiry, 308. 
Siamese brothels during this period. ${ }^{121}$ Indeed, the anti-trafficking act was put into place in conjunction with an immigration act that restricted the entry of persons without proper documentation, or who suffered from diseases as specified by the government or who were "of bad character or are likely to create disturbances or to endanger the safety of the public of the Kingdom of Siam." "122 "Bad character" was understood to mean communist. According to government reports, 348 Chinese women were excluded in 1928 and 1929. Several girls were also repatriated to China each year on the grounds that they had been brought in directly for the purpose of prostitution. ${ }^{123}$ The Siamese government had an arrangement with the Chinese Society for the Protection of Women and Girls to repatriate girls to Hong Kong.

At the 1936 League of Nations Bandung Conference on Traffic in Women and Children, the delegate from Siam reported a decrease in the traffic of women because " $[t]$ he numbers of Chinese brothels and prostitutes have become considerably smaller. This circumstance has been partly due to the economic depression and partly to the stricter control of immigration." ${ }^{\mathrm{i} 24}$ At later meetings Siamese delegates noted decreasing numbers of registered brothels and licensed prostitutes believed, in part, to stem from increased controls

${ }^{121}$ While the total number of registered brothels fell slightly after 1928 , officials reported an increase in clandestine prostitution, which they felt was in part a reflection of the numbers of women who gave up their licenses but continued to practice prostitution outside the brothel system. League of Nations Commission of Enquiry, 313.

${ }^{122}$ S.6, "Immigration Act B.E.2470 (1927) in League of Nations Commission of Enquiry, Annex I, 324.

${ }^{123}$ Commission of Enquiry, 321.

${ }^{124}$ League of Nations Bulletin, 1 July 1936, c.f. Landon, 95 , 
on Chinese immigration: "In past years the majority of those who frequented brothels were Chinese from Hainan whose women seldom migrated with their men. The number of Hainanese female immigrants who have become more domestic in their habits has increased. This is believed to have an indirect effect on the traffic."125

Chinese women were assumed to enter prostitution unwillingly, to have been trafficked either explicitly for the purpose of prostitution or as mui tsui (young girls used for domestic service). Landon's opinion was that "the girls themselves as a general rule do not choose to enter the business. They are sold or forced into it, sometimes by famine or economic conditions in China." 126 He understood the Chinese acceptance of former prostitutes as brides to be recognition of this forced status. ${ }^{127}$ Indeed, the Chinese Chamber of Commerce that arranged to return women to China through the Society for the Protection of Women and Children, also assumed this to be the case. Elizabeth Sinn argues that the Society operated on the basis of "Chinese patriarchalism", assuming that women had to be under the protection of a man. ${ }^{128}$ Indeed, the Director argued that pimps were necessary in prostitution as go-betweens and brokers. When asked whether he thought women could

${ }^{125}$ Response of the Thai delegate, League of Nations Bulletin, 1 July 1936, c.f. Landon, 95.

${ }^{126}$ Landon, 98.

${ }^{127}$ Landon, 98. There is evidence in Landon's own writings, however, of women travelling independently between China, Thailand and Malaysia who may have worked as prostitutes at various times. See Landon, 97-98.

${ }^{128}$ See Elizabeth Sinn, Chinese Patriarchalism and the Protection of Women in 19th Century Hong Kong (n.p. n.d.). 
operate independently, i.e. without a pimp, in prostitution, the Director of the Chinese Chamber of Commerce in Thailand remarked "No I don't think so. Suppose a girl comes to see me, I say I don't want her, but if a man, we call him a broker, comes and says she is a fine girl, we say, "All right, bring her along", and the broker gets money, perhaps 20 per cent."129 Only women working under pimps could work in prostitution according to this view. ${ }^{130}$ The $^{\text {ing }}$ discourse around prostitution in China itself was, according to Gail Herschatter, changing rapidly at this time. A discourse of 'pleasure' associated with the courtesan culture of the early 1900s was quickly being replaced by a discourse of victimization and national humiliation in prostitution. ${ }^{13 t}$

Vijiravudh sought to distinguish Siamese women from the 'unfortunate' and downtrodden Chinese women. Vijiravudh's nationalism drew on an image of Siamese women as mothers to the nation, as educated and refined. Women were to have a role in the "prosperity of the country" and in the important goal of "civilization" (transcribed directly from the English). They were to act as intelligent and efficient wives and mothers who could

${ }^{129}$ c.f.League of Nations Commission of Enquiry, 314.

${ }^{130}$ Police reports to the League of Nations, however, noted that many women 'liberated' from brothels either returned or took up 'sly' prostitution - casting doubt on their 'forced' status. While this situation did not seem surprising to Siamese police or even troublesome, League officials were obviously frustrated by the legal status of brothels and the resulting inability or unwillingness of Siamese officials to prosecute for procuring.

131 Gail Hershatter, "Courtesans and Streetwalkers: The Changing Discourses on Shanghai Prostitution, 1890-1949," Journal of the History of Sexuality 3.2 (1992): 247. 
entertain Western visitors in the Western manner, be intelligent companions for their husbands, and raise children to be good citizens. ${ }^{132}$ The king wanted to ensure that Siamese women appeared educated and civilized to Westerners. ${ }^{133}$ In an essay on women's status the king bemoaned the fact that foreigners criticized Thailand for its treatment of women and concluded:

This situation is most shameful! Are we Thai so callous - with the hide of an elephant or a rhinoceros - that we are not disturbed? Even if you yourself are not a bad person as are some of our nationality, and many of them are nobles, shouldn't you help by speaking up and complaining? Can you silently look on while the outside world speaks of our customs as those of a jungle people? Please understand that others are taking our measures! Please do think this over. ${ }^{134}$

Only the "jungle people" treated their women as slaves, according to the king, and Siam must not be seen as a "jungle people" like Malaya, Borneo and Africa. The king clearly understood the hierarchy of colonialism and sought to position Siam as part of the 'civilized', rather than 'barbarian' world of the 'jungle people'. ${ }^{135}$

${ }^{132}$ Suwadee, T. Patana, "Thai Society's Expectations of Women 1904-1935: An Approach to Women's History," Paper Presented to 12th IAHA Conference (University of Hong Kong, 24-28 June 1991) 6.

${ }^{133}$ Suwadee, 8.

${ }^{134}$ Vijiravudh, “A Symbol of Civilization: The Status of Women," c.f. Vella, 153.

${ }^{135}$ However, the king echoed the understanding that inequality was a problem among the elites rather than the populace. The King pointed out that, when it came to the status of women, "our Thai country people are much closer to 'civilization' than people in Bangkok or large towns." Vijiravudh, "A Symbol of Civilization," c.f. Vella, 152. 
Nonetheless, Vijiravudh and the traditional elite faced another threat in the form of the growing strength of republican forces within Siam. With the end of Chulalongkorn's reign in 1910 and, with it, the Chakri Reformation, the bureaucracy had grown in strength considerably vis-à-vis the monarchy. The monarchy now had to prove itself capable of leading a modern state as discussions of the appeals of republicanism swept through the Bangkok elite following the Chinese revolution in 1911. Indeed, a coup against the monarchy by civilian and military bureaucrats was attempted in $1912 .{ }^{136}$ Vijiravudh's retinue had to tread carefully to prove that the traditions of monarchy should not be quickly overthrown in the rush to 'civilization'. Vijiravudh's brand of nationalism closely linked the monarchy to the essence of Siamese national identity. As Chaiyan Rajchagool has argued:

$\mathrm{He}$ [Vijiravudh] advocated the ideas of royalism as qualities that were not only compatible with being Thai but essential to being so. He wrote that any change from these was alien to the 'Great Thai Tradition', and denounced socialism, limited monarchy, and so on as harmful, anti-Thai, and made other slanderous smears on these ideas... ${ }^{137}$

The king built up his own "Wild Tiger Corps" based on the model of the Boy Scouts movement, to instill loyalty to the crown, at least among the select few. As well, the king defended the practice of polygamy in nationalist terms as better for the 'mothers of the nation' in providing some stability and protection for minor wives, rather than the "modern"

${ }^{136}$ Chaiyan Rajchagool, The Rise and Fall of the Thai Absolute Monarchy (Bangkok: White Lotus, 1994) 155-158.

${ }^{137}$ Chaiyan Rajchagool, 161. 
practices of "cohabitation" without marriage or the taking of mistresses. He called to task the "modern young Siamese" who claimed to be opposed to polygamy, for acquiring secret wives - buying the women from their parents and getting rid of these "secret wives" when the men tired of them. At least, the king argued, the old arrangement of polygamy provided some security for minor wives. ${ }^{138} \mathrm{He}$ also criticised the practice of cohabitation, writing "have pity on our women and girls! Help them to obtain some justice and equality. Help them to become honoured as the future mothers of our nation." ${ }^{139} \mathrm{He}$ opposed a proposed law on monogamy - arguing that the practice of polygamy was too deeply ingrained in Siamese society - and instead put forward a law that would ensure protection for minor wives and their children within the polygamous system. Polygamy, according to the king, was a way of maintaining respectable status for the mothers of the nation.

A number of elite men took up the defence of polygamy as a nationalist duty. They tended to reflect the more popular aspect of Vijiravudh's nationalism - its anti-Chinese sentiment - arguing that polygamy helped to increase the population of ethnic Thais as opposed to Chinese. Elite women, however, increasingly voiced opposition to polygamy, making connections between polygamy, prostitution and lower (rather than higher) social status for women. Women elites directed their attacks at the power of elite men over women symbolized in polygamy and they used their position within nationalist and 'civilizational'

${ }^{138}$ Vella, $155-157$.

${ }^{139}$ c.f. Vella, 155. 
rhetoric to legitimize their arguments. They argued that polygamy had led to a lower social status for women that made taking up their roles as 'educated and civilized' very difficult. One article argued that because of this low status in polygamy, new customs such as Western-style social dancing did not indicate women's 'civilization' but were simply another way for men to extend their power over women. ${ }^{140}$ Until polygamy was outlawed, women could not take part in the 'civilizing' project. Elite women also linked polygamy to potential increases in prostitution by arguing that the neglected offspring ("fatherless girls") of minor wives might turn to prostitution. ${ }^{141}$ Articles in women's magazines such as Satrithai further criticized prostitution as the result of women's economic responsibilities to the family, male seduction, parental neglect and the lack of education. ${ }^{142}$ Elite women were sending a clear message that if society wanted them to be symbols of a 'civilized nation' they could not do so within the confines of polygamy.

It was not until after the fall of the absolutist monarchy in 1932, however, that polygamy finally came to its legal end. In August 1932 some 200 women lobbied the governing 'People's Party' to ban polygamy. In October 1935, the government enacted the newly revised legal code. Section 1451 stated that "....whoever has already registered for

${ }^{140}$ Vella, 155.

${ }^{141}$ Scot Barmé, "Struggling for Equality: Critique of Polygamy in Siam During the 1920s, paper presented at Thai Studies 6th International Conference, Chiang Mai, Thailand, 14-17 October, 1996.

${ }^{142}$ Suwadee, 22. 
marriage will not be entitled to register again, unless that person has proved that the former registration is invalid due to the death of the partner, divorce or declaration by the court that it is invalid...." ${ }^{\text {143 }}$ The enactment of the new legal code, and with it the official end of polygamy, marked the final step in the achievement of the "standard of civilization" in the eyes of the Western powers. Accordingly, it brought an end to Siam's semi-colonial status as the unequal treaties were rescinded between 1936 and $1939 .{ }^{144}$

\section{Conclusion}

This history makes clear the centrality of gender and sexuality to the establishment of national identity and difference. Gender and sexuality, particularly women's sexuality, were used to demarcate the lines of civilization and become points of acquiescence and resistance to imperialism and/or Westernization in Thailand. They are not peripheral to the process of establishing national identity and sovereignty and to international relations, but central constitutive elements. The formal end of polygamy was key in establishing Thailand's full sovereignty and international status as a civilized country. For the Western powers polygamy - as improper gender and sexual identity - indicated the Thai monarchy's inability to rule, its failure to behave in the rational masculine manner that, in the West, constituted legitimate power. Meeting Western standards of proper gender behaviour, therefore, became

${ }^{143}$ Suwadee, 23.

${ }^{144}$ Gong, The Standard of Civilization, 237. 
key in establishing Siam's independence and international stature. At the same time, however, gender also became territory on which national identity was constructed and debated. The monarchs defended polygamy as central to Siamese culture and state structure and registered brothels were maintained in the face of the international abolitionist campaign by defining the problematic aspects of prostitution as a Chinese rather than a Siamese problem. In all, women's bodies, in both polygamy and prostitution, were the contested territory of imperialism and nationalism. 


\section{Chapter 3: The Criminalization of Prostitution}

Gender was an important part of the establishment of national identity in the postabsolutist era. Phibun's nationalist program, although often attributed to the replication of fascist nationalism, also reflected the state-building programs of Western democracies of the late 1800 s.' In the West, social hygiene and reform programs worked to discipline and internalize social identities, while legitimizing the nation-state as a tool for the greater public good. In Thailand, however, the absence of a growing middle-class meant that these reforms were largely state-directed and maintained. Their failure to naturalize themselves into society at large meant that many of Phibun's most obvious campaigns lacked any social support and died out with Phibun's removal from power in 1957. However, the campaigns did establish a partial infrastructure for a social welfare state - including a Department of Public Welfare, an expanded infrastructure for public health and education, and programs for women, which operated to socialize them into particular roles. This reconfiguring of state structure and gender roles - symbolized by elite women's participation in the modern project of social welfare - appealed to the internationally hegemonic discourses of Keynesian states and modernity.

Through these changes, a small professional elite was created, including many women who identified themselves with social reform causes. In the post-absolutist era the debate over prostitution reflects in part the struggle for this coterie to gain greater influence

'See Walter Vella, The Impact of the West on Government in Thailand (Berkeley: University of California Press, 1955) 382. 
in the military-bureaucratic structure. Although this small elite did not enjoy the support of a large middle class it did enjoy the support of international society, giving it greater leverage over some aspects of national policy than it might otherwise have had. This was particularly the case in the 1950s when the Thai government was actively courting the support of the US. The nationalist agenda, therefore, opened a pathway to social and political influence for elite women. Nonetheless, resistance to changes in relations between the sexes, including in prostitution law, remained, as new leaders drew on older images of political potency for legitimacy in a new age.

\section{Post-Revolutionary Prostitution Law, 1932-1966}

In the early post-revolutionary era Siam was under increasing pressure from the League to abolish the system of licensed brothels. Licensed brothels continued to be defended by some elites, however, as the best way to control the spread of venereal disease. Some government bodies, however, particularly the very powerful Ministry of the Interior, increasingly showed a willingness to entertain the possibility of eventual abolition. The League of Nations Commission of Enquiry's visit in 1932 had led to some investigation of the activities of pimps, who, under the licensing system, had not previously been the object of investigation by police because women were considered to enter the trade relatively 'freely'. In 1936, in response to the League of Nations' Bandung deliberations on the

${ }^{2}$ League of Nations. Commission of Enquiry into Traffic in Women and Children in the Far East, "Siam: Internal Conditions Relating to Traffic." Report to the Council 
control of prostitution, a Committee Considering the Abolition of Licensed Brothels was established. The Committee argued that brothels at least allowed for closer control of prostitutes and, therefore, of the spread of venereal diseases. The government did not, therefore, support the draft League of Nations' convention of 1937, which called for the "almost immediate eradication of licensed brothels," and instead opted for a policy of "progressive and gradual.... abolition of the system of licensed houses and the adoption of suitable administrative medical and social measures to accompany the same." A plan for the prevention of venereal diseases was drawn up in 1938 (although not enacted) that suggested the maintenance of brothels and licensed prostitution was important in the fight against venereal disease:

Prostitute should live in a special place in order not to be so hard to control, the details of control should follow Bangkok's program because non-licensed prostitutes in provinces are continuously increasing. They are a source of venereal disease. Some prostitutes came to Bangkok because of low income elsewhere [sic]. ${ }^{4}$

(1933) 314 , note 1 .

${ }^{3}$ Minutes of the Committee for Considering the Abolition of Licensed Brothels and the Welfare of Women and Children, 1937 \& 1938 c.f. Morris G. Fox, "Problem of Prostitution in Thailand," Social Service in Thailand (Bangkok: Dept. of Public Welfare, Ministry of the Interior, 1960) 140.

${ }^{4}$ The proposed act suggested that measures should be divided in two parts, urban (i.e. Bangkok) and rural. The Bangkok plan differs only in the addition of further regulatory measures of the citizenry such as prohibiting marriage licenses without certificates showing the absence of venereal disease. Clearly, the government felt that such measures would only be workable in the city where control over the population was easier to effect. Exhibit B, "Proposal for Venereal Disease Control in Thailand, B.E. 2481 (1938) Fox, 
Indeed, the effects of the Great Depression had been devastating in rural parts of the country, and a growing number of women turned to prostitution to support themselves and their families. ${ }^{5}$ In 1939 the issue of the increasing number of unregistered brothels was raised in the National Assembly. One member reported that while sixty-seven brothels were registered with the police he himself had discovered 274 in Bangkok alone. He had also discovered four girls from Denchai under the age of thirteen. In response to his suggestion of higher penalties for unlicensed brothels the Acting Minister of the Interior replied that higher fines would likely be ineffective in reducing the trade in underage girls. ${ }^{6}$ The Ministry, instead, argued for the gradual abolition of licensing. Elite male opinion continued to maintain that such a measure would not be helpful in controlling disease or maintaining decorum. A Bangkok Chronicle editorial warned that the abolition of licensed brothels in the Straits Settlements had lead to "no appreciable decrease in the spread of disease and 'rickshaw parades,' 'street-corner soliciting,' and other unseemly manifestations...."

149.

${ }^{5}$ On the Great Depression in Thailand see John Girling, Thailand: Society and Politics (Ithaca: Cornell UP, 1981) 58-59.

${ }^{6}$ Kenneth Perry Landon, The Chinese in Thailand (New York: Russell and Russell, 1977) 96.

${ }^{7}$ Bangkok Chronicle, January 10, 1940, c.f. Landon, 97. 
Newspaper articles on the issue often defended a stricter, Japanese style of control as the best response to these problems. ${ }^{8}$

The outbreak of the Second World War in 1939, and the occupation of Thailand by Japanese troops in 1941 until 1945 leant new weight to the argument that disease control must be foremost in considerations of prostitution policy. While the Japanese are now well known to have taken 'sex slaves' in occupied Asian territories during the war, there is as yet no available evidence on the extent to which this occurred in Thailand. As a 'friendly' occupied country, Thai women may have been spared the degradations of Korean women during the war. Most often, Korean women were brought in to 'comfort stations' in Thailand to service Japanese soldiers. ${ }^{9}$ Nonetheless, the increased mobilization of the male Thai population along with the continuing poverty of the rural regions, and the presence of Japanese troops no doubt contributed to a rising concern over prostitution activities. The Public Health Department's newly formed Venereal Disease Prevention and Suppression Committee had proposed a crack-down on prostitution in 1942. Their suggested legislation struck a balance between regulation and abolition of prostitution. It prohibited "sexual

${ }^{8}$ Some raids on illegal brothels were made in response to the increased concern. (Landon, 96). In 1940 the Ministry of the Interior decided to abolish the licensing system. However, stricter medical examinations for prostitutes were put into place. (Landon, 9697). As well, prices for prostitute and brothel licenses were increased. Purcell, 13. The increased charges were part of a program of increased taxes and tariffs aimed at the Chinese merchant class. See Victor Purcell, The Chinese in Southeast Asia, 2nd edition, (Kuala Lampur: Oxford University Press, 1965) 136.

${ }^{9}$ Investigations during the recent tribunals over the sexual slavery of Asian women during the war have turned up only one case in Thailand. 
relations for money", pimping and brothel-keeping (punished by stiff fines or up to one year's imprisonment) while allowing for the operation of brothels "in necessary cases" under the supervision of a local government official with the agreement of the Health Officer and the Minister of Public Health. ${ }^{10}$ While this legislation failed to be put into place, in the aftermath of the war the Ministry of the Interior disallowed the opening of any new brothels as a step towards full abolition. ${ }^{11}$

Gradually, over the 1950s the Ministry of the Interior introduced new measures to punish procuring and to 'rehabilitate' women in prostitution. In 1960 the government introduced a law which for the first time criminalized prostitution, despite public opposition, bringing the country's law into line with the United Nations' convention on prostitution.

The Ministry of the Interior's determination to bring about the abolition of licensed brothels was part of the Phibun government's attempt to gain international stature for the country.

\section{Phibun and the New (Inter)Nationalism}

While the unequal treaties had been ended by 1939 , the government began a nationalist program to modernize the country under the authoritarian leadership of Field

\footnotetext{
${ }^{10} \mathrm{Health}$ officers were to be further empowered to order anyone with a venereal disease to seek treatment, including most importantly, according to the Committee, prostitute women. Fox, Exhibit C, 151-152.

II "Prostitution in Selected Countries of Asia and the Far East," International Review of Criminal Policy, 13 (1958): 53.
} 
Marshall Phibun (Plaek Phibulsongkarm) beginning in 1938. Phibun sought to reconfigure Thai identity in the eyes of the world as well as Thais. To mark the beginning of a new era he changed the name of the country from Siam to Thailand and set about educating Thais in the proper mode of "civilized" behaviour. When the British and American governments failed to provide support to Thailand against the Japanese during the Japanese invasion of Indo-China, Phibun brokered a guarded cooperation with the Japanese. This cooperation with Japan during the Second World War, however, meant a renewed struggle to maintain Thailand's sovereignty after the war. Britain demanded that Thailand pay war reparations. ${ }^{12}$ The United States, however, blocked the British move. The US had never received a formal declaration of war from the Thai ambassador in the US, who instead convinced the US government to fund an underground resistance movement. The US government argued, therefore, that Thailand should not be treated as a defeated enemy. US interest in maintaining Thailand's friendship was heightened by growing concerns over the rise of communism in Asia. With the support of the US, Phibun returned to power, re-orienting Thai foreign policy squarely in favour of the US and backing US anti-communist measures in Southeast Asia.

12 The British sent Lord Mountbatten with troops to "open relations" with Thailand in March 1944. M.R. Seni Pramoj, a senior statesman, felt that accepting the terms set down by Lord Mountbatten would result in colonization. The American government was suspicious of British motives: "in their eyes Moutbatten, a great-grandson of Queen Victoria with close relatives in most of Europe's royal families, looked likely to have as his main objective the restoration of the British empire in the Far East.... Fears were expressed too that, with Mountbatten in command of this theatre, Britain would seek to expand its empire to encompass Thailand." Judith Stowe, Siam becomes Thailand: A Story of Intrigue (London: Hurst \& Co., 1991) 271. 
Phibun was determined to establish Thailand as a 'modern' and civilized nation in the eyes of the Western powers, both before and after the war. To this end he, and his lieutenant, the propagandist Luang Wichit Wathakan, established a program of national social and cultural renewal that aimed at forcing Thais to meet Western standards of appropriate cultural behaviour-including dress, social conduct, hygiene and language forms. Proper cultural behaviour was considered key in maintaining the sovereignty of the nation. As expressed by one member of government, improper behaviour could lead to "foreigners ridiculing Thailand as being uncivilized, possessing no high morality and therefore not qualified to the same sovereign status as other nations." 13 Phibun passed a series of Cultural Mandates in the early 1940 s that stipulated proper dress and manners. According to Kobkua Suwannatha-Piat: "[it] became an offence to act or behave in public in a manner that would humiliate or tarnish the image of Thailand."14 Dress reform, for example, was considered particularly important in maintaining this image. Men, rather than wearing the traditional pamuang (a cloth wound around the body and hitched up between the legs) or Chinese silk trousers, were to wear hats, shoes, socks, jackets and trousers; and women, who sometimes wore only a sarong with a simple cloth wrapped around the upper part of the body and could even go topless at home, were admonished to don a hat, skirt, shoes and a blouse that

${ }^{13}$ Chief Secretary to the Cabinet to Wichit Wathakan, 8 June 1939 c.f. Kobkua Suwannatha-Piat, Thailand's Durable Premier: Phibun through Three Decades, 19321957 (New York: Oxford UP, 1995) 153-154, note 26.

${ }^{14}$ Kobkua, 126. 
covered the shoulders. ${ }^{\text {Is }}$ Phibun connected the French reluctance to return territory to Thailand directly to the Thai failure to dress properly and to maintain a good image. As Kobkua writes:

Phibun was singularly annoyed with a movie on 'Siam' showing Thai women hawkers on the roadside chewing and spitting betel-nut, men crowding around a game of fishfighting, and people in general going about their daily chores wearing only Chinese shorts... and no singlet. The Prime Minister felt that such a public image greatly harmed the Thai request for the return of their territory from France. 'The French could very well say that if this is what we are, how dare we demand for the return of the territory. It'd be more appropriate that [the territory] remain under their rule. They at least can keep it clean and hygienic. ${ }^{16}$

Maintaining Thailand's sovereignty, by this understanding, demanded close attention to the dress and deportment of its citizens because of the image relayed to the world audience. Although the Cultural Mandates were at first based simply on public exhortations by the Prime Minister's office, after 1942 more coercive measures of fines and arrest were employed, particularly in matters of dress code violations to ensure that proper dress was maintained in public places. ${ }^{17}$

\footnotetext{
${ }^{\text {Is }}$ Thamsook Numnonda, "Pibulsongkram's Thai Nation-Building Programme during the Japanese Military Presence, 1941-1945," Journal of Southeast Asian Studies 9.2 (Sept. 1978): 238.

${ }^{16}$ Kobkua, 115.

${ }^{17}$ Scot Barmé, Luang Wichit Wathakan and the Creation of Thai Identity (Singapore: Institute of Southeast Asian Studies, 1996) 158.
} 
Phibun clearly understood the operation of cultural power in international relations.

He argued that "[the] exhibition of high culture by the people is one sure way of maintaining the sovereignty of the nation."18 As his biographer points out:

Certainly, Phibun must have been very conscious of the Westerners' patronizing attitude towards any socio-cultural practices different from their own. He had lived in France for three years and must have had some unpleasant encounters with the white man's political and cultural superiority complex. ${ }^{19}$

Foreign observers also recognized that the nationalism campaign was part of exercising Thailand's new found international role, having cast off the last of the unequal treaties of previous era only very recently. Sir Anthony Eden reported to the Foreign Office that:

[the origin of the campaign] is probably to be found in the Thai desire to Westernize and modernize everything Thai which, rooted in the inferiority complex of an oriental people which has only recently succeeded in establishing its theoretical equality of status with the European Powers ... [and

${ }^{18}$ Phibun, c.f. Kobkua, 111 . It is perhaps of no small importance that it was precisely during this time that Anna Leonowans' writings of the 1850s on harem life in Siam were revived and republished (in 1944, by none other than the wife of Kenneth Landon, representative of the US State Department in Thailand) and subsequently produced as the Rogers and Hammerstein musical "Anna and the King of Siam" (in 1951). The musical then became an internationally popular film and was immediately banned in Thailand for its portrayal of King Mongkut as a cruel and backward despot. Even today "Anna and the King of Siam" meets with hostility in Thailand. In 1998 the government refused to allow filming of a new version to take place on Thai territory. See "Shall they dance? Probably not in Bangkok's backyard," National Post 7 December 1998, D4.

${ }^{19}$ Kobkua, 129. 
has been] accentuated in the last year or so in proportion to Thailand's growing prominence in world affairs. ${ }^{20}$

The nationalist program also sought to inculcate a 'Thai national identity' in a country where many still identified themselves as Chinese, Lao or Shan. An 'imagined community' of nationals still did not exist, and Phibun sought to impose this identity from above. Indeed, the purpose of the Cultural Mandates was to implant the idea of a 'Thai national culture' $(\text { wathanatham) })^{21}$ shared by the 'Thai people' - a people who were defined, conversely, by their adherence to these cultural principles. ${ }^{22}$

Along with appropriate customs, Phibun sought to enforce proper gender identities. The dress reforms served to heighten gender distinctions in dress (from the traditional sarong-like "panung/pakamaa" for both men and women). Phibun also took offense to the ambiguous gender of some women's names and insisted that men's and women's names be

${ }^{20}$ Sir Anthony Eden c.f. Kobkua, 129.

${ }^{21}$ Wathanatham (culture) was a new word which made its first appearance in the 1930 s replacing 'civilization' as a popular term. Wichit sought to clarify its meaning (which had caused some confusion) as having both a material form (architecture, dress and art) and a moral/behavioural aspect which led to "national progress and stability." Barmé, 160-161.

22 While Phibun's chief propagandist Wichit (and, some argue, the real progenitor of the hypernationalism of this period) made claims to a racially distinct body of 'Thai people' (that, not coincidentally given Wichit's irredentist mission, included the Lao and Shan who lived outside the current boundaries of Thailand as well as inside) the concept of 'Thainess' was used more broadly to denote certain behaviours, a 'culture' of Thainess rather than a Thai race. Both aspects were often present in the use of the concept of 'Thainess' (khwampen Thai) which allowed for a certain elasticity in its application. See Barmé, 147-151. 
distinct. Phibun further sought to regulate marital relations between the sexes. Bureaucrats were told to kiss their wives upon leaving for, and returning from, work in presumed western fashion. ${ }^{23}$ Wives were encouraged to join their husbands on healthy walks and "improve relations with her husband's friends." 24 Proper gender relations and gender identity in the eyes of the West remained an important part of maintaining Thai sovereignty in this postimperialist era.

Men and women were also given distinctive roles in the new nation. Thai men were to prescribe to a code of valour, which, Thamsook argues, echoed the Bushido chivalric code of Japan, emphasizing love of country over one's own life, hard-work and fighting readiness as well as proper dress, self-sufficiency in food and provision for, and honour of, children, women and older people. ${ }^{25}$ Women, for their part, took on a new importance as guardians of 'culture' and 'mothers of the nation'. Phibun announced, "women are mothers of every Thai as women are mothers of all things. They are the mothers who give birth to children and they are the mould of the nation.... Mothers are the mould of the character of men since childhood.... If we have no good mould, we can never build the Thai nation...."26

${ }^{23}$ Kobkua, 127.

${ }^{24}$ Thamsook, 240.

${ }^{25}$ Thamsook, 240. The adoption of a 'work ethic' among Thais was also a concern of Phibun's, who was sensitive the criticism that "the Thai played at work and worked at play," Vella, 384.

${ }^{26}$ Wichit Wathakan, “On Propaganda,” 1 February 1943, c.f. Kobkua, 158, note 79. The Thai-ification aspect of Phibun's nationalism is also important here. Malay-Thais and Chinese Thais were targeted to ensure that they were sufficiently Thai. This could 
Women's newly emphasized role in enculturating citizens opened space for women's political and social activity in the public sphere. With the fall of the absolute monarchy, women activists had hoped for legislation that would advance equality between the sexes. Women's magazines, according to Suwadee Patana, often quoted the governing People's Party motto of "rights, liberty and equality" to argue for women's equality. ${ }^{27}$ The new antipolygamy law, however, failed to protect women's independence and instead increased a husband's control over his wife's business affairs. As well, while polygamy was no longer officially legal, the practice remained in place. Men were still able to register all their children, whether or not they were the offspring of a formal marriage. ${ }^{28}$ Finally, women had little redress against their husbands' taking a minor wife, because a husband's adultery was not considered grounds for divorce whereas a wife's was. ${ }^{29}$

As Gail Omvedt has argued, these legal changes:

presumably be obtained through the adoption of cultural practices and not through eugenicist measures but the ethnic undertones of Phibun's revolution are a matter of great controversy, as reflected in the debates over the change in name from Siam to the more ethnically specific Thailand (from Tai, an ethnic group mainly residing in central Thailand).

${ }^{27}$ Suwadee T. Patana, "Thai Society's Expectations of Women 1904-1935: An Approach to Women's History," paper presented to 12th IAHA Conference, University of Hong Kong, 24-28 June 1991, 22.

${ }^{28}$ Craig Reynolds, "A Nineteenth Century Thai Buddhist Defense of Polygamy and some Remarks on the Social History of Women in Thailand," paper prepared for the Seventh Conference of the International Association of Historians of Asia, Bangkok, 22-26 August 1977, 29.

${ }^{29}$ Suwadee, 23. 
...merely institutionalized a bourgeois form of patriarchy which made it more difficult for women to get a divorce, and required that the husband's consent be given for any contract entered into on the part of the wife. (Outlawing polygamy legally while it continued socially meant only that second wives no longer had any protection; ironically, women who often controlled significant property could no longer act independently of their husbands: in this way, "modernization" - carried through largely by Sino-Thai legal experts acting on western advice - meant worsening the position of Thai women.) $)^{30}$

While women were given equal voting rights in the new constitution and the right to run in elections for the legislature in 1932, no woman was elected until 1949 and the numbers of women in the legislature remain extremely small today. ${ }^{31}$ The growing fear of communism pushed socialist women's organizing out of the political field. One women's newspaper Ying Thai, which opposed the government's invitation for women to be candidates in elections on the grounds that "the honour given to a few women did not guarantee equal treatment to the other seven million women," was shut down in the early 1930 s on suspicion of communist leanings. ${ }^{32}$

${ }^{30}$ Gail Omvedt, Women in Popular Movements: India and Thailand during the Decade of Women (Geneva: UNRISD, 1986) 44.

${ }^{31}$ Robert Lingat, Le statut de la femme au Siam (n.p., 1959) 283.

32 Amara Pongsapich, "Women's Social Protest in Thailand," Journal of Social Research 10 (1987): 6 . Women's organizing was greatly affected by the politics of the post-revolutionary era. The early 1930 s marked a struggle between social-democratic, liberal and authoritarian ideas, which ended with the institutionalization of authoritarianism in the person of General Phibun who took the premiership in 1938/39. The fear of communism resulted in a strident anti-communist act being passed in the mid- 
One of the few routes to influence provided by the post-revolutionary government depended on women's role as objects of beauty. The new civilian government drew on women's image to promote the imposition of constitutionalism, creating a 'Miss Siam' beauty contest ; a blend of the 'traditional' - women's role as wives and objects of beauty and the 'modern'- women's role as public figures. ${ }^{33}$ As William Callahan points out, the Miss Siam contest served to graphically undermine royal legitimacy. "The legitimacy and power of the absolute monarchy was shrouded in mysterious secret rituals like the 'Water Curse'," but, after the 1932 revolution the 'queen' of Thailand was a 'beauty queen' - "a commoner chosen by other commoners in a very public contest. ${ }^{" 34}$ Women's role as 'objects of beauty', did not entirely deny them subjecthood, rather 'beauty queen' status has become

1930s. With the growing anti-socialist feeling, women's groups that focussed on issues of women labourers were also pushed out of the political field. The editor of the newspaper was the first female law graduate in the country, she along with other middle-class women, including one with a master's degree from the US, formed the Women City Club in 1932, which expressed concern for working women (Amara, 6). A public welfare approach to issues such as prostitution, however, had more space for survival - building on the nationalism of governments in the post-revolutionary era and the support of international pressure.

${ }^{33}$ While the beauty contest has since been cited as evidence of women's inferiority in Thailand, according to van Esterik, beauty contests held at village fairs before 1932 were originally part of the complex of Buddhist ideas on beauty and moral goodness. Beauty, therefore, was less a sexual notion than a sign of moral integrity. Penny van Esterik, “ Gender and Development in Thailand: Deconstructing Display," Women. Feminism and Development, eds. H. Dagenais and D. Piché (Montreal: McGill - Queen's University Press, 1994) 271-272.

${ }^{34}$ William Callahan, "The Ideology of Miss Thailand in National, Consumerist, and Transnational Space,” Alternatives 23.1 (Jan.-Mar. 1998): 37. 
a route to social and even political influence for women of all classes. Elite men made use of the beauty queen system to find wives and mistresses. The beauty queen and the military man became a central model of elite marital relationships in the post-1932 era. ${ }^{35}$

The institutionalization of women's role in national identity building provided a new route to political influence. It was a route still limited by its dependence on women's role as wife and mother, but it also provided avenues into the new profession of social welfare work. In 1942 the link between women and national culture was institutionalized in the National Cultural Council, which was divided into five departments: Spiritual Culture, Traditions, Arts, Literature, and Women. ${ }^{36}$ The Women's Department was actually proposed, and then chaired, by Phibun's wife, Lady Laiad. ${ }^{37}$ The Women's department became a vehicle for upper class women to proselytize on behalf of the government's nationalist program. ${ }^{38}$ It took

${ }^{35}$ The most recent (ex)military man to become Prime Minister in Thailand, Chavalit Yongchaiyudh, is married to a former beauty queen, who currently acts as a judge in the Miss Thailand pageant. Callahan, 47-48.

${ }^{36}$ Thamsook, 237.

${ }^{37}$ Darunee Tantiwiramanond and Shashi Ranjan Pandey. By Women, For Women: A Study of Women's Organizations in Thailand, (Singapore: ISEAS, 1991) 43. Lady Laiad shared with her husband a vision of a modernized Thai state in which women played a central role as defenders of culture. "We are also proud to say that, as mothers and housewives, Thai women take it as one of their principal duties to make their children cultured. Courtesy, an optimistic outlook and the long-cherished conventions and traditions on the part of Thai women combine to instil in them the love of honour and to encourage the preservation of national culture." Lady Laiad Pibulsonggram, "Thai Women," Aspects and Facets of Thailand, ed. Witt Siwasariyanon (Bangkok: Public Relations Dept., 1958) 47.

${ }^{38}$ In his postwar defense of the early nationalism program Phibun argued that it was designed to prevent Japanese cultural takeover. The Women's Department in particular, 
up the social hygiene campaign, training women in proper dress, housekeeping and childcare. Lady Laiad also founded a private women's organization, the 'Women's Cultural Club', in order to gain the active participation of elite women outside the government. The club had similar goals to the Women's Department including encouraging proper home-making and making them "more compatible partners of their husbands."39

The National Cultural Commission was revived in the post-war Phibun administration as the Department of Culture ${ }^{40}$, but the work of enculturating women was increasingly in the hands of Lady Laiad's private organization. In a 1950 visit to the United States, Lady Laiad studied how American women's groups were organized to network across the country and she determined to spread her Cultural Club beyond the borders of Bangkok. Each province would set up its own Women's Cultural Promotion Association presided over by the wife of the governor, giving the associations quasi-official status. ${ }^{41}$ Although the official work of training professional social workers became the prerogative of Thammasat

was hoped to drain women workers away from the occupying Japanese, making office operations difficult and preventing 'fraternization', see Thamsook, 242.

${ }^{39}$ c.f. Darunee and Pandey, 44.

${ }^{40}$ According to William Siffin, the Ministry was "was not appreciated by many male officials" and was abolished after Phibun's fall from power in 1957. William Siffin, The Thai Bureaucracy: Institutional Change and Development (Honolulu: East-West Centre, 1965) 155.

${ }^{41}$ Darunee and Pandey, 44. 
University in 1954, the Associations continued to teach 'modern practices' to poor and rural women as part of their philanthropic efforts. ${ }^{42}$

Women's visibility as participants in the modern projects of national cultural promotion and social welfare was an important component of Phibun's attempt to increase Thailand's international stature. The government sought to present Thai women to the world as modern and emancipated. In Thailand's debut speech to the United Nations General Assembly, the Minister of Foreign Affairs, Arthakitti Banomyong emphasized Thailand's status as a modern nation, pointing out that "men and women enjoy equal rights under the Constitution and fundamental freedoms are guaranteed without distinction as to race, sex, language or religion." ${ }^{, 43}$ As UN headquarters opened up in Bangkok and the UN took on women's issues as an area of concern, Bangkok was often host to these international interests. The WCC in tandem with some newer women's organizations - particularly branch organizations of international women's groups - would play host to these meetings. ${ }^{44}$ Lady Laiad, having consulted with the International Council of Women on its role as an advisory

${ }^{42}$ Kobkua, 139.

${ }^{43}$ Ministry of Foreign Affairs, Statements by Chairmen of the Delegations of Thailand at the Second to Fortieth Sessions of the UNGA (1947-1985) (Bangkok: Ministry of Foreign Affairs, International Organizations Department, 1986) 1.

${ }^{44}$ Branch organizations of international women's groups made their appearance in the early post-war period - the Young Women Christian's Association in 1947, the Siamese Association of University Women in 1948, the Women Lawyers' Association in 1950, the Home Economics Association in 1956 and the Girl Guides in 1958. 
body to the UN, formed a new umbrella organization in 1956 - the National Council of Women of Thailand [NCWT] - to represent Thai women at the international level. ${ }^{45}$

Lady Laiad was herself a central link in developing closer relations with international organizations. She acted as President of the UN Association of Thailand and was elected President of the 1956 Assembly of the World Federation of UN Associations. She constantly took up the theme of Thailand's status as a modern nation participating fully in international affairs on par with other modern nations. In a speech to the American Association in the 1950s, Lady Laiad clearly attached women's emancipation to the overthrow of absolute monarchy and the process of modernization, lending the credibility of women's emancipation to the new regime:

... since Thai women in the old days were not conscious of their rights or freedom they played only a subordinate part in the community, and this caused a lack of balance among the people as a whole. Since the change over from Absolute Monarchy to a constitutional one, Thai women, according to the Constitution, have been given equal rights which thereby has enhanced the prestige and status of Thai women as a whole. Today it may be said that the position of Thai women is very high. ${ }^{46}$

At the same time, elite women were viewed as protectors of 'traditional' culture. As Lady Laiad argued:

\footnotetext{
${ }^{45}$ Darunee, 28.

${ }^{46}$ Lady Laiad, 47.
} 
The impact of modern civilization has caused radical changes in nearly all aspects of human life, including the customs which form a part of culture. In spite of these changes Thai women still preserve old customs and manners which they hold dear. However, some of these Thai customs could be omitted and cultural traditions have been somewhat adapted to meet the ever-changing conditions in the country. ${ }^{47}$

Importantly, Lady Laiad argued further that it was the 'old customs' and 'old culture', that had "a wholesome effect on the mental attitude and behaviour of Thai women, who remain reserved and place honour above all things." ${ }^{48}$ While they may be moving the country into the modern era, elite women ensured that they were firmly planted in 'tradition' - particularly in matters of morality - in order to retain their claim to being 'mothers of the nation.'

Elite women's social work role was very important in establishing international credibility. Lady Laiad emphasized Thai women's participation in the modern, international, project of social welfare:

Thai women have for many decades assumed a leading role in the social fields, though they have hitherto played a subordinate part politically and economically. I can safely and with pride say that social welfare service in this country has been from the very beginning the main concern of Thai women. Indeed they performed the major part in bringing about the birth and subsequent development of the Thai Red Cross, the orphanage and many other existing social welfare institutions.... Thai women have also helped in developing close contacts with other countries in the social field. Those foreigners familiar with Thailand realize how enthusiastic and

${ }^{47}$ Lady Laiad, 48.

${ }^{48}$ Lady Laiad, 47. 
co-operative Thai women are in devoting themselves to the cause of humanity. ${ }^{49}$

In the age of development and the social welfare state such devotion reflected the hegemonic discourse of liberal humanism of the international community as represented in the UN.

\section{Prostitution Policy in an International Era}

In its drive to become a respected member of the international community the Phibun government enthusiastically involved itself in the UN. In the mid-1950s, Thailand was a hive of UN activity. UN organizations working in Thailand by that time included ECAFE, FAO, UNICEF, WHO, UNESCO, ICAO, ILO and the UN Technical Assistance Board. ${ }^{50}$ The period also marked a rise in interest in human rights issues around the globe. Concern about the treatment of women and the problem of prostitution became a central part of the UN social agencies' agenda, particularly by actively seeking adherence to the new 1949 "Convention for the Suppression of the Traffic in Persons and of the Exploitation of the Prostitution of Others".

The 1949 Convention was based on the 1937 League of Nations Draft Convention, which had died with the League itself, and echoed its moral reform approach. In particular, the new convention, like the old, excluded the possibility of prostitution as a choice (limited or otherwise). Rather, the prostitute was viewed as a victim of pimps or procurers. It was

\footnotetext{
${ }^{49}$ Lady Laiad, 57.

${ }^{50}$ Ministry of Foreign Affairs, Statements, 14.
} 
assumed that no 'normal' woman would choose to enter prostitution and that women required (male) protection and social/psychological reform. While the language of the convention was liberalized to reflect the aims of the 1948 Universal Declaration on Human Rights, the rights that were protected under its aegis were the moral rights of the community. As Deborah Steinstra argues:

The 1949 Convention uses human rights language and conveys that "prostitution and the accompanying evil of the traffic in persons for the purpose of prostitution are incompatible with the dignity and worth of the human person and endanger the welfare of the individual, the family and the community." With these words, the Convention suggested that the protection of individuals, families and the community outweighs the rights of individuals to engage in prostitution. The rights to be protected are those that are judged 'moral' by the international community. ${ }^{5 t}$

The predominant understanding of prostitution in the post-war period also leaned heavily on psychoanalytical models of human behaviour. Prostitutes were presumed to be sexual deviants who had an inordinate propensity for promiscuity which required psychological treatment. The prostitute was now an object not only of medical, but also of psychological, concern. She required readjustment to 'normal' sexual behaviour. ${ }^{52}$ Thus, the Convention emphasized the punishment of those who led others into prostitution. At the same time, it discounted the consent of the woman involved, who was presumed not to be able to choose.

${ }^{51}$ Steinstra, 195-196.

${ }^{52}$ This psychological medicalization of prostitution paralleled that of homosexuality as a potentially treatable abnormality. 
Instead, the Convention advocated the "rehabilitation and social adjustment of the victims of prostitution." ${ }^{53}$ Prostitutes, therefore, were positioned in the Convention as objects of reform rather than as acting agents.

Of particular concern was the normalization of women's sexual behaviour into an appropriately passive sexual role. While the 1959 follow-up "Study on the Traffic in Persons and Prostitution" did not support the imposition of rehabilitation measures on unwilling subjects - those who are "not in the least victims of circumstances" - it assumed that many would benefit from and take advantage of facilities for rehabilitation including those who may not be prostitutes per se but who "engaged in notorious promiscuity." The study argued that "promiscuity often leads to prostitution - in fact, it is often argued that between promiscuity and prostitution there is a difference only of degree" and recommended "early detection and treatment of promiscuous propensities and mental deficiencies." ${ }^{\text {"54 }}$ The 1959 study preferred to adopt the liberal language of 're-education' as promoted by the International Abolitionist Federation, noting that "in recent years, the process of rehabilitation of persons engaged in prostitution has been characterized by an increasing trend towards re-education; that is, rehabilitation through education to discipline the mind

${ }^{53}$ Article 16, United Nations Convention for the Suppression of the Traffic in Persons and of the Exploitation of the Prostitution of Others.

${ }^{54}$ United Nations, Department of Economic and Social Affairs, Study on Traffic in Persons and Prostitution (Suppression of the Traffic in Persons and of the Exploitation of the Prostitution of Others (New York: United Nations, 1959) 21. 
and character and to develop and cultivate the personality both mentally and morally." "R5 "Reeducation" was meant to emphasize voluntary participation and the respect of the "liberty and dignity" of the person concerned, but it also emphasized the need to re-attach the person to the family unit - "the development of new psychological and family roots in preparation for married life." ${ }^{.56}$ Difficulties in re-education were understood to derive from: ... the fact that these women generally show weakness of character, lack of will-power, instability, impulsiveness, suggestibility, etc. They have generally no aptitude for work, not even for domestic work, and some of them are physically sick or mentally deficient. ${ }^{57}$

In other words, the rehabilitationist approach clearly aimed to 'normalize' women who did not conform to the Western middle-class norm of female social and sexual behaviour - the virtuous wife and mother.

In its effort to bring about greater cooperation by member countries with the Convention, which had few signatories in its early years, the UN launched investigations into the traffic in persons and the exploitation of prostitution in the late 1950s. Committees to investigate prostitution and establish prevention and suppression measures had already been established in India, Sri Lanka, Burma, the Philippines, Indonesia and Japan in the late 1940s

\footnotetext{
${ }^{55}$ United Nations, Study on Traffic, 30.

${ }^{56}$ United Nations, Study on Traffic, 31.

${ }^{57}$ United Nations, Study on Traffic, 31.
} 
and early $1950 s .{ }^{58}$ In the late 1950 s, Thailand remained the only Asian member of the UN with legalized brothels.

Steps to abolish the legalized system, however, were already under way by 1956 . A small number of government officials and elite women were at work on the issue of prostitution, such as Dr. Khun Pierra Veijabul, a member of the Ministry of Public Health (Venereal Diseases Division) since 1937, who had trained in medicine in France and established the Foundation for the Welfare of Women in $1956 . .^{59} \mathrm{Dr}$. Pierra was representative of the small coterie of elite, professional women who studied abroad in this early period and were part of the Women's Cultural Club. She sat on the Committee Considering the Abolition of Licensed Brothels in the late 1930s, and, at the same time, she established the Maternity and Child Welfare Foundation. ${ }^{60}$

Dr. Pierra made the abolition of prostitution and rehabilitation of prostitutes a personal campaign. In 1956, during a relatively open period of Phibun's government, Dr. Pierra established the Foundation of the Welfare of Women which listed its purposes as: education of prostitutes to "encourage them to return to a normal life"; housing, treatment, education and training, to prostitutes who seek rehabilitation; research on the causes and

${ }^{58}$ International Review of Criminal Policy, 13 (October 1958): 50.

${ }^{59}$ National Identity Board, Thai Life: Thai Women (Bangkok: National Identity Board, Prime Minister's Office, 1983) 41.

${ }^{60} \mathrm{Dr}$. Pierra's profession would have brought her immediately into the upper ranks of the bureaucracy. See Siffin,193, on the ranking of civil servants. 
prevention of prostitution, and research on venereal disease prevention and treatment. It also sought to widen public awareness and involvement by persuading the public in the campaign to "help prostitutes to return to a normal life." Reflecting the growing internationalism of the period, the Foundation also proposed to maintain international linkages with like-minded organizations. ${ }^{61}$ The Board consisted almost entirely of government officials, the largest proportion from the National Institute of Culture (which included the Women's Department) ${ }^{62}$ as well as some from the Ministry of Health, the Police Department, the Department of Public Welfare, and the Municipalities of Thonburi and Bangkok. Five of the 18 members were doctors, which reflected the continued social hygiene emphasis of prostitution measures.

The above bodies - the National Institute of Culture, the Department of Public Welfare and the Police Department - had begun providing some vocational training to former prostitutes previous to $1956 .{ }^{63}$ They had also cooperated in returning "some newly recruited or prospective prostitutes to their homes. ${ }^{\text {664 }}$ Twenty-two young women were returned to their

${ }^{61}$ Fox, Exhibit D, "Constitution of the Foundation for the Welfare of Women", 154. Indeed, Dr. Pierra gained a large international reputation, receiving the Albert Einstein Award for humanitarian work from the United States in 1963 and being made a Commander of the Legion of Honour by the French government (National Identity Board, Thai Life: Thai Women, 41.

${ }^{62}$ Fox, Exhibit D, 157.

${ }^{63}$ Fox's report gave an approximate number of 20,000 prostitutes in Thailand, half of them in Bangkok. Only 500 odd, however, were registered with police. Fox, 141.

${ }^{64}$ Fox, 162. 
homes by the Department of Public Welfare in the period May through December $1956 .^{65} \mathrm{~A}$ system of warning young girls of the practices of procurers ("often older women with promises of work or schooling in Bangkok") was in place in some provincial railway stations by $1956 .^{66} \mathrm{~A}$ revised Penal Code also came into effect in 1956 , which strictly punished procurement, trafficking and deception or coercion for sexual purposes, including prostitution. $^{67}$

Phibun was anxious to demonstrate a cooperative international image as part of the 'free world.' Such an image was important to guarantee continued military aid from the United States in the face of communist insurgencies in Asia. He had completed a series of state visits around the world in 1955, along with Lady Laiad, to promote this image abroad. Growing criticism in the US of the use of foreign aid to prop up a repressive regime such as Phibun's led him to vow to 'democratize' Thai politics. In the 1956-57 period, Phibun legalized political parties, allowed for public discussion of politics and removed many police and army troops from Bangkok. Lady Laiad and Phibun also asked for further steps to be

${ }^{65}$ Fox, 145.

${ }^{66}$ Fox, 145.

${ }^{67}$ Centre for the Protection of Children's Rights, "Case Study Report on Commercial Sexual Exploitation of Children in Thailand," (Bangkok: Centre for the Protection of Children's Rights, October 1996) 12-13. 
taken to suppress prostitution and the government began consultations with the United National Regional Social Defence Officer on how to rewrite the prostitution laws. ${ }^{68}$

Despite Phibun's desire to abolish prostitution in line with Western demands, there was a reluctance among other elites and the general public. Morris Fox, the Social Welfare Advisor to the UN, who produced a report on prostitution in Thailand for the Thai Public Welfare Department in 1957, noted that Thai men tended to view prostitution as "an accepted part of life," while women viewed it as a "necessary evil." He stated that "only a few persons in official or unofficial circles are working toward its suppression." ${ }^{\circ 99}$ As a 1958 Public Relations Department publication reported:

To sleep out at night or to stay away from home is neither unusual nor badly regarded for a boy. They generally have their first sexual experience at the age of sixteen or seventeen with a prostitute. There is no stigma attached to the frequenting of prostitutes by either married or unmarried men. Prostitution is legal. ${ }^{70}$

The report goes on to defend the male sexual prerogative by dismissing the concerns of elite women as self-indulgent, stating that only the woman of the upper class "in which the

${ }^{68}$ Fox, 140-141, 163. Phibun also vowed to close the opium dens by 1957 - in a move designed to discredit his close rival General Phao who had been caught in an opium smuggling scandal (for a description of this period see Darling, Chapter V). It was in this political climate that Phibun and Lady Laiad supported new measures be taken vis-à-vis prostitution.

${ }^{69}$ Fox, 143.

${ }^{70}$ Vibul Thamavit and Robert D. Golden, "The Family in Thailand," Aspects and Facets of Thailand, ed. Witt Siwasariyanon (Bangkok: Public Relations Dept., 1958) 2. 
woman regards herself as the equal of her husband, is offended by his extramarital activity, [and] has the leisure to be upset by her emotional difficulties." ${ }^{.77}$ The same report, however, notes with some discomfort the rapid changes underway in Thailand - expressed in terms of young women's behaviour:

Westernization has lately received much comment in Bangkok. It is generally felt that insofar as it results in an improvement in living standards, better houses and diet, it is desirable. But it is also said to be destroying the old Thai hospitality. 'Broadness of heart' is being replaced with the narrower concepts and individualism of the West. Young girls are feeling the liberative influence of American ideas especially regarding dating and dancing, and this is considered to be affecting morality. The number of virgin brides in Bangkok where Western influence is strong, for example, is estimated $15 \%$ lower than in the country, and the wildness of Bangkok society girls imitating Western fashions taught by Hollywood films is notorious. ${ }^{72}$

'Westernization' was read in very gendered terms, reflecting the importance of women's behaviour to national identity.

The 1950s and 1960s in Thailand - which was a period of increased American presence - were marked by this tension over the maintenance of male sexual prerogative and the desire to maintain female purity in the face of 'foreign influence'. Certainly the changes of the 1950s were provoking some concern among the urban population. Millions in American military aid had been poured into the Thai economy since 1950 . American military

\footnotetext{
${ }^{71}$ Vibul and Golden, 8.

72 Vibul and Golden, 8.
} 
and government advisors had swarmed the city, and the Thai military had ballooned in size and expense. The outpouring of criticism after the relaxation of control in 1956 and 1957 testified to this concern. ${ }^{73}$ For example, the Public Relations report noted that the demand for material goods in order to live like Westerners was, according to the authors, leading to stress, family disintegration and corruption, as well as "large numbers of nearly destitute people living in the worst kinds of slums" in the city. ${ }^{74}$ Fox noted increasing coverage of the issue of prostitution in the newspapers in the late 1950s - "some devoting considerable space to it"- as well as the existence of an "almost universal concern for the young innocent girls who are tricked or 'seduced' into prostitution," and the influence of prostitution on children in the immediate neighbourhood, where children earned money by running errands for the brothels. ${ }^{75}$ There was also some fear that the growing "wildness" of Bangkok girls was a direct route into prostitution. The "taxi dance halls," where young women went to dance and socialize were considered a site where girls and women were procured for prostitution. ${ }^{76}$ These concerns were translated into a need for increased control over female sexuality.

In 1957 a proposed prostitution law was put forward that echoed these concerns, emphasizing the reform of women engaged in prostitution. Indeed, the first sections of the

\footnotetext{
${ }^{73}$ See Frank C.Darling, Thailand and the United States (Washington D.C.: Public Affairs Press, 1965) 146-153.

${ }^{74}$ Vibul and Golden, 8-9.

${ }^{75}$ Fox, 144-145.

${ }^{76}$ Fox, 142.
} 
proposed act to abolish prostitution dealt with the establishment and responsibilities of reform institutes which were to be under the authority of the Department of Public Welfare. The building of a rehabilitation institution for those who sought to leave prostitution voluntarily was already underway and plans for another institution were in the works. The legislation proposed that the institutions provide medical treatment, vocational training and "placement in a suitable job." The reasoning behind the legislation emphasized that few prostitutes voluntarily sought help and that the public did not yet take the problem seriously. ${ }^{78}$ The proposed legislation stated "whoever habitually consents to be hired for sexual relations for compensation shall be deemed to be a prostitute" clearly defining a 'problematic personality' that required treatment. Indeed, the legislation anticipated difficulties with inmates of the reformatories, by providing stiff penalties for whoever "willingly avoids going, violates the order or runs away". The bill did allow that not all prostitutes entered the trade willingly. Instead it provided punishment of up to seven years in prison, or up to ten thousand baht, or both, for whoever "treats any girl with any deceptive methods or threatens, compels, or forces her in any way in order to attract her into the

\footnotetext{
${ }^{77}$ Fox, Exhibit G, 162.

${ }^{78}$ Fox, Exhibit G, 162.
} 
prostitution business." ${ }^{, 79}$ The penalties were lighter, however, than those listed in the 1956 Penal Code. ${ }^{80}$

Thailand under Sarit

Before the proposed legislation could go much further, the government was again overthrown in a military coup lead by Field Marshal Sarit Thanarat in 1958, a long time rival of Phibun. Sarit built his legitimacy on the growing resentment towards Western interference in Thailand, which Phibun had supported. Sarit described the kind of democracy brought in after the war as an attempt to impose foreign institutions on Thailand and appealed instead to what he defined as 'traditional Thai values': social orderliness and proper conduct. Sarit presented himself as a father to the nation who listened to the people's wishes and implemented them, that implementation being interpreted as the real substance of democracy rather than the representative battles of political parties. He argued:

The present system is able to represent the wishes of the Thai people. The concept of the people's sovereignty does not mean that the people directly exercise legislative, executive, or judicial power, but the concept implies that these powers should represent the aspirations of the nation.... Therefore,

${ }^{79}$ Section 13, "Prohibition of Prostitution Business Act, BE 2500 (1957) in Fox, Exhibit F, 160.

${ }^{80}$ The 1956 Penal Code punished procurement for sexual purposes with 1 to 10 years imprisonment and a fine of two thousand to twenty thousand baht, with even steeper fines for procuring those under 18. Centre for the Protection of Children's Rights, 13. 
sovereignty of the people is not merely nice sounding words but reality. ${ }^{81}$

According to Sarit, what the Thai people really wanted was strong leadership and progress, not 'democracy' in the Western sense. Sarit used this reformulation of 'traditional Thai values' to underwrite the legitimacy of his dictatorship.

Despite his anti-Western rhetoric at home, Sarit maintained Thailand's policy of cooperation with the West, particularly the US, to oppose communism, and receive American military aid in return. His brand of nationalism continued to appeal to Western notions of civilization. Sarit resolved the tension between a pro-Western foreign policy stance and his anti-Western domestic rhetoric through the manipulation of class, gender and sexuality. Sarit built up his legitimacy through his appeal to the 'traditional Thai' practice of polygamy, while imposing moral discipline on lower class men and women.

In representing himself as a legitimate leader, Sarit styled himself a nakleng - a 'hooligan' - drawing on the imagery of the gangs of young men who were used to protect the villages from elite/administrative intrusion in the 1890 s and who, in the 1950 s and onward, were often recruited by the communist insurgency in the face of Thai/American military intrusion. ${ }^{82}$ Sarit became (in)famous for surrounding himself with beautiful women. He was "widely admired for having the effrontery to acquire mistresses on such a grand scale" as part

${ }^{81}$ c.f. Thak Chaloemtiarana, Thailand and the Politics of Despotic Paternalism, (Bangkok: Thammasat University, 1979) 160.

${ }^{82}$ Pasuk Phongpaichit and Chris Baker, Thailand: Economy and Politics (New York: Oxford UP, 1995) 72. 
of his "nakleng" image. ${ }^{83}$ Sarit was known to maintain a "house-cum-harem" (as it is called by Thak) where he spent time among his mistresses as well as having houses built for several other mistresses in Bangkok. The year after Sarit died two books were published on Sarit's affairs which listed 81 women in Sarit's life. ${ }^{84}$ The women were known to include "beauty queens, movie stars, night club hostesses, university and secondary school students, young and not so young. His elaborate network of procurers was the envy of many."85

Charles Keyes argues that there was a political motive to these relationships, that Sarit "often chose as one of his mistresses a member of a family or group he wished to control politically" in this way furthering his legitimacy as a great man by emulating the harems of past rulers. ${ }^{86}$ Indeed, Sarit also fostered marital linkages among the elite involving members of the royal family to sponsor elite marriages - gradually integrating bureaucratic, royal, political and business families and conferring them with legitimacy. ${ }^{87}$ Among those so joined were the daughter and son, respectively, of Sarit's two lieutenants, Narong and Praphat - the son being widely understood as the heir to political power. Sarit's "nakleng" image was indeed a rejection of the outlawing of polygamy during the early years

${ }^{83}$ Thak, 338-339.

84 Thak, note $3,336-337$.

${ }^{85}$ Thak, 338-339. It was also discovered during an investigation into the terms of Sarit's will that Sarit had used government funds to maintain his mistresses. Thak, 337.

${ }^{86}$ Charles F. Keyes, Thailand: Buddhist Kingdom as Modern Nation State (London: Westview Press, 1987) 81.

${ }^{87}$ Thak, 324-325. 
of constitutional monarchy and the Western standards of proper marital behaviour espoused by Phibun and it appealed to the common practices of elite men. ${ }^{88}$

In this period the Department of Culture, with its women's bureau, was disbanded and the NCWT became temporarily inactive. In part, the leadership of the NCWT by Lady Laiad made continuation awkward. It was also difficult, however, to find a space for elite women's voices in this new milieu. In 1959, the NCWT finally met again, naming Princess Ngarmjit as chair. It was hoped that with her royal status, she would still have some influence with government. ${ }^{89}$ Some access to power was also available to non-elite women through their sexuality if 'in service to the state' by becoming mistresses and wives to powerful men. In the decades following Sarit's rule, women continued to be able to use 'beauty queen' status as a stepping stone to political and economic power both as wives and as businesswomen.

At the same time, while espousing these behaviours for himself, Sarit initiated a campaign of 'social orderliness' which targeted the street nakleng of the cities - now designated by Sarit by the more negative term antaphan - and prostitutes. The increasing migration into the city - reflecting the changing reality of rural Thailand, where since the

\footnotetext{
${ }^{88}$ Western observers indicated disgust with this behaviour in terms echoing their imperialist precursors. T.H. Silcock characterizes Sarit as "traditional lavish oriental despot" in his 1967 article. See T. H. Silcock, "Outline of Economic Development 1945 - 6," Thailand: Social and Economic Studies in Development (Canberra: ANU Press, 1967) 21.

${ }^{89}$ Darunee and Pandey, 45.
} 
early 1950 s roads built by the military and funded by the Americans were changing the economics and migration patterns of the countryside 90 - was linked by Sarit to a social disintegration, a failure in proper behaviour, and a threat to stability. That is, migration was presented as a cause of social instability rather than a symptom of economic deterioration. The migration also reflected the pull of labour-poor Bangkok after the crackdowns on Chinese immigration. ${ }^{91}$ (Those intellectuals who criticised the elite exploitation of the peasants such as the famous Thai Marxist critic Jit Phoumisak, were branded communists already well established as a dirty word - and 'un-Thai.') ${ }^{92}$ Prostitutes, anthapan and pedicab drivers were symbolic of 'improperness' and disintegration. The government sought to reintegrate into the rural areas the young men who had left the productive work of agriculture "in favour of the unproductive profession of pedicab driving." 93 The unproductiveness of such activity was underscored by the link Sarit drew from it to opium smoking. Sarit also linked such improper behaviour to communism and the communist attempt to undermine the 'free world' through such things as addictive drugs. Sarit announced in 1959 that opium use in Thailand would terminate on July 1 , after which:

${ }^{90}$ Between 1960 and 1970 , the ratio of men to women migrating to city shifted from 131:100 to 115: 100. (Darunee, and Pandey, 18); see also Pawadee Tongudai, "Women, Migration and Employment: A Study of Migrant Workers in Bangkok," PhD diss., New York University, 1982.

${ }^{91}$ Bruce London, Metropolis and Nation in Thailand: The Political Economy of Uneven Development (Boulder: Westview Press, 1980) 90.

\footnotetext{
92 Thak, 214-215.

${ }^{93}$ Thak, 197-198.
} 
we will be able to fully state that we are a civilized nation and national prestige will be liberated from international criticism.... the sale and use of opium is illegal, and I maintain that it is a major crime and whoever resists will be severely punished. Alien offenders will be deported and Thais will be marked as traitors who refuse to make sacrifices for the nation....94

However, rather than punishing those who failed to conform to his ideal of a people "agrarian in outlook and condition, leaving the government to look after their material needs," and who were "contented to remain on the land and go about their daily tasks in an orderly and proper manner," Sarit used his role as 'father of the nation' to reform his wayward children..$^{95}$ In this fatherly role he attacked the problem of pedicab drivers and prostitutes through rehabilitation. He banned pedicab drivers from the capital in 1959 and organized rural communities to reorient them to agricultural life as well as providing loans to start up a new life in agriculture. Prostitutes, on the other hand, were to be rehabilitated into 'domestic' roles. Rather than recognizing peasant women's role in the economic sustenance of the family, Sarit's program sought to reform them into the proper middle-class female roles of wife and mother. The tool for their rehabilitation lay close at hand in the proposed guidelines for a new prostitution law.

\footnotetext{
${ }^{94}$ Sarit c.f. Thak, 198.

95 Thak, 163.
} 
Table II: Prostitution Policy 1932-1966

1936 League of Nations Bandung Conference on Traffic in Women. Establishment of Committee Considering the Abolition of Licensed Brothels.

1937 League of Nations Draft Convention on Trafficking.

1938 Proposed Plan for the Prevention of Venereal Diseases. (Not enacted.)

1941-1945 Japanese occupation.

1942 Proposed legislation for the Prevention and Suppression of Venereal Diseases. (Not enacted.)

1949 United Nations Convention International Convention for the Suppression of the Traffic in Persons and of the Exploitation of the Prostitution of Others.

1956 Adoption of revised Penal Code.

1957 Prohibition of Prostitution Business Act proposed. (Not enacted.)

1958 Military coup. Sarit government formed.

1960 Act for the Suppression of Prostitution.

1966 Entertainment Places Act.

The new 1960 law defined prostitution as the "indiscriminate acceptance of sexual intercourse or acceptance of any other act or the performance of any act for the satisfaction of the sexual desire of another for hire whether the acceptor of the act and the performer of the act are of the same or different sexes." As Sukanya Hantrakul has pointed out, this

96 "Act for the Abatement of Prostitution", B.E. 2503, Royal Thai Government Gazette Vol. 2, No. CCXII, (Nov. 28, 1960): 562-563. For the first time, legislation on prostitution did not distinguish as to sex - both male and female prostitution are covered in the act. Fox's report had mentioned some incidents of male prostitution in Bangkok. 
definition of prostitution emphasized the promiscuity of the act rather than the monetary exchange. The 1960 law outlined much more precisely the acts which constituted the offence of prostitution, penalizing street solicitation, as well as brothel prostitution, which received a stiffer sentence. ${ }^{97}$ It was sufficient for a person to "wander" or "loiter" about the streets or public places in a "manner or way which appears to be an appeal to communicate for prostitution purposes" for her or him to be charged - a reflection of Sarit's concern to 'clear the streets' for public approval. ${ }^{98}$ Those convicted of prostitution were expected to pay a fine of up to two thousand baht or a prison term of up to six months. Owning or managing a place of prostitution received the highest punishment of up to a year imprisonment or a fine up to four thousand baht or both. Procuring received a sentence of up to three months in prison or a fine up not more than one thousand baht or both. These penalties were even lighter than those suggested in 1957 and, therefore, much lighter than those in the Penal Code. ${ }^{99}$ The provisions on deceiving and forcing a person into prostitution from the 1957 proposed law were dropped. Prostitutes were assumed to be freely acting agents.

Fox, 143.

${ }^{97}$ Also in the 1909 act. See Sukanya Hantrakul, "Prostitution in Thailand," paper proposed to the Women in Asia Workshop, Monash University, Melbourne, July 22-24, $1983,6$.

${ }^{98}$ Section 5 (2) “Act for the Abatement of Prostitution B.E. 2503," (1960) Royal Thai Government Gazette 2.212 (Nov. 28 1960): 561.

${ }^{99}$ Sections 8 and 9, "Act for the Abatement of Prostitution," 562. 
As with the 1957 proposal, however, prostitutes were also subject to remand to a reformatory for up to a year for "[medical] treatment and/or vocational training." 100 The women were not expected to submit to this training willingly so provisions were made to punish those who escaped or break the "disciplinary rules and work regulations" set by the Public Welfare Department for the centres. ${ }^{101}$ The disciplinary function of the centres, to turn problem women back into good women, underwrote its 'vocational training'. Sukanya Hantrakul quotes from a 1963 Department of Public Welfare document on the Pak Kred reformatory "Vocational training... is designed to afford recreation and to keep the trainees occupied with work to such an extent that there is not much time for idle thoughts and emotional disturbances which may lead to the difficulty in administration." 102 Indeed, accounts of escapes - by swimming across a 200-metre wide canal - have circulated since the establishment of the Pak Kred reform home in $1960 .^{103}$

Sukanya Hantrakul's study of the reform institutions set up under this law showed that the institutions "equip most reformees for nothing better than employment as domestic - $\quad$ servants." 104 The final training period before discharge, involved

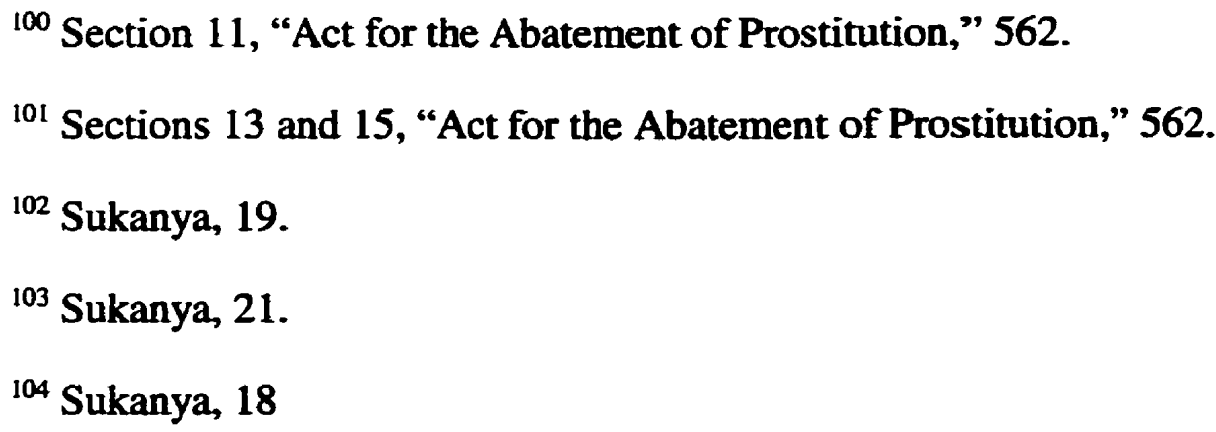


1) Training in regard to the proper arrangement of sleeping quarters and methods of child care by officials specialising in health and sanitation. 2) Training in regard to proper home care and cooking by officials specialising in home economics.

3) Training in regard to proper codes of conduct in relations to morals and mannerisms by qualified personnel. ${ }^{105}$

There was also "follow-up after discharge to ensure resumption of a normal and decent way of life." 106 Even in the 1980 s the occupational training provided consisted of "weaving footrugs, sewing and weaving clothes, laundry work, book-binding, beauticians (manicures) and cooking. ${ }^{107}$ The choice of occupational training depends on the results of an IQ test ${ }^{108}$ - a reflection of the assumption of intellectual failure in prostitute women. The provisions also reflect an assumption of sexual deviancy - the concern over "the proper arrangement of sleeping quarters" came from social hygiene thinking which related sleeping arrangements to unnatural sexual appetites and reflects a class bias against those (rural and working class) who slept in one (often the only) room. The domestic emphasis of the provisions is also clear as is the concern to 'tame' unruly women into proper sexual and cultural conduct.

Training in "morals and mannerisms" clearly reflected Sarit's campaign on 'traditional Thai values', but the new law also satisfied the concerns of the international

${ }^{105}$ Ministry of the Interior, c.f. Sukanya, "Prostitution in Thailand," Development and Displacement: Women in Southeast Asia, eds. Glen Chandler, Norma Sullivan and Jan Branson (Clayton, Australia: Centre of Southeast Asian Studies, Monash University, 1988) 125.

${ }^{106}$ Sukanya, "Prostitution," 1988, 125.

${ }^{107}$ Sukanya, "Prostitution," 1983, 18.

${ }^{108}$ Sukanya, "Prostitution," 1983, 18. 
community to abolish prostitution and reform female moral and sexual behaviour. Sarit, meanwhile, could maintain his legitimacy through more 'traditional' modes of male sexual prerogative. That is, the appeal of this re-configuration of gender identity and sexual relations was not widespread. It is not surprising, therefore, that a mere six years after the 1960 law was put into place Narong and Praphat proclaimed the "Entertainment Places Act" that effectively re-instated a regulated form of prostitution.

\section{Conclusion}

Prostitution policy in Thailand changed significantly between the end of absolute monarchy in 1932 and the beginning of the 1960s as it moved from legalization and regulation to criminalization. Such a shift in policy needs to be understood in the light of the Thai government's attempts to move away from its former 'semi-colonized' status. The 1960 law to criminalize prostitution and reform prostitute women was clearly part of the attempt to present Thailand as part of the modern world and Thai women as modernized as well as to shape and regulate behaviour of Thai women as 'mothers of the nation'.

The lack of depth of the 'official nationalism' that underwrote this campaign, however, meant that this re-imagining of gender identities and sexual relations had little support beyond a small circle of elites. Indeed, the continuing resonance of constructions of masculinity and leadership based on male sexual prowess granted the Sarit government a wider legitimacy than that enjoyed by his 'modernizing' predecessor. Nonetheless, the attempt to re-define more 'modern' gender identities institutionalized a role for reforming 
elites in reforming and regulating women's behaviour-resulting most apparently in the 1960 law which criminalized prostitution. It was only during the 1960 s, however, that a deeper sense of Thai national identity, as defined by the middle-class, particularly students, began to take root in Thailand. 
Chapter 4: Peasants, Prostitutes and Thai National Identity, 1960-1980

Prostitution is rarely read in terms of resistance. Even in the era of the student demonstrations and peasant uprisings of the 1960s and 1970s in Thailand, prostitution is rarely seen as part of the resistance of country to city, baan to muang. Rather, it is read in terms of cultural and economic breakdown in the face of modernization and Westernization. This is primarily because during the years of the 1960 s through the 1970 s, prostitution and prostitutes became symbolic of the systematic degradation of the countryside in the drive for development and security and the Westernization of Thailand through the arrival of American troops. Prostitutes were 'symbolic' because they themselves were rarely, if ever, participants in the debates, rather they were spoken for, or invoked by, various groups in addressing causes of and solutions to economic and political problems. Prostitutes' voices reflecting on their experiences, were silenced and their lives were simplified into a process of victimization by larger social forces.

The understanding of the prostitution problem that developed over the 1980s and 1990s, needs to be viewed in terms of the political discourse over gender, culture and national identity that had its birth in the student democracy movement beginning in the 1960s. In this period the peasantry, and peasant women in particular, became emblematic of the struggle to define Thai national identity. The newly active middle-class student body argued for the overthrow of the military dictatorship and the institution of a socialdemocracy. The student movement based its claim to legitimacy in its appeal to Thai nationalism in the face of a growing American military presence, as a US-Thai alliance 
formed to fight against communist 'insurgency' in Southeast Asia. The symbolic importance of women, and women's sexual behaviour, in maintaining national culture and identity made the growing sex-trade around US air-force bases in the North-east a central subject of social and political debate. At the same time, the Thai military and conservative bureaucrats worked to pacify the countryside and inscribe a Thai identity based on 'Nation, Religion and King' on a rebellious peasantry. In the reconfigured politics of the post-democracy era, the peasant, too, became a symbol and an anchor of Thai culture. Peasant women, therefore, were doubly marked with national identity; and those that entered the growing prostitution industry were the source of a great deal of social anxiety in the following years.

Since the exponential growth in prostitution numbers in the 1960 s, the 'prostitution problem' has consistently been read as the result of cultural decline. Pasuk Phongpaichit and Chris Baker, for instance, argue that in the 1960 s village culture was increasingly under attack, village elders' and other 'natural' leaders' authority was eroded and village cohesion de-emphasized. It was this decline in "the importance of ancestry and place" and "the decay of local communities" that "lead to large-scale migration by rural girls (and later also boys) to work in prostitution for the US soldiers, for an increasingly prosperous urban market, later for the tourist trade, and finally as an export commodity." Such a reading assumes rather than analyses the link between women and culture. The problem of such a reading of the events of the 1960 s is that it subordinates rural peasants' and prostitute women's own

' Pasuk Phongpaichit and Chris Baker, Thailand: Economy and Politics (New York: Oxford UP, 1995) 75. 
readings of their realities and fails to see how, precisely in this period, the link between peasant women and national culture was forged, a link that worked to the benefit of elite rather than peasant women and that worked against prostitute women, who were blamed for abandoning and undermining cultural traditions.

The increasing migration of women and girls into the sex-industry did not go unnoticed in the rural areas, but there is reason to believe that it was differently interpreted by various groups in different parts of the country. As Pasuk and Baker themselves point out, young women traditionally made up a large portion of seasonal migrants. ${ }^{2}$ Women also figured among rural travellers as traders, entertainers and spirit mediums. Sexual taboos and gender differentiations also differed across regions. In the North, where animism remained strong in spite of the predominantly Buddhist character of the country, women acted as guardians of the spirit. Sexual relations before marriage were viewed as an offense to the familial spirits which could be ameliorated through an offering of gifts from the couple to the woman's familial spirits in a phit phii (wronging of the spirits) ceremony. Some analysts now view this particular ceremony as one of the linkages between women's sexuality and monetary value that has made prostitution more acceptable in the North. ${ }^{3}$ Others, such as anthropologist Eric Cohen, have pointed out that "... there is often no crisp separation in Thai

${ }^{2}$ Pasuk and Baker, 189.

${ }^{3}$ Chris Lyttleton, "The Good People of Isan: Commercial Sex in Northeast Thailand," The Australian Journal of Anthropology 5.3 (1994): 266. 
society between emotional and mercenary sexual relationships." Even more importantly, across the country women were viewed as wage earners and were expected to contribute a major part of the family income to show their gratitude to their parents. Peasant women, according to several anthropological studies, were economic partners in the household working outside the home in the fields and markets, inheriting property equally with their brothers, and participating as wives in major household decisions, as well as controlling the family finances. ${ }^{5}$

Most importantly, prostitute women themselves, particularly the largest regional group from the North, consistently interpret themselves as family wage-earners. ${ }^{6}$ Many women working as prostitutes, particularly those from the North, remit a large portion of their wages back to their families in the rural areas. ${ }^{7}$ In the context of rural resistance, this can be seen as a 'Robin Hood' act, where young women are determined to take advantage of the resources offered by urban modernity and to transmit them back to the villages. There is also an 'in your face' resistance to elite codes of female moral conduct and propriety.

${ }^{4}$ Eric Cohen, "Thai Girls and Farang Men: The Edge of Ambiguity," Annals of Tourism Research 9 (1982): 405; See also J.F. Embree, "Thailand: A Loosely Structured Social System" American Anthropologist 52.2 (1950): 186. Sukanya Hantrakul, "Sexual Culture of Thai Women," The Nation 2 Sept. 1996: A4.

${ }^{5}$ Mary Beth Mills, "Rural Women Working in Bangkok: The Rocky Road of Social Change," Final Report to the National Research Council of Thailand, n.d., 4.

${ }^{6}$ Pasuk Phongpaichit, From Peasant Girls to Bangkok Masseuses (Geneva: International Labour Office, 1982) 14-18.

${ }^{7}$ Pasuk discovered in the early study that most of the women she interviewed remitted one-third to one-half their wages to their families. Pasuk, 22-25. 
Lenore Manderson has re-evaluated the sex-shows of Bangkok's notorious sex-district Patpong Road as sites of female sexual reclamation and resistance. ${ }^{8}$ And, as we shall see in the next chapter, there were attempts to organize prostitutes as political actors in their own right. Such attempts, however, consistently failed in the face of the dominant discourse of prostitutes as either 'victims' or 'misguided' and in need of elite guidance. An understanding of prostitutes as women struggling to make sense of their own lives, and the changing circumstances around them, did not fit within this script of prostitution as the result of cultural decline.

What the present chapter seeks to illustrate is the process whereby national identity was inscribed onto peasants and prostitutes. This identity did not come forth 'naturally' from a pre-existing cultural core, rather, it was part of a disciplinary discourse of national identity and culture that silenced other possibilities and histories. While this chapter can only hint at what these silenced possibilities may be - that being the task of reformist historians and anthropologists - it follows the construction of this identity by political elites and it shows how this identity served to enforce a notion of a monolithic and backward peasantry in need of instruction from elites, erasing the resistance and agency of peasants and peasant women. This process established a dominant understanding of prostitution as the result of cultural

${ }^{8}$ Lenore Manderson, "Public Sex Performances in Patpong and Exploration of the Edges of Imagination," Journal of Sex Research 29.4 (1992): 451-475. See also Walter Meyer, Beyond the Mask: Toward a Transdisciplinary Approach of Selected Social Problems Relation to the Evolution and Context of International Tourism in Thailand, PhD Dissertation (Geneva: University of Geneva, 1987) 337, on go-go dancing as "a ritual of protest." 
decline. Prostitute women were accordingly interpolated into policy and politics as 'problems' in need of elite solutions, and, in particular, of infusions of 'correct' cultural identity. This process clearly established elites as the 'proper' authorities - in the face of the challenge mounted by students and peasants - and gave elite women a foothold in positions of power as the ultimate arbiters of tradition and cultural identity. Most importantly, having established the peasantry and peasant women as symbols of national culture, this discourse silenced their political and social agency and their voices, but granted agency to the elite women who could guide peasant women into the modern era.

\section{Politics in the 1960s and 1970s}

The 1960s were a period of enormous economic growth and social change in Thailand. The country had received considerable economic and technical aid from its ally the United States since the early 1950s. In this period, the growing American involvement in Vietnam and the concern about the containment of communism in Asia led to heavy investment in national development as a way to maintain national security. Indeed, according to Thak Chaloemtiarana, the official raison d'etre shifted from the need for national improvement to the need for security. ${ }^{9}$ Officials wanted to ensure 'attachment to government' in rural/outlying areas through the provision of services. ${ }^{10}$ More importantly, they needed to

${ }^{9}$ Thak Chaloemtiarana. Thailand and the Politics of Despotic Paternalism (Bangkok: Thammasat University, 1979) 255.

${ }^{10}$ Thak, 264. 
ensure attachment to Thai national identity and sovereignty. Identity outside of central Thailand was still not a nationalized 'Thai identity'. The Northern Thai, for instance, maintained the shared sovereignty idea of a vassal state. A 1967 study showed that a widely held sentiment in the North was that expressed by one leader:

\begin{abstract}
About sixty years ago we were conquered by the Central Thai. We offered them...signs of respect and loyalty. They became our ... 'officials' or 'rulers' ... and we pay them taxes. When the Communists come, they may conquer the Central Thai. Then we will offer them (respect and loyalty and call them rulers). We will pay them taxes and all will be as before. We are the common people; what happens to officials does not concern us... Whatever side wins, we will...call them our leaders. ${ }^{\text {II }}$
\end{abstract}

Thus, the 'imagined nation' did not reach far beyond the Central Plains and the urban centres of Thailand.

Sarit's nationalization program of "Nation, Religion and King" was brought to the countryside through an education push that included the building of thousands of primary schools in rural areas. School teachers, government officials and Sangha monks appeared in the villages with increasing frequency. These efforts themselves generated resistance. The teachers, monks and officials came "represent[ing] new sources of knowledge which claimed to be superior to village-based knowledge." ${ }^{2}$ The focus on road-building and communication to service American military needs led to increased hardships for peasants in the form of

\footnotetext{
" c.f. Bruce London, Metropolis and Nation in Thailand: The Political Economy of Uneven Development (Boulder: Westview Press, 1980) 96.

${ }^{12}$ Pasuk and Baker, 74-75.
} 
expropriated land and increased taxes. Migration into the city increased, along with the class divide between urban elite and rural poor. ${ }^{13}$

The exploitation of the countryside led to increased resistance to Bangkok's intrusions from the outlying areas. It was this resistance that Sarit had sought to undermine by classifying peasants in the city as a threat to stability and by implementing 'development' plans to pacify the countryside. The development/security push, however, was itself an instigator of unrest. Sarit's hand-picked successors - Thanom Kittichakorn and Praphat Charusathien - extended the security/development regime after Sarit's death in 1963. In response to these changes, the Communist Party of Thailand (CPT), since the 1920s a largely urban, Chinese dominated party, formally changed strategy from urban working-class based revolution to rural-based revolution at a 1961 party congress, moving its headquarters to the north-east to build a rural party base and to make contacts with the communist parties in China, Laos and Vietnam for training, finally launching an armed struggle in $1965 .{ }^{14}$ The Thanom-Praphat regime responded to the rural communist presence with search and destroy missions in the north-east. In one 1966 incident, a search-and-destroy team "tortured suspects, raped women, and carried out summary executions of supposed communists."15 This and many other incidents of aggression by police and soldiers led to self-defence units

\footnotetext{
${ }^{13}$ London, 90.

${ }^{14}$ Pasuk and Baker, 291. John Girling, Thailand: Society and Politics (Ithaca: Cornell UP, 1981) $115,252-256$.

${ }^{15}$ Pasuk and Baker, 294.
} 
in villages being approached by guerillas to join the communist insurgency. The hardships brought by the anti-communist drive actually increased the appeal of the communists who promised, for instance, to end police corruption. ${ }^{16}$

At the same time, the influx of aid from the United States and the industrial boom that flowed from military investment led to a burgeoning of the middle class and an increase in the gap between rich and poor. Sarit embraced the development rhetoric of the international economic community, sending the King abroad to advertise Thailand's endorsement of pathana (development). ${ }^{17}$ The First Development Plan, instituted in 1961, echoed the World Bank and International Monetary Fund's push for economic growth through economic liberalisation. Sarit had thrown off Phibun's limited economic nationalism to open the country to foreign investment, banning trade unions, abolishing limits on landownership, enforcing low wages and offering "very favourable conditions for the repatriation of corporate profits." ${ }^{18}$ Between 1960 and 1970, the number of people classified as "administrative, executive, and managerial" expanded almost ten times (from 26,000 to nearly 250,000 ) and "professional and technical" personnel more than doubled. ${ }^{19}$ As well, university education expanded rapidly. The number of students in university grew five fold

${ }^{16}$ Pasuk and Baker, 294.

${ }^{17}$ Sarit had resurrected the monarchy as a symbol of Thai identity.

${ }^{18}$ Benedict Anderson, "Introduction," In the Mirror: Literature and Politics in Siam in the American Era, Benedict Anderson and Ruchira Mendiones, eds. (Bangkok: Duang Kamol, 1985) 19.

${ }^{19}$ Girling, 177. 
from 18,000 in 1961 to 100,000 in $1972 .{ }^{20}$ The income of these educated, middle-class groups grew accordingly. By 1969 average urban incomes were two and a half times rural income levels. ${ }^{21}$ Urban centres expanded rapidly. Bangkok grew from a city of 2.6 million in 1960 to 4.6 million in 1970 and 5.9 million in $1975 .^{22}$ Half the increase in the urban working force was the result of immigration from the countryside. ${ }^{23}$ Nonetheless, Pasuk and Baker argue that the flow of labour from countryside to urban areas was not so great given that the "expanding agrarian frontier still absorbed nearly sixty per cent of the new addition to the labour force between 1960 and $1980 \ldots . .$. In 1980, seventy-one per cent of all labour was still working in agriculture." ${ }^{24}$ Seasonal migration was also a long-standing practice in rural areas and the effect of the growth spurt of the 1960s and 1970s was to intensify this process as migrants joined the urban informal sector. Migrants were mostly young, often in their teens, and nearly half were female - reflecting the important role of women in sustaining the rural household economy. ${ }^{25}$ The remittances of these young women from more profitable

\footnotetext{
${ }^{20}$ Girling, 177.
}

${ }^{21}$ Robert J. Muscat, Thailand and the United States: Development, Security and Foreign Aid (New York: Columbia UP, 1990) 193.

${ }^{22}$ Pasuk and Baker, 186.

${ }^{23}$ Pasuk and Baker, 187.

${ }^{24}$ Pasuk and Baker, 188.

${ }^{25}$ Pasuk and Baker, 198. 
labour in the urban areas kept many rural families from starvation. Many of these women became part of the growing prostitution industry of the tourist and urban centres.

In the 1970 s the political effects of these changes were felt in full force. Benedict Anderson characterizes the early 1970s in Thailand as an era in which the rising expectations of the growing petit bourgeoisie - a product of massive American investment - were thwarted by the withdrawal of American troops, the inability of the bureaucracy to take on many of the newly educated students, a sudden onset of inflation, and the exclusion of this class from political power. ${ }^{26}$ The students took up a socialist/nationalist campaign that criticised both the continuing undemocratic rule of the sakdina (feudal) elite and the interference of foreign powers, particularly the United States and Japan. In 1972 the National Students' Committee of Thailand launched a boycott of Japanese goods - protesting the growing predominance of Japanese firms and investment in Thailand. Their actions amplified a campaign launched by thirty trade associations the year before and the growth of economic nationalism among some business people, state managers and intelligentsia. ${ }^{27}$ The students' nationalist stance made it difficult for the government to criticise them outright, even as the students' condemnation of Japanese influence implied elite Thai connivance with outsiders to bilk the Thai

\footnotetext{
${ }^{26}$ Benedict Anderson, "Withdrawal Symptoms: Social and Cultural Aspects of the October 6 Coup," Bulletin of Concerned Asian Scholars 9.3. (July - September, 1977): 17-18.

${ }^{27}$ Pasuk and Baker, 321, note 9; Kevin Hewison, Bankers and Bureaucrats: Capital and the Role of the State in Thailand. (New Haven: Yale University Southeast Asia Studies, 1989) 107.
} 
economy. ${ }^{28}$ And, for the time being, the students' nationalist campaign worked in favour of the capitalist elite who were growing impatient with military rule and interference with business. $^{29}$

Thanom and Praphat's dictatorial power had been increasingly opposed by business groups and civil society. Thanom had finally called elections in 1969. The results were a stunning setback for the military and the bureaucracy. In the new legislature forty-six percent were businessmen, twenty percent were professionals, and only twenty-one percent were civil/military bureaucrats. The results appeared to indicate the growth of a democratic political culture. The Parliament proved to be very active in criticising authoritarianism, corruption in government and military arms spending. ${ }^{30}$ In frustration, Thanom revoked the constitution and dissolved an increasingly fractious Parliament in 1971. The King, sensitive to the winds of change, was openly unhappy with this move. He encouraged the newly active student movement to continue to oppose corruption in government. ${ }^{31}$

Even elements of the military were unhappy with the situation in which Thanom and Praphat appeared to have lost touch with the military itself. In 1971 the head of the army, General Krit Sivara, was asked by members of the military to carry out a coup against the

\footnotetext{
${ }^{28}$ Ross Prizzia, Thailand in Transition (Honolulu: University of Hawaii Press, 1985) 190.

${ }^{29}$ Pasuk and Baker, 299-300.

${ }^{30}$ Pasuk and Baker, 300.

${ }^{31}$ Pasuk and Baker, 301.
} 
Thanom regime. He refused, but the growing activism of the student movement was rapidly making such a move unnecessary. When several students were arrested in October 1973 for handing out leaflets demanding constitutional government, the student body rose up en masse and insisted on their release. Several days later there were approximately 400,000 people from all walks of life - marching on the streets of Bangkok..$^{32}$ A police riot ensued and the government asked General Krit and the army to step in and crush the 'revolt'. When Krit refused, the King asked Thanom and Praphat to resign and leave the country. ${ }^{33} \mathrm{~A}$ new era in Thai politics began with the appointment of a liberal-minded Supreme Court Judge, and favourite of the King, Sanya Thammaksi, as Prime Minister.

This period of "open democracy" lasted a scant three years, however, as the rightwing gathered its strength in the face of labour unrest and student demonstrations leading to the bloodbath of 1976 when students, demonstrating against the return of Thanom, were attacked by right-wing forces. Many were killed and many more were forced to flee to the hills to seek protection with the CPT. The right had made progress through the careful cultivation of a conservative national identity based on "Nation, Religion and King." After the overthrow of the military government in 1973, right-wing groups within the military were increasingly concerned to stem the tide of 'communist' influence they saw among the

${ }^{32}$ The crowds included the bar-girls themselves, according to one observer. See David Van Praagh, Thailand's Struggle for Democracy: The Life and Times of M.R. Seni Pramoj (New York: Holmes and Meier, 1996) 149.

${ }^{33}$ Girling, 192-193. 
students and the peasants. The fear of communist insurgency, continuing labour unrest and Kukrit's pledge to discontinue American military support provoked the military to reassert its role.

The Internal Security Operation Command (ISOC) ${ }^{34}$ became the coordinating body for the military's resurgence. ISOC supported the organization of two right-wing vigilante groups - the Red Gaurs and Nawaphon. ${ }^{35}$ Leaders and members of the Peasants' Federation of Thailand were systematically murdered, followed by the leaders of the socialist parties. On the 6th of October 1976, right-wing activists, including Nawaphon, the "Red Guars" and the Village Scouts, attacked a student demonstration outside Thammasat University. More than a thousand students were killed. An army coup that evening ended Thailand's period of democracy and led to the installation of a right-wing, virulently anti-communist supreme court judge, Thanin Kraivixien, as Prime Minister. The government ordered the arrest and imprisonment of "elements dangerous to society."

${ }^{34}$ ISOC was originally CSOC - the Communist Suppression Operation Command established in the mid-1960s "under US auspices to co-ordinate counter-insurgency." Pasuk and Baker, 307.

${ }^{35}$ The Red Guars refers to a type of wild boar, while Nawaphon translates literally to 'Ninth Power', which is thought to refer to the current monarch - the ninth king of the Chakri Dynasty.

${ }^{36}$ Girling, 193. 
Radical right-wing organizations such as Nawaphon and the Red Guars ${ }^{37}$ espoused an extreme nationalism. The head of Nawaphon stirred up crowds of onlookers with shouts of "do you love your King? Do you love Thailand? Do you hate communism?"38 Their discourse connected the monarchy, religion and anti-communism as the correct Thai identity. All those who appeared to oppose 'Nation, Religion and King" were branded 'communists' and this soon included Prime Minister Kukrit. The protesting students were defined as "not Thai" but "Vietnamese," this being understood to also mean communist. ${ }^{39}$ As Thongchai Winichakul remembers, Police Lieutenant Colonel Salang Bunnag and a radio host joked about the beating of students, suggesting that their inability to speak clearly after the beating indicated that they must be Vietnamese. ${ }^{40}$ Thongchai also points out how the students were

${ }^{37}$ CIA influence is also believed to be behind these groups, particularly Nawaphon which was formed by a Thai student who had been studying in the US and who claimed to be linked to the CIA. Pasuk and Baker, 307-308; David Morell and Chai-anan Samudavinjia, Political Conflict in Thailand: Reform, Reaction. Revolution (Cambridge, Mass: Oelgeschlager, Gunn and Hain, 1981) 239.

${ }^{38}$ Pasuk and Baker, 307.

${ }^{39}$ In April 1975 Saigon fell to the communists as did Phnom Penh. The Spectre of communist takeover on its borders lent credence to fears of communist advance in Thailand - particularly through a linkage of students, peasants, the CPT and the new communist regimes. Pasuk and Baker, 306.

${ }^{40}$ Thongchai, "The account of an eyewitness," The Nation 5 October 1996: A4. Thongchai records the conversation thus: "'Definitely, they must be the Yuan (Vietnamese),' one suggested. 'Of course they are Yuan. Otherwise why couldn't they speak Thai at all?' the other seconded." Another senior police officer and famous writer Manas Sattyarak excused the death of one student by saying "His complexion is so white. Perhaps he is a Yuan." Thongchai, The Nation, 5 October 1996: A4. Other people on the scene on October 1976 also remember this kind of reference, see the memoir of a mother who went looking for her son after the massacre "I saw [soldiers] burning the students. 
constantly referred to as "the rioters" or "the deceived" in recountings of the October 6 massacre. ${ }^{41}$ Not only was the terminology designed to render the students foreign and a threat to Thailand, but it went so far as to render them inhuman. One monk, Phra Kittivuttho, was a prominent supporter of Nawaphon who, in opposition to Buddhist precepts, stated in 1976 that killing communists was not a sin, since they were not human. ${ }^{42}$ This urban anticommunist propaganda had its village shadow in the form of rumours of "penis-shrinking potions" being spread as part of a Vietnamese communist conspiracy in the Northeast, leading to attacks on Vietnamese owned businesses. ${ }^{43}$ Other rumours described vampires (who looked exactly like students) sucking the blood of village children to provide transfusions for wounded communist guerillas. ${ }^{44}$ Thus this discourse of the right-wing clearly carried strong ethno-national messages ${ }^{45}$ In this context, the student movement was forced

Those children were still squirming in the flames. They [the right wing] kept saying that they weren't students, but Yuan." Lek Wittayaporn quoted in Pennapa Honthong "Living with memories of a lost son," The Nation, 6 October 1996: A9.

${ }^{41}$ Thongchai, "Struggle," A5.

${ }^{42}$ Pasuk and Baker, 309.

${ }^{43}$ Katherine Bowie, Rituals of National Loyalty: An Anthropology of the State and the Village Scout Movement in Thailand (New York: Columbia UP, 1997) 19.

${ }^{44}$ Bowie, 19.

${ }^{45}$ The violent backlash against the student movement is often read as the reaction of deeply conservative society, fearful of change, against radical students, who were pushing for too many changes too quickly. But, as Charles Keyes has noted, the right-wing groups' support among middle and lower-middle classes "can be seen as part of the latters' desire for, and push toward, greater participation in politics comparable to that also sought by the leftist movements." Charles Keyes, Thailand: Buddhist Kingdom as 
to maintain its nationalism in an attempt to appeal for political legitimacy. In doing so, however, the movement often painted women as symbols of national purity or degradation. Prostitute women came to be seen as representative of the decline of the Thai nation.

The Growth of the Prostitution Industry

It was in the context of these wide social and political changes that prostitution became a national issue. In the 1960 s prostitution numbers began to expand rapidly, from approximately 20,000 women working in the trade in the late 1950 s to 171,000 persons "clearly engaged in prostitution related activity" by $1964 .{ }^{46}$ Almost all analyses of the prostitution situation in Thailand today point to the arrival of American servicemen in increasingly large numbers in the 1960s as the reason behind the enormous growth of the prostitution industry.

The link between prostitution and the military has long been established. Certainly the idea that soldiers required sexual servicing was deeply entrenched in the American military system. As Cynthia Enloe has pointed out:

Modern Nation State (London: Westview Press, 1987) 94-95.

${ }^{46}$ A 1964 police Department report stated that "there were 426,908 'special service girls' of various occupations out of which 171,973 persons or about 40.28 percent of this group were clearly 'prostitutes'." Saisuree Chutikul, Children in Especially Difficult Situations: I (Thailand), report to UNICEF (Bangkok: National Youth Bureau, Office of the Prime Minister, June 1986) 38. 


\begin{abstract}
A military base isn't simply an institution for servicing bombers, fighters, aircraft carriers, or a launch-pad for aggressive forays into surrounding territories. A military base is also a package of presumptions about the male soldier's sexual needs, the local society's sexual needs, and about the local society's resources for satisfying those needs. Massage parlors are as integral to Subic Bay, the Mammoth US naval base in the Philippines, as its dry docks. ${ }^{47}$
\end{abstract}

The importance of prostitution, in military officials' minds, to the maintenance of 'order' on American bases has been discussed in the context of the American military presence in Korea and the Philippines. ${ }^{48}$ The provision of sexual services through prostitution is considered an important emotional outlet and reward for war-weary soldiers; a strategy for preventing the rape of local - ally - women; a counter to potential homosexual acts among the troops; and, when properly controlled, a way to limit the spread of venereal disease, which is a major threat to the health of soldiers.

At least some of the interaction with American servicemen, however, occurred under the rubric of 'hired wife', where servicemen lived with local women, receiving sexual, emotional and housekeeping services in exchange for money, upkeep or gifts. In the countryside, where marriages were still largely unregistered, the arrangement was not

${ }^{47}$ Cynthia Enloe c.f. Katherine Moon, Sex Among Allies: Military Prostitution in U.S. - Korea Relations (New York: Colombia University Press, 1997) 11.

${ }^{48}$ See Moon, Sex Among Allies; Cynthia Enloe, Bananas, Beaches and Bases: Making Feminist Sense of International Politics (Berkeley: University of California Press, 1990). 
necessarily viewed as prostitution by the women involved. ${ }^{49}$ However, the servicemen usually did not take their Thai wives with them when they returned to America; some of these women then began to work in the growing tourism based sex-industry. ${ }^{50}$ The stronger cultural restraint on re-marriage in the Northeast, where the airbases were located, facilitated the transition from working as a 'hired wife' to working in the sex-industry. ${ }^{51}$

The attitudes of the American military men, who, for the most part, viewed the women as prostitutes, also contributed to the decline in women's status. American soldiers

${ }^{49}$ The interpretations of women who were the 'hired wives' of servicemen or worked in brothels and bars near the bases in this period have not been investigated. They most likely would reflect the kind of pragmatism most sex-workers display in viewing their own lives. Another important aspect of the displeasure expressed by townspeople with the American presence was the number of mixed-race children produced through these unions. Jeffrey D. Glasser, The Secret Vietnam War: The United States Air Force in Thailand, 1961-1975 (Jefferson, N.C.: McFarland, 1995) 103. Nearly two-thousand such children were born between 1964 and 1970, Anderson, 24, note 20. The Pearl S. Buck Foundation, which helps fatherless Amerasian children, estimated in 1996 that it has helped nearly 6,000 children since 1967. Carole Fane, Francoise Joaquin and Wendy Madrigal, "Mixed Fortunes," Asia Magazine, 2-4 August 1996, 11. Mixed race children were treated with contempt and tended to display corresponding behavioral problems although today mixed race (particularly white/Asian) young people are in the forefront of the entertainment business (several Miss Thailands have been "luk krung" (half and half)) to the point where there is some concern over the imposition of Western standards of beauty, Fane et. al., 11.

${ }^{50}$ See the account of one such wife in Dave Walker and Richard S. Erlich, Hello my Big, Big Honey: Love Letters to Bangkok Bar Girls and Their Revealing Interviews (Bangkok: Dragon Dance, 1992) 92-98.

${ }^{51}$ The continuation of the 'hired wife' phenomena to cater to tourists has led some to question whether the term 'prostitution' really captures what is occurring in the touristoriented sex-industry. See Eric Cohen, "Thai Girls and Farang Men: The Edge of Ambiguity," Annals of Tourism Research 9 (1982): 410-420. 
viewed the Thai as "amoral," according to one account of a former serviceman. He recounts that "there was a popular attitude among Americans that activities such as prostitution and cohabitation were perfectly acceptable [to the Thai]." ${ }^{52}$ A more damning account of American GIs attitudes is given by Nigel Brailey who argues that the Americans in Thailand during the Vietnam war had a 'gook' mentality towards Vietnamese and Thai alike. Certainly such attitudes and the failure of military men to maintain their family responsibilities once they left the country, meant that cultural expectations were shattered and women were increasingly looked down upon by their communities.

Indeed, the presence of the American servicemen was not entirely acceptable to local officials who expressed their displeasure at the comuption of the young women at private meetings between the US Air Force representatives and local officials. ${ }^{54}$ At the same time, "it was common knowledge that certain local officials at every base had a financial interest in the bars, massage parlours, and other activities that catered to GIs." 55 Concerns about venereal disease led to towns near bases instituting a system of registration and VD control

${ }^{52}$ Glasser, 103.

${ }^{53}$ Nigel J. Brailey, Thailand and the Fall of Singapore (Boulder: Westview Press, 1986) 25 . The racist/sexist attitude towards women this entailed is well documented in accounts of military behaviour in Vietnam.

${ }^{54}$ Glasser, 103.

${ }^{55}$ Glasser, 103. 
cards, despite the formal illegality of prostitution. ${ }^{56}$ Nonetheless, local concern about the effects of the presence of US servicemen led to the establishment of the Civic Action Program promoting public relations between the bases and the local population through the provision of medical services to local townspeople, rebuilding programs and distribution of consumer goods. ${ }^{57}$

The Thai government's encouragement of the prostitution industry, however, became clearer over the years as the government built up the tourist industry on the basis of the infrastructure developed for the American military. The bars, nightclubs and massage parlours built to entertain visiting American military personnel became part of a vast network of tourism-targeted infra-structural development. This process was facilitated by legal changes that created the legal category of 'special service girls' distinct from illegal prostitution. In 1966 the government introduced the Entertainment Places Act, which was ostensibly designed to "control the operations of certain kinds of entertainment places which affect the public order and morals. ${ }^{\text {"58 }}$ The law merely codified the police practice of ignoring military-oriented prostitution by establishing the legal category of 'special service girls' who provided entertainment in bars, nightclubs and massage parlours. At one level, the law

\footnotetext{
${ }^{56}$ Glasser, 103. In $1965,76,000$ prostitutes registered their medical records with government offices. Thai Development Newsletter, 27-28 (1995) 87.

${ }^{57}$ Glasser, 104.

${ }^{58}$ Malee Pluksponsawalee. "Women and the Law," Women in Development: Implications for Population Dynamics, eds. Suchart Prasith-rathsint and Suwanlee Piampiti (Bangkok: National Institute of Development Administration, 1982) 158.
} 
appeared to respond to concerns over prostitution by allowing officials to inspect such establishments and to shut them down if sexual services were being offered. The law also appeared to provide heavier punishments for pimps and owners than those in the 1960 Prostitution Act. ${ }^{59}$ In reality, however, the act further protected owners and operators by allowing them to hire women under the rubric of 'entertainers' and, yet to profit from prostitution as long as it occurred 'off site'. A system of 'bar fees' was developed so that customers could 'hire out' a woman by paying a set amount to the bar to take the woman to a nearby hotel for sexual services.

Women in the trade, however, remained at risk for punishment. The act provided for the arrest of those rendering sexual services who would, as in the Prostitution Act, be remanded to rehabilitation centres by the Public Welfare Department after completion of their punishment. ${ }^{60}$ Indeed, this is the only section of the 1966 Act that has been regularly used. The lighter penalties for pimping and running a place of prostitution under the 1960 Act are used in the few cases where offenders are prosecuted. ${ }^{61}$ Clearly the government was paving the way for the use of women as entertainment attractions, nonetheless it placed the blame for women crossing the line from 'special services' to prostitution only on women's

${ }^{59}$ The term 'special services' was created by the Police Department in the early 1960 s. Thahn-dam Truong, Sex, Money and Morality: Prostitution and Tourism in Southeast Asia (London: Zed, 1990) 157 note 4.

${ }^{60}$ Wathinee Boonchalaksi and Philip Guest, Prostitution in Thailand (Bangkok: Institute for Population and Social Research, Mahidol University, 1994) 20-21.

${ }^{61}$ Wathinee and Guest, 20-21. 
shoulders. As Truong points out, taken together the 1956, 1960 and 1966 acts show "seduction of minors, prostitution and entertainment are seen as three separate issues rather than as part of a connected whole." ${ }^{162}$ While women were responsible for their entry into prostitution according to the government, they were not to be allowed to act independently within prostitution. The 1966 act, while giving some status to prostitutes, gave this status on condition of prostitutes working within a place of entertainment, thereby continuing to cede control to owners and managers and penalizing independent prostitutes.

The tourism industry thus only stood to profit from such a policy. The 1966 Act was followed a year later by a deal with the US to allow US forces in Vietnam to come to Thailand on 'Rest and Recreation' (R\&R) leave, effectively expanding the 'special services' industry ${ }^{63}$ The foreign-oriented sex-industry now grew beyond the location of the airbases to other centres, such as the southern coastal town of Pattaya, which was selected as an $R \& R$ site. ${ }^{64}$ The contribution to the economy was immediate as spending rose from US\$5 million in 1967 to an estimated US $\$ 20$ million in $1970 .{ }^{65}$ The financial interests in the entertainment and, increasingly, tourist industries, were enormous. A 1974 survey showed over 20,000

\footnotetext{
${ }^{62}$ Truong, 156.

${ }^{63}$ Truong, 161.

${ }^{64}$ Wathinee and Guest, 8.

${ }^{65}$ Truong, 161.
} 
entertainment places had been established nationwide (including bars, nightclubs, and brothels). ${ }^{66}$

Increasingly, these places were being used not only by servicemen but by visiting tourists, the numbers rising from 80,000 foreign tourists to Thailand in 1960 to nearly 3 million by $1986 .{ }^{67}$ The Thai government had undertaken a tourism promotion policy in the 1960s, following the recommendations of a report commissioned by the US Department of Trade and Commerce and widely touted by various international organizations that advocated a tourism promotion strategy for economic development in the Asia-Pacific region. ${ }^{68}$ Thanhdam Truong argues that the sudden, intensive investment in tourism infrastructure (particularly hotels) in the late 1960 and early 1970 s created a significant oversupply of accommodation and entertainment facilities. ${ }^{69}$ Once the military demand for these services began to drop off, the need to fill these spaces led to an intensification of tourism as part of the export-led growth strategy that was taking hold in the 1970s, a strategy that, according to Truong, "widened the $\mathbf{R} \& \mathbf{R}$ market to a more international market."70 Prostitution services - sold, for instance, through joint venture links between hotels, travel agencies and

\footnotetext{
66 Truong, 161.

${ }^{67}$ Truong, 172.

${ }^{68}$ Truong, 118-122.

69 Truong, 167.

70 Truong, 167.
} 
airlines to 'sex tour' groups - became a lucrative way to fill the empty hotel rooms left by American servicemen. Truong argues, therefore, that:

... the relationship between tourism and prostitution can no longer be seen only as an issue of employment alternatives available to women, but also as an issue related to the internal structure of the tourist industry and to vested interests of a financial nature. ${ }^{71}$

Thus the structural basis of prostitution became well entrenched during the 1970 s.

The 1966 Act clearly showed that the government was not adverse to, in fact it even promoted, the use of women as entertainment attractions - even as tourism officials argued that prostitution was merely an unfortunate side-effect of poverty. ${ }^{72}$ Women's images were used as promotional vehicles for tourism, as in the advertisements for the rational airline: "Some say it's our beautiful wide-bodied DC-10s that cause so many heads to turn at airports throughout the world. We think our beautiful slim-bodied hostesses have a lot to do with it." ${ }^{, 73}$ Beauty, desirability and service were symbolized through the feminine body. Thus, the state could promote Thai services internationally without damaging the masculinity of the Thai state and elites, which was attached to the 'possession' of women as a sign of virility

71 Truong, 172.

${ }^{72}$ As the director of the Tourism Authority of Thailand explained to the Far Eastern Economic Review in 1976: "Yes, we have to admit that we have prostitution, but it is the same in every country...It might be partly true [that tourism encourages prostitution], but prostitution exists mainly because of the state of our economy, because everyone needs to earn their income. If we can create jobs, we can promote per capita income and do away with prostitution." c.f. Truong, 179.

73 Truong, 179. 
and power. Indeed, in the context of growing dependency on American military aid, the Thai military/state's feeling of emasculation by the 'more virile' Americans may have been redressed through the overt sexual use and proffering of women, to prove Thai military masculinity. ${ }^{74}$

While the military and tourism industry may account for some of the demand for prostitution, they do not account for the supply. Further, the focus on these 'foreign' causes for prostitution has obscured the role of domestic demand. Even today, tourism accounts for a very small proportion of the prostitution industry. According to a number of analysts, the majority of clients of prostitutes are Thai. ${ }^{75}$ As Sukanya Hantrakul points out: "The GI ways of recreation were overwhelmingly adopted by the Thai males with their aiready permissive code of conduct.. ${ }^{.76}$ Nonetheless, Thai men as clients of prostitutes rarely make an appearance in the analytical material or in the media. ${ }^{n}$ Nor is the behaviour of the Thai military

${ }^{74}$ See Katherine Moon, "East meets West” for a discussion of the sex-trade and postcolonial masculinity.

${ }^{75}$ See Sukanya Hantrakul, "Prostitution in Thailand," paper proposed to the Women in Asia Workshop. Monash University, Melbourne, July 22-24, 1983, 34. Sukanya points out further that most prostitution in Thailand takes place in 'traditional brothels' which "play a more vital role in the continuation of prostitution in the country. Not only because they are more ancient but also because they have maintained popularity and access to massive [numbers of ] Thai males of average middle class and lower economic class." Sukanya, 12. Pasuk argued in 1981 that about half of the clients in high-class massage parlours were Thai, Pasuk, 17.

${ }^{76}$ Hantrakul, 34.

${ }^{77}$ One notable exception is Varaporn Chamsanit and Kritaya Archavanitkul's study of teenage male clients of sex-workers "Male Clients of the Sex Trade in Thai Society: A Pilot Study of Male Teenagers' Buying Sex," Paper Presented in the Sixth Northwest 
examined except in terms of the military elites' attitudes towards women. The Thai military's forays into the rural areas to suppress communism no doubt involved the use of local prostitution services and may have expanded them. ${ }^{78}$ Indeed, while the continuity between acting as a hired wife and becoming a prostitute may hold for women in Isaan, the Northeast province, where the bases were located, it leaves unexplained the entry of women from the Northern region, who predominate in the sex-industry. Here the more important explanatory factors seem to be northern society's emphasis on a daughter's duty to support the family and the national ideology of femininity that prizes the fair-skinned women of the north as particularly beautiful and 'soft' in their manner. As Pasuk Phongpaichit has argued: "If it was the Viet Nam war which drew in the North-east girls, it was the institution of the beauty contest which provided the channel for the girls from the North." supported by military-bureaucratic elites who, like Sarit, married former beauty queens or took them as minor wives.

These aspects of the sex-trade, however, were often ignored in the overwhelming focus on the effects of Western influence in expanding the trade. In the political climate of

Regional Consortium for Southeast Asian Studies Conference on 'South East Asia and the New Economic Order', University of Washington, Seattle, Nov. 4-5, 1994.

${ }^{78}$ Brock and Thistlewaite argue that "the military is notorious for its use of the sextrade to break in new recruits and for its frequent use of brothels." Rita Nakashima Brock and Susan Brooks Thistlewaite, Casting Stones: Prostitution and Liberation in Asia and the United States (Minneapolis: Fortress Press, 1996) 61.

${ }^{79}$ Pasuk, 37. 
the 1970 s the appeal to nationalism was paramount in launching a critique of the militarydominated government without being accused of being communist. Such nationalism, however, presented prostitute women as symbolic of the decline of 'real' Thai culture - now understood to mean rural, peasant culture. While women students organizations tried to bring attention to the elite gender culture that treated women as sexual objects, they continued to view prostitute women as 'fallen' women. That is the divide between 'good' women and 'bad' remained unchallenged and prostitute women appeared as in need of assistance in order to return to what was constructed as good, peasant tradition.

\section{Rural Resistance}

The 1960s are consistently described by analysts as a period of the intrusion of Western culture into the previously untouched Thai culture of the rural areas ${ }^{80}$ As Pasuk and Baker point out, however:

Before the road-building programmes began in the 1950s, many rural settlements were remote, relatively self-sufficient, and jealous of their independence. They were not, however, isolated. Another layer of rural culture was overlaid on the sparse stipple of rural communities. People travelled through

\footnotetext{
${ }^{80}$ This was the dominant interpretation of cultural nationalists such as Sulak Sivaraksa, as we shall see below. It was, however, challenged by some intellectuals such as the neo-Marxist scholar Nidhi Aeusrivongse who praised Sulak for "having the courage to raise the issue of the bad influences exerted by the American bases, reminded him that the Thai have been absorbing Western influence for more than a century." Benedict Anderson, "Introduction," In the Mirror: Literature and Politics in Siam in the American Era, eds. Benedict Anderson and Ruchira Mendiones (Bangkok: Duang Kamol, 1985) 27.
} 
the region constantly. Villagers loaded carts with spare rice, forest products, and preserved proteins and circulated through neighbouring villages to trade and barter. Young men travelled in search of knowledge and power. Entertainers toured the villages. In the tenth month, families customarily travelled to visit distant elderly relatives. Forest monks and spirit mediums passed through the settled regions on journey between remote outposts. These 'wandering networks' acted as transmission lines for knowledge, information, and ideas. ${ }^{81}$

Rural cultures, therefore, were hardly fixed and unchanging but in a constant state of reformulation.

In the context of growing urban and American interference in rural life and repression of rural people, the rural residents did express their unhappiness with the sudden changes but, rather than being the reaction of a 'pure', 'traditional' culture against foreign influence, rural resistance mechanisms made use of the international flow of ideas and culture to express rural grievances. The expansion of radio and roads throughout the countryside in the 1960 s enabled rural entertainers to broadcast their music more widely. The phleng luk thung (country songs) "reflected the appearance of new media which knitted together a single rural audience, and the emergence of new and common concerns arising out of the rural population's common confrontation with the city."82 The songs drew on the earthy humour of the villages while expressing a cynicism about urban interference. Their style, however, also reflected the urban and international influences of Latino stagecraft and nightclub music.

\footnotetext{
${ }^{81}$ Pasuk and Baker, 69.

${ }^{82}$ Pasuk and Baker, 76.
} 
Backup dancers (usually female) in flashy costumes became a requisite part of live performances. This musical culture appears to mark some space for an acknowledgement of sexuality in public discourse in the rural areas and a willingness to draw on other cultures for inspiration..$^{83}$

Later, however, as this musical form became part of an organized movement, in tandem with student activists demonstrating against foreign interference and government fascism, a more restrictive representation of female sexuality became increasingly dominant. By the mid-1970s female migrants had become a major theme of the luk thung songs as representatives of the hardships wrought by cultural dislocation. Songs were written about life inside a brothel, being the hired wife of a US soldier, or working as a masseuse in Germany. ${ }^{84}$ One study of luk thung titles in the late 1980 s showed "as many as one fifth

${ }^{83}$ The backup dancers provide an interesting cultural continuity between rural girls and Patpong dancers. While some have marveled at the ability of 'traditionally modest' and body-conscious rural girls to take up topless dancing in go-go bars the similarity between the back-up dancer and go-go girl style is quite remarkable. In my own field research in Chiang Mai in 1996 I was struck by the similarity in body movement and expression of the back-up dancers in performances at a local political rally and those of go-go dancers in Patpong. Mary Beth Mills also noted that in a traveling show in the Northeast in 1988 "A troupe of maw lam singers (a song style associated with the Northeast but increasingly popular nationally) performed in front of a chorus line of scantily dressed dancers. The young girls changed costume (under the portable stage) between numbers, adding to the titillation of the excited young men in the audience. This format echoes the presentation of maw lam stars on popular television broadcasts seen nationwide." Mary Beth Mills, "Rural Women Working in Bangkok: The Rocky Road of Social Change," final report to the National Research Council of Thailand, n.d, 18, note 12.

\footnotetext{
${ }^{84}$ Pasuk and Baker, 78.
} 
dealing with prostitution, including sympathetic treatments by male singers" who often linked prostitution to the need to earn money for the family. ${ }^{85}$ Thus, for the rural cultural elite, prostitution became symbolic of rural cultural/economic decline and exploitation. The space for female sexual self-determination disappeared.

Resistance to urban intrusion also took the shape of what those in power termed the 'communist insurgency' 86 The local disgust with the behaviour of the Americans, who "brawled with Thai over girls and money," became part of the communist arsenal of arguments to support their contention that the Thai government was acting as a puppet of the United States. ${ }^{87}$ Dissident organizations decried the presence of the "US imperialists" who, according to the Thailand Independence Movement, "have propagandized their reactionary thoughts and rotten culture into our society." 88 The Thailand Patriotic Front announced in its inaugural statement in 1965, that "The U.S. imperialists suck our people's blood and each

${ }^{85}$ Pasuk and Baker, 78-79.

${ }^{86}$ The extent of an actual 'communist insurgency' is still unknown, and it was certainly much less than was claimed by counter-communist forces. (At the height of the reaction even moderate conservatives such as Kukrit Pramoj were termed 'communists' by the far right.) However, villages soon discovered that at least claiming to be subject to a communist insurgency would lead to an influx of aid and services from the military and the government. Today, therefore, analysts consider some reporting of numbers to have been inflated.

${ }^{87}$ Donald Kirk, Wider War: The Struggle for Cambodia. Thailand and Laos (New York: Praeger, 1971) 71; Brailey, 250.

${ }^{88}$ Movement for the Independence of Thailand, 1964, c.f. Donald E. Weatherbee, The United Front in Thailand: A Documentary Analysis (Columbia: Institute of International Studies, University of South Carolina, 1970) 31. 
year take away tremendous amounts of wealth from our natural resources; at the same time they spread the rotten and poisonous American culture among our youths." 89 The Thailand Patriotic Youth Organization vowed to "oppose the derogatory culture and degenerating way of life of U.S. imperialism that are poisoning the minds of the Thai youth. [And] fight for the promotion of the excellent culture, tradition, and morality of the Thai nation." 90 The dissidents also responded to the concern over sexual relations between Thais and Americans by claiming that the American servicemen "barbarously rape Thai women" as well as injure and torture Thai people. 91 The emphasis on rape was designed to highlight the victimization and innocence of the Thai people in the face of US aggression (supported by the "corrupt", "fascist" and "dictatorial" Sarit-Thanom government).

That rape did indeed occur is very likely given the attitude of the American forces personnel towards Thai women. To add insult to injury, even though the Americans had not formally negotiated a Status of Forces Agreement to exempt American personnel from Thai law, the Thai authorities usually handed offenders back over to base authorities without laying charges. ${ }^{92}$ Conscious of the anger this must have engendered among the populace near the bases, the Patriotic Front statement linked these events to imperial disrespect of Thai

\footnotetext{
${ }^{89}$ Thailand Patriotic Front, 1965, c.f. Weatherbee, 38.

${ }^{90}$ c.f. Weatherbee, 52.

${ }^{91}$ Thailand Patriotic Front, 1965, c.f. Weatherbee, 38.

${ }^{92}$ Glasser, 103.
} 
sovereignty: "Worse still, they trample underfoot Thai law...." and loss of sovereignty in the American military's treatment of Thai women was made clear.

The Communist Party, for its part, made a pledge to adhere strictly to "ten disciplinary principles” adopted from Mao's Three Main Rules of Discipline and Eight Points for Attention, which included the order "do not take liberties with women." Communist Party of Thailand promised that:

Women shall enjoy equal rights as men in the political, economic, cultural, educational and vocational fields; [and it will] bring the role of women into full play in the revolutionary movement and production; promote fully welfare work among women and children, ensure education and work to the youth. ${ }^{95}$

Women, women's bodies and women's sexuality were clearly becoming a battleground for issues of national identity, culture and self-determination and there was no room for the kind of ambiguities over women's sexuality suggested by other discourses.

\section{Students, Elites and the Threat of Cultural Decline}

Resistance to the current regime was building throughout the 1960 s not only in the countryside but among urban elites as well. The growth of a well-educated and economically ascendent middle class spawned impatience with the dictatorial style of Sarit's successors

\footnotetext{
${ }^{93}$ c.f. Weatherbee, 38.

94 Weatherbee, 710.

${ }^{95}$ Communist Party of Thailand, 1968, c.f. Weatherbee, 69.
} 
Thanom and Praphat. As the number of university students had climbed, so had middle-class intellectual activity and unhappiness with continuing autocratic rule. Dissent was also apparent in conservative intellectual circles. In 1963, the renowned Buddhist intellectual Sulak Sivaraksa began the journal Social Science Review, in the pages of which critiques of Thai politics and society began to appear. Sulak also focussed on the American influence on Thai society and culture. ${ }^{96}$ He bemoaned the "mindless imitation" of Western practices without "careful evaluation". Cognizant of the workings of imperialism, he warned his fellow citizens in 1970 that such behaviour "invites paternalistic attitudes from our Western partners." 97

A conservative nationalism such as that expressed by Sulak was becoming apparent among the wider circle of urbanites, including those from small-town lower middle-class backgrounds who had gone to the city for higher education in the late 1960s. Suchit Wongthes, who later became a prominent supporter of the student movement, expressed a similar cultural nationalism. His early writings focused on the decline of Thai culture in the face of Americanization. These writings also illustrate the degree to which cultural decline was linked to women's inappropriate behaviour. In Suchit's stories women symbolize the corruption of Thai culture. In his short-story "Second Nature" the local boy who has "made good' returns to his village to visit his sweetheart and finds his village and his sweetheart

${ }^{96}$ Pasuk and Baker, 304.

${ }^{97}$ Sulak Sivaraksa, "Siam versus the West", 1970 reproduced in Sulak Sivaraksa, Siam in Crisis (Bangkok: Kamol Keemthong Foundation, 1980) 202. 
completely changed. As Anderson explains, "A countryman at heart (or at least so he thinks), he dreams of 'showing up' the corrupted (Americanized, by implication) women of Bangkok by marrying the simple village girl he had left behind back home."98

It is the women who appear as the personification of the corruption of culture both in Bangkok and in the villages. The local girlfriend appears pitifully ignorant in her attempts to mimic urban culture without the sophistication of urban women -wearing the stretch pants that now signify 'looseness' in the sophisticated urban centre of Bangkok, and engaging in the entertainment spectacles from which 'nice girls' should demure. ${ }^{99}$ Suchit wrote:

He wanted to tell to her [sic] that stretch-pants were repulsive; but he held back, reflecting that he still had a few days left to explain to her that Bangkok boys with education and good taste regarded all girls who wore stretch-pants as low-grade whores; for any girl who clothed her body with such provocative tightness must be basically hard and far too forward. The young men were all agreed that a real Siamese beauty would never be brazen enough to display her bag of sexual tricks like that before the public. ${ }^{100}$

In this passage Suchit links Western consumer goods, particularly clothing, to an impure sexuality and lack of Thai-ness (no 'real Siamese beauty' would wear those clothes). It also

${ }^{98}$ Benedict Anderson, "Introduction," In the Mirror: Literature and Politics in Siam in the American Era, eds. Benedict Anderson and Ruchira Mendiones, (Bangkok: Duang Kamol, 1985) 45.

${ }^{99}$ Suchit Wongthes, "Second Nature," In the Mirror: Literature and Politics in Siam in the American Era, eds. Benedict Anderson and Ruchira Mendiones (Bangkok: Duang Kamol, 1985) 98-99, 103 note 8.

${ }^{100}$ Suchit, $98-99$ and 103 , note 8. 
puts the male narrator in the position of authority, along with his friends, as the arbiter of what constituted 'real Siamese beauty', as well as proper behaviour.

This conservative attitude towards the role of women in culture did not change with the increasing radicalization of the Thai student movement. Thai students studying in the US in the late 1960s learned of the use of Thailand as a base for US military operations through the activities of the anti-war movement and were able to relay that information back home where few were fully aware of the extent of American involvement. ${ }^{101}$ The number of US troops had increased from 3,000 at the end of 1964 to 9,000 in 1965 and jumped to 35,000 in 1966 and a high of 48,000 in $1969 .{ }^{102}$ Benedict Anderson notes that the students' critique of the changes taking place were a curious mix of disappointment with the Thai government for its failure to secure adequate American support to maintain Thai security in the face of communist encroachment and anger at the effects of the American military presence on Thai culture. Anderson argues that such a mixture was "... expressed in the combination of such sentiments as 'why have you let us down in Indochina?' and 'Look how you've corrupted our girls!" 103 The nationalism of the student movement, however, was a key strategy in garnering legitimacy in the face of the conservative, military government which had the backing of the palace and the Buddhist religious order, the Sangha. The students felt that they

\footnotetext{
${ }^{101}$ Pasuk and Baker, 304.

${ }^{102}$ Pasuk and Baker, 304

${ }^{103}$ Anderson, "Withdrawal Symptoms," 18.
} 
spoke for the "true Thais" - the peasants who were looked down upon by those in urban areas who had "come to regard Westerners as superior human beings". ${ }^{104}$

Indeed, the moral effect of the American presence became a central theme of this nationalism. Sukanya Hantrakul recalls that the predominant attitude among the student activists on the issue of prostitution was one of nationalist machismo - condemning the use of "our" women by foreigners. ${ }^{105}$ In 1972, the students marched on the American embassy and denounced the US presence as the primary cause of "the rotten Thai society in which we are now living, one with 'hired wives', prostitutes and half-breed children of all colours" clearly drawing the threat to the nation in terms of a threat to the purity (both moral and racial) of women's bodies. ${ }^{106}$ The students documented the growth of prostitution and the entertainment industry as proof of the demoralizing effect of the American military presence. A 1972 report published in the main vehicle for student critique, the Social Science Review, showed that by 1972 the town of Takli, the site of an American airbase since 1961, had more bars and nightclubs (forty-six) than temples (forty-four). The report added that in the wake of a 1972 all-bombing campaign, and the concomitant wave of American military men, "the number of prostitutes checking in for VD inspections rose from ninety-one in January 1972

${ }^{104}$ Sulak, 202.

${ }^{105}$ Conversation with Sukanya Hantrakul, Bangkok, October 1996.

${ }^{106}$ c.f. Chai-Anan and Morell, 165. 
to 2,954 six months later in June." ${ }^{107}$ The decline of 'traditional culture' was signalled through the rise of 'the prostitute'.

The nationalist stance of the students gave them a ground from which to attack elites for their participation in the moral degradation of Thai culture. Even such highly respected figures as Buddhist monks were exposed to attack from the students who sought not to undermine Thai culture but to 'restore' and 'purify' it. ${ }^{108}$ Well-known nationalists, such as Suchit Wongthes and Khanchai Bunpan, openly criticized the moral conduct of monks who endorsed "immoral establishments such as bars, night clubs, and massage parlours." ${ }^{109}$ At the same time they denounced elite, classical Thai literature as "erotic and morally corrupt with no social value." 10

Over the course of the 1970 s the students' critiques increasingly drew on the work of native Thai Marxists such as Jit Poumisak and Gularp Saipraisdit, which had been banned by the military government. Yuangrat Wedel has argued that the Thai brand of Marxism was distinct from Maoism and international socialism in its emphasis on Buddhism and Thai national/cultural identity. "I This nationalism remains clear in the analysis of women's

${ }^{107}$ c.f. Anderson, 23, note 19.

${ }^{108}$ Mattani Kutnin Modern Thai Literature: The Process of Modernization and the Transformation of Values (Bangkok: Thammasat UP, 1988) 74.

${ }^{109}$ Mattani, 75.
${ }^{\text {} 10}$ Mattani, 75.
${ }^{111}$ Yuangrat, 198-202. 
position and the use of women's bodies. Jit, for instance, clearly saw women entering prostitution as a function of economic need both in the feudal (sakdina) and capitalist eras, but also invoked the influence of European intrusion, echoing the concerns of the contemporary era:

The nature of prostitution in the sakdina age and the capitalist age was identical i.e. many women who could no longer endure conditions of hunger and suffering had to sell their bodies. In periods when Europeans came to trade in the krung, their free-spending habits induced an even larger number of women who could not break free of such conditions to take up this occupation. At the end of the Audhya period it was notorious that increasing numbers of unfortunate women were being forced to grit their teeth, shut their eyes, and sell themselves to foreigners. ${ }^{112}$

The illegitimacy of the feudal elite was illustrated through their own treatment of women and their sexual "perversion." The feudal elite "did nothing to correct the situation, because it saw women's 'basic nature' as being lustful. All the sakdina did was wait around to collect the tax." Indeed, Jit characterized the sakdina class as licentious and sexually "perverted," "using women as objects in which to release their desire. A woman's condition was thus that of a female animal waiting to receive the Land-Lord's lust." ${ }^{113} \mathrm{Jit}$ studied classical literature

${ }^{112}$ c.f. Reynolds, 134.

${ }^{113}$ c.f. Craig J. Reynolds, Thai Radical Discourse: The Real Face of Thai Feudalism Today (Ithaca: Cornell UP, 1987) 57. 
to find examples of how women were viewed as "good only when she has an interesting body, good only for sexual release."114

Jit's own moralism becomes apparent in his condemnation of elite depravity, which was illustrated by the unnatural confinement of women in the harem. According to Jit, this meant that lesbianism (homosexual) among the women in the
inner quarters and in harems in the households of the nobility
was to be found everywhere. The sex life of the ruling masters
became more and more perverted for example satisfying their
desires by sodomy. ${ }^{15}$ Jit's invocation of sexual depravity demonstrates the symbolic importance of women's bodies in provoking a nationalist response, a need to save Thai women from the 'perverted' ruling class and the foreigners to whom the women are 'sold'. Women themselves appear as objects passed from hand to hand rather than as agents.

The student movement of the late 1960s and early 1970s could openly espouse such criticisms on the grounds of defending Thai culture against encroaching American imperialism. Nonetheless, the external focus and nationalism of much of the students' critique also allowed the government to appropriate the rhetoric of the students. Thanom himself told the American military that their behaviour was prompting Thai hostility to "foreign culture based on materialism."

\footnotetext{
${ }^{\mathrm{II}}$ c.f. Yuangrat, 100.

${ }^{115}$ c.f. Reynolds, 57.

${ }^{116}$ Kirk, 183; Brailey, 254, note 78.
} 
own government, and its complicity in the changes being wrought in Thai society, by focussing on "foreign culture":

Foreign culture based on materialism has flowed swiftly into Thailand, being brought into the country directly by tourists or indirectly by mass media,.... These changes are rapid and have in a short time shockingly damaged the good morale and culture of certain groups of people.... pretty girls turn to the business of being mistresses, bar hostesses, masseuses, or prostitutes, [while their brothers] rob and extort honest persons. ${ }^{[17}$

It is important to note, however, that Thanom made this pronouncement at approximately the same time as the government was forced to admit to the use of Thai airbases in the northeast to bomb North Vietnam, hitherto suspected by some members of the public but not generally well known. Kirk argues that "Thanom may have wanted to counterbalance the adverse propaganda effect of this admission by appearing to agree with sceptics and critics who had already expressed doubts privately about U.S. activities." ${ }^{118}$ Clearly, however, the nationalist rhetoric did not challenge conservative elite's views about the role of women.

The Thai student movement made prostitution an issue of great social and symbolic importance during the 1970s. The prostitute powerfully evoked women's link to national culture and identity and her abuse was synonymous with the abuse of the nation. Rachel Harrison has uncovered the symbolic importance of the prostitute in modern Thai literature as a woman unable to be a mother - demonstrated by complications in pregnancy and

\footnotetext{
${ }^{117}$ c.f. Kirk, 183.

${ }^{\mathrm{1} 8}$ Kirk, 183.
} 
childbirth. ${ }^{119}$ While Harrison links this view of prostitute women to Buddhist beliefs about the dangers of uncontrolled female sexuality and traditional gender structures that define 'good' women in terms of their duty to the family, it is no small coincidence that a number of these stories appeared in the 1960 and 1970 s when concerns about the reproduction of the nation were very high. ${ }^{120}$ The symbolic importance of these stories at the time is in their intimations of a nation unable to reproduce its citizens; of women who fail to be 'good mothers' reproducing the nation, but who are instead 'prostitutes', who cannot be mothers and who, therefore, embody national decline.

As symbols, prostitute women were granted little agency. Their voices were interpreted through social and political commentators. Harrison's analysis of male writers' treatments of prostitution in this period finds an ambivalence in their dealings with the prostitution issue. She notes that even as they detail sensational information about prostitution - which indicates some first hand experience - they pose the prostitute as an object of pity and a symbol of social/cultural decline. The commentary in one short story illustrates this objectification of women in prostitution:

Every time I meet a woman in this situation there are the same old questions and the same old thoughts: here was yet another Thai prostitute, a woman leading a lifeless life, existing only

${ }^{119}$ See Rachel Harrison, "The 'Good' the 'Bad' and the Pregnant: Why the Thai Prostitute as Literary Heroine can't Be seen to Give Birth," Proceedings of the 6th International Conference on Thai Studies, Chiang Mai, Thailand, 14-17 October 1996: $31-44$.

${ }^{120}$ Harrison, 43. 
in order to satisfy the sexual desires of men, without the least understanding of the deadly blows society dealt her. She merely led this terrible, putrid life until the day when she would become little more than a lump of rotting flesh. How many such women have I met since I encountered my first prostitute? I can't even remember who the first one was, nor do I even know whether she is still alive. ${ }^{12 t}$

Prostitute women are seen as pitiable both as victims of society but also because they are "without the least understanding." It is not surprising that these authors should view the prostitute as in need of rescuing and a perfect symbol of the state's failure to govern properly. As one author concludes his story on prostitution: "All I want to know is what the country intends to do about all this." Another poses his narrator as an observer who wishes to "save her rather than sleep with her." 122 The Thai student movement spoke on behalf of the prostitute, using her degradation as a weapon against the "corrupt" government and Western/capitalist intrusion. Prostitute women's own interpretations of their lives - for example, as workers trying to support their families - were rendered mute. Their ability to intervene in political affairs and to put forward their own interests or desires, such as better working conditions, was extinguished.

${ }^{121}$ Ko'n Krailat "Let me alone be the one to have feelings" c.f. Rachel Harrison, "The Writer, the Horshoe Crab, his "Golden Blossom" and her Clients: Tales of Prostitution in Contemporary Thai Short Stories," Southeast Asia Research 3 (Sept. 1995): 143.

122 c.f. Harrison, "The Writer," 139-140. 


\section{University Women's Groups}

Female students were very much involved in the student movement, and they tried to inject the question of women's lower social status into the movement's debates. A small group of women students at Thammasat University formed the organization Klum Ying (Women's Group) in 1973 and began publishing the periodical Lep (Fingernails) with articles on women's liberation in the West, birth control, abortion and sexual freedom (for which both male and female students wrote). ${ }^{123}$ The early student women's organizations of the 1970 s took issue with the portrayal and use of women as sex objects and their patronizing treatment as 'flowers' (i.e. decorative objects) -a metaphor frequently used in describing women. ${ }^{124}$ They linked prostitution to the rise of capitalism and to the male demand for women as sex objects and symbols of male prestige.

The most well known of the women activists was Jiranan Pitpreecha. In 1975 a small group of women at Chulalongkorn University published Jiranan's The Fourth World, a Marxist feminist reading of women's oppression. According to Jiranan, the blend of capitalism and Thai values led to women being reduced to the status of "commercial goods or objects to denote prestige," as in the collection of numerous wives. Jiranan accordingly read prostitution as an outgrowth of the 'decorative' status of women. She argued that

${ }^{123}$ Mattani, 117.

${ }^{124}$ See for example, Jiranan Pitpreecha "The Audacity of Flowers", 1973. A NCWT 1976 report quotes Kanlaya's poem "I am a human being" the first line of which is "I am not a flower," Mattani, 119. 
women were forced to become "minor wives, mistresses and even prostitutes to cater to the male need for prestige." 125 She characterized the beauty contest as a "capitalist device aimed at improving the stock of living merchandise." ${ }^{126}$ Following the writings of Gularp Saipradit, another Thai Marxist of the 1950s who paraphrased Engels' "The Origin of Family, Private Property and State," 127 Jiranan wrote "women are influenced also by the capitalist view of labour. Thais look at people as means of production and see women as a means which produces less profit (than men) without considering them as human." 228 For Jiranan and her colleagues, women were devalued through capitalism as well as the sexual culture of polygamy and concubinage that promoted a view of women as sexual objects.

According to Yuangrat Wedel's analysis, the students' view of the role of women stemmed "from their complete antagonism to the values of the sakdina system which they saw as their political, moral, economic and philosophical enemy." Redressing the situation required a complete revolution in order to end such oppression. ${ }^{129}$ However, Yuangrat argues, the culture against which they rebelled was an urban and elite culture which did not reflect the reality of the countryside where a more egalitarian relationship between the sexes was

${ }^{125}$ c.f. Yuangrat Wedel, Radical Thought: Thai Mind: The Development of Revolutionary Ideas in Thailand (Bangkok: Assumption Business College Administration, 1987) 143.

${ }^{126}$ Yuangrat, 143.

${ }^{127}$ Yuangrat, 71.

${ }^{128}$ c.f. Yuangrat, 142.

${ }^{129}$ Yuangrat, 101-102. 
the norm. Yuangrat points out: "To a certain extent the radical view is an attempt to modernize the rural role of women and adapt it to the city. Women, the radicals wrote, should participate in the economic and political decisions of the society." ${ }^{130}$ It is not at all clear, however, that the students themselves saw it this way. The distinct division between 'good' women and 'bad' women that the students maintained indicates their continued adherence to middle-class values and standards.

Rachel Harrison's research on the prostitute in Thai literature of the 1970s notes the development of a sympathetic attitude towards prostitutes which blames the development of capitalism for prostitution, but she also notes a continuing divide between 'good' and 'bad' women. Harrison argues that while male and female writers tended not to differ greatly in their writing on the topic of prostitution, she does suggest that:

Thai women's fictional writing on prostitution has, on the whole, only served to confirm traditional gender-based beliefs through its compliance with the given hierarchies of male/female roles in Thai society. That it does so with apparent sympathy for the prostitute does not detract from its underlying standpoint that, despite herself or otherwise, the prostitute has transgressed from the realm of the 'good' woman to that of the 'bad'. ${ }^{13 t}$

${ }^{130}$ Yunagrat, 103.

${ }^{131}$ Rachel Harrison, 'The 'Good' the 'Bad' and the Pregnant: Why the Thai Prostitute as Literary Heroine Can't be Seen to Given Birth," Proceedings of the 6th International Conference on Thai Studies: Theme V: Women, Gender Relations and Development in Thai Society (Chiang Mai: 14-17 October, 1996) 39. 
The growing recognition that prostitution may result from economic circumstances, therefore, only led as far as a sympathy for the prostitute for having failed to remain a 'good' woman. It did not challenge the 'good girl/bad girl' divide. Some put further distance between themselves and prostitute women by continuing to argue that there may be some "psychological abnormalities" that led women into becoming prostitutes. ${ }^{132}$ Being 'good girls', like the nationalism of the student movement as a whole, gave the women's groups a legitimacy in the wider society as 'promiscuous' sexual behaviour for women continued to be condemned.

\section{Conclusion}

As we shall see in the following chapters, the 'prostitution problem' is very much viewed today as the product of 'cultural decline' in the face of growing Westernization and globalization. Such a reading of prostitution, however, assumes that cultural identity is indeed embedded in peasant women and poses their 'sexual degradation' as symbolic of cultural and national decline. This assumption erases the struggle over national identity, the resistance of the peasantry to centralized control, and the forcible imposition of that identity by the state in the form of the military's intensive training programs. The 1960s and 1970s, as we have seen, was a period of intense struggle over national identity, particularly between

${ }^{132}$ Harrison, "The writer," 145. 
the rural and urban areas. Peasant women, in particular, were emblazoned on the national imaginary as symbols of national culture.

This reading is itself the product of the politics of the 1960s in 1970s in which prostitution first came to be recognized as a 'problem' in the full political and social sense. The arrival of the American forces in the context of peasant unrest and dislocation had led to a sudden increase in the number of women working as prostitutes and hired wives, particularly in the Northeast of Thailand in the 1960s, and, in the 1970s these numbers expanded still further with the growth in the tourism industry. While women working in the sex industry may have experienced themselves as family wage earners, or as women willing to take risks in order to take advantage of the modern and the foreign, to the growing middleclass student movement they represented the degradation of Thai culture through Americanization. For the students, rural women's bodies marked the borders of the Thai nation. Their sexual use by foreigners indicated an invasion by a foreign 'other', the production of mixed-race children signalled a dilution of the ethno-racial essence of the nation. Prostitute women soon became icons of cultural decline. By posing prostitute women as symbols rather than agents, such an understanding underwrote elite programs to discipline and guide peasant women in the following years. 


\section{Chapter 5: Elite Women and the Reconstruction of Thai Identity}

The period after the crackdown of 1976 was marked by the establishment of a new hegemonic construction of Thai identity. By the early 1980 s the 'communist threat' had been contained by the security forces in Thailand and an eight-year period of 'semi-democracy' under General Prem and his alliance of royalists, military and provincial politicians began. ${ }^{\mathrm{I}}$ Although the fear of communist encroachment remained strong in this period, even the military had come to view outright repression as the wrong approach. The Kriangsak Chomanan government had successfully squeezed out the Communist Party of Thailand (CPT) by renewing formal links between Thailand and China, the CPT's major backer. One of the foremost scholars on the Thai radical movement also argues that the students themselves had come to see the CPT and its pro-Beijing, Maoist stance as counter to their own democratic ideals and were slowly slipping back into the towns and cities and out of the jungle. ${ }^{2}$ Prem and his entourage sought to stabilize Thai society in the wake of the events of the 1970s. Most importantly, the 'Premocracy period' marked a re-configuring of a stabilized national identity grounded in the rural areas.

This period of 'Premocracy' has been characterized by John Girling as a classic example of Gramsci's "transformismo" or passive revolution: "the growth of an ever-more

${ }^{1}$ Pasuk Phongpaichit and Chris Baker, Thailand: Economy and Politics (New York: Oxford University Press, 1995) 346.

2 Yuangrat Wedel, "Current Thai Radical Ideology: The Returnees from the Jungle," Contemporary Southeast Asia. 4.1 (June 1982): 12-14. 
extensive ruling class, through absorption of elements from other social groups within the established framework."3 Peasant revolution was replaced by guided democracy and development. Progressive elites and technocrats found a foothold within the government, advising on development programs and managing economic growth. While the military retained its influence through the Senate and its threats of force, its appeal was declining as business and the middle class grew in importance. Nonetheless, the military continued to provide the 'stable' atmosphere in which business could prosper - infiltrating unions and weakening the working class, pacifying the countryside and policing the security of "Nation, Religion and King."

The active construction of a peasant-based national identity had been a key part of the security forces' agenda beginning in the 1970s. The peasant unrest of the 1970s had made it clear to some organizations within the military and security apparatus that national identity needed to be inculcated within, rather than forced upon, the rural peasantry. This national reconstruction project opened opportunities for elite women to participate in the construction of the 'good peasant woman.' Prostitute women, established as symbolic of the decline of national culture, were central among those who were to be 'retrained' as 'good peasant women.' By participating in this project elite women legitimized their own role in national affairs as 'good Thai women' protecting and promoting 'Thai culture'. In such a role, elite

\footnotetext{
${ }^{3}$ John Girling, "Thailand in Gramscian Perspective," Pacific Affairs 57.3 (Fall 1984): 396-397.
} 
women - who continued to suffer unfair divorce provisions and unequal access to political power - were able to criticize and make demands for changes in male behaviour.

\section{Crackdown and Reconstruction: Re-configuring Thai Identity}

In the early 1970 s, even before the student uprising of 1973 , the Internal Security and Operations Command headed by Saiyud Kerdphun turned to 'a 'political' strategy of killing communism against the patently unsuccessful military strategy of trying to kill communists." The Border Patrol Police formed the Village Scout Movement in the far north-east as a way of instilling loyalty among the villagers and vigilance against communist insurgency. The Village Scouts organization was a major state undertaking at what Katherine Bowie has called "cultural management": "an effort to both mould the consciousness of the more compliant citizens and to intimidate the more intractable elements into inaction, thereby changing the balance of forces in favour of the state."5 The movement attempted to win over the hearts and minds of the peasant populace through an intense indoctrination program of "love of King, country and religion." Its nine-point code included a commitment to preserve Thai customs and rituals, and the use of Thai products. ${ }^{7}$ The movement was

${ }^{4}$ Pasuk and Baker, 312.

${ }^{5}$ Katherine Bowie, Rituals of National Loyalty: An Anthropology of the State and the Village Scout Movement in Thailand (New York: Columbia UP, 1997) 350.

${ }^{6}$ David Morell and Chai-anan Samudavanija, Political Conflict in Thailand: Reform, Reaction, Revolution (Cambridge, Mass: Oelgeschlager, Gunn and Hain, 1981) 242.

${ }^{7}$ Morell and Chai-anan, 243. 
quickly absorbed by the central state apparatus as part of the national security and identity building project. After 1973 the Ministry of the Interior became involved in nationalizing the movement beyond the north-east by giving recruitment quotas to local officials. ${ }^{8}$

A prime function of the Village Scouts movement was the attachment of the peasantry to the monarchy. While the monarchy had been largely sublimated under the Phibun regime, Sarit had drawn on the monarchy as a more 'indigenous' base for legitimacy. In the Thanom-Praphat era, the King and Queen began to make regular appearances around the countryside, supporting 'royal projects' in agriculture (the King) and handicrafts (the Queen). These activities took on increased significance in the post-1976 era as conservative elements in the military and bureaucracy began to advocate an enlarged role for the monarchy in the national culture. ${ }^{9}$ The Public Relations Department and the military owned television stations increased coverage of the royal family. On military television the royal report became a daily segment of the news. ${ }^{10}$ In this coverage, the monarchs were clearly presented as "friends of the peasant." importance through several different military supported movements. ${ }^{2}$

${ }^{8}$ Pasuk and Baker, 309; Morell and Chai-anan 243.

${ }^{9}$ Pasuk and Baker, 315.

${ }^{10}$ This coverage was far-reaching by the end of the $1980 \mathrm{~s}$. Television reached more than $90 \%$ of urban households by the mid-1980s and over $70 \%$ of rural households in the late 1980s, Pasuk and Baker, 315.

" Pasuk and Baker, 316.

${ }^{12}$ Pasuk and Baker, 316-319. 
The Village Scouts were a prime example of the programs being undertaken by elements in the military and bureaucracy to reassert control in this period. Among the chief architects of the counter-insurgency measures were names that were to make their mark on Thai politics for the next twenty years: Prem Tinsulanond - who became Prime Minister in 1980 and oversaw the 'guided democracy' of those years; Saiyud Kerphun who, after the demise of ISOC, became head of Poll Watch, the election 'watchdog' organization; and General Chavalit Yongchaiyudh who was elected Prime Minister in 1996, in what he termed a "graceful rise" to the top after many years as head of the New Aspiration Party and member of several coalition governments. Prem's idea of counter-insurgency was to use Maoist guerilla methods against the insurgents, using not only military might but offers of development assistance and amnesty for complete surrender. Along with the Village Scouts (which had a membership of three million by 1980), the counter-insurgency forces organized the National Defence Volunteers and the Military Reservists for National Security. ${ }^{13}$ These paramilitary groups and officials "made it clear that failure to join the organizations might indicate disloyalty or communist tendencies." ${ }^{4}$ A number of women's groups designed to promote national security, anti-communism and Thai identity were also formed between 1976 and 1985. These were often associations of officials' wives; for example, "The Housewives to Protect Thailand," "Army Housewives," "Air-force Housewives" and

\footnotetext{
${ }^{13}$ Pasuk and Baker, 314-315.

${ }^{14}$ Pasuk and Baker, 314.
} 
"Housewives of the Ministry of the Interior." 15 The paramilitary organizations also offered propaganda through lectures and entertainment programs that "often emphasize the evils of communism, the heroism of Thai ancestors, Thai national identity, and the democratic process which includes how to properly elect parliamentarians."16

A 1977 coup put General Kriangsak Chomanan into power and saw a return to somewhat more open government. The "Thai-ification" programs of the counter-insurgency were successful enough that the government felt comfortable to welcome back its 'delinquent' student population. Those who had been ejected as 'un-Thai' were now to be reabsorbed into the population - their radical ideals dashed in the jungle. In 1979 , the government allowed some student, labour and farmer groups to organize on a very limited basis. ${ }^{17}$ And, in 1980 , Prem and Chavalit designed Order $66 / 2325$, which offered amnesty to the students who had taken refuge in the hills after the 1976 crackdown. ${ }^{18}$ At the same time, the government formed the National Cultural Commission and the National Identity

${ }^{15}$ Darunee Tantiwiramanond and Shashi Ranjan Pandey, By Women, For Women: A Study of Women's Organizations in Thailand (Singapore: ISEAS, 1991) 30.

${ }^{16}$ Pasuk and Baker, 314. These were the key ingredients in the establishment of "Premocracy" (a combination of Prem's name and democracy) in the 1980s. Saiyud's move to Poll Watch (an impressive sounding if highly ineffectual organization, which is best known for failing to prosecute the well-publicized practice of vote-buying) nicely encapsulates this change in tactics.

${ }^{17}$ Charles Keyes, Thailand: Buddhist Kingdom as Modern Nation State (London: Westview Press, 1987) 101.

${ }^{18}$ Pasuk and Baker, 313. 
Board to stitch the national psyche back together by defining and promoting khwampen thai (Thainess).

The Commission's mandate clearly recognized the political importance of having " $a$ culture," stating that culture, "a distinctive characteristic of nationhood," was essential in maintaining the stability and integrity of the nation. ${ }^{19}$ National security was firmly attached to the maintenance of a particular national identity - especially in the rural areas. The national culture championed by the new organizations relied on the three-tiered vision of the nation as promoted by King Vajiravudh - king, bureaucrat and peasant. The National Identity Board stated: "Despite increasing industrialization, some 40 million ... Thais still live in villages where democracy is practised in its purest form." ${ }^{20}$ In 1984 , the National Identity Office boasted:

The village is a peaceful place, its slow pace reflecting the serene, unassuming nature of the villagers themselves... most farmers are content to earn enough to support their families...wealth is not something most villagers actually crave.... The natural affection Thai villagers feel for their land minimizes population migrations. Moreover, villagers have little ambition to change their lifestyles. ${ }^{21}$

${ }^{19}$ Craig Reynolds, "Introduction: National Identity and Its Defenders," National Identity and Its Defenders, ed. Craig J. Reynolds (Chiang Mai: Silkworm Books, 1991) 14.

\footnotetext{
${ }^{20}$ National Identity Office, "Thailand in the 1980s," c.f. Pasuk and Baker, 319.

${ }^{21}$ National Identity Office, c.f. Pasuk and Baker, 319. Emphasis added.
} 
This re-interpretation of village culture and the peasantry reflected not only the peasant identity enforced by the counter-insurgency movements but it echoed the romanticism of the student movement about village culture. This reinterpretation, however, stood in stark contrast to the events of the 1960s and 1970s. This new representation of 'Thainess' held into the 1990s. Craig Reynolds argues that "the current official formulations of what is quintessentially Thai never fail to include the peasant and the village."22

The peasant as the conceptual anchor for Thai identity had particular ramifications for peasant women because of the already established link between women and 'tradition'. Peasant women who engaged in prostitution had failed to live up to the behavioural norms of 'peasant culture' as defined by the government. They were interpreted as having stepped outside the boundaries of acceptable behaviour and in dire need of re-integration.

\section{Elite women and National Identity}

Women were also part of the changing face of the professional elite. Several new professional women's associations were formed in the 1960 s and $1970 \mathrm{~s} .{ }^{23}$ Many of the

${ }^{22}$ Craig J. Reynolds, "Introduction: National Identity and Its Defenders," National Identity and Its Defenders, ed. Craig J. Reynolds (Chiang Mai: Silkworm Books, 1991) 18. The government also produced Thai Life in English "for the consumption of foreign visitors [which] suggests something else about the government's promotion of Thai culture, namely, the connection between Thai culture and tourism. The marketing of Thai culture domestically and to foreign visitors subsidizes or underwrites the cost of efforts to preserve Thai culture seen to be under threat by Western ways," Reynolds, 15.

${ }^{23}$ Darunee and Pandey, 29. The remarkable status of women in the economic and business world in Thailand was the subject of some debate in anthropological circles. The 
reforms sought by these organizations aimed at removing discriminatory laws that blocked women's equal access to careers and legal equality. The Women Lawyers' Association (WLA), began to push for women's equal treatment in the workforce, targeting those laws that limited the professional level a woman could attain in the military and bureaucracy. They also worked to correct employment practices that led to women factory workers being paid thirty percent less than men. Most importantly, however, the WLA sought to change those laws that affected married women's status, particularly the divorce laws which allowed a man to sue for divorce on the grounds of his spouse's adultery but did not allow a wife the same privilege. The law was considered a key pillar in the maintenance of elite male sexual prerogative and the double sexual standard. ${ }^{24}$

In January 1970, the Association presented a five-point recommendation on legal changes in the status of women to the Cabinet. The recommendations addressed the concerns

relatively 'higher status' of women in these fields (as compared to women in East and South Asia) was sometimes attributed to the tenets of Buddhism which restricted men from engaging in commercial activities (money being a worldly matter) but not women who held lower karmic status. Thomas Kirsch, "Text and Context: Buddhist Sex Roles/Culture of Gender Revisited" American Ethnologist 12.2 (1985): 1975 and Penny van Esterik, Women of Southeast Asia (DeKalb, Ill.: Northern Illinois University Center for Southeast Asian Studies, 1982). The relative equality of men and women in Thailand was also the tenor of research by Jane and Lucien Hanks which was published in the 1963 volume of UNESCO on the state of the world's women.

${ }^{24}$ The threat a minor wife poses to a primary wife - in terms of financial as well as emotional support - underlies many Thai wives' toleration of their husbands' visiting prostitutes, who are considered to be much less of a threat. See the study by Mark Van Landingham et. al. Friends, wives and Extramarital Sex in Thailand: A Qualitative Study of Peer and Spousal Influence on Thai Male Extramarital Sexual Behaviour and Attitudes. Bangkok: Institute for Population Studies, Chulalongkorn University, 1995. 
of married middle-class women, including the declaration of marriages registered after the first marriage automatically void; the right of married women to choose their own career without their husband's approval; women's right to control property in their names without their husband's consent; women's right to sue for divorce on the grounds of a husband's aduitery, and the deduction of maintenance after a divorce directly from a husband's wages. ${ }^{25}$ The Cabinet, however, turned down their proposals for legal amendments. ${ }^{26}$

The 1973-1976 period provided renewed opportunity for the WLA's lobbying efforts. The National Assembly appointed in the wake of October 1973 put sixteen women into the 299 member Assembly. ${ }^{27}$ Prime Minister Sanya, an expert on family law, was also known to be sympathetic to the women's lobby. ${ }^{28}$ In 1974 , his government enshrined equal rights for men and women in the new constitution. Sanya announced "under the present social,

${ }^{25}$ Women Lawyers' Association of Thailand, Status of Women in Thailand (Bangkok: Women Lawyers' Association, 1972) 39-45.

${ }^{26}$ Darunee and Pandey, 77.

${ }^{27}$ Of the temporary National Assembly appointed in 1973, 5.2 percent were women (122 out of 2,347). The smaller version of the Assembly put in place later in 1973 included sixteen women out of a total of 299 . In the 1974 elections, three women were elected out of a total of 269 members (1.1 percent). Rangson Prasertsri, Women in the Parliament of Thailand: Their Characteristics and Attitudes, $\mathrm{PhD}$ diss. University of Mississippi, 1982, 8, note 25.

${ }^{28}$ See his 1962 article for a UN Seminar on "The Status of Women in Family Law," which argues that women should have equal rights, but should remain in charge of the family. Sanya Dharmasakti, "The Situation in Thailand", A Working Paper for the UN Seminar on the Status of Women in Family Law. Tokyo, Japan, May 8-21, 1962, reprinted in Bangkok Women Lawyers Association of Thailand, Status of Women in Thailand (Bangkok: Women Lawyers' Association, 1972). 
economic and political conditions, as far as the status of women is concerned, the age of privilege of men is passing and the era of equality is approaching." ${ }^{29}$ Equality provisions, however, continued to meet with only partial success, particularly in marital matters. While the women's lobby forced changes to the divorce law in 1976, the changes only went so far as to allow a women to sue for divorce, if she could prove that her husband and another woman were indeed living together as husband and wife. This clause severely limited the applicability of the new provision since most men remained resident with their wives while establishing separate homes for their mistresses. It also continued to encode male sexual privilege, viewing a man's primary responsibility to his wife as financial rather than a matter of loyalty or sexual responsibility. The continued double standard was also made clear in changes made to the Civil and Commercial Code at the same time, that provided:

that a man who is betrothed to a woman may, after having renounced the betrothal agreement, claim compensation from any man who has had sexual intercourse with the woman and has known or ought to have known of her betrothal. Further, Section f1446 provides that a man who is betrothed to a woman may, without having to renounce the betrothal agreement, claim compensation from any man who has had sexual intercourse or attempted to have sexual intercourse with the woman against her will, if the fact that the woman had been betrothed has been known to him. ${ }^{30}$

${ }^{29}$ Women Lawyers' Association, 31.

${ }^{30}$ Kobkul Rayanakorn, Special Study on Laws Relating to Prostitution and Traffic in Women (Bangkok: Foundation for Women, 1995) 36. 
This provision clearly reinforced male control over women's bodies and the importance of women maintaining their sexual purity. While the new, 1977, constitution did not include gender equality, the government enacted legislative changes, begun in 1976, that included an act granting the right for "a woman to perform a legal act without her husband"s consent if it concerns her own properties." ${ }^{\text {"31 }}$ Women were also included in the fourth national development plan which "gave equal status to men and women in government service and established an affirmative action plan to increase the numbers of women in higher levels of government. ${ }^{32}$ Changes in regulations were made to allow women to assume diplomatic posts to foreign countries, and senior administrative posts in private business and international agencies.

Nonetheless, elite women's position was clearly wedded to their role in the maintenance of culture and 'tradition' as wives and mothers. Sanya, like most elites, saw women's role in the household as chief among her duties and necessary for family contentment. ${ }^{34}$ Prime Minister Kukrit's attitude towards women was also paternalistic. Kukrit

${ }^{31}$ Srisurang Poolthupya, "The Changing Role of Thai Women." Seventh Conference of the International Associaiton of Historians of Asia, Bangkok, August 1977, 15.

${ }^{32}$ Abhinya RathanamongkoImas, Developmental Stances of Thai Women Elites: A Study of Socialization, Social Roles and Social Policy Presciptions, PhD Dissertation. Indiana University, 1983, 3.

${ }^{33}$ Kattiya Karnasuta, "Education and Development Programs for Thai Women," Aspects of Thai Women Today (Bangkok, Thailand National Commission on Women's Affairs, 1980) 43.

${ }^{34}$ Women Lawyers' Association, 32. 
endorsed the 'traditional' beliefs about women's role, writing an article in the largest national newspaper (which he owned) in 1972 approving the Ten Oaths of the Women's Safety Pin Club which include accepting male superiority, being "gentle, sweet and beautiful" and playing the role of loving, supportive and unquestioning wife. ${ }^{35}$

Women's symbolic role in national culture is illuminated in Kukrit's most famous work of fiction. The central character of Kukrit's epic novel "Four Reigns," a historical fiction set in the first half of the century, clearly demonstrates the virtues of a good wife. Ploi's devotion to her husband is unflinching - even offering to allow him mistresses in his old age to "rejuvenate" him. Here, interestingly, Kukrit takes the modern/Western practice of monogamy (the husband politely declines Ploi's offer because of his love for her) and applies its positive connotations to his picture of the past. ${ }^{36}$ In this he reflects the elitist/royalist concern to construct the past as both 'traditional Thai' and equal to 'civilized'/Western culture. Ploi remains devoted to king and religion as well as husband and family and watches with fear, and little understanding, as the 'old world' of the monarchy, religion and stately tradition passes away under a new modernized, and westernized regime marked by war, political struggles and business concerns. Ploi embodies 'Thai culture' and 'Thai womanhood' as defined by the royalist elite. She watches anxiously as her daughter,

${ }^{35}$ Kukrit in Siam Rath, March 20, 1972, c.f. Mattani Rutnin, Modern Thai Literature: The Process of Modernization and the Transformation of Values (Bangkok: Thammasat University Press, 1988) 114.

${ }^{36}$ See Mattani, 90. 
a 'modern woman' of the day, parts with the old ways and marries a businessman of Chinese descent committed only to making money. The marriage, however, ends in divorce. While derided by student activists in the 1970s as a "mouthpiece of the Thai royalist elite" rather than the Thai people, the novel remained extremely popular - being reprinted many times, serialized in newspapers and turned into a television movie and a stage drama in $1973 .{ }^{37}$ Many female elites supported Kukrit's views of proper Thai womanhood, including, for instance, women like Thanphuying Dittakarn Bhakdi who was advising the Department of Social Welfare on issues such as prostitution. Thanphuying Dittakarn - despite being professionally trained -firmly believed that women should be committed first to husband and family and should not work while raising a family. ${ }^{38}$ The largest women's organization, the National Council of Women of Thailand (NCWT), in its social outreach programs, encouraged the adoption of "proper Thai values" by all Thai women. ${ }^{39}$

Thus, while elite women's professional roles expanded, women continued to be discriminated against in these roles - again in ways that denote their 'border-marking' roles. The importance of women's bodies to the Thai nation was reflected in several practices and regulations. Krannich and Krannich note that "legal changes in the status of women have not

${ }^{37}$ Mattani, 82 \& 79.

${ }^{38}$ Interview with Thanphuying Dittakharn Bhakdi, Bangkok, 1 Nov. 1996.

"Thanphuying" denotes a status higher than that of "Khunying."

${ }^{39}$ Darunee and Pandey, 51-52. 
necessarily resulted in corresponding changes in government personnel practices. ${ }^{, 40}$ The Department of Public Welfare, for instance, which housed a large number of female bureaucrats, kept women out of superintendent positions in its project for resettling the landless poor. Male supervisors were concerned that women "must be kept out of settlements because of the physically demanding and dangerous conditions. After all, many settlements are located in remote and politically sensitive areas. ${ }^{, 41}$ Similarly, running for political office remained plagued with difficulty for elite women whose sexual conduct - especially while campaigning in the far reaches of the country - was the object of constant speculation and rumour. ${ }^{42}$

While women's role was still envisioned as wife and mother (which, in Thailand, did not exclude working for the family income), for elite women this role encompassed working for the good of society. In particular, elite women saw themselves as bringing peasant women back into the fold by orienting them to their proper identity and behaviour. Thanin's views on women reflected the concerns of the royalist elite. In a lecture on "Women and

${ }^{40}$ Caryl Rae Krannich and Ronald L. Krannich, "The Emerging Leadership Role of Women in Urban Thailand," International Journal of Women's Studies 3.4 (1980): 358.

${ }^{41}$ Krannich and Krannich, 359.

42 As late as 1996 female politicians complained that one of the major barriers to women's entry into the political arena was the sexual innuendo cast their way while campaigning and in office. See Suwanna Asavaroengchai and Tanida Sirorattanakul, "Deadly Serious Soap Opera," Bangkok Post 27 Nov. 1996: Outlook, 1. Also, Juree Vichit-Vadakan, "Women in Politics in Thailand," Women in Politics: Australia, India, Malaysia, Philippines and Thailand, ed. Latika Padgaankar (Bangkok: UNESCO, 1993) 198. 
National Development" he announced that women should: "1. Be a good wife, bring up good sons and daughters. 2. Work to help the family economically. 3. Help society in national development. ${ }^{443}$ Elite women were willing and able to take advantage of this role for political influence. ${ }^{4}$

Indeed, elite women generally exhibited more conservative attitudes on social issues than their male counterparts and they were at least as conservative on political issues. Elite attitudes about sexual morality were clearly reflected in the 1979 statement by the "Committee for Promoting Moral Values of Thai Ladies" which endorsed the moral advice of the Law of the Three Seals: “A good woman should not let more than one man gain access to her body. ${ }^{, 45}$ Rangson Prasertsri's research on women in the Parliament of $1979-1983$ showed the only significant difference between men and women in Parliament was that women were somewhat more conservative than men on social issues. ${ }^{46}$ Half of the women

${ }^{43}$ Srisurang, 23.

${ }^{44}$ Women, while slowly making legal gains, are still a tiny group in the electoral political scene. That they are not loathe to seek power by other means is indicated by Thanin's complaint about the back-room politicking of political wives as detrimental to national development, Srisurang, 24.

${ }^{45}$ Harrison, "The 'Good',"40. Sukanya Hantrakul, "Prostitution in Thailand," Development and Displacement: Women in Southeast Asia, eds. Glen Chandler, Norma Sullivan and Jan Branson (Clayton, Australia: Centre of Southeast Asian Studies, Monash University, 1988) 117.

${ }^{46}$ Rangson 127. Both Rangson and Abhinya note the high socioeconomic status of the women elites. Rangson found that the women came from a much higher socioeconomic background than the men in Parliament, Rangson, 27. Abhinya notes that most of the Thai women elites were from the "comfortable classes," Abhinya, 64. 
in a survey of women in government and business also pointed to "moral and crime problems" or "incorrect social values because of the importance of improper culture" as the major social problem facing Thailand. ${ }^{47}$ Further, elite women demonstrated a commitment to the maintenance of traditional order and stability. They strongly supported efforts such as the Village Scouts and accepted that military intervention might be needed in order to preserve stability. ${ }^{48}$ As Abhinya argued, however "if women are apparently apolitical, it is because they lack a stake in politics, and if women are conservative, it is because patriarchy has obliged them to acquire a stake in the traditional order." 49 Indeed, it was by drawing on elite women's 'traditional and conservative' role in promoting national culture that elite women were able to carve out a space for themselves in the political sphere. Elite women would be the ones to inculcate correct behaviour in other women. This role gave elite women a legitimacy and influence in political and social affairs.

\section{Prostitution and the Elite}

The growing prostitution problem was also on the agenda of the new elites. The attitude of the conservative elite towards prostitution is illustrated in Kukrit's 1954 short

${ }^{47}$ Abhinya, Appendix II, Table 32.

${ }^{48}$ Abhinya, 43. This same survey of women in government and business classified half of the women surveyed as "conservative" i.e. accepting the need for military intervention to preserve stability. The majority of those conservatives were top government officers, university professors and volunteer social workers (the "khunyings"), Abhinya, 32, 61.

${ }^{49}$ Abhinya, 104. 
story about a prostitute. "Phanni" is a poor, rural, fatherless girl, who becomes a domestic servant, falls in love with and is seduced by the son of the household, thus bringing down on her the wrath of his mother, her employer. In escaping this intolerable situation Phanni is sold into a brothel where she is well treated and gradually comes to enjoy the life of a prostitute and determines to make her fortune by it. Phanni's greed, rather than her sexual activity, is the central theme in the story. As her greed grows, her character becomes less and less appealing. Kukrit paints her as falsely playing innocent to entice more money out of her customers. Her lack of worldly sophistication is played up in the way she mangles both the Thai and English languages in her attempts to appeal to foreigners. Phanni is coarse and unrefined as well as grasping and greedy. Her difference from sophisticated, "modern yet modest" elite Thai women could not be more apparent. In the end, Phanni lies dead on a beach ogled by the youths that find her. Kukrit dismisses his protagonist as unworthy even of escape in death, her body lives on as a sullied object. Kukrit writes: "Even after she had breathed her last, Phanni's body still aroused lust, and was still public property." does the story play on the Buddhist condemnation of lust and greed as the source of unhappiness, but it emphasizes Phanni's reaching beyond her station in life: a country girl who goes to the city to make her fortune is doomed to failure. Country girls, the moral of the story seems to say, should stay where they belong rather than challenging the given order of

${ }^{50}$ Kukrit Pramoj; "Phanni," Many Lives, trans. Meredith Borthwick (Chiang Mai: Silkworm, 1995) 70. 
things, including elite rule. Prostitution, in this fictive world, served as a punishment for those who would try to gain what they did not deserve. It also served as a reminder of the legitimacy of elite rule, of elites' inherent ability to properly control wealth and power.

Elite attitudes, therefore, revealed a certain level of condemnation of, and disgust with, prostitute women. From this view, prostitute women were themselves to blame for their predicament in life; they were deserving of neither pity nor aid. The predominant belief was that prostitute women were in some way mentally defective. ${ }^{51}$ Some elite women, however, were beginning to challenge the way women in prostitution were treated. While many continued to view prostitution itself as 'inevitable' - the product of male sexual needs combined with the availability of morally loose women - they objected to allowing women in prostitution to suffer needlessly. Indeed, incidents of forced prostitution had begun to appear in the press. In 1971, for example, the newspaper Thai Rath, published a letter from a woman working as a prostitute in the Suan Mali Hotel in Bangkok that told of the atrocious working conditions of the 220 (mostly Northern) women working there. ${ }^{52}$ Newly formed elite women's organizations - including the Association for the Promotion of the Status of

${ }^{51}$ Interview with Pasuk Phongpaichit, Bangkok, Nov. 1996.

52 Sukanya Hantrakul, "Prostitution in Thailand," Paper proposed to the Women in Asia Workshop (Monash University, Melbourne, July 22-24, 1983) 9-11. 
Women and the Committee on Women's Welfare Protection - took up the issue of prostitution in the early 1970 s and pressed for legalization measures. ${ }^{53}$

For Thanphuying Dittikharn Bhakdi, who formed the CWWP in 1971 as part of the National Council on Social Welfare, legalization was a necessity in order to control prostitution. Thanphuying Dittikharn felt that the police were ineffectual in controlling the trade, evidenced by the fact that only twenty-five percent of prostitutes were found guilty. In addition, the punishment, according to Thanphuying Dittikharn, was insufficiently harsh to keep women out of the trade. ${ }^{54}$ Thanphuying Dittikharn's training as a medical doctor was also, no doubt, part of her reason for supporting legalization as a way to control venereal disease. ${ }^{55}$ She accepted that prostitution could not be abolished "as long as there were men" but believed it could be controlled. Thanphuying Dittikharn recalls:

I started attacking the problem by considering the fact that we should have just resolved the houses of illfame, we should go and rearrange the situation. That's what we thought. That these houses should be one, registered; two, there should be perhaps a police force that should go in and see whether someone was forced to come in and so forth, and then we should have a social worker, and doctors to go in and take

${ }^{53}$ Darunee and Pandey, 124. A former President of the Association of Women Lawyers and official in the Foreign Ministry, Khunying Kanitha Wichiencharoen established the Association for the Promotion of the Status of Women to address the legal rights of poor working women.

${ }^{54}$ Darunee and Pandey, 124.

${ }^{5 s}$ Darunee and Pandey, 124. 
care [of the women]. If a woman wants to be a prostitute she has to be taken care of. ${ }^{56}$

The overall thrust of legalization measures was to increase the reformative power of the state vis-à-vis prostitutes. Clearly, elite women did not view the state's involvement per se as problematic; rather the state's role should be reformative rather than punitive.

A number of elite women also felt that it was unfair for prostitute women to suffer blame and misfortune when so many profited from the trade. Khunying Chandhanee Santaputr was also involved in proposing changes to prostitution legislation. She remembers that among the "educated classes" the concern was over the profiteering of the brothel owners. Many felt the owners should be taxed to provide funds to take care of prostitute women. ${ }^{57}$ Others, however, were critical of the continued acceptance of prostitution. MP Khunying Jintana Yossoontorn argued that it was the dislocations of modernization that were to blame for prostitution, not the women themselves. She refused to endorse the bill for legalization on the grounds that it would damage the image of Thai women by making prostitution acceptable. Prostitution, she felt, needed to be addressed through the improvement in the standards of living for women. ${ }^{58}$ Some elite women showed further sympathy for poor women in prostitution who would be "branded" for life as prostitutes

${ }^{56}$ Interview with Thanphuying Dittikharn Bhakdi, Bangkok, 1 Nov. 1996.

${ }^{57}$ Interview with Khunying Chandhanee Santaputr, Bangkok, 12 Nov. 1996.

58 Bangkok Post, May 30, 1977, c.f. ISIS International Bulletin 13 (1979) 7; Darunee and Pandey, 125; Interview with Khunying Chandhanee Santaputr, Bangkok 12 Nov. 1996. 
through registration measures. Others, such as Khunying Chandhanee, were more concerned to focus on those who took advantage of the women, arguing that the "brand" would be on the brothel owners not the women. ${ }^{59}$ Among these few women a more sympathetic attitude toward prostitute women was developing, one that recognized the unfairness of 'blaming' prostitute women. Nonetheless, most still felt that the registration of prostitutes would be in prostitute women's own best interest. While a bill for legalizing prostitution did make it through Parliament in 1974, indicating wide acceptance among politicians, it was not promulgated before the dissolution of the House in $1975^{60}$

Indeed, by this time the strength of the student movement's critique of prostitution was apparent. Prostitution was increasingly viewed by students and elites alike as symbolic of the degrading effect of foreign culture on the peasantry. For elite women, the postrevolution reconstruction offered an expanded role and legitimacy in national affairs in counter-acting this foreign influence and 're-integrating' peasant women into 'Thai identity.' In the second half of the 1970 s and into the 1980 s prostitution was addressed through development programs rather than legislation, reflecting the hegemonic reconstruction project of the period. On the advice of women's organizations such as the CPWW, the Community Development Department of the Ministry of the Interior launched a number of women's development programs including a non-formal education project for rural women,

\footnotetext{
${ }^{59}$ Interview with Khunying Chandhanee.

${ }^{60}$ Interview with Khunying Chandhanee.
} 
run by Thanphuying Dittikharn, to deter them from entering prostitution. ${ }^{6 t}$ Such development projects were part of the newly forming hegemonic structure of the post-revolution period to bring the countryside into the national project. The non-formal education program, for instance, was clearly constructed to accord with the Ministry of the Interior's interests in reforming peasant identity as well as reflecting elite women's concern to promote 'tradition'.

Elite interpretations of prostitution increasingly reflected a concern over the 'loss of tradition' presumed to be present in such behaviour. Women in prostitution, according to this interpretation, had failed to have character and moral strength, and to uphold traditional values in the face of foreign influence. This failure could be corrected through elite guidance according to elite women. Peasant women who were tempted to enter the prostitution industry needed to (re)learn traditional skills and become good $^{62}$ workers in industries such as traditional crafts (which were part of an effort to market Thailand externally) domestic service or services such as sewing and hairdressing.

This understanding was expressed by a Professor of History at Thammasat University, Srisurang Poonthupya, who argued in 1977 that the increase in prostitution resulted from foreign influence. Srisurang's representation of the problem powerfully

${ }^{61}$ Darunee and Pandey, 125.

${ }^{62}$ This adoption of the capitalist work ethic is at odds with the importance of 'fun' (sanuk) in attitudes toward work in Thailand. See Penny van Esterik, "Gender and Development in Thailand: Deconstructing Development," Women, Feminism and Development, eds. H. Dagenais and D. Piché (Montreal: McGill - Queen's University Press, 1994) 271-272. 
resonated with the government's linkage of national identity, women and the peasantry. She argued that American influence had created the new phenomena of "partners" (hostesses/prostitutes) and "a-go-go" dancers "who seem quite shameless to ordinary Thai women. They dress themselves in minute bikinis and dance suggestively on stage to make the men feel the need for prostitutes afterwards. ${ }^{, 63}$ According to the professor, Japanese influence had meant "unskilled women who like easy money will go to work in the 'massage parlour'.... "64 And European influence had resulted in "blue movies" and the "exported Thai wife" phenomenon. Clearly drawing the distinction between elite protection of culture and peasant susceptibility to foreign influence, she argued:

the bad [foreign] influence causes a section of Thai women, especially the poor and the ignorant, to sink down to the lowest level. The Thai Government and the more fortunate Thai women realize the seriousness of the situation and are looking for a solution to the problem. ${ }^{65}$

For elite women, the answer lay in teaching lower-class and peasant women the traditional skills they appeared to have abandoned in the search for "easy money." That this was the function of the Queen's endorsement of local handicrafts, as well as the programs offered by elite women's groups, such as the NCWT, was illustrated in the same paper:

Girls from upcountry, who are often enticed by the fun and easy life of the city to become prostitutes, will be encouraged

\footnotetext{
${ }^{63}$ Srisurang, 21.

${ }^{64}$ Srisurang, 21. Emphasis added.

${ }^{65}$ Srisurang, 22.
} 
to learn the traditional skill of their region. For example, they learn how to weave or how to make the lacquerware. The native products are being promoted by Queen Sirikit as well as the Government. The personal care of the Queen who often visits them in their home makes these girls proud of their work and their region. In this way, it is hoped that the bad foreign influence will eventually lose its grip on Thai women. ${ }^{66}$

The "fun and easy life of the city" and "bad foreign influence" were juxtaposed to the "traditional skill of their region" and the "native products" promoted by the Queen. Rural and national identity - evoked in the powerful symbolism of the Queen - were fused in opposition to, and superiority to, the foreign and urban. Such discursive renderings of women clearly indicates their proper place in rural/national identity. Such representations powerfully resonated with the government's reconstructions of peasant/national identity.

The content of the classes offered by the Committee for the Promotion of the Welfare of Women to prevent peasant women from turning to prostitution in the city, clearly reflects the concerns of the elite and the state to pacify the countryside by inculcating what they considered to be 'traditional Thai values'. The courses taught "general knowledge, proper conduct and ability towards honest livelihood," which involved both skills and religious training, ${ }^{67}$ with a basic course in "sewing, handiwork, cooking, nutrition, hygiene, social

${ }^{66}$ Srisurang, 22. Emphasis added. The NCWT was teaching women new skills "cooking, hairdressing, manicurists, dress making, and making artificial flowers." Srisurang, 22.

${ }^{67}$ The training was carried out by Buddhist nuns - a radical move for the time as nuns were little respected. 
manners, moral precepts and citizenship."68 The leadership course for both the nuns and girls who had completed the basic course - who were designated as "village leaders" and who would go on to work as instructors - included not only skills training but "Thai history and culture, comparative religions, the Thai language, and the concept of 'Land of Dharma and Prosperity’,"69

Philip Hirsch explains the Land of Dharma and Prosperity program as:

... based on ideological training sessions that emphasize unity, individual virtue through abstinence from "abayamuk", the Buddhist vices of drink, gambling, and adultery. Model Phaendin Tham Phaendin Thong villages to be emulated are often villages where these vices used to be rampant and associated with violence but conversion of the nakleng (strongman) village head or kamnan to Phaendin Tham Phaendin Thong results in a new era of peace and harmony. ${ }^{70}$

Hirsch argues that the program is part of a totalising discourse of the ideal Thai village designed to render the countryside "administrable" and therefore politically controllable by "imposing ideas about the village, thus serving as an instrument of state power."71 This discourse is found also in military schemes such as the $66 / 2523$ policy "which from 1980 set

${ }^{68}$ Committee for the Promotion of Welfare for Women. National Council on Social Welfare of Thailand (CWPP), Women's Development through Non-formal Education: 1971-1989, reported by Khunying Dithakar Bhakdi (Bangkok: National Council on Social Welfare of Thailand, October 1989) 2.

${ }^{69}$ CPWW, 4.

${ }^{70}$ Philip Hirsch, "What is the Thai Village?" National Identity and Its Defenders, ed. Craig J. Reynolds (Chiang Mai: Silkworm Books, 1991) 330.

${ }^{71}$ Hirsch, 328. 
about the task of 'pacifying' the Thai countryside by political as well as military means, largely through a variety of initiatives that came under the rubric of rural development." ${ }^{72}$ In this discourse:

The Thai village emerges as a particular physical, social, and administrative ideal toward which such programs aspire. The ideal is a subtle blend of, among others, populist and traditionalist ideas, administrative convenience and control, urban and modern values, and democratic forms. ${ }^{73}$

The Land of Dharma program then, serves to impose the centre's concept of rurality on the countryside. They are "an attempt to impose a rural identity that at once incorporates Thainess and positions the village within a larger entity." So positioned, 'the village' and, therefore, the villagers, are more easily controlled by the urban elite. Thus the programs were clearly designed to bring the countryside into Thai national identity. As part of this agenda the CWPP program was clearly designed to bring peasant women under the control of the Thai state, by ensuring their identification with 'Thai-ness' and the protection of Thai culture.

${ }^{72}$ Hirsch, 328.

${ }^{73}$ Hirsch, 330.

${ }^{74}$ Hirsch, 331. These notions of rurality are sometimes part of a globalized discourse on the rural. As Hirsch points out, "Ironically, certain of the markers - such as white fences and wagon wheels - are reminiscent of 4-H clubs in the mid-western United states, quite probably reflecting the North American training of many Thai officials," Hirsch, 331. They probably also reflect the global trade in images through film and television. 
Assessments of the Committee for the Protection of the Welfare of Women program throughout the years (it ran until 1989) often pointed to the importance of this aspect of the program. The Governor of Buriram (in the highly sensitive and poverty-stricken Northeast) reported that in assessing the program in his area: "Of particular importance is their understanding of the need to preserve the Thai tradition and culture, shown by their gracious manner and courtesy, which is highly impressive." And in Loey (in the north), an area "threatened by Communist insurgency": "They also learned about hygiene, family planning and citizenship, to the gratification of government officials and villagers alike."75 The continued usefulness of the courses for capitalist enterprise in the 1990 s is made clear by requests such as one by a glove making factory in Songkhla to provide such training for their employees. $^{76}$

Elite women were able to gain political and social power in re-moulding the character of peasant and lower-class women to properly reflect what was now deemed Thai culture and national identity. As well, these other women needed to be inculcated with the correct attitudes for being a good worker by adopting a work ethic which would lead to national development and prosperity. Through the Village Scouts and other social re-training programs, elite women instructed peasant women in proper cultural values, the lack of which was understood to lead to improper behaviour, especially prostitution. In this way, elite

\footnotetext{
${ }^{75}$ CPWW, 12-13.

${ }^{76}$ Interview with Thanphuying Dittikarn Bhakdi, Bangkok, 1 Nov. 1996.
} 
women were able to resolve the tension between increasing their own social and political power and avoiding social disruption, since their increased role was based precisely on keeping other women in line with 'tradition'. ${ }^{77}$ Elite women were clearly being positioned as the only ones who could inject the inspiration for change.

The defense of the role of elite women, however, occurred not only in a national but an international context. In accordance with international development ideology, peasant women also had to be brought into the modern era. As Abhinya argues, Thai women elites "regard technological underdevelopment in Thailand as arising from the lack of technological know-how and training from poverty and from psychological and personality handicaps such as laziness, uneconomical habits, lack of initiative, selfishness, and lack of moral standards." ${ }^{78}$ Further, Abhinya points out that:

Thai women elites, and perhaps Thai elite groups generally, tend to assume that Thailand lacks both capital and will to originate economic progress, and that it is necessary to inject the inspiration for change and the ability to change from the outside. This assumption implies a need for an attempt to manipulate and change the socio-cultural characteristics of the

77 "A woman has the role of citizen, mother and wife. So she should play the part in bringing up children into good citizens which is the proper duty of a wife. She should help certain groups of women or prostitutes to earn their living. She should help certain groups of people who are low down in society such as prisoners, old people, orphans, physically handicapped people, to be able to earn their living in some professions [sic]," Srisurang, 23.

${ }^{78}$ Abhinya, 39. 
people to fit the claimed norms of Western industrial societies. ${ }^{79}$

Elites like Prime Minister Thanin blamed the "laziness" of the people for their poverty:

Not a small number of Thais are lazy. No one will deny this fact. This is a major cause of poverty in our land. A large number of us work on a day-to-day basis. If they earn more, they stop working; but, more, they also turn to drinking and gambling. When they earn extra income, they think it is time to celebrat $[\mathrm{e}] .^{80}$

Here too elite women were constructed as the only possible source of development and modernity. Professor Srisurang argued that "the majority of women, especially in the lower class or in the rural area are still submissive to their husbands. They still feel it is the right thing and are quite happy in their condition. Only the educated women demand more rights and more active roles." ${ }^{81}$ Thus, peasant women's activism, their participation in rural resistance and their taking it upon themselves to capture the benefits of modernization for their families by migrating to Bangkok for work, was dismissed by elite women as further proof of their 'backwardness'.

The Committee for the Protection of the Welfare of Women, under Thanphuying Dhittikharn Bhakdi reflected the same approach to peasant women. ${ }^{82}$ From its three year

${ }^{79}$ Abhinya, 40.

${ }^{80}$ c.f. Kevin Hewison, Bankers and Bureaucrats: Capital and the Role of the State in Thailand (New Haven: Yale Center for International and Area Studies, 1989) 125.

${ }^{81}$ Srisurang, 24.

${ }^{82}$ Funders for the project included the Asia Foundation 1973 -77, USAID, 1978-1984 and special grants from the Australian and Canadian Embassies. CPWW, preface. 
study of prostitution it had concluded that the lack of education beyond Prathom (Level) 6 left village girls unequipped with either skills or a "sense of direction with which to face the future" - a lack which left them open to becoming victims of circumstance and led into "undesirable" situations, particularly upon migration to the cities. ${ }^{83}$ In assessing the results of the first program in 1972 Thanphuying Dittikharn wrote that:

In a short period of 3 months beautiful but shy Dokkamtai girls were transformed from completely passive and unresponsive persons into alert and attractive individuals, with good deportment and self-confidence. They also learned how to keep their homes neat and clean, how to cook, how to sew for their family needs, and how to dress appropriately for different occasions. ${ }^{84}$

Not only the measure of 'success' and development clearly reflect state and elite concerns to instil 'Thai values' but the instigation of that change comes from elite Thai women who convert the "passive and unresponsive" village girls into "self-confident" women who at the same time have "good deportment", i.e. hold true to "Thai values". Thus, elite Thai women, and through them peasant women, have successfully negotiated the opposition between (Western) modernization/development and Thai tradition. ${ }^{85}$

\footnotetext{
${ }^{83} \mathrm{CPWW}, 1$.

${ }^{84}$ CPWW, 9.
}

${ }^{85}$ Thus, for example, the Committee does not object to women migrating to the cities, only that they should migrate for "honest work", i.e. work that falls within the bounds of 'traditional values' for women such as domestic service. The CPWW report notes that some officials object to girls migrating and therefore refuse to collaborate in program. "Ironically though, there are employment agencies who round up the girls by the truck loads and transport them out of the villages, with vague promises of good jobs and good 
Girls who resisted such instruction were interpreted as lazy. For instance, when village girls resisted the CPWW's program for domestic service training the CPWW reported that "village girls are not interested in the course, considering it degrading to serve in the homes" and "many of the girls do not wish to work. They are accustomed to poverty and inertia. ${ }^{86}$ However, as Mary Beth Mills points out:

[domestic service] carries little aura of modernity (excluding new domestic technology) which is one reason why village women seek urban employment in the first place. In addition, servants' wages are generally lower than those for all other types of urban employment available to migrant women, even when free room and board are counted. A 1980 survey of Northeastern women working in Bangkok found a mean monthly income for domestic servants, including payment in kind, of 800 baht or US $\$ 32$ (Pawadee 1982: 103). This compares to 1200 baht (US\$48) per month for factory production workers (ibid). ${ }^{87}$

Women who needed to support their families and who were seeking some of the promise of the modern era for themselves would understandably find domestic service "degrading". 88

pay." CPWW, 27-28.

${ }^{86} \mathrm{CPWW}, 27-28$. A 1978 survey showed that less than $4 \%$ of the rural women questioned wanted to work as house-maids. As the study points out "Among this 4\%, most are from the Northeast, the poorest region." Dept. of Community Development, Ministry of Interior, Report of the Survey on Problems and Needs of Rural Women, conducted May 1978, c.f. Kanitta Meesook, "The Economic Role of Thai Women," Aspects of Thai Women Today (Bangkok: Thailand National Commission on Women's Affairs, 1980) 25.

${ }^{87}$ Mary Beth Mills, "Rural Women Working in Bangkok: The Rocky Road of Social Change," final Report to the National Research Council of Thailand, n.d., 8.

${ }^{88}$ Indeed, servants in elite homes are expected to show respect to their employers by, for instance, maintaining a lower body position than their employers, kneeling to serve 
That they did resist domestic service demonstrates their refusal of the strengthening grip of the elite on the peasantry.

\section{The Progressive Elite and Premocracy}

The period of Premocracy offered a new opportunity for elite women who sought to redress gender relations to influence policy, particularly through the drive for "socially relevant" development both by the government and the international community. While more progressive elite women sought increasingly radical changes in gender relations - by, for instance, openly criticizing male sexual behaviour - they sought their legitimacy in appeals to the maintenance of tradition and culture.

The declaration of 1975 as International Women's Year by the UN had led the government to seek out capable women to undertake its management. It had turned to Khunying Ambhorn Meesook, then Director General of the Department of Education. Khunying Ambhorn was a representative of the socially-concerned intellectual elite of the 1970s. She was a major supporter of the New Force Party - the socialist/intellectual party formed primarily by university professors and supported by such notables as Puey Ungphakorn. ${ }^{89}$ As a member of this newly progressive elite, Khunying Ambhorn was

seated members of the family etc.

${ }^{89}$ Mattani, 61; Chai-anan and Morell, 111. Khunying Ambhorn served in the National Assembly under Sanya. She held a PhD in Comparative Education from Harvard, had served in the Free Thai movement during the war, had been awarded the title of Khunying in 1961, and had risen to the post of Director General in the Department of Education by 
sympathetic to student demands in the 1970s and sought to revise the educational curriculum to reflect a greater cross-section of Thai society according to the students' critiques of the elitist nature of Thai teaching of literature. At the same time, reflecting the attitudes of the new development elite, Khunying Ambhorn opposed the "top-down" development approach so prevalent in conservative government and elite circles, including the approach of some women elites. As she notes:

...we were holding a lot of seminars and workshops, promotion of awareness, both in Bangkok and upcountry. And I said we must start working with the grassroots women. And I had to fight with my friends, Khunying Dittikharn for one, you see we were in America together, as students, both married in US, it just like a family. And I got her started on this women's thing you know. She is quite conservative and she was fighting with me all along, she said you can't do it, they grassroots women they can't do anything. I said why do you work with them if they can't do anything. She said, I want to help them. I said you can't help them by giving them things. Nothing wrong with it, but that's not enough. It went on and on, even after Copenhagen. I invited her to come with me when I was holding workshops upcountry. She said, 'what's it all about?' I said, 'we must encourage them to think for themselves and to think for themselves what they wanted out of life.' ... I wanted to point out to her that her method wouldn't work, although she claimed that it would. Now I'm changing my mind, because it did work. ${ }^{90}$

1974. She also had a long association with UNESCO, serving on the Thailand Commission for UNESCO since the late 1960s. Interview with Khunying Ambhorn Meesook, 11 Nov. 1996.

${ }^{90}$ Interview with Khunying Ambhorn Meesook, Bangkok, 11 Nov. 1996. 
Although she did not consider herself a feminist she was a seasoned bureaucrat and activist on education issues and resented the paternalising attitude of men in government dealing with the issue of women. At the Mexico conference she could see that the attitude around the world was not much different, she was one of a very few professionals at the conference. She recalls:

We were there and I was very much amused, I was director general of education but the rest of them were Imelda Marcos with her huge entourage and today they wear blue, the following day pink, a lot of jewels - so we said we play it their way around, we are professionals. From developing countries they sent wives, first ladies, whatever, and also from the West. ... in 1975 the whole world's attitude toward the plight of the women was this way, it was a put up job, to please the little women. I resented it. I was not a feminist but when I was faced with this I said this won't do. And mind you, [it] is still going on in many countries, including this country.

While progressive elite women sought to bring down the legal barriers that still faced women in 1970s Thailand, they understood that the radical protest approach of Western feminists would not work in Thailand. As Ambhorn remembers:

It was there I met these women from Australia and the US and they were very frightening, Germaine Greer and Betty Friedan, they were absolutely frightening, too aggressive, you see we learn something. After the conference when we came to the follow-up activities, you see these ladies they won't go anywhere, they can do it in their countries but it won't work in our countries. And that has been the philosophy here in

${ }^{91}$ Interview with Khunying Ambhorn Meesook, Bangkok, 11 Nov. 1996. 
dealing with men, we have to have a velvet glove. Oh they were shouting and banging. ${ }^{22}$

Instead, in the Thai context, careful negotiation was required. As Ambhorn points out:

If you want to know about Thailand - and I consider myself a professional - I mean that women's affairs can be very delicate, because Thai men can be very clever, they don't antagonize us they flatter us, which is more dangerous than being aggressive. Which is what I've told them. During that time they have laughed in my face: 'Oh ajaan, we think we have given everything to our women folk and all this and all that, why should women want to be free of all this?' I said, 'it is because we ourselves are not perfect, we have to improve ourselves and we want to help the men to free from prejudices and narrow-mindedness.' They said, 'oh don't talk to her, she gives it back to us. ${ }^{93}$

Khunying Ambhorn's approach was echoed in the introduction of the report to the Copenhagen meeting, which, while emphasizing the need for change in attitudes towards the roles of the sexes, pointed out that "in the past, Thai women have been admired for their subtlety. Thai women of the present day can learn something from this tactic so that equality and participation can be achieved harmoniously and happily." ${ }^{\text {94 }}$ The necessity of this tactic became clearer over the 1980s as non-governmental women's groups considered too critical of male behaviour were often labelled as 'westernized' and therefore without political

${ }^{92}$ Interview with Khunying Ambhorn Meesook, Bangkok, 11 Nov. 1996.

${ }^{93}$ Interview with Khunying Ambhorn Meesook, Bangkok, 11 Nov. 1996.

${ }^{94}$ Vipa Chulachart, "Introduction," in Thailand National Commission on Women's Affairs, Aspects of Thai Women Today (Bangkok, Thailand National Commission on Women's Affairs, 1980) 5. 
legitimacy. Given the events of the mid-1970s, those advocating women's rights were concerned to present themselves as non-threatening to the established order. Khunying Ambhorn, for example, understood the dominant political discourse and knew she would have to deal with the fundamental conservatism of the Thai government and its continued fight to contain communism at the turn of the decade. As she describes:

I remember [that] to start one of the series I had seven ministries working together - interior, agriculture, industry, etc. They didn't think about it but they had been working with women alot. And even the ministry of justice. Not to mention the PM. They say they can't work together - they're so individualistic. I said well lets try, using women's issues, because then people thought it was not dangerous, non partisan, non political. So it worked to our advantage. We asked for money - 'okay, okay.' Whereas they were worried about communist encroachment, not realizing it was really women who had a lot of influence in the family, whether or not their men become communists depending alot on the women. But we who were working on this, we kept it very quiet. That's our technique, and you can put it in your thesis for the others to learn, because we have done rather well, not antagonizing the men but including them. But some of them are very clever, they caught on. Thanat Khoman, who was the minister of foreign affairs, said in a meeting that 'Khunying Ambhorn is a very dangerous lady. ${ }^{9}$,

Foreign Minister Thanat's comment reflected the precarious position of those trying to get women's issues on the development agenda. The potential subversiveness of gender issues is clearly underlined. Elite women had to carefully balance their roles as wives, mothers and defenders of culture with their desire to change women's status. Appealing to 'traditional'

\footnotetext{
${ }^{95}$ Interview with Khunying Ambhorn Meesook, Bangkok, 11 Nov. 1996.
} 
culture - acting in a way considered 'Thai' as opposed to a 'Western,' and treating men with kid gloves - allowed elite women access to power.

Elite women were also able to gain a foothold in the corridors of power by the changing imperatives of the state for more 'socially conscious' development without destroying 'traditional Thai culture' as defined by the state. Delegated all the responsibility for the issues arising from the conference, Khunying Ambhorn decided a coordinating body on women's issues was needed, as per the recommendations of the Conference. This was the beginning of efforts to establish what is today the National Commission on Women's Affairs at the Prime Minister's Office. While the Prime Minister's Office ignored Khunying Ambhorn's request for such an agency, she went to the National Economic and Social Development Board, the advisory body on development issues responsible for the Five-year National Development Plans, for help. ${ }^{96}$

A group within the NESDB was sympathetic to the need for socially relevant development, advocating the 'basic needs' approach of the ILO. This same group was able to obtain greater emphasis on rural poverty in the Fifth Development Plan (1982-1986) ${ }^{97}$ and had supported NGO initiatives, setting up a joint committee to promote cooperation between NGOs and government in 1981 . Some within the NGO movement were critical of the new committee which was seen as harnessing NGOs as a resource for the preparation of the

\footnotetext{
${ }^{96}$ Ambhorn was temporarily removed from her post after the 1976 crackdown, Mattani, 61.

${ }^{97}$ Pasuk and Baker, 386.
} 
development plan, but it was afterwards inactive. ${ }^{98}$ The Board appointed Khunying Ambhorn chair of the newly formed "National Commission on Women's Affairs" (NCWA) that included Princess Prem Purachatra, Khunying Dithakarn Bhakdi (NCSWT), Khunying Chandhanee Santabutr (NCWT)). With funding from the US, she put together a task force to write a twenty year women's development plan to integrate into the government's five year plan and to present at the mid-decade conference in Copenhagen ${ }^{99}$ On to her team she drew, among others, Dr. Saisuree Chutikul from the Education Board (later to become chair of the re-established NCWA), M.R. Dr. Chalermsuk Boonthai from the Department of Health (later Secretary of the National Commission of Women of Thailand), as well as a number of academics including Pasuk Pongpaichit (Economics) and Naphat Sirisamphan (now head of Women's Studies) from Chulalongkom University and Malee Pruekpongsawalee from Thammasat University (now head of Women's Studies). The committee's report moved far away from standard celebratory publications of famous women in Thai history, or elite women's contributions, and it made some remarkable demands, such as for men's increased responsibility for birth control and housework. ${ }^{100}$ The results of the preliminary study and seminar in 1978 were included in the report of the NCWA to the 1980

${ }^{98}$ Ernst Gohlert, Power and Culture: The Struggle against Poverty in Thailand (Bangkok: White Lotus, 1991) 35.

${ }^{99}$ Interview with Khunying Ambhorn.

${ }^{100}$ See, for example, the NCWT publication 1975 "Honour and Work of Women" Darunee and Pandey, 21. 
Copenhagen meeting and then further developed into a twenty-year women's development plan.

Elite women clearly understood the need for modernization as perceived by the government, and they could make use of their position as conduits between tradition and modernity. Elite women would lead the way for other Thai women to become 'developed' and 'modernized' without jeopardizing Thai culture. Both the preliminary and the long-term reports clearly reflect a liberal approach towards women in development - the need to bring women in to the development process (envisioned as intensified production and generation of national wealth), which is associated with better living standards (health, education, income) and reduced social conflict (including reduced urban migration). Echoing elite beliefs about the abilities of the common people, the committee argued that women's efficiency needed to be increased, women needed to be taught initiative (presumably by the elites) and to overcome their 'traditional roles' in order to fully contribute to greater production and national development.

At the same-time, however, the reports emphasized the importance of the maintenance of traditional moral and cultural values, in fact, by using the instruments of women and development, particularly education, to ensure that women expand their role in cultural promotion. The initial report remarked that "existing society tends to prefer material values and is more interested in art works that violate moral and ethic[al] codes" and that the media, arts community and parents have not sufficiently cultivated "cultural, ethical and moral codes." The report, therefore, recommended that women "combine their efforts to fight 
against emerging allurements and values that are detrimental to moral and ethic[al] codes"; that the government define guidelines for the promotion of the nation's cultural heritage, including the conservation of traditional "arts, handicrafts and folkways" and that "women groups and the government should carry out campaigns for the application of the principles of Buddhism's precepts in daily life." 101 The report also emphasized the importance of this task of the preservation of national identity, especially among those who "live in remote areas who are under influence of other cultures" - a clear reference to the need for women's cultural vigilance in the face of communist incursion. ${ }^{102}$ Elite women, therefore, walked a careful line between tradition and modernity, maintaining national identity while modernizing society.

Prostitution was featured as an example of women's need for development and guidance. The report presented prostitute women as misled: "Many rural women are being led or persuaded to become prostitutes. This causes a prevalence of venereal diseases."103 Prostitution, the preliminary report stated, needed to be resolved by addressing both socioeconomic problems and attitudes, for instance, through education which "should inculcate

${ }^{101}$ Thailand National Commission on Women's Affairs (NCWA), "Status of Thai Women," Aspects of Thai Women Today, presented as a background document to World Conference of The United Nations Decade for Women, Copenhagen, 14-30 July 1980 by the Delegation of Thailand (Bangkok, Thailand National Commission on Women's Affairs, 1980) 66-67.

\footnotetext{
102 Thailand National Commission on Women's Affairs, 64, 67.

${ }^{103}$ Thailand National Commission on Women's Affairs, 70.
} 
more appropriate social values, and should be designed to enhance more employment opportunities." 104 The report also stated that prostitution should be addressed through legal measures to suppress "the crime of forcing women to enter prostitution and being ill-treated," to control venereal disease, and to promote the development of occupations that yield higher income. ${ }^{105}$ The government "should devise appropriate measures and seriously enforce these measures to control various entertainment services...."106 The long-term development plan, however, went further; demanding that not only should there be heavier punishment for owners and procurers but "criminal liability for prostitutes must be abolished and replaced by occupational training and health care." ${ }^{107}$ Elite women, plagued by unfair divorce laws and limited in their professional and personal lives by gender constraints, resented the unfairness of laws that punished women for sexual misconduct but failed to punish men.

The call for cultural vigilance also allowed for a critique of male behaviour. The initial report argued "necessary measures should be developed to improve social surroundings such as controls on the use of women pictures in advertisement to depict sex

104 Thailand National Commission on Women's Affairs, 71.

105 Thailand National Commission on Women's Affairs, 71, 59.

106 Thailand National Commission on Women's Affairs, 71.

${ }^{107}$ Royal Thai Government, Thailand National Commission on Women's Affairs, Summary of Long Term Women's Development Plan (1982-2001) , prepared by the Task Force on Long term Women's Development Plan, with the Cooperation of USAID Thailand and the Department of Technical and Economic Cooperation, 1981, 25-26. 
appeals [sic], as well as other sex based entertainments, etc." ${ }^{108}$ It also questioned the promotion of tourism "that draws tourists with carnal pleasures as attractions." 109 The final report went so far as to demand that the government curb "the entertainment activities offered by officials who welcome visiting government officials or guests by providing sexual services of local girls." ${ }^{10}$ Further, "traditional attitudes" that allow sexual licence to men and attribute inferiority to women

... have had the effect of inhibiting women's enthusiasm to
develop themselves. When faced with family problems or
economic pressure, therefore, some women are led to sell
themselves into prostitution. Factors contributing to such a
plight are: lack of discipline, declining morals, sensual
temptations, and examples of excesses which are far more
abundant than reminders of moral conduct and human dignity
in our modern society, apart from this, the attitude that
prostitution is an 'evil necessity' has also contributed to the
continuing expansion of this profession."II

Elite women were thus able to critique male sexual privilege as a barrier to 'development'. At the same time 'traditional' women who were thrown unprepared into the modern world were doomed to end up in undesirable situations, such as prostitution. Development particularly education - as overseen by elites, was the conduit between the traditional and the best of the modern.

\footnotetext{
${ }^{108}$ Thailand National Commission on Women's Affairs, 71.

${ }^{109}$ Thailand National Commission on Women's Affairs, 62.

${ }^{110}$ Royal Thai Government, 27.

${ }^{111}$ Royal Thai Government, 24.
} 


\section{Conclusion}

Over the course of the 1970s and early 1980s elite women took on new importance in their roles as protectors and promoters of 'traditional Thai culture'. The hegemonic project of reconstructing Thai identity in the countryside opened new paths to social power for elite women. Prostitution, which in the democracy revolution had come to be seen as symbolic of the decline of or lack of national culture among peasant women, was now to be addressed through the inculcation of 'proper Thai values' in peasant women by the elite. Such a role for elite women was strongly legitimated by the post-revolutionary government's national project of identity reconstruction. By linking into this project, elite women gained new prominence and power. This same project was present in the language of 'development' that was taken up by progressive elites. By appealing to the reconstruction project, women elites gained enough legitimacy to be able to make public criticism of the male sexual prerogative, a prerogative that was institutionalized in the divorce law so resented by elite women. Prostitute women, however, became objects of governmental reform. Interpreted as unable or unwilling to help themselves, as incapable of coping with the changes wrought by rapid modernization, they were interpolated into development programs and plans as in need of elite guidance and intervention rather than as social agents who deserved a voice in determining their own future. 
Chapter 6: The New Non-governmental Movement and the Prostitution Question. Prostitution Law under Premocracy

In the 1980 s, Thailand underwent rapid economic growth and social change. The Prem government carefully managed this expansion by allowing the expression of social interests but controlling their potentially disruptive influence. Labour was repressed, while labour organizations were infiltrated to prevent union unrest. Non-governmental organizations were allowed to form but strictly monitored by the military and security apparatus. Premocracy, the period of 'guided democracy' under Prem, worked to absorb and neutralize potentially radical elements, providing a stable atmosphere for rapid economic growth despite severe repression.

The prostitution-linked tourism industry was a central contributor to this rapid growth. While prostitute women made demands for better working conditions and pay, their campaigns failed to find much support among the weakened labour unions or the newly formed non-governmental community. For the women's groups that came together in the aftermath of the 1976 crackdown, it seemed most important to draw attention to the exploitation of women through prostitution, rather than to prostitute women's labour rights, as the government and the tourism industry used women's bodies to attract greater profit. Prostitute women were often painted as innocent victims of greater forces. In the larger community, this was often translated as victims of evil foreigners. Such portrayals strengthened rather than challenged the elite image of prostitute women as rural girls who required re-enculturation by elite women. It also resulted in government responses that 
increased controls over prostitute and lower-class or rural women, rather than empowering them.

Premocracy, politics and growth

The period of government under Prem Tinsulanonda (1980 - 1988) marked the consolidation of a national hegemony based on a particular understanding of national identity and interest. The Prem government balanced the forces of military and business under the rubric of 'guided democracy' - democracy that served the 'national interest' of stability, security and growth. While non-governmental organizations were allowed to form, they were closely monitored to ensure they did not damage this national interest. Indeed, the military itself usurped many of the potentially radical critiques of the left-wing and emerging social movements by claiming its role was the protection of 'national interest' against the 'foreign interests' served by urban capital. ${ }^{1}$

While the claim of 'national interest' was used to keep the military's hold over politics and the business community, it was also used to ensure that labour and social organizations did not disrupt the return to a 'good investment climate.' Prem, himself, sought to balance business and military forces, supporting the technocrats within the bureaucracy such as the National Economic and Social Development Board (NESDB) - to carefully

${ }^{1}$ Hong Lysa, "Warasan Setthasat Kanmu'ang: Critical Scholarship in Post-1976 Thailand," Thai Constructions of Knowledge, eds. Manas Chitakasem and Andrew Turton (London: School of Oriental and African Studies, University of London, 1991) 107. 
manage the country's return to prosperity. At the same time, he allowed the military to maintain careful control over democratic groups to ensure continued stability and, therefore, a good investment climate. The strikes and demonstrations against foreign economic control in the 1970s had taken their toll on foreign investment. Investment confidence returned only with the October 1976 coup and, even then, the excessiveness of the Thanin regime kept much foreign investment at bay for fear of internal unrest. The new hegemony under General Kriangsak and then Prem restored investor confidence once again. ${ }^{2}$ Indeed, the Thai economy became increasingly open in the post-1976 period. The fourth development plan (19771981), balanced the concerns of business and the military and "urged foreign investment, but economic growth was to be tempered with 'social justice', and there was an emphasis on decentralisation, employment, and income distribution."3 Nonetheless, the policies were "designed not to channel too much social investment into the countryside, not doing anything which would raise the expectations or the bargaining power of the farmers, not allowing the rural interests to develop any real political torque."4 The plan marked the ascendancy of an export-oriented industrialization strategy as advocated by the World Bank and the

${ }^{2}$ Kevin Hewison, Bankers and Bureaucrats: Capital and the Role of the State in Thailand (New Haven: Yale University Southeast Asia Studies, 1989) 110.

${ }^{3}$ Hewison, 110.

${ }^{4}$ Pasuk Phongpaichit, "From Peasant Girls to Bangkok Masseuses," Ecumenical Coalition on Third World Tourism (ECTWT), Tourism, Prostitution, Development (Bangkok: ECTWT, 1983) 76. 
International Monetary Fund. ${ }^{5}$ The economy grew quickly, reaching levels of seven to eight percent growth per year almost steadily from the late 1970s, hitting double digits in the late 1980s and continuing to grow until the fiscal crisis of 1997 . The economic policy of the 1980s was summed up in Deputy Prime Minister Boonchu's open-door policy known as "Thailand Incorporated" wherein "Thais would retain control of economic policy-making, but that there would be fewer restrictions on the movements of capital, both domestic and foreign." 6

This spectacular rate in growth was in large part achieved through cheap labour. Labour was repressed by the government in order to provide a profitable investment climate for business. The strikes of the mid-1970s were often forcibly put down. The attack on striking Dusit Thani hotel workers in 1975 by right-wing thugs and the smashing of women textile workers' picket lines in 1974 presaged the violent crackdown on students in $1976{ }^{7}$ Benedict Anderson argues that perhaps the most important factor in encouraging the 1976 crackdown was the way the Thai press presented the strikes of the mid-1970s as "antinational' in the sense that they scared away the foreign investors on whom the 'national economy' so depended. ${ }^{8}$ In the 1980 s, the military completely co-opted the labour

${ }^{5}$ Hewison, 120.

${ }^{6}$ Hewison, 110-111.

${ }^{7}$ Hewison, 124.

${ }^{8}$ Benedict Anderson, "Withdrawal Symptoms," Bulletin of Concerned Asian Scholars 9.3 (July-Sept. 1977) 18. 
movement. The Labour Council of Thailand was headed by two men closely linked with ISOC who used the organization to support military bids for power. ${ }^{9}$ In 1980 the Bangkok Post could boast:

While the minimum daily rate in Bangkok is proposed to be 54 baht (US \$2.20) in the North and North-east... Thai workers have been found by many companies to be willing, dextrous, remarkably quick learners and conscientious, dependable workers... Another point about Thai labour is that it is not militant. There have been many strikes, of course, but in general most disputes are settled amicably and indeed, this year, some of the country's labour leaders have said publicly that they will accept whatever wage increases the Government deems suitable. The reason for this stand is that labour leaders understand the present situation in the country and have decided that unity is more important than large wage increases. ${ }^{10}$

Under the Prem government, the labour leadership had been coopted into working for 'unity' and the national interest over and above workers' rights.

The social cost of such co-optation was high. As Hewison expresses it, despite changes in the early 1980 s to develop a more regularised relationship between capital and labour:

The state does not encourage unionism, and the majority of workers remain outside the union movement, exploited and

${ }^{9}$ Pasuk Phongpaichit and Chris Baker, Thailand: Economy and Politics (New York: Oxford University Press, 1995) 202.

10 "The labour situation," Bangkok Post, Supplement, 21, reprinted in Ecumenical Coalition On Third-World Tourism (ECTWT) Tourism, Prostitution, Development: Documentation (Bangkok, Ecumenical Coalition on Third World Tourism, n.d) 77. 
oppressed. Those unions which do exist are routinely infiltrated by the military. Child and 'slave' labour, unsafe and unhealthy conditions in sweatshops, and subsistence wages remain facts of life for many of the working class. ${ }^{\text {II }}$

The NESDB reported in 1985 that 350,000 children from eleven to fifteen years of age (among whom the girls outnumbered the boys) were working in factories and households, fifteen percent of them in Bangkok. They were working more than eight hours a day and for very little pay. ${ }^{12}$ In 1985 , Thailand's well-known human rights advocate, lawyer Thongbai Thongpao reported to the Regional Council on Human Rights in Asia that the minimum wage was insufficient for daily expenses, given the rising prices brought on by inflationary pressures. To make matters worse: "over sixty percent of workers still were not paid according to the minimum wage."13 Young women were particularly affected by the labour conditions. Export manufacture had become the biggest industry, staffed mainly by young female labour, where working conditions were notoriously poor. ${ }^{I 4}$

${ }^{11}$ Hewison, 125.

${ }^{12}$ Water F. Meyer, Beyond the Mask: Toward a Transdisciplinary Approach of Selected Social Problems Relation to the Evolution and Context of International Tourism in Thailand, $\mathrm{PhD}$ dissertation, University of Geneva, 1987, 306.

${ }^{13}$ Thongbai Thongpao, "The State of Human Rights in Thailand in 1985," Thai Development Newsletter, 3.4 (1986): 13.

${ }^{14}$ Pasuk and Baker, 198-199. 
Young women were also finding work in the burgeoning service and tourism industry. Some government officials explicitly stated that the 'entertainment' industry was a key part of Thailand's economic recovery:

Within the next two years, we have need of money. Therefore I ask all governors to consider the natural scenery in your provinces, together with some forms of entertainment that some of you might consider disgusting and shameful because they are forms of sexual entertainment that attract tourists. Such forms of entertainment should not be prohibited if only because you are morally fastidious. Yet explicit obscenities that may lead to damaging moral consequence should be avoided within a reasonable limit. We must do this because we have to consider jobs that will be created for the people. ${ }^{15}$

Women were to serve the 'national interest' in economic growth with their bodies. This, however, brought them no status as workers with rights. It emphasized, rather, the sacrifice of any social concerns in the service of economic growth.

\section{The Prostitution-tourism Industry}

The tourism industry had become a cornerstone of Thailand's economy. Building on the $R \& R$ industry of the 1960 s and 1970 s and on recommendations from the World Bank, the government supported increased investment in tourism infrastructure, through the

${ }^{15}$ c.f. Siriporn Skrobanek, The Transnational Sex-Exploitation of Thai Women, Master's research paper, Institute of Social Studies, 1983, 39. 
establishment of the Tourism Authority of Thailand headed by an army officer. ${ }^{16}$ The profits from tourism leapt from 200 million baht in 1960 to over 37 billion baht in $1986 .{ }^{17}$ The government aggressively marketed tourism, declaring official tourism years in 1980 and 1987. Tourism became the "single most important export policy success of the 1980-88 period, especially the 1987 Visit Thailand Year. By 1988 tourism accounted for approximately fifteen percent of income from the export of goods and services." ${ }^{18}$ Truong argues that the favourable position granted to large scale enterprises in the hotel industry through investment policy meant small scale operators had to find new ways to compete that included partnerships with tour operators. In doing so, "a dearth of regulations have allowed tour operators to include more and more services of a personal nature, in particular sexual

${ }^{16}$ The military's connection to the tourism industry began, of course, with the R\&R deal in 1966. Truong points out that the negotiations for the treaty were conducted by a Thai Air Force general whose wife was co-director of the first tour agency - Tommy Tours. As she points out "It is important to bear in mind that .. army officers played leading roles in the formulation of tourism policies." As well, the military is most noted for its prevailing gender ideology which "views the accumulation of women and wives as a source of military prowess" .... so its involvement in the formulation and execution of tourism policies must have provided some continuity to discursive and social practices which consider female sexuality as a source of male pleasure and wealth. The sanction of prostitution in the entertainment sector defined as the 'special services sector' or the 'personal services sector' is a logical outcome of such practices," Thahn-dam Truong, Sex, Money and Morality: Prostitution and Tourism in Southeast Asia (London: Zed, 1990) 160-161.

${ }^{17}$ Truong, 163.

${ }^{18}$ Chris Dixon, "Thailand's Rapid Economic Growth: Causes, Sustainability and Lessons," Uneven Development in Thailand, ed. Michael J.G. Parnwell (Brookfield: Avebury, 1996) 42. 
services, to give their packages particular appeal."19 Thus, advertisements for tours to Thailand often featured the availability of Thai women.

Global tour operators peppered their literature with references to the 'exotic' women of Thailand. Sex-tour operators and marriage agencies were explicit in describing the sexual fantasies available with "passive", "adoring" and "willing" "sex-slaves" in Thailand who could be had for a full night at very low costs. Unlike the "overbearing" and "demanding" women of Europe and North America, Thai women were, according to these advertisements, happy to serve. White men could live like kings in this exotic kingdom. ${ }^{20}$

Such enticements were also often included in business magazines and advertisements by official Thai organizations. Thai International Airline, for one, was known to use women's 'sexual allure' in its advertising. One advertisement stated: "Smooth as silk is a beautifully prepared meal served by a delicious hostess."21 While a 1974 police survey had placed the number of women working in prostitution at approximately 400,000 , by 1980 that number had reached somewhere between 500,000 and 700,000. In 1978 officials estimated that at least 248 hotels in Bangkok "hosted prostitution as a means to increase gross

${ }^{19}$ Truong, 170.

${ }^{20}$ See the advertising collected in ECTWT.

${ }^{21}$ c.f. Truong, 179; see also the discussion in Chapter 4, 202. To this day, Thai Airways forces its stewardesses to retire at age 45 and the company retains the right to dismiss those who bear more than two children. The company clearly puts great stock in the sensual appeal of its air hostesses. See Tunya Sukpanich, "The unfair contract," Bangkok Post, Perspective, 15 Dec. 1996: 3. 
income." 22 The estimation of numbers of women involved in the prostitution industry continued to climb throughout the 1980 s, reaching more than two million by one estimate in the early $1990 \mathrm{~s}^{23}$ The actual numbers involved, however, continue to be hotly debated by researchers and the media. The highest numbers reflecting increased anxiety over the incidence of prostitution rather than the incidence itself.

Prostitute women were by no means passive victims in this process, but their attempts to organize were quickly put down by the anti-labour government and discouraged by those around them. The repression of labour meant prostitute women had no allies to draw on in the battle for improved working conditions. Although women were predominant in the new export industries that were fuelling the Thai 'economic miracle', their activism had been brutally crushed in the 1970s. Siriporn Skrobanek argues that "rape as well as other forms of sexual harassment were employed to suppress the struggle of female labourers."24 Attempts made by female labourers to organize in the 1980 s were quickly suppressed.

${ }^{22}$ Truong, 167.

${ }^{23}$ Wathinee Boonchalaksi and Philip Guest, Prostitution in Thailand (Bangkok: Institute for Population and Social Research, Madihol University, 1994) 31. The 'numbers debate' continues in research on prostitution in Thailand, because of the difficulty in attaining accuracy in such an underground, and often temporary, activity estimates have varied wildly from the conservative numbers of the Department of Public Health (approximately 75,000 in 1992) to 2.8 million. A number of researchers agree on an approximate number of 700,000 while still others argue that rigorous methods produce a much lower number of 200,000 to 300,000 working in the industry in any given year, Wathinee and Guest, 31-33.

${ }^{24}$ Siriporn, 26. 
Nonetheless, prostitute women continued to demand better working conditions. In 1981, one hundred masseuses at the Amarin hotel in Bangkok staged a protest for the right to refuse clients. ${ }^{25}$ In the same year, prostitutes held at the reformatory for women went on strike. While the protest was broken up by police, there was little interest from the press or women's groups in the prostitute's actions which did not fit within the frameworks for understanding prostitution held by these groups. ${ }^{26}$ In 1984 , a group of prostitute women formed "Night Girls' Right Guard" to fight for prostitutes rights but they were pressured to dissolve the organization both by families who were afraid of the stigma and by owners and police. ${ }^{27}$ Another attempt to organize prostitute women in 1987 met the same fate. While individual prostitute women continued to resist management authority in their own ways for example, by taking money 'under the table', coming to work late, using toilets reserved for customers etc. - organized action was extremely difficult. ${ }^{28}$ Besides the lack of support for labour rights, prostitute women also faced an increasingly violent trade run by the very people expected to enforce and uphold the law. Police, military and politicians were well known to be involved in running the trade.

25 Meyer, 327.

${ }^{26}$ Sukanya Hantrakul, "Prostitution in Thailand," paper proposed to the Women in Asia Workshop, Monash University, Melbourne, 22-24 July 1983, 31.

${ }^{27}$ Gail Omvedt, Women in Popular Movements: India and Thailand during the Decade of Women (Geneva: UNRISD, 1986) 49. See also Gail Pheterson, A Vindication of the Rights of Whores (Seattle: Seal Press, 1989) 67.

${ }^{28}$ See Cleo Odzer, Patpong Prostitution, Phd dissertation, New York: New School, 1994. 
The appeal to address prostitution was taken up instead by non-prostitute, middleclass and elite organizations who, in the 1980 s at least, tended to focus on the victimization of women in prostitution and trafficking rather than on sex-workers' rights. Such organizations worked within the narrow confines of 'Premocracy' - the tightly controlled period of 'democratic development' which carefully reconstructed and guarded Thai national identity grounded in the peasantry while promoting rapid economic growth. In this context, elite women's ability to appeal to the maintenance of tradition while promoting development enabled them to achieve the strongest voice on prostitution policy. But non-governmental women's organizations also tried to draw attention to prostitution, in particular, as an exemplar of the sexual and economic exploitation of Thai women in a globalized economy. In their portrayal of women as victims rather than agents, however, the early feminist campaigns tended to reinforce biases against prostitute women as women who needed rescue and reform by government and elites, rather than political actors in their own right.

\section{New Women's Organizations and the Sex-exploitation of Women}

The new feminist non-governmental organizations that came together in the early 1980s were interested in addressing grassroots women's needs rather than "sacrificing for the nation" as emphasized by traditional women's groups. However, they still operated from middle-class sensibilities and at some distance from "grass-roots women." 29 In many senses

\footnotetext{
${ }^{29}$ Darunee Tantiwiramanond and Shashi Ranjan Pandey, By Women. For Women: A Study of Women's Organizations in Thailand (Singapore: ISEAS, 1991) 93.
} 
the groups picked up where feminist organizing during the 1973-1976 period had left off. ${ }^{30}$ These new women's groups viewed prostitution as the product of the globalization of the economy and the increasing dependence of Thailand on the tourist industry as well as women's lower status and sexual exploitation in a male-dominated society. The new groups were able to draw on the increasingly sophisticated political economy studies produced by European Marxism and by survivors of the left in Thailand but cooperation with unions was difficult in light of the continuing anti-communism of the period and the sustained infiltration of unions themselves. The groups were also unique in bringing to the forefront previously unspoken issues of rape and violence against women. In challenging gender norms these women's groups were often accused of being 'western' - particularly when they were seen as too 'anti-male' or 'critical', even by other non-governmental organizations. ${ }^{31}$

In 1980 a newly formed group, 'Friends of Women' (FOW), agreed to focus on education and relief for poor women through an information centre, a magazine, research and

${ }^{30}$ Although differences of opinion remain within the NGO movement as to the direct link between the student movement and the NGO movement of the 1980s. See Gawin Chutima, "Thai NGOs and Civil Society," Thai NGOs: The Continuing Struggle for Democracy (Bangkok: Thai NGO Support Project, 1995) 136-137.

${ }^{31}$ This became a problem within the women's organizations themselves, which led to a split of some women from the group Friends of Women when members opened a 'women's café' that excluded men. Some members of Friends of Women were uncomfortable with the exclusion, fearing they would be labeled 'radicals' or 'lesbians' and 'foreign' to Thai culture, Darunee and Pandey, 110. See also 'NGOs Working on Women's Issues," Thai Development Newsletter (1992) 54. The women's groups have never fit comfortably with the rest of the NGO movement which sees itself as addressing broader issues of poverty rather than 'women's issues'. 
legal counselling. ${ }^{32}$ The group mainly included young, university educated middle-class women and a few men (including trade union worker and former student activist Suparb Passa-ong $)^{33}$ Before the group could fully establish itself, the issue of sex-tourism was dropped in their laps by Japanese and Filipino women's organizations protesting Prime Minister Senko Suzuki's tour of ASEAN countries in early 1981. Times had changed since the student protest of Japanese goods in the late 1960s, however, and criticism of the Japanese Prime Minister was seen by the government, elite and business groups as threatening to Japanese investment in Thailand. FOW along with several other nongovernmental organizations sent a letter to the Japanese Prime Minister outlining the problem of Japanese sex-tours to Thailand. ${ }^{34}$ The letter did not attack the tourism industry per se, but stated only that Japanese tourists should focus on Thailand's other attractions rather than Thai women. It was careful not to 'blame' Japanese men but explained:

True enough, Japanese male tourists do not constitute the sole factor for the rapid growth of the sex trade. In a maledominated society, such as Thailand, women have limited opportunities to share economic and political power and are shamefully considered as 'second class' citizens.

\footnotetext{
${ }^{32}$ Darunee and Pandey, 94.
}

${ }^{33}$ Darunee and Pandey, 107, note 3.

${ }^{34}$ Labour representatives' involvement in the group declined over the first few years because some members of FOW felt uncomfortable with their presence. One suspects this was not only because of the inevitable debates over the primacy of class or gender but because of the association of labour with the radical politics of the 1970s. Darunee and Pandey, 103-104. And, indeed, labour itself was weakening under the onslaught of military infiltration. 
Consequently in time of crisis, such as the present economic crisis, women are singled out as easy 'sacrifices'. Such sacrifices involve low wages and the marketing of their bodies as commodities. ${ }^{35}$

Clearly the group sought to focus on the issue of women's economic exploitation. Nonetheless, the new organization wanted to avoid appearing as 'leftist'. Trade union representatives slowly left FOW because what they saw as 'women's issues', such as the sex trade, rather than 'labour issues' dominated the agenda. Other members of FOW also felt uncomfortable with the union presence because the unions might be more concerned with workers' issues than women's rights. ${ }^{36}$ The split reflected the growing illegitimacy of labour issues in 1980s Thailand, making it very unlikely that a labour approach to prostitution could be established in the wider political sphere.

The new Friends of Women organizers felt unprepared to deal with the growing complexity of the prostitution issue. The initial campaign had exposed the international sextourism trade and there was growing evidence of Thai women working overseas as prostitutes. Siriporn Skrobanek conducted further research on the condition of Thai women in the sex-industry abroad. Siriporn's work situated prostitution (both of Thai women overseas and in Thailand) within the context of global capitalist exploitation of the Thai economy as the capitalist elite both global and local exploited the labour of poor Thai women

35 "An Open Letter to the Japanese Prime Minister from Thai Women," 19 January 1981, reproduced in Darunee and Pandey, 1991, Appendix D, 176.

${ }^{36}$ Darunee and Pandey, 103. 
through the sex-tourism industry. ${ }^{37}$ She argued that, in the globalized economy, Thai women are relegated to 'secondary status' as workers, finding work in foreign countries in exploitative factory work, prostitution or the 'monopolized labour' of marriage. Siriporn linked the trans-national exploitation of Thai women's sexuality and labour to the sexual division of labour and the maintenance of peripheral capitalism - as women's work benefitted both central capital and their remittances helped maintain lower pay in the periphery. Rural Thai families could depend on their daughters' work overseas to supplement their incomes and capitalist industry could therefore continue to underpay their workers. The impoverishment of the countryside during the 1960 s pushed women into the urban labour market, where the prevailing gender ideology forced women to work in jobs that were based on assumptions about their 'feminine' characteristics. ${ }^{38}$ Thus, Thai women in prostitution at home and abroad, according to Siriporn, needed to be seen as part of the world system of capitalist patriarchy.

Upon her return from the Netherlands, Siriporn and a few women colleagues formed the Women's Information Centre (WIC) to inform women of the dangers of going to work abroad and to provide other information and counselling to poor women. ${ }^{39}$ WIC eventually became part of an independent group, the Foundation for Women (FFW), which was also

${ }^{37}$ Siriporn, 37-40.

${ }^{38}$ Siriporn, 26.

${ }^{39}$ Darunee and Pandey, 110; Thai Development Newsletter 2.3, 21-22 
headed by Siriporn and focussed on issues of women's labour, prostitution and violence against women.

In these early years of organizing, however, the new women's groups tended to view prostitution as inherently 'wrong', as something no woman could possibly choose. Instead of seeing prostitute women as 'bad girls' however, the new groups insisted that prostitute women were victims, forced into an evil trade through economic and sexual exploitation. While such a portrayal drew swift attention to the unfairness of the economic burden being foisted upon women in the 'Thai economic miracle' and the sexual power of men, it also tended to reinforce an understanding of women as inherently sexually passive. Prostitute women, once again, were viewed as in need of protection rather than social agents who should be given the right to determine their own path.

Much as in the 1960 s, by clearly aligning themselves on the side of 'good' women, the organizations hoped to maintain some legitimacy in a society that viewed their demands for women's rights as 'foreign'. In the early campaigns, for example, women's groups emphasized the exploitation of women in an illegal trade. One organizer recalls:

... [at first] we always [saw] the bad side to this kind of business, that women have to serve as sex objects for money, [are] oppressed by men, [are] oppressed by brothel owners ... and it's illegal. So far as I remember, the complaint that we made at this time is, even some of the posters said, that prostitution is illegal. The caption [was] to attract the public, so that the people can see 'oh it is illegal, it's against the law, it's not good to [be] involved'....

${ }^{40}$ Interview with Rangsima Limpisawas, Bangkok, 26 Nov. 1996. 
Such campaigns served to reinforce the idea that prostitute women were involved in something that was harmful to society and themselves and required punishment or reform.

It was not the groups' intention, however, to increase punitive measures against prostitute women. Instead, they sought to call attention to women's abuse by larger economic and social forces to counter dominant portrayals of prostitute women as 'soft-headed', 'funny' or simply women who enjoyed sex. ${ }^{4 l}$ Research by concerned groups uncovered a pattern of deception and fraud in the entry of women and girls into prostitution, such as agents who promised 'good work' in the city only to drop women off at a brothel, as well as mistreatment and abuse by owners and pimps. The groups worked to draw attention to the cases of women who had been forced into the trade. A 1982 seminar on 'Measures to Address Legal Measures Related to Prostitution' estimated that ten percent of the women working in prostitution were deceived and forced into the trade. ${ }^{42}$ One hundred and fifty representatives of study groups gathered at the Police Department on March 9th, 1982 to submit a petition demanding action against cases of deception and coercion of women into prostitution and a four page report on such cases ${ }^{43} \mathrm{~A}$ fire in a brothel in Phuket in 1984 that

${ }^{41}$ Interview with Pasuk Phongpaichit, Bangkok, 8 Nov. 1996.; Sukanya Hantrakul, "The Spirit of a Fighter: Women and Prostitution in Thailand," Manushi 18 (1983): 31; Mattani Rutnin, "The Role of Thai Women in Dramatic Arts and Social Development," Customs and Tradition. The Role of Thai Women, International Conference on Thai Studies, Bangkok, 22-24 Aug. 1984, 7.

${ }^{42}$ Sukanya, 13.

${ }^{43}$ Sukanya, "Prostitution and Human Rights," 9-11. 
killed six young women brought national attention to the problem of force in prostitution. The women had been unable to escape the fire because they were chained into their rooms. ${ }^{44}$ The groups held memorials and exhibitions on the fire to draw public attention and workshops on the trafficking in women out of the rural areas and into the sex-trade in the urban centres and abroad. ${ }^{45}$

The new women's groups also supported international efforts against trafficking in women which condemned prostitution as a human rights abuse against women and portrayed women as victims of male sexual violence. An international conference in 1982 led by American radical feminist Kathleen Barry and attended by Siriporn highlighted the abuse, deceit and violence that was assumed to be an inherent part of prostitution. While Thai women's groups were in later years to distance themselves from - and indeed oppose Barry's organization, in these early years Siriporn, for one, admits that she shared Barry's views on the need to abolish prostitution as inherently exploitative of women. In later years Siriporn and the organizations she led came to realize that prostitute women's own demands could not be met through an abolitionist stance.

Highlighting the victimization and abuse in prostitution was the growing evidence of the involvement of children in the Thai prostitution trade. A 1983 study completed after a raid on a Bangkok teahouse found a number of children between thirteen and fourteen years

44 "Tourism Promotion and Its Effects on Thai Women," Thai Development Newsletter 4.1 (1986): 10-14.

${ }^{45}$ See the regular reports in the Thai Development Newsletter 1985-1989. 
old. ${ }^{46}$ The Social Welfare Department also reported an increase in the number of children (under the age of fifteen) among its charges, up from 2.5 percent in 1978 to 6.3 percent in 1981. The majority of women in prostitution (nearly sixty percent) were found to be between the ages of sixteen and twenty-one ${ }^{47}$ Children were believed to be sold into prostitution by their parents for advances or to pay off debts. ${ }^{48} \mathrm{~A}$ number of children's protection groups were formed throughout the 1980 s and 1990s as concern over the prostitution of children increased. ${ }^{49}$ The conflation of children's exploitation in prostitution with women's involvement in prostitution, however, expressed in discussions of "women and children" in prostitution presented women as children, in need of protection and unable to make their own choices.

Nonetheless the focus on the victimization, abuse and exploitation of women was clearly needed in order to draw attention to the negative impacts of the rapid economic growth underway in Thailand. It also sought to address complacent attitudes over male sexual privilege, as women's groups fought to have rape and child sexual abuse addressed as serious social issues. (At the time, marital rape was legal and the age of consent was set

${ }^{46}$ Saowarop Panyacheewin, "Child Prostitution" Bangkok Post 7 December 1983, reprinted in ECTWT, 30.

${ }^{47}$ Malee Pluksponsawalee, "Women and the Law," Women in Development: Implications for Population Dynamics, eds. Suchart Prasith-rathsint and Suwanlee Piampiti (Bangkok: National Institute of Development Administration, 1982) 157.

${ }^{48}$ Truong, 181.

${ }^{49}$ For instance, the Children's Rights Protection Centre. 
at thirteen years so that there was little protection from male spousal abuse or child abuse. ${ }^{50}$ ) The victimization focus undermined the portrayal of Thai women in both domestic and foreign advertising as easily available sexual playthings, a portrayal that increased the sexual harassment and acceptability of the harassment of women. It was particularly uncomfortable for upper and middle-class, non-prostitute women who travelled overseas who often faced ridicule, discrimination and harassment on the assumption that they, as Thai women, must be prostitutes. ${ }^{51}$ In their understandable concern to address these issues, therefore, women's groups often emphasized women's victimization in prostitution rather than their agency. Such portrayals of prostitution as inherently exploitative and demands for its abolition undermined prostitutes' efforts to organize for better working conditions and pay.

The focus on force and victimization in prostitution, therefore, put some distance between prostitute women and feminist organizers in these early years. Prostitute women viewed themselves as workers and wage earners according to research carried out in the late 1970s by Pasuk Phongpaichit. Pasuk's work was one of the first in-depth studies of women and girls migrating into the Bangkok prostitution trade from the North and the Northeast. Pasuk's study challenged traditional understandings of the women as psychologically 'unfit'

${ }^{50}$ See Sucheela Tuanchainan, "Sexual Violence against Women and the Women's Movement in Thailand," Thai Development Newsletter 3.4 (1986): 5-6.

${ }^{51}$ Siriporn herself noted instances during her research when she was assumed to be a prostitute. Almost all of the women I interviewed in 1996 reported similar instances of sexual harassment overseas on the basis of the assumed 'sexual availability' as Thai women. 
and 'sexually overactive' by clearly situating the trade within the uneven economic relationship between rural and urban Thailand. But her analysis left room for women's agency in the prostitution trade. She pointed to how lucrative the trade was relative to other available wage labour and insisted that migration into prostitution had to be understood as an 'entrepreneurial move' given limited opportunities:

[prostitute women] were engaging in an entrepreneurial move designed to sustain the family units of a rural economy which was coming under increasing pressure. They did so because their accustomed position in that rural society allocated them a considerable responsibility for earning income to sustain the family. ${ }^{52}$

Indeed, her initial interest in the subject had been piqued by a newspaper article in the late 1970s which related the story of a local post-office running out of money with which to honour all the remittances to be paid to local families. ${ }^{53}$

Pasuk's study, however, was greeted with some criticism from women's groups who felt her analysis did not draw sufficient attention to the patriarchal culture that encouraged women's sexual service. As Pasuk saw it, however, it was perhaps more important - given the economic situation - that prostitute women were at least not subjected to the kind of cultural condemnation that occurred in other countries. She relates:

But I was also criticised by people on the feminist side that I paid too much attention to the economic imperative...not

\footnotetext{
${ }^{52}$ Pasuk Phongpaichit, From Peasant Girls to Bangkok Masseuses (Geneva: International Labour Office, 1982) 74-75.

${ }^{53}$ Interview with Pasuk Phongpaichit, Bangkok, 8 Nov. 1996.
} 
enough attention to social factors. Often the argument I heard was there must be a social acceptance that's why its proliferated, which in a way there is to some extent. The way people cope with prostitution here is certainly different from say in India. And that's the difference and a lot of people then from there jump to say that the proliferation must be explained by social/cultural factors. My argument is that I don't think in terms of numbers, the openness here yes, women don't have to be locked up, but in terms of numbers I doubt if we have more than in Indonesia or in terms of percentage than in India. But the openness is a plus, at least these girls still can have a relationship with their family, with whoever in their subculture. But in those societies where it is closed, the slave like trade is much more pronounced. I think it is worse than here. ${ }^{54}$

At the same time, other activists like Sukanya Hantrakul, warned that the continued focus on forced prostitution was avoiding the larger cultural and economic place of prostitution in Thai society. Sukanya felt that the focus on the 'evil foreigner', both in the anti-tourism and the anti-trafficking campaigns, had encouraged feelings of nationalistic machismo among men. At the same time it had neglected to address the larger issue of a "sexual culture" in which "sex is harnessed to an economic end" whether through marriage or prostitution. ${ }^{55}$ Sukanya also felt that the focus on the victimization of women in

${ }^{54}$ Interview with Pasuk Phongpaichit, Bangkok, 8 Nov. 1996.

${ }^{55}$ Sukanya, "Prostitution," 35-36. See also Sukanya, "Sexual Culture of Thai Women" The Nation 2 September 1996. Sukanya continued to ask in 1996 "Is the raison d'etre for sex from a woman's point of view still overwhelmingly plagued by some political factor in the broadest sense of the word - or/and by economic gains? Are women today, professionally liberalised and liberated, as they are under our democratic law, capable of perceiving sex in other forms rather than as an act of appropriation? Literally speaking, do they still see sexual relations with men in terms of a win-or-lose bargain both within and outside the institution of marriage?" Sukanya raised the question of whether this 
prostitution failed to challenge the sexual role assigned to women. She pointed out that in earlier years the portrayal of:

...innocent young girls being 'corrupted' and 'destroyed' by males - local and foreign - the conservative reformer as well as the feminist succeeded in arousing people's rage against male vice. Women were in turn urged to be more virtuous, obedient, non-assertive especially in sexual relations. The anti-vice campaign had always come to mean the repression of the vicious woman and imposed guilt conscience on both the prostitute and her client and finally became nothing but a power instrument of certain agencies under different labels. ${ }^{56}$

By campaigning against prostitution, seen only as the sexual abuse of women, some feminists, according to Sukanya, were denying women the right to sexual activeness and instead reinforcing control over and repression of women's sexuality. As Sukanya argued:

\begin{abstract}
Although a number of concerned people ranging from women's groups, social reformers, human rights advocates to the authorities, have shown their feelings of anxiety over forced and child prostitution, they could not help showing their feelings of repugnance toward the pervert woman who allows more than one man to gain access to her body. For them, as well as for more repressive moralists, the desire to protect innocent women is largely overshadowed by an impulsive wish to impose a certain moral code of conduct. ${ }^{57}$
\end{abstract}

linkage accounted for the reputation of Thai prostitutes as 'natural' or 'more like a girlfriend than a prostitute' to the men who came to Thailand "because the 'sex-formoney' transaction seems to be a 'natural' sexual inclination?"

\footnotetext{
${ }^{56}$ Sukanya, "Prostitution," (1983) 35-36.

${ }^{57}$ Sukanya, "Prostitution," (1983) 34-35.
} 
Indeed, in these early years of women's organizing against prostitution, the focus on rural women's migration into prostitution either in urban centres or overseas reinforced elite's and government's role in protecting and disciplining peasant women into 'proper cultural behaviour' as well as sexual behaviour.

The campaigns against prostitution tended to draw from and reinforce the wider political discourse of the decline of rural Thai identity in the face of the foreign influence, particularly in the form of increasing tourism. This discourse around prostitute women reenforced the linkage between women's sexual purity and the purity of national identity, which echoed the critiques of the student movement. In the era of Premocracy and the reconstitution of national identity as rural identity, the focus was on rural women's bodies and their protection. The rural roots of the women involved played a key part in underlining the 'innocence' and victimization of women who could not be expected to have known any better. A Foundation for Women report linked forced prostitution in particular to rural women, stating in their report that "[it] is mostly innocent, ignorant, young girls from rural areas who are lured into forced prostitution." 58 Again, in this discourse prostitute women's self-interpretations as workers and family wage earners are rendered mute and their calls for better working conditions made illegitimate, drowned out by calls for protective and rehabilitative measures that will restore 'village culture' to its idealized form, mainly as envisioned by the urban middle and upper classes.

${ }^{58}$ Siriporn Skrobanek, "Strategies against Prostitution - The Case of Thailand," Thai Development Newsletter 4.1 (1986) 23. 
The movement of women out of the country into prostitution, or from the countryside into the city, to prostitute themselves to foreigners re-ignited some of the defensive nationalism of the 1970s. The progressive newspaper The Nation, born out of the 1970s, echoed the nationalism of the student movement in a political cartoon which depicted Japanese sex-tourists as kamikaze pilots diving into a woman's breasts (representing Thailand's sex industry). ${ }^{59}$ That the women entering the trade were rural women deepened the sense of cultural crisis because the peasantry was rapidly being established as the root of Thai culture through the efforts of the National Identity Board and other government and elite organizations.

While the mainstream media increasingly accepted that poverty was the driving factor behind prostitution, tourism and foreigners were understood to be the source of the demand. The fire in Phuket - a major tourist destination - also intensified the spotlight on the role of the tourism industry in prostitution. In the wake of the fire a panel on tourism and prostitution was held by the Friends of Women, the Women's Information Centre, the Child's Rights Protection Centre and the Northern People's Relations Group. Panellists pointed to the growing tourism in the northern provinces, the decline of traditional ways of life and the growth in prostitution. Propote Sritet of the Northern People's Relations Group argued: "Since tourism has reached the North, my part of the country, we can claim that there

${ }^{59}$ Arun, The Nation, 1981 reprinted in ECTWT, 15. 
is practically no village void of girls in prostitution." ${ }^{60}$ The follow up article in The Nation reported that "tourism ... has altered the way of living of local people, especially the northerners. Girl prostitutes from the North have been the most popular and desirable, with the new trend favouring the hill-tribe girls." societies such as the hill-tribes - who were widely viewed as 'backward', but a colourful part of Thai culture - highlighted the threat to Thai nationhood.

Increasing this sense of national anxiety, numerous reports of Thai women working overseas as prostitutes also began to appear in the media. The concern over protecting women from foreigners was made clear in a 1978 law which required any foreign man proposing to marry a Thai woman to obtain an affidavit from his embassy stating his occupation and income, as well as two letters of reference from referees living in his home country. The change was prompted by the growing concern over the practice of European men taking Thai women abroad as their wives but then forcing them to work in prostitution. ${ }^{62}$ In 1977, the Director of the Social Welfare Department estimated that one thousand Thai women were working in West Germany as prostitutes "voluntarily or involuntarily." The

60 "Tourism Promotion and Its Effects of Thai Women" Thai Development Newsletter 4.1 (1986) 13; also "Promoting Tourism May Encourage Prostitution" Nation Review 4 February, 1986 reprinted in Thai Development Newsletter 4.1 (1986) 14.

61 "Promoting Tourism May Encourage Prostitution," Nation Review 4 February, 1986 reprinted in Thai Development Newsletter 4.1 (1986): 14.

${ }^{62}$ Kobkul Rayanakorn, Special Study on Laws Relating to Prostitution and Traffic in Women (Bangkok: Foundation for Women, 1995) 29-30; "Sex Tourism to Thailand." ISIS International Bulletin 13 (1979): 10-11. 
director's rescue of a deaf-mute woman who was lured to Germany with the promise of marriage and then forced into prostitution created a stir in the newspapers. ${ }^{63}$ In December of 1982, 154 Thai women were sent home from Singapore for practising prostitution there. The Labour Department also estimated that 5,000 women were in Hong Kong working as prostitutes. ${ }^{64}$ In the wake of the anti-sex tourism campaign against Japanese men, the number of Japanese tours had decreased but the number of women going to Japan had increased concomitantly. Another 5,000 Thai women were thought to be working as prostitutes in Japan by $1984 .{ }^{65}$ Thai women were also working in Switzerland, Germany, Greece, Cyprus, the Middle East. Reports of the mistreatment of Thai women abroad and their growing numbers appeared frequently in the media during the early 1980 s. $^{66}$ By 1984 the Parliamentary Social and Cultural Committee reported that Thailand had the region's highest number of overseas prostitutes at approximately $16,000 .{ }^{67}$

\section{Official Response}

The response of officials, as Sukanya had feared, was a protective (and restrictive) one towards women. In the language of territorial border guarding, the director of Phayao

\footnotetext{
${ }^{63}$ Ilse Lenze, "Tourism Prostitution in Asia," ISIS International Bulletin, 13 (1979): 6.

${ }^{64}$ Sukanya, "Prostitution," (1983): 32.

${ }^{65}$ Meyer, 358.

${ }^{66}$ See Meyer, 354-361.

${ }^{67}$ Truong, 182.
} 
provincial primary education office (a province noted for the number of women involved in the Bangkok trade) established a project for the "defence and 'blockading' of northern women to prevent them from becoming prostitutes." Penal Code to increase the penalties on procurers of girls under the age of 18 and to address the problem of trafficking by punishing those who used "deceitful means, threat, violence, unjust influence or more of coercion by any other means" to take away a woman for an indecent act. ${ }^{69}$ The government's intent to control women rather than clients or procurers, however, was made clear in a 1982 Cabinet regulation which stated that if the Foreign Ministry suspected that a woman who had made a passport application had a "dishonest motive for travel" then the matter could be referred to the Department of Welfare for investigation of the woman's status and records. Although the measure was seldom used, the potential for increased difficulties in obtaining a passport increased the cost in bribes and therefore in debts that women have to pay to recruitment agents. ${ }^{70}$

The government also made special arrangements with foreign governments to prevent trafficking. For instance, the Thai government made arrangements with the Hong Kong government for both governments to screen Thai women travelling to Hong Kong. ${ }^{71}$ Several hundred Thai women were turned away from Hong Kong immigration or deported from that

68 “Working on White Slavery," Thai Development Newsletter 3.2 (1985): 22.

${ }^{70}$ Kobkul, 29.

${ }^{71}$ Meyer, 355. 
country each year during the early $1980 \mathrm{~s} .{ }^{72}$ Such measures effectively curtailed women's selfdetermination and freedom of movement, making them objects of state control 'for their own good.' That these measures primarily affected uneducated, lower class and peasant women is indicated in the sorts of differentiations made by the Singaporean government in weeding out 'acceptable' (non-prostitute) and 'unacceptable' Thai women on the basis of their English language skills. ${ }^{73}$ Such standards obviously reflected a class-based differentiation of women who were likely to be educated and presumably capable therefore of independence and 'moral behaviour' and those who were not.

At the same time, the Thai government introduced a new bill on prostitution measures in the House, which sought to increase punitive measures against pimps and procurers. Public support, particularly among women, for increased punishment of pimps and procurers had been on the rise since the Phuket fire. ${ }^{74}$ The government's bill was particularly harsh in dealing with owners and managers who were found to have children working as prostitutes

${ }^{72}$ Meyer, 356.

${ }^{73}$ Meyer, 354-355.

${ }^{74}$ One large scale survey taken during the mid-1980s showed 32.2 percent of respondents favoured revising the law to increase penalties on procurers and 23.9 percent favoured legalization, with women more likely to favour increased penalties and men more likely to prefer legalization. UNESCO, "Thailand," Identification of Issues Concerning Women and Their Consideration in Development Planning (Bangkok: UNESCO, 1987) 61. 
and it strengthened punishments for "confinement" for prostitution purposes in an attempt to address the enslavement of women in the trade. ${ }^{75}$

Harsher measures against pimps and procurers were unlikely to be of help to many prostitute women, however. Stronger criminal enforcement and greater police attention had traditionally worked to their detriment. In the early 1980 s a series of brothel raids had been carried to assuage public opinion, which had resulted in a number of women being arrested for prostitution while owners and procurers conveniently managed to 'escape. ${ }^{76}$ Whenever stronger measures against prostitution were enforced it usually resulted in harsher realities for prostitute women. Kickbacks to police officials increased costs to the brothel owners, who, in turn penalized prostitute women. Brothel raids were often arranged in advance so that prostitute women who were no longer 'profitable', could be arrested. Indeed, the fear of arrest kept many women from reporting abuse or deceit by brothel owners or procurers and led them to cooperate with owners to avoid police interference.

There was little faith that increased criminal penalties would, in any case, be effective. Women's groups voiced concerns about the enforcement of the law. ${ }^{77}$ A number

75 "Cabinet Okays Stiff Anti-Prostitution Bill," Human Rights in Thailand Report 10.1 (1986): 19.

76 "Tourism Promotion and Its Effects on Thai Women," Thai Development Newsletter 4.1 (1986): 10.

77 "An Open Letter on the Case of Prostitutes Killed in a Fire at Phuket," Thai Development Newsletter 2.3 (1984) 22-23. "Women's rights groups voice support for anti-prostitution bill," Thai Development Newsletter 4.1-2 (1986) 5-6. 
of cases of forced prostitution in the early 1980 s had pointed to the involvement of corrupt officials and politicians. NGOs took up the theme of government collusion in the sex industry - pointing to the failure of police to take action despite the blatant operation of the industry, and when there was the occasional campaign to net operators they were more often than not dealt with through light or suspended sentences. ${ }^{78}$ The 1984 fire in Phuket made the issue of police corruption and involvement in prostitution clear. An article in the popular newspaper Thai Rath pointed out that although the fact that the brothel kept women in confinement was well known to police, officials and politicians, no arrests had been made before the fire because of police involvement with the brothel. ${ }^{79}$

Reports of official involvement in the trade became commonplace. Officials responsible for hill-tribe development projects were reported in The Nation to be involved in trafficking young hill-tribe women into prostitution. ${ }^{80}$ Allegations by women working in Greece in 1983 that the Thai Consulate General was involved in the trafficking of women were confirmed by the Foreign Ministry. ${ }^{81}$ The WLA had taken up a case in 1982 where sixty-two young women were rescued from a hotel following a letter sent by one of the

${ }^{78}$ See the reports to the meeting on white slavery held in Chiang Mai in 1984, "Working on White Slavery" Thai Development Newsletter 2.3 (1985): 20-21.

79 “The Interview with Phuket Chief Inspector" Thai Rath 30 Jan. 1984 c.f. “An Open Letter on the Case of Prostitutes Killed in a Fire at Phuket" Thai Development Newsletter 2.3 (1984): 22.

\footnotetext{
80 Truong, 182.

${ }^{81}$ Meyer, 361.
} 
women to the Crime Suppression Division saying the women were being held against their will. When the case was transferred to the police force in the district where the hotel was located all the women were sent back to the hotel. The Women Lawyers Association took over the case and several high-ranking police officers were transferred and five people accused of holding the women were prosecuted. ${ }^{82}$

Police themselves admitted that corruption on the force was a major problem. A Police Colonel who wrote a master's thesis in 1974 on the prostitution problem admitted that police were themselves involved in pimping women. ${ }^{83}$ In a 1981 article in Business in Thailand, a Police General also admitted that “often, the police can't do anything because they know that the men behind the operation of some brothels are those whose pictures are frequently seen in the newspapers, attending big parties with top ranking policemen or government officials." ${ }^{84}$

Another General, in a study of "The State Control of Prostitution," outlined four main "points of connivance" between police and the prostitution industry: first that many policemen had "some relationship with the owners of the establishments or in many cases are the owners of establishments themselves, honest policemen of lower rank have been prevented from doing their duty for fear of their superiors' harassment"; second, where

${ }^{82}$ Sukanya, "Prostitution," (1983): 28.

${ }^{83}$ Sukanya, "Prostitution," (1983): 15.

${ }^{84}$ Wiboon Nakornjarupong "Patronage and the night queens," Business in Thailand (Nov. 1981) 48 c.f. Sukanya, "Prostitution," (1983): 15. 
arrests are made they are of the women rather than the operators; third, during investigations little attempt is made to search for the operators, if they are caught they can bribe police to release them; finally, whenever operators are arrested for forcing women into prostitution they "negotiate with the women and their families to pay compensation. Even though these are crimes against the public which cannot be settled by the individual parties, the police mediate and set these people free." 85

Women's groups began to campaign against the corruption of officials involved in the industry. Friends of Women asked the Minister of the Interior to employ "drastic measures" to punish corrupt police. In the face of such involvement, the group realized that only decriminalization of prostitution (through the abrogation of the Prostitution Suppression Act) would "prevent brothel proprietors, pimps and corrupted policemen from intimidating women who are willing to take up this profession." ${ }^{\text {"86 }}$ Even elite women such as MP Dr. Yupha Udomsak began to suggest that if neither registration of prostitutes nor the prosecution of clients were possible, "then it might be better to permit prostitutes to work freely."

Insofar as we cannot do anything to change the national economic situation, we may have to accept the existence of

${ }^{85}$ c.f. Malee, 160.

86 "An Open Letter on the Case of Prostitutes Killed in a Fire at Phuket," Thai Development Newsletter 2.3 (1984): 23.

87 "Working on White Slavery," Thai Development Newsletter 2.3 (1985): 21. 
prostitution. Laws should be made, therefore, in order to protect them and render justice to them. ${ }^{88}$

Dr. Yupha along with several other MPs put forward a draft bill on prostitution that gave some recognition to the fact that some prostitute women were more victim than perpetrator and called for the abolition of the 1960 act, which viewed prostitutes as criminals. The proposed bill provided that "prostitutes would not be harshly dealt with" as long as were not "loitering with intent" or "soliciting." While such a provision was a far cry from decriminalization it indicated a shift in perspective. The proposed bill also allowed women to choose whether or not they would go into rehabilitation. At a 1985 workshop attended by a number of NGOs as well as Dr. Yupha, it was reported that most women charged with prostitution in Chiang Mai fled while awaiting trial not because of the $200-500$ baht fine but for fear of being sent to the rehabilitation centres where the disciplinary measures and behavioural training were greatly resented by the women. ${ }^{90}$ At the same time, a special investigation force would be established to inspect suspected brothels and root out forced prostitution while providing medical aid to prostitute women. ${ }^{9 t}$

88 "Tourism Promotion and Its effects on Thai Women," Thai Development Newsletter 4.1 (1986): 12.

89 "Flesh Traders in for Stiff Penalties," ECTWT, 110.

90 “Working on White Slavery," Thai Development Newsletter 2.3 (1985): 20.

91 "Flesh Traders in for Stiff Penalties," ECTWT, 110. 
Critics pointed out, however, that under the circumstances registration of prostitution would also be open to continued abuse. As Sukanya argued "under the legalization system, deception and coercion could be easily made voluntary by simply forced or fake signatures of the victims, thus becoming registered and legal prostitutes for life. ${ }^{92}$ A senior police officer commented that the special force to inspect brothels suggested in the 1986 MPs' bill could itself just end up as another group of "bloodsuckers." 93 Other women leaders worried, in the expression of the time, that the "dark influence" of brothel owners could prevent arrested prostitutes from giving evidence. ${ }^{94}$

Elite women also drew attention to the need for changes in male behaviour and attitude in order to achieve more effective law enforcement, linking the failure of the law to the failure of men. A 1985 conference hosted by the Girl Guides and the APSW on "men's development for women's development" concluded that:

A major cause of women's plight in the service sector is the attitude and conduct of men. Most evidently, the prostitution problem in Thailand has grown in proportion partly because there is a ready market for prostitutes, with men as the consumers. Moreover, trafficking of women and profiteering from this trade, coupled with lax enforcement of laws on prostitution, are often due to the activities of certain men. If one is to curb such problems, then one must address oneself to how men can help in finding solutions. The solutions depend not only upon a re-orientation of men's attitude and

${ }^{92}$ Sukanya, "Prostitution,” (1983): 27-28.

${ }^{93}$ Bangkok Post, June 14, 1984 in ECTWT, 110

${ }^{94}$ Thai Development Newsletter (Dec. 1986): 5-6. 
conduct as the consumers, but also a more responsible role on the part of men as the law-enforcers. ${ }^{95}$

The NCWA's report to the Nairobi Conference in 1985 made similar points, arguing that there were anti-prostitution laws on the books therefore "the main lacuna is not that of absence of law but lax law enforcement." ${ }^{.96}$ It admitted that "frequently it is the so-called lawenforcers and concomitant vested interests who profiteer from the trade. Therefore, strict law enforcement is highly unlikely." ${ }^{.97}$ The report emphasized several times that male attitudes were the problem, noting: "Thai laws are not discriminatory against women, de facto women are discriminated against because of enforcement of the laws which in turn is due to the attitudes of certain males." 98 Elite women, therefore, sought to reshape male behaviour to conform with the standards of female behaviour - to adhere to the same standard of sexual morality.

In an attempt to force men to meet up to this standard Dr. Yupha further sought to have the client's role in prostitution punished. Although she convinced the House Committee on Social and Cultural Affairs, which she chaired, she found it was "unacceptable to the majority of the National Assembly because the overwhelming majority of MPs are men. Only

${ }^{95}$ National Commission on Women's Affairs (NCWA), Women's Development in Thailand (Bangkok: National Committee for International Cooperation, National Commission on Women's Affairs, 1985) 148-149.

${ }^{96}$ NCWA, 51.

${ }^{97}$ NCWA, 50

${ }^{98}$ NCWA, "Foreword" n.p.; NCWA, 100-101. 
thirteen are women." 99 Sukanya argued that in any case, such a step would simply have meant further moral regulation. She argued instead that:

Prostitutes must be decriminalized. Clients who have never been subject to legal punishment must remain to be so. It would be most repressive thing to see 'moral police' whose duty is to regulate people's sexuality by punishing both the woman and the man in the deal. ${ }^{100}$

Elite women, however, argued that men's behaviour needed to be reformed.

In the end, the MPs' version of the bill also faced powerful opposition in the form of the conservative Ministry of the Interior. The Ministry was headed throughout Prem's leadership by either a bureaucrat or a soldier as part of Prem's pact with the military in exchange for their continued support. ${ }^{101}$ While the Ministry housed the newly reconstituted National Commission on Women's Development, the Ministry had continued to oppose equal employment measures for women in the bureaucracy and the military as a "threat to national security." 102 Predictably, the committee lacked independence and authority and backed the Ministry's call for harsher penalization of procurers and pimps while increasing control over prostitute women by giving courts the power to remand prostitutes to

99 "Working on White Slavery," Thai Development Newsletter 2.3 (1985): 21. The issue of punishing clients was also raised in meetings with police, public welfare officials and prosecutors but resistance to the idea led to an agreement to "drop the issue." "New Vice Control Bill Completed," Bangkok Post 29 Aug. 1984, reprinted in ECTWT, 108.

${ }^{100}$ Sukanya, "Prostitution," (1983): 29.

${ }^{101}$ Pasuk and Baker, 346.

102 "Working on White Slavery," 21. 
rehabilitation rather than to the Public Welfare Department. ${ }^{103}$ The measure suggested that the Ministry saw prostitutes as criminal offenders rather than victims of economic or social forces.

The Cabinet version of the bill, in the style of Premocracy, reflected a compromise between the two drafts. The bill's preamble recognized the "prostitutes are not criminals" and that many were forced into prostitution by economic and social pressure in conjunction with a lack of education. The bill provided, nonetheless, for the punishment of prostitutes with fines and jail terms. It also extended the provision for rehabilitation to include private NGOs which could establish vocational training centres as well as the Public Welfare Department. ${ }^{104}$ Thus, despite growing evidence that police and officials were themselves deeply involved in the prostitution trade, the government continued to support increased state control over prostitute women. ${ }^{105}$

\section{Conclusion}

In the aftermath of the 1970 s the issue of workers' rights was extremely difficult to raise. The unions were infiltrated and weakened and the government championed rapid

\footnotetext{
103 "Cabinet Okays Stiff Anti-Prostitution Bill," 19.

104 "Cabinet Okays Stiff Anti-Prostitution Bill," Human Rights in Thailand Report 10.1 (Jan-March 1986): 19; "Women's rights groups voice support for anti-prostitution bill," Thai Development Newsletter 4.2 (1986): 5.

tos The bill died on the order paper with the collapse of the cabinet coalition in 1986.
} 
growth at the expense of workers' rights. While prostitute women made demands for better working conditions in the growing brothels and bars, their efforts were often ignored by the women's groups who sought instead to draw attention to the victimization of women in prostitution. Such a focus was an important counterweight to the language of government and tourism agencies that presented Thai women as freely available sexual objects. However, it presented prostitute women in a light that strengthened the notion that prostitute women required re-education and guidance in order to maintain their cultural identity. That is, such representations were easily coopted within the 'Premocratic' state, which sought to establish itself as a legitimate state that reflected social needs and inputs rather than an authoritarian state, and helped to consolidate elite power, particularly the power of elite women within the state. The emphasis on force and victimization, particularly in relation to rural women and the thriving tourism industry, also drew on, and reinforced, newly consolidated notions of national identity. Again, such representations invoked relations of power, specifically the restoration of 'proper Thai identity' to rural, peasant women by elite women.

While some women's organizations later came to argue for treating prostitution as a problem of labour conditions in the context of the early 1980s there was little or no political space to make such an argument and be heard. Unfortunately this also meant that prostitute women's own political actions and demands were often ignored and led to measures that threatened prostitute women with greater instability and loss of control over their lives. 


\section{Chapter 7: Prostitution and the 'New Man', Prostitution Policy in the 1990s}

While arguments for the reform of male behaviour and attitudes appeared to have little chance of succeeding in the mid-1980s, international criticism and growing middleclass frustration with corruption in government leant weight to the argument in the 1990 s. For years in Thailand the masculine model was the military man as head of the militarybureaucratic state, complemented by his 'beauty queen' wife. This was illustrated most clearly in the Phibun-Sarit era, but it continued on in elite behaviour into the current era. However, a new discourse of masculinity emerged in the 1990 s, one which emphasized rational, technocratic governance and responsibility to family as opposed to the military model of male sexual prerogative and state power.

The new discourse on masculinity emerged in the context of growing dissatisfaction with governmental performance in dealing with such looming problems as prostitution. Measures to combat prostitution had been continually defeated in the face of vested interests, governmental corruption and government instability. As the middle class grew in size and economic power it became more insistent on efficient and rational government and increasingly resentful of corruption and government's inability to deal with the problems of rapid modernization. It was also very sensitive to growing international concern over prostitution in Thailand, particularly the involvement of children in the sex-trade and the threat of AIDS that became apparent in the late 1980s. Failure to deal with these problems led to threats of boycotts of Thai products by the European Union and the United States as well as a potential drop in tourist numbers as the AIDS threat grew. These concerns were 
articulated as the 'image problem' in the 1990 s when the international community trained its spotlights on Thailand.

Increasingly, the urban populace, with its dependence on international business and global money markets, connected the need to project a rational and efficient image to economic survival in a globalized era. The 'internationally embarrassing' aspect of various government failures was consistently played up in the press, signalling the importance attached to international reputation and the potentially disastrous economic results. The potential political repercussions were clear. As one Western diplomat argued in the wake of the economic collapse of 1997: "with the global markets voting no confidence in Thailand .... there is a sense that they can't afford a bunch of slimy politicians running the country anymore.""

The language of the 'image problem' was deeply gendered. The Thai state was presented as not properly masculine for its failure to efficiently deal with its problems. Elites concerned with addressing the problem of prostitution where able to draw on the image problem' to argue that 'efficient' and 'rational' government required a change in male attitudes and behaviour. A properly masculine state, by this view, must protect and provide for the (feminine) nation by protecting Thai culture and national identity (embodied in women), not selling them to foreigners or abusing them. A 'new man' was needed to address Thailand's problems. The 'new man' was considered a thoroughly modern Thai, dressed in

\footnotetext{
' c.f. Thomas L. Friedman, "Is Thailand singing a new song?" The Globe and Mail 16 Dec. 1997, A27.
} 
a business suit, rather than the "chut kharachakan" or uniform of the military-bureaucracy. The new man was faithful to his wife and cared for his children. He applied rational, technocratic reason to governance not self-enrichment or self-aggrandizement. This concern over image became powerful enough in the mid 1990s to allow for changes to the prostitution law that for the first time would provide for the punishment of clients, in particular, the clients of child prostitutes. The focus on children allowed for a discussion of men's roles as fathers, most importantly. The 1990 s was, however, a period of struggle over these competing discourses of the state and masculinity.

\section{Prostitution and the 'Image Problem'}

The protests against sex-tourism in the early 1980s had brought both national and international attention to the militarized masculinity of the Thai state. Even as some state representatives sang the praises of sex-tourism for a development scheme and many profited from it, there was awareness that Thailand's 'image' was under fire. The out and out acceptance of prostitution, through measures such as registration, were continually avoided. Both in 1981 and in the aftermath of the Phuket fire, the registration of prostitutes was raised as a possible measure to address the prostitution problem, and both times it was rejected by the government. ${ }^{2}$ Police representatives were in favour of registration but the government

${ }^{2}$ Renate Wilke, "Protest is not Ineffective," Der Uberblick April 1981 reprinted in Ecumenical Coalition On Third-World Tourism (ECTWT), Tourism. Prostitution. Development: Documentation (Bangkok, Ecumenical Coalition on Third World Tourism, n.d) 105 . 
was opposed to the idea because it would "damage the country's image." A government/ private subcommittee set up by the Prime Minister's Office in 1984 (staffed entirely by men) recommended a "cordon sanitaire" approach to prostitution. The committee proposed that the sex-industry areas of Bangkok and Pattaya be demarcated as 'red-light zones' controlled by the Bangkok Metropolitan Administration and Pattaya City along with the Public Health Ministry's Infectious Disease Control Department in order to ensure "peace, order and hygiene". ${ }^{4}$ Tourism officials were most concerned, however, with protecting tourists in order to ensure the continuation of the tourism industry rather than the well-being of prostitute women.

At the same time, the committee showed grave concern with the problem of Thailand's image. It suggested addressing Thailand's image by ensuring that officials "mention only good things about the country in seminars or meetings held abroad." Legal action against the "shameless promotion" of the tourism industry and the "unscrupulous entertainment places which offer sexual services and shows for tourists" was also proposed by the team. As well, the committee report outlined public relations measures such as providing hand-outs to Thais travelling abroad "carrying suggestions about the duty of Thais

3 "Working on White Slavery," Thai Development Newsletter 2.3 (1985): 21.

4 "Penalties Urged for Sex Tour Agencies,". Bangkok Post Aug. 1984, reprinted in ECTWT, 109.

${ }^{5}$ See "Offical Blessings for the 'Brothel of Asia'," Southeast Asia Chronicle, No.78, reprinted in ECTWT, 41-42. 
to help promote their country's image" and meetings with the Press to "point out the damage to Thailand caused by certain news reports which were blown out of proportion."6

In the $1990 \mathrm{~s}$, the government became increasingly sensitive to portrayals of Thailand and the Thai government in the international media. In 1993, Time magazine ran an article on prostitution - complete with a cover photo of a Thai bar girl - that claimed there were some 2 million prostitutes in Thailand. 'Also in 1993 there was the famous 'Longman's Dictionary Incident' in which the entry "Bangkok" included the description "a capital city with many prostitutes." A loud and indignant government protest led to its withdrawal. In 1995, however, a Microsoft CD-ROM encyclopaedia described Bangkok as a "flesh trade centre where there was danger of contracting AIDS."8 A BBC production on Thailand identified the country as a dangerous tourist destination, in particular because of the threat of contracting AIDS. ${ }^{9}$ The government's concern over these representations was not simply about the blatant global reproduction of sexist and racist images of Thai women, nor was it concerned so much with vulgar generalizations about Thai people, rather the most important issue was the representation of the Thai government's ability to govern in a 'modern,' 'responsible' way.

6 “Penalties Urged for Sex Tour Agencies," Bangkok Post August 1984, reprinted in ECTWT, 109-110.

${ }^{7}$ Wathinee Boonchalaksi and Philip Guest, Prostitution in Thailand (Bangkok: Institute for Population and Social Research, Mahidol University, 1994) 17.

${ }^{8}$ Thai Development Newsletter, 27-28 (1995): 15.

${ }^{9}$ Wathinee and Guest, 17. 
Indeed, representations of the prostitution problem in Thailand focussed on the Thai government's complicity in the sex-trade and its ineffectiveness in shutting it down. Often these representations echoed the colonial constructs of the Thai state as 'effeminate' and unable to rule in a proper, responsible and (gentle)manly manner. One of the articles that appeared on the issue in 1991 in Rolling Stone Magazine made the connection between Thailand's 'unmanly' attitude and the prostitution problem stating: "why is Thailand the whorehouse of the world? The 'land of smiles' is famously compliant, a crossroads country that has survived and kept its independence by accommodating itself to the vagaries of power." 10 The language clearly suggests that Thailand (a monolithic entity) lacks the strength to stand up for itself. It is weak, but worse, it is willing. Targeted to an American audience which pictured the American government's role in international relations as decisive and powerful, the message was one of blaming the victims for their 'unmanly' behaviour. Further, like the prostitutes themselves, the Thai state was pictured as having acquiesced in its own powerlessness. The blame was squarely shifted onto the shoulders of the Thai government and people and the context of their choices - the limitations they face in a

${ }^{10}$ Richard Rhodes, "Death in the Candy Store" Rolling Stone Magazine, 28 Nov. 1991,70 . Emphasis added. This in a magazine that less than ten years previously had celebrated Western male sexual abandon in Thailand and advised its readers "Used to be man could get a blow job while taking a dump in any barn in Bangkok, or so they say .... Here is where you drink till your face goes numb, here is where you find your darkeyed orb for the evening, here is your frat house, your locker room, and your Elks club." c.f. Catherine Hill, "Planning for Prostitution: An Analysis of Thailand's Sex Industry," Women's Lives and Public Policy, eds. Meredeth Turshen and Braivel Holcomb. (Westport: Praeger, 1993) 132. 
globalized market, for instance - are made invisible. This move effectively erases the imbalanced power relations between Thailand and the developed West. Bishop and Robinson have documented many instances of international press coverage which follow the same pattern of representation, always presenting Thailand and 'the story' of the sex-trade in a decontextualized way so that "First World culpability is reduced to deviant individual behaviour, effectively eliding broader social analysis." "Such representations powerfully underwrite First World intervention as the 'other country' appears to require intervention 'for its own good.' By the early 1990 s, the UN had placed Thailand on a 'watch list' for its failure to fully address child prostitution and the US and the European Union were threatening trade sanctions if policing efforts were not improved..$^{12}$

In a parallel colonial construction of the masculinity of the 'other', Thai men were characterized as 'sexually rapacious. ${ }^{13}$ Again, such a representation placed the blame for the prostitution problem squarely on the shoulders of Thai culture. The author of the Rolling

${ }^{11}$ Ryan Bishop and Lillian S. Robinson, Night Market: Sexual Cultures and the Thai Economic Miracle (New York: Routledge, 1998) 52.

${ }^{12}$ Steve Kendrick, "Sex Trafficking in Kids: When will Thailand get Angry?" Business in Thailand 25.5 (15 May 1994): 41-42.

${ }^{13}$ Such contradictory images of colonized men as both 'feminized' and 'hypermasculine' are in fact key to the sustainability of the stereotype. As Jan Pettman points out, in the colonial era: "A contradictory bundle of images could be activated simultaneously or in different situations. Colonised/black men were seen to have too little of some masculine characteristics, such as responsibility and stability, and too much of others, especially in terms of a sexualised hypermasculinity, which was a threat to white women, and to the black/colonised women too." Jan Pettman, Worlding Women (New York: Routledge, 1996) 33. 
Stone piece claimed that Thailand was "committing sexual suicide" through its uncontrolled sexual activities. The author listed the percentages of Thai men that visited prostitutes, had sex with multiple partners, never used condoms, maintained minor wives and so on. ${ }^{14}$ There is a consistent sense of uncontrolled sexual excess - harking back to the colonial representations of Thailand as oversexed, dissolute, a repository of feminine excess (and potential infection). As Chris Lyttleton has also pointed out, there is an increasingly common construction of Thai manhood "predicated on images of unrestrained male libidinousness and sexual profligacy [which] is considered a national character trait" especially in frequent repetition of reports that at least ninety percent of Thai men go to prostitutes. In 1991 and 1992, reports to this effect appeared in the New York Times, Far Eastern Economic Review and Newsweek.${ }^{15}$ Such attention to Thai male behaviour underwrites the sense that Thai men are unable to care for their women and children, and therefore lacking in the ability to govern that Western men are assumed to have. ${ }^{16}$

${ }^{14}$ Rhodes, 65.

${ }^{15}$ Chris Lyttleton, "The Good People of Isan: Commercial Sex in Northeast Thailand," The Australian Journal of Anthropology, 5.3 (1994): 265. As Lyttleton points out, such studies underrepresent rural men but are considered to cover the entire population. Lyttleton argues that "attitudes to commercial sex and frequency of patronage vary both individually and regionally."

${ }^{16}$ The elision of Western culpability is also reinforced here as it is Thai male sexuality that is considered generically problematic rather than the 'deviant individuals' involved in Western sex-tourism. As Julia O'Connell Davidson has revealed in her interviews with Western sex-tourists in Thailand there is a sense of moral superiority among the sextourists themselves who see themselves as more refined and proper in their sexual behaviour in ways that contrast to racial others, specifically Arab sex-tourists, who are 
The neo-colonial construction of Thailand in the international debate over prostitution was also made apparent in the protests launched against child prostitution in Thailand. The Don't!Buy!Thai! web-site established in 1996 portrayed Thailand as reprobate and Thais as evil child traffickers. It counterposed the benefits of American justice to the obviously backward and evil Thai state. The site's homepage announced: "We want Americans to boycott anything made or manufactured in Thailand. Thailand sells its children like products. It trafficks in the flesh of its own babies. For money. And the only thing that will stop it is the loss of money." 17 Americans were thereby justified in punishing Thais by Thailand's own moral backwardness according to this representation.

The site was supported, tellingly, by Dark Horse Comics, a company which had produced a comic book called "The Ultimate Evil." In the comic, Batman does battle with a child sex-ring in a fictional Southeast Asian nation called "Ubon Khai". ${ }^{18}$ Throughout the site's propaganda, Americans are pictured as the saviours of innocent children from the evil Thais. The Batman connection is no coincidence. The American public is called upon to be the world's 'caped crusader' against the inhumane (and monolithic) Thais. The imagery

pictures as rapists, cheaters and homosexuals. Julia O'Connell Davidson and Jacqueline Sanchez Taylor, Sex Tourism: Thailand (Bangkok: ECPAT, 1996) 12-13.

${ }^{17}$ Andrew Vachss, “D!B!T! Mission Statement”, D!B!T! homepage, http://users.aol.com/bdtlori/dbt1.html.

18 “The Don't!Buy!Thai! Campaign," The Nation 21 Feb. 1996, A6. "Ubon Khai" translates from Thai roughly as 'Sell-town'. 
echoes the racially charged panic over the so-called 'white slave trade' at the turn of the century. The 'warrior' language is made very clear:

If the formation of Don't! Buy! Thai! could be regarded as placing a gun to the country's collective head, the recent news of the downturn in the Thai economy and the resignation of Prime Minister Banharn [in October 1996] is confirmation that the gun is, in fact, loaded. And they know it. ${ }^{19}$

The Thai government protested both the comic and the web-site, emphasizing the Thai state's ability to respond to the problem of child prostitution. In a letter to the comic's author, Andrew Vachss, the Thai vice-consul in the United States wrote: "The Thai Government has not turned a blind eye to it but has instead tackled the problem with vigorous resolve."20 In the same vein, the "Public Official Response" distributed to Thai embassies during the Chuan administration stressed that it had been the Thai government which had raised awareness of and attention to the problem:

Operations to eliminate child prostitution, jointly conducted by the police and the Interior Ministry together with NGOs resulted in the revelation that a considerable number of young girls and children from neighbouring countries have illegally entered Thailand and worked as prostitutes. The Thai Government has disseminated information relating to this illegal activity in order to make the public aware of this growing problem and in no way has attempted any cover-up.

19 "Support for D!B!T! from Mr. Sompop Jantraka, A True Warrior Against the Enslavement of Children" Received via e-mail January 16, 1997 [on D!B!T! website] Written by Lou Bank, Dark Horse Comics.

${ }^{20}$ Letter from Akrasid Amatayakul, Charge d' Affaires, reproduced on D!B!T! website, http://users.aol.com/dbtlori/dbtl.html. Accessed January 1997. 
The Government has mounted a campaign and effort to redress the problem, which originated from sources outside the Thai Kingdom..... The foregoing problem became public knowledge as a direct result of the campaign mounted by the Thai authorities to eradicate it, especially the problem of child prostitution. ${ }^{2 \mathrm{I}}$

Clearly, the government sought to establish its capacity and modernity in the eyes of the international audience.

The 'image question' has become a very powerful political tool. Questioning the capacity and masculinity of the Thai state was considered an attack on the survival and security of the state. The government blamed Thai non-governmental organizations, which worked internationally to address the sex-trade issue, as 'damaging Thai national image'. The NGOs were accused of playing up the prostitution problem in order to increase their foreign support. The two million number quoted in Time magazine came under sustained attack as the product of a particular child rights' group's attempt to obtain more foreign funding. This kind of dismissal of NGOs as foreign-backed and foreign-controlled was common enough among the security-minded officials of the Thai state within the Ministry of the Interior and the Thai military. Similar views were also expressed by such 'progressive' politicians as Chuan who attacked groups working on issues of child prostitution and trafficking of women for "exaggerating the problems and tarnishing Thailand's image abroad". ${ }^{22}$ By equalizing all

${ }^{21}$ Royal Thai Government, Foreign Affairs, "Question of Child Prostitution in Thailand." Public Official Response. n.d. Emphasis added.

22 "Note from Human Rights Watch/Asia" Women's Studies News 7.15 (November 1995): 38. 
threats to state image-making as 'outsiders' those in power hoped to neutralize their effect often making not so subtle references to the communist threat of the previous era. Chuan also made the connection between NGOs and foreign funders by saying in 1993 that NGOs have disseminated negative information about the country to obtain foreign aid. Chuan criticized the press for disseminating negative images and asked diplomats in the Asia Pacific region to try to improve Thailand's image by providing "accurate and clear explanations to the international media" to counter unfair representations. ${ }^{23}$

So seriously was the image problem taken that in 1996, the Thai Foreign Ministry ordered an investigation into Thailand's image abroad. After several months of gathering media reports on Thailand from around the world the report was released in April 1997. The report found a mostly negative portrayal of Thailand in the foreign media. Prostitution figured largely in the coverage of Western media and child prostitution was the key issue. The response from Prime Minister Chavalit Yongchaiyudh's Secretary-General was anger that the Foreign Ministry would go so far as to publish this report. ${ }^{24}$ When, in September 1996 - during a non-confidence debate - the Thai-language daily Matichon published a report

\footnotetext{
${ }^{23}$ Human Rights Watch noted increasing surveillance of groups working on these issues and described an incident in which a relief centre for HIV/AIDS was harassed by local authorities and police to get them to move out of the area. The centre was closed after staff received death threats and the centre was bombed. No official inquiry was held into the incident. "Note from Human Rights Watch/Asia," Women's Studies News 7.15 (Nov. 1995): 38.

24 “Foreign media report raises ire of PM's secretary," The Nation 17 April 1997, online.
} 
on foreign investors' views of the Thai Government, a Cabinet member accused Matichon of being a "traitor that is undermining the reputation of the country," saying further that, "the press has gone too far in using the views of foreigners, let alone locals, to oust the Government." ${ }^{25}$ Other coalition members were quick to distance themselves from Samak's comments. General Chavalit, nonetheless, approved the establishment of a media control committee to monitor press stories on Thailand. The press cried censorship, although it soon discovered that the activities of the committee consisted of a bank of computers with no-one to monitor them. ${ }^{26}$ Nonetheless, the representation of the Thai government by both foreign and local media has been a constant theme during the last two years of economic meltdown, as the government blames this coverage for "scaring away investors" by playing up certain stories about the government and the economy. ${ }^{27}$

In an effort to respond to the image problem, the Tourism Authority of Thailand had, in 1994 , hired a private firm (for $\$ 800,000$ US) to polish Thailand's image, according to a report in the Bangkok Post. ${ }^{28}$ The managing director of the firm argued that Thai hospitality might be misinterpreted by foreigners: "It is widely known that Thai women are unique for

${ }^{25}$ Samak Sundaravej c.f. Bangkok Post, 11 Sept. 1996, A1.

${ }^{26}$ See reports in The Nation, June 1997; Bangkok Post June 11, 1997, on-line

27 “Media blitz to prop up govt image," Bangkok Post 3 Nov. 1997, on-line.

${ }^{28}$ c.f. "Sex tourist information goes out on global computer link," Thai Development Newsletter 27-28 (1995): 16. 
their hospitality and this may be regarded as submissive and easy by foreign cultures."29 Of course, the use of Thai women to represent Thai hospitality remained. As the Thai Development Newsletter pointed out, a member of the House Standing Committee on Tourism said in 1994 that the country's image could be improved through a campaign promoting service and hospitality. A film starring Miss Thailand, entitled "Land of Smiles and Hospitality" was to be filmed for CNN and STAR TV for overseas marketing of Thai tourism..$^{30}$

International 'image' had become a central concern in the 1990 s. Business and the middle class were globally linked and foreign investment was a central part of the booming Thai economy. Thus, while few had spoken out against the military takeover in February 1991 , in the face of 'unacceptable levels of corruption' in the Chatichai government, business and middle-class support began to fade when it became clear that the international markets were less than pleased with the move. The coup, however, had been initially acceptable to many because of the appointment of Anand, who promptly lived up to his reputation as a democrat by removing military figures from executive posts in state companies ${ }^{31}$ and

29 "Sex tourist information goes out on global computer link," Thai Development Newsletter 27-28 (1995): 16.

30 "Sex tourist information goes out on global computer link," Thai Development Newsletter, 27-28 (1995): 16.

${ }^{31}$ Although as Pasuk points out the larger structure of military power remained intact despite Anand's highly publicised moves. Pasuk Phongpaichit, "The Thai Middle Class and the Military: Social Perspectives in the Aftermath of May 1992," The May 1992 Crisis in Thailand: Background and Aftermath, ed. Peter A. Jackson (Canberra: National 
reforming the bureaucracy and political institutions. Anand also appointed 'capable technocrats,' who were considered progressive, to his Cabinet - including Thailand's famous population control advocate and public health expert Dr. Meechai Veeravaidhya and Dr. Saisuree Chutikul. Such steps were extremely appealing to a middle class that had grown tired of government corruption and ineptitude.

The New Middle Class, Government Capacity and Local Notables

The 1980s were marked by growing corruption in Parliamentary politics and increasing dissatisfaction with this development by the urban middle class. Indeed, the rapidly changing balance of forces within Parliament doomed the government's bill on prostitution to die on the order papers, as once more the government went to election in 1986. The bill's demise reflected the growing influence of 'provincial notables' who profited from the prostitution industry. The dominant party, Social Action, headed by Kukrit Pramoj and originally an alliance between metropolitan business (Boonchu) and liberal royalists (Kukrit), had dissolved into nine competing factions reflecting the growing power of the 'provincial notables. ${ }^{, 32}$ In what was to become a major and repetitive feature of Thai politics

Thai Studies Centre, Australia National University, 1993) 32.

${ }^{32}$ Boonchu himself had close connections with well known provincial 'godfathers' Sia Jiew (who made his money in hotels) and the infamous Kamnan Pho, making his support for tourism prostitution not surprising. Pasuk Phongpaichit and Chris Baker, Thailand: Economy and Politics (New York: Oxford UP, 1995) 337. 
in the following decades, those factions which had not been awarded cabinet seats manoeuvred to bring about the collapse of the government coalition and new elections. ${ }^{33}$

The local notables built their political influence through their links to the military and police officials, their spectacular wealth and the loyalty of the rural citizenry. The local notables had made their wealth in illegal businesses such as smuggling, gambling and prostitution, garnering protection by establishing connections with military, police and officials both through bribery and family ties. ${ }^{34}$ As well, military leaders had often recruited local businessmen to build organizations like the Village Scouts in the anti-communist campaign which established enduring ties of loyalty between rural villagers and local notables. ${ }^{35}$ To the poor, the local notables offered a system of social support, lacking from the official bureaucracy. One local notable explained:

People cannot rely on kharatchakan [bureaucrats]. Kharatchakan have only small salaries. But I have much and I can distribute much. Whenever I sit in the local ran kafae [coffee shop] people can come and consult with me. I am a man of the people already. I am more accessible than kharatchakan. On any matter where the karatchakan cannot help, I can. And I do it willingly and quickly. It's all very

${ }^{33}$ Pasuk and Baker, 344.

34 The extent of organized crime's involvement in the prostitution industry, while always assumed, has come under academic scrutiny only recently because of the dangers involved. See Pasuk Phongpaichit's forthcoming book, Guns, Girls, Gambling, Ganja: Thailand's Illegal Economy and Public Policy (Chiang Mai: Silkworm, 1999).

${ }^{35}$ Pasuk and Baker, 335. 
convenient for the people.....Most of what I do is about giving employment and improving the local facilities. ${ }^{36}$

Local notables gave money to the poor, sponsored weddings and funerals and helped to find jobs for local people. In doing so they garnered loyalty, or enforced it when it was not forthcoming. Hired guns were used whenever their services were required, including obtaining Parliamentary seats. ${ }^{37}$ At first, local notables were content to fund the entry of business politicians into politics, using their connections to arrange vote-buying schemes. By the mid-1980s more and more local notables were entering the race themselves. Newspapers increasingly referred to ittiphon meut (dark influences) to suggest the involvement of the local notables. ${ }^{38}$

The power of the local notables in Parliament increased in the 1986 Cabinet under the Democrats led by Bangkok businessman Bichai Rattakun when a number of provincial bosses were appointed to Cabinet while the Bangkok-based core of the party was largely ignored. ${ }^{39}$ Their power increased further after the 1988 election when Prem stepped aside as Prime Minister and General Chatichai Choonhaven, leader of the Chat Thai (Thai Nation) Party became the first elected Prime Minister since the 'democracy period' of the 1970 s. The

${ }^{36}$ c.f. Pasuk and Baker, 335.

${ }^{37}$ Pasuk and Baker, 335-336. See also, Benedict Anderson, "Murder and Progress in Modern Siam," New Left Review 181 (May-June 1990): 33-48.

${ }^{38}$ Pasuk and Baker, 336-337.

${ }^{39}$ Pasuk and Baker, 344-345. 
Chatichai government, however, quickly became known as the "buffet cabinet" for reaching new heights of kin muang (literally eating the country, a common term for government and the kickbacks associated with it). The military overthrew the Chatichai government in February 1991 and installed Anand. Anand's moves to reform the bureaucracy and move aside influential military men were widely applauded in Bangkok. After a general election in March 1992, however, General Suchinda reneged on his promise not to seek the Primeministership. In May, members of the Bangkok middle class took to the streets in protests led by Chamlong Srimuang, the former mayor of Bangkok and leader of the newly founded Palang Dharma party - a party devoted to anti-corruption and social progress. In the clashes between the military and the protestors at least fifty people were killed and many more went missing. ${ }^{40}$ Dubbed the "cell phone mob" for the prominent representation of business-people in the crowd, the protest showed that the middle class would no longer accept outright military rule, not so much on the principle of democracy (although this too was important to some) but largely because of the perceived need for rational and efficient government, which could not be provided by the military directly but which could be provided by such enlightened technocrats as Anand.

40 "Summary of Political Events in Thailand 1991 and 1992," The May 1992 Crisis in Thailand: Background and Aftermath, ed. Peter A. Jackson (Canberra: National Thai Studies Centre, Australia National University, 1993) 4-6. 
Increasingly, for the middle class, governance was about competence. ${ }^{41}$ The middle class was rapidly growing weary of the shake downs and the need for 'connections' that blocked their path to professional and financial progress. ${ }^{42}$ As one business writer noted:

Thailand's new professional class does not have the benefit of [the kinds of connections held by members of the economic, military and bureaucratic elites]. As 'outsiders' in traditional business circles, it is in their interests for connections to play a decreasing role in Thai business. Many members of the middle class also believe that businesses based on individuals' ability are bound to be more effective than those based on personal connections. This conviction has been transposed from the business sector to the government. A company in which the managing director and executives are people of low administrative quality, brought in through rampant nepotism, would not last long in Thailand's competitive business sector. The Thai middle class is losing patience with a government similarly assembled. ${ }^{43}$

Importantly, it was the rural sector that appeared to be blocking the kinds of changes that the middle class wanted to see. The rural-military-dark influence connection was the subject of growing resentment by the urban middle class, which continued to see its political

${ }^{41}$ Anek Laothamatas c.f. Kevin Hewison, "Emerging Social Forces in Thailand: New Political and Economic Roles," The New Rich in Asia: Mobile Phones, McDonald's and Middle-Class Revolution, eds. Richard Robinson and David S.G. Goodman. (New York: Routledge, 1996) 155.

${ }^{42}$ See Richard Basham's discussion in "Democracy Means Never Having to Say You're Sorry: Notions of Freedom and Fairness in Thai Attitudes Towards Democracy," The May 1992 Crisis in Thailand: Background and Aftermath, ed. Peter A. Jackson (Canberra: National Thai Studies Centre, Australia National University, 1993) 15-17.

${ }^{43}$ Virat Saengthongkham, et. al. "Coming of Age" Manager (July 1992) c.f. Basham 16-17. 
aspirations founder on the basis of rural voting power. Some eighty percent of the seats in the National Assembly were from the rural areas and the vote buying schemes and connections kept the 'dark influences' and corrupt politicians in power. The middle class blamed the peasants, who sold their votes to these corrupt politicians, for the continuation of 'old style' politics and the failure to develop a modern, efficient public sector. May 1992 was clear evidence that the urban middle class would no longer put up with either military rule or inefficient and corrupt government. It sought a reformed society and government that could address the growing problems associated with rapid modernization such as prostitution. Accordingly, the middle class - in line with elite women - also challenged the military model of masculinity underlying the 'old style politics' of the 'devils' - as promilitary parties became known during the May 1992 incident. The new 'angels' of democracy were also a new kind of man - efficient technocrats like Anand and morally upright like Chamrong.

\section{International Image and the New Man}

Progressive members of the middle class used the 'image question' to challenge the government and press for progress on the 'prostitution problem.' In 1996, the Bangkok Post's own editorial argued that "turning the issue of prostitution in Thailand into that of national honour and dignity, the authorities have cleverly used nationalistic sentiments to 
their own advantage."44 Another Post editorial emphasized that Thailand must get its "own house in order" and cease the "easy finger-pointing and foreigner-bashing that enable us to avert our eyes from the real problem," pointing out that sixty percent of Thai men were revealed to have had sex with more than one partner "and that of those promiscuous men, fewer than one-third use condoms." It argued further that:

If we are honest, we will admit that the vast majority of patrons of Thai brothels are Thai men.... These are difficult, searching questions that only Thai people - not foreign 'sex tourists'; not the editors of Longmans Dictionary - can and must answer. ${ }^{45}$

For the aspiring middle class what was undermining the country's image - and, relatedly, its economy - was the 'political ineptitude' and corruption of political leaders. Vitit Muntarbhorn, a professor of law, activist on children's rights (Special Rapporteur on the Sale of Children), and media commentator, was emblematic of this growing understanding. In his three-part series, in the Nation in October of 1996, on Thailand's image abroad, he began with a critique of the political system dominated by military power and "old-time" promilitary politicians which stifled the development of a civilian, "transparent" political system. The military crack-down on pro-democracy demonstrators in May 1992, he argued, was a result of "the long-standing acquiescence or collusion between self-interested

44 "Sex tourist information," Thai Development Newsletter 27-28 (1995): 16.

45 "We must tackle our problem first," Bangkok Post 1 Sept. 1996, 6. Emphasis in original. 
"civilian' politicians and key military leaders."46 May 1992 was the "blot" on Thailand's image, according to Vitit.

Similarly, the post-election fiasco of 1996 , in which government formation was stalled while coalition members fought over choice Cabinet seats, was decried as a shameful and embarrassing spectacle. In a Bangkok Post editorial after the election, entitled "Enough shame; end the farce," the editors wrote:

Thais are ashamed because of the foreign spotlights shining on the country. Our politicians are always the first to complain of harm to the country's image when we are criticised by foreigners. But their antics of the past week and their downright refusal to pick a new premier and get on with business is the worst image our nation can project. Last week's censure debate was the climax to a long period of political and economic decline. It is natural that foreigners and their press are watching proceedings with interest. It is natural they are appalled by our politicians' actions. ${ }^{47}$

Part of this shame was linked explicitly to middle-class interests in an international, globalized world. The editors pointed out that Thais were particularly ashamed because the debacle had caused the postponement of an international meeting on the Growth Triangle, and the cancellation of the foreign ministers' appearance at the UN General Assembly annual meeting. In particular, the editors called on Bangkok businessmen to demand that the government get on with the job of governing.

\footnotetext{
${ }^{46}$ The Nation, 8 Oct. 1996, A4

47 “Enough Shame, End the Farce," Bangkok Post, 27 Sept. 1996, 12.
} 
The new elite and middle class have drawn on 'western' images of masculinity to challenge 'old-style' governance as 'old-style' masculinity. The political debate pitches the 'old man' of Thai politics - the greedy, oversexed, military dictator - against the 'new man' of the Thai middle class - rational, efficient, and fatherly, a defender rather than a user of women and a protector of children. A political cartoon from the 1996 election clearly illustrated this characterization of the old order - in which a bloated, desirous General Chavalit is characterized as grasping after "The Prime-ministership," which is depicted as a nubile young woman desperately trying to escape his clutches. ${ }^{48}$ By contrast Chuan, the usual champion of the middle class, was often depicted as a 'knight in shining armour'. The construction clearly parallels the Western construction of self and other where the self is a sexually-restrained, rational gentleman and the 'other' over-sexed and uncontrolled.

The Chavalit cartoon hints that not only is Chavalit's obvious greediness for the Prime-ministership unbecoming, but so is such sexual rapaciousness. It reflects a changing consciousness among a certain segment of the middle class about proper male sexual behaviour as being within the confines of the monogamous marriage in contrast to the common practice of elite men taking mistresses and minor wives and visiting prostitutes. It also links that behaviour to the ability to govern. In opposition to the political legitimation earlier leaders, such as Sarit, gained from his sexual exploits, political leaders in today's Thailand face approbation and loss of political acceptability, among the middle classes at

\footnotetext{
${ }^{48}$ Nok, cartoon, Bangkok Post 25 Oct. 1996, 10.
} 
least, for similar types of behaviour. Speculation about Chavalit's past wives and womanising ways became a continuing theme in the media after his election, not only as titillating gossip but as a form of political criticism. ${ }^{49}$ The appearance of one Cabinet minister's minor wife on the steps of the Parliament demanding compensation provided further fodder for the media and opposition politicians..$^{50}$ Female politicians in the house made accusations against two Cabinet ministers of maintaining former beauty queens as minor wives. ${ }^{51}$ Chuan, on the other hand, appears regularly on family outings with his wife and young son. The only other woman in Chuan's life upon whom the media reports is his mother, a market vendor in the South who is considered an icon of the 'real Thai people'. Indeed, in the changing patterns of family life in the middle class, new expectations for male behaviour were formed. The "warm family" became a central theme in middle class family values. Not reliant on their children's labour as in the rural areas, the middle-class family could adopt the values of extended and protected childhood. The discourse of men's role within the family was also changing. Increasingly, middle class women were demanding

${ }^{49}$ See, for example, "PM's Second Wife Recalls her First Love," The Nation 28 March 1997, on-line; "PM admits to womanising during youth," The Nation 30 March 1997, on-line.

50 "Snoh's 'other wife' mounts vigil at Government House," The Nation 2 Feb. 1997, on-line.

S1 "Anonymous ministers accused of adultery," The Nation 13 Sept. 1996, A6. 
adherence to monogamy..$^{52}$ The discourse of middle-class families emphasized the 'warm' (monogamous, committed) family. Mary Packard Winkler argues:

Monogamy is a fashionable ideology with discursive power. Images of men spending time with their kids and helping wives with chores are evoked in the media and in casual conversation, and seem particularly valued among liberal, cosmopolitan groups like intellectuals and some businessmen. Men in these groups may be among the few who do not get chided by their pals for being 'afraid of the wife' if they decline a night of carousing. 53

The Seventh National Development Plan (1992-1996) was the first plan to formally recognise the importance of the family in maintaining social values. A National Committee for the Family was formed in 1991 which produced television broadcasts, radio spots, essay and art competitions promoting the family and, in particular, promoting male roles as

52 This is not to say Thai women were passively accepting their husbands' behaviour. While many remain convinced of the 'nature' of male behaviour as promiscuous, women also assume some strategic control over their husbands' behaviour by accepting visits to prostitutes but not the taking of a minor wife, who would pose more of a threat to the family and family resources. See Mark VanLandingham et. al Friends, Wives and Extramarital Sex in Thailand (Bangkok, Institute of Population Studies, Chulalongkorn University: 1995) and Kanchana Tangchonlatip and Nicholas Ford, 'Husbands' and Wives' Attitudes towards Husbands' Use of Prostitutes in Thailand," UK/Thai Collaborative Research Development in Reproductive and Sexual Health: Proceedings of the Symposium on the Mahidol-Exeter British Council Link (Bangkok, Institute of Population and Social Research, Mahidol University, November 1993). The stories of open female anger are also rife, with Thailand's medical community claiming the greatest proficiency in penile re-attachment surgery. Stories of women cutting off their husbands' penises in a fit of rage appear frequently in the newspapers.

${ }^{53}$ Mary Packard Winkler, 13; See also Maliwan Yongyuth and Radda Larpnun, "New Age, New Man?" The Nation 17 Nov. 1996, B1-B3. 
husbands and fathers and encouraging men to "take a greater share of the household chores and responsibility for child-rearing, and to remain faithful to their wives. (Particularly in view of the spread of HIV/AIDS)." ${ }^{54}$

With the discovery of the rapid transmission of HIV among non-commercial heterosexual partners in the 1990 s, the need for men to change their sexual behaviour became clear. Dr. Weerasit Sitthitrai, deputy director of the Red Cross Programme on AIDS, and an adviser to the Prime Minister's office on AIDS during the Chuan administration, argued in 1993 that addressing the AIDS problem in Thailand would require a complete change in attitudes and behaviour: "Men should look at buying sex as the most disgusting thing in the world. All about chauvinism and power."5s

Favourite corruption fighter Police Lieutenant General Seri Temiyavej - a champion to the new middle class for standing up against corruption in the police force and battles against the local notables like Kamnan Pho - exemplify the 'new manhood'. In an article on his exploits in The Nation, Seri characterized his difference from fellow officers as "I never accept bribes, gamble nor commit adultery like the others." ${ }^{\text {"6 }}$ Changing attitudes among young men were made apparent with a 1997 poll of nearly 4,000 men in their late teens and

\footnotetext{
${ }^{54}$ National Commission on Women's Affairs (NCWA), Thailand's Combined Second and Third Report to the Committee on the Elimination of Discrimination against Women (Bangkok: NCWA, July 1996) 21-22.

55 "Apocalypse Soon" The Nation, Mid-Year Report 1993, reprinted in Thai Development Newsletter 31 (1996): 24.

56 "Justice in Action," The Nation 15 February 1998, C3.
} 
early twenties at high schools, vocational colleges and universities. Over sixty percent of those polled felt it was "not OK" to have sex with sex workers, although almost half of them had in fact done so. Fewer still, twenty-nine percent, felt it was "good to have your first sexual experience with sex workers, in order to learn about sex" - a common explanation for young men's visits to brothels. ${ }^{57}$

Men's role as fathers was also challenged by the "warm family" concept. In the middle-class media of 1990s Thailand, 'new men' like academic, and popular television host, Pinthong Chermsak praised the joys of fatherhood, ${ }^{58}$ and advertisers began to target "househusbands' for the sale of household products. ${ }^{59}$ 'New men' have spearheaded the children's rights organizations; for example, Vitit Muntarbhorn (Special Rapporteur on Child Slavery to the UN and head of Child Rights Asianet), Koson Srisang (ECPAT), Sanphasit Kumpraphan (CPCR), Wanchai Roujanavong (Coalition to Fight against Child Exploitation) Sompop Jantranka (DEP). Sanphasit was the subject of a full-page feature article in the Bangkok Post in September of 1996, as a "champion of children's rights," which outlined his tireless work for children, his own commitment to wife and family and his condemnation of men's behaviour: 'Men's promiscuous behaviour can greatly damage a marriage. Some

${ }^{57}$ Results of the Foundation for Women/ Assumption University Poll Research Centre's poll in Voices of Thai Women 26 (October 1997): 13-15.

${ }^{58}$ Radda Larpnun, “Academic's education a child's affair," The Nation 17 Nov. 1996, B2.

${ }^{59}$ Marissa Chantamas, "'House-husbands' now targeted by advertisers," The Nation 17 Nov. 1996, B2. 
men say they can't control their sexual desire so they have to visit a brothel or sleep around." He admitted that when he accompanied friends to brothels as a youth: "I would wait for them outside. I felt too guilty to go in. If you don't even know a woman, why sleep with her just for sex?" Many elite men, including the editor of Krungthep Thurakij(Bangkok Business), continued to defend 'traditional' male sexual practices, but obviously felt themselves to be under attack. The editor wrote in an open sympathy letter to Chavalit in the wake of the latest minor wife scandal: “Mr. Prime Minister you have my sympathy. I am, after all, a real Thai man like you sir."61 In March 1993, the Governor of Songkhla province in the south of Thailand, suggested that prostitutes should be prevented from returning to their home villages during the Thai New Year celebrations se they could participate in Songkhla's parade which "would make the procession more colourful, particularly when they are in Hawaiian dress or scantily clad...I think they will attract foreign tourists". ${ }^{62}$

Nonetheless the ideal of the 'new man' continued to gain political force. The decision by the conservative middle-class newspaper the Bangkok Post to halve the size of the "Trink column" - a regular feature on what's new in the sex-trade scene - attests to the fact that the 'new men' are gradually gaining ground in the media world. Rather than seeking to 're-assert

${ }^{60}$ c.f. Kulcharee Tansubhapol, "Champion of children's rights," Bangkok Post 21 Sept. 1996, Outlook, 1, 8.

${ }^{61}$ Kasem Adchesai, "Of love, lust and human nature." The Nation 21 March 1997, online.

${ }^{62}$ c.f. Wathinee and Guest, 17. 
their masculinity' in the face of Western hegemony through their possession of women, the 'new Thai man' asserts a 'technocratic', 'controlled' and 'rational' masculinity that is seen to be the key to membership in international society. ${ }^{63}$ In this discourse, only such a man will resolve Thailand's political and economic problems and move the country into a new era of rational governance and prosperity as well as international respectability. This representation clearly sought to differentiate middle-class, 'new-style' men from the Thai men characterized by the international press.

Prostitution Policy in the 1990s: Disciplining Men

The rejection of attempts to control prostitution through registration in the late $1980 \mathrm{~s}$ and early 1990s reflected the growing strength of the new middle class. The issue of most concern to government was the rapid rate of HIV transmission. In the late 1980s and early 1990s the rapid spread of HIV infection in Thailand grew to rates that were considered to threaten a national crisis. At a 1990 meeting on "the Role of Government and nonGovernment Organizations in preventing and Correcting Sexual Business Service," Dr. Meechai quoted extremely high rates of HIV infection among prostitutes in the northern city of Chiang Rai - known for its high concentration of prostitutes - at fifty-six percent of the total population of prostitutes, up from thirty-five percent in 1989 and less than one percent

${ }^{63}$ See Katherine Moon, "East Meets West: Sex Industries in East Asia," (Toronto: ISA, 1997) 6-8 for a discussion of the re-assertion of masculinity in Asia. 
in $1988 .{ }^{64}$ Meechai, whose name has become synonymous with condoms in Thailand and who has mass public appeal, also supported the World Health Organization estimate that some 300,000 Thais carried the AIDS virus and that by the year 2000 , two to four million Thais would be infected. ${ }^{65}$

The response of senior officials within the Ministry of Public Health was to call for the arrest of infected prostitutes, who would be sent to the Welfare Department's retraining program. ${ }^{66}$ Green cards were to be issued to prostitutes who tested negative. There was, however, strong pressure for more education as opposed to punitive measures from less senior officials within the Ministry. Even as the Ministry moved towards cooperation with brothel owners to mount condom distribution campaigns, it also pushed for "draconian" control legislation that would empower Public Health officials to enter private homes to force AIDS victims to enter treatment, and to compel entertainment facilities to provide medical services for their employees and to ensure clients used protection. Any sex establishment that did not use condoms (which was assumed to be evidenced by sex workers

\footnotetext{
${ }^{64}$ Chatsumarn Kabilsingh, Thai Women in Buddhism (Berkeley: Parallax Press, 1991) 74.

${ }^{65}$ Penny van Esterik, "Thai Prostitution and the Medical Gaze" Gender and Development in Southeast Asia, eds. Penny van Esterik and John van Esterik, CCSEAS XX Vol. II (Montreal: Canadian Asian Studies Association, 1991) 143. In a letter to The Nation Meechai argued that the number infected in 1990 might be closer to 800,000. S.D. Bamber, K.J. Hewison and P.J. Underwood, "A History of Sexually Transmitted Diseases in Thailand: Policy and Politics" Genitourinary Medicine 69 (1993): 153.

${ }^{66}$ Bamber et. al., 154; van Esterik, 145.
} 
visiting clinics) would be temporarily closed. ${ }^{67}$ The proposed legislation was strongly opposed by Meechai as well as a number of NGOs for its authoritarian measures. The bill targeted "promiscuous people" for enforced testing and pressured medical workers to reveal the identities of those who tested positive to the Ministry. The NGO Coalition against AIDS also objected to the green card idea as ineffective, particularly since it would likely lead to a false sense of security among clients who would become careless in their use of protection. EMPOWER objected to the targeting of prostitute women rather than their clients.

The objections to the bill forced the Ministry to put the bill to more extensive Parliamentary debate and it died on the order papers with the 1991 coup.$^{68}$ The rejection of the bill reflected a growing resistance to authoritarian government among the urban middle class. The Nation newspaper had run an editorial decrying the:

'strong-man' approach to the spreading pandemic [which] is politically attractive because it gives officials the appearance of taking action. It also satisfies the sensitive moralities of those who still cling to the illusion that Aids [sic] affects only 'bad' or 'sexually promiscuous' people, who should be 'punished' for their depraved lifestyles. ${ }^{69}$

Indeed, former strongman Thanin Kraivixian had been a major supporter of the bill arguing for "strict control of 'irresponsible' people such as prostitutes, homosexuals, drug addicts and

${ }^{67}$ van Esterik, 145; Ji Ungphakorn "Politics and 'morality' of Aids in Thailand" The Nation 13\&21 March 1994, reprinted in Thai Development Newsletter 31 (1996): 27.

${ }^{68}$ van Esterik, 145.

${ }^{69}$ c.f. Bamber et. al., 154. 
prisoners. ${ }^{70}$ Strong international criticism was also aimed at the government's measures, for example, an international conference on AIDS in Bangkok - where the bill was promoted by the Ministry of Public Health - was boycotted by many international delegates and the World Health Organization. ${ }^{71}$

The vocal criticism of the bill was evidence that while the new middle class wanted decisive action on the prostitution problem, they were not willing to accept authoritarian measures or the abrogation of fundamental rights. The appointment of Anand by the coup makers quelled any fears that personal rights would be in fundamental jeopardy. Indeed, the Anand government took several progressive steps in ensuring and furthering women's rights.

The end of the Prem premiership, and the gradual loosening of the hold of the military over the government, re-opened space for women's lobbying in 1989. MP Khunying Supatra Masdit (later Minister to the Prime Minister's Office) was able to lobby the Chatichai government to restore the NCWA, this time as a permanent advisory and coordinating body under the Prime Minister's Office where it remains today. ${ }^{72}$ Under Anand, Dr. Saisuree, a long time advisor on Youth was appointed Minister for Women, Children, Youth, Education and Social Development. In this role she oversaw the NCWA. Anand's progressive cabinet opened the window for long-awaited changes. On February 25, 1992 the

${ }^{70}$ Bamber et. al., 154-155.

${ }^{71}$ Bamber et. al., 154.

${ }^{72}$ Darunee Tantiwiramanond and Shashi Ranjan Pandey, By Women, For Women: A Study of Women's Organizations in Thailand (Singapore: ISEAS, 1991) 33. 
law on citizenship was changed to grant equal rights to women and men to transmit Thai citizenship to their children. ${ }^{73}$ The government also extended maternity leave in the public sector to sixty days, from thirty, with an optional extra thirty days. ${ }^{74}$ Saisuree suggested that parental leave be extended to men as well, while the proposal was rejected in cabinet, one reporter found a "luke warm" reaction among the men she interviewed. ${ }^{75}$

While a legalization bill was proposed by Minister Saisuree during the Anand administration, there was little support from the new democratic forces for such a measure. The bill would have provided legalization measures for prostitute women over the age of 18 who worked voluntarily and had their health checked regularly. Saisuree's position reflected that of a number of elite women on the NCWA anti-prostitution committee, which in the face

${ }^{73}$ National Commission on Women's Affairs, "Women and the Law," Perspective Policies and Planning for the Development of Women (1992-2011) (National Committee on the Perspective Plan and Policies for Women's Development, National Commission on Women's Affairs, Office of the Prime Minister, 1995) 12-12.

74 "60-day maternity Leave Approved" Friends of Women Newsletter 2.2 (Dec. 1991): 11-12. While Saisuree, supported by women's groups, had proposed 90 day leave the measure was strongly opposed by the Finance Minister, the government eventually settled on 60 days with an extra 30 automatically available from a civil servant's usual 45 days annual leave. Women's groups also campaigned to have the leave extended to the private sector. "Open Letter to Prime Minister on maternity leave" Friends of Women Newsletter 2.3 (Dec. 1991): 15. The new nationality law also had drawbacks, giving Thai officials the ability to revoke Thai nationality from those whose parents were temporarily or illegally in Thailand - part of the growing backlash against illegal migrants. Vitit Muntarbhorn, "Sex, Snobbery and Social Development," Voices of Thai Women 8 (Jan. 1993): 18.

${ }^{75}$ Chaiyaporn Chaicharoen "Maternity leave for men: Some revelations" The Nation 15 June 1991, reprinted in Voices of Thai Women 5 (July 1991): 18-20. 
of continuing male sexual prerogative, resistance to decriminalization or punishment of clients, and the growing AIDS threat, considered legalization the only viable alternative. However, as she notes:

When I was minister I said, well, in a way, "pachot" - okay if you want to do it, let's do it [legalization] - and suddenly General Chamrong and his group, the Buddhist people, said no, no this is a Buddhist country you cannot do that. We can't do that because that means you're approving it. $^{76}$

The legalization bill, however, was lost with the end of the Anand administration in September 1992 and the election of Chuan Leekpai to the Primeministership. ${ }^{77}$

Saisuree continued as advisor to the Chuan government on youth and women's issues - spearheading a campaign to reform prostitution law particularly in order to protect children. The legalization bill had sought to enforce stronger measures against child and forced prostitution in line with growing concern over these problems. ${ }^{78}$ During the Chuan

${ }^{76}$ There is a sense of resignation in the expression "pachot" as in "fine, I give in." Interview with Dr. Saisuree Chutikul, Bangkok, 27 Nov. 1996.

${ }^{77}$ The idea of registration has not gone away, however. The Department of Public Welfare still acknowledges that it is "looking into" the possibility as a method to crack down on the exploitation of children. The idea was supported by Khunying Phankrua PM Chavalit's wife. "Labour sets up hot-line for child abuse complaints," Bangkok Post, 17 January 1997. The NCWA's own anti-prostitution committee remains divided on the issue of legalization.

${ }^{78}$ Asia Watch and the Women's Rights Project, A Modern Form of Slavery: Trafficking of Burmese Women and Girls into Brothels in Thailand (New York: Human Rights Watch, 1993) 30. 
government Saisuree and the NCWA recommended that the government focus its efforts on child prostitution.

In 1990 the Children's Rights Protection Centre announced that it estimated there to be two million prostitutes in Thailand, 800,000 of them children. While the government, including Saisuree, vehemently denied that the numbers were accurate, the announcement heightened public awareness of the child prostitution problem. ${ }^{79}$ Reflecting this concern, the Seventh National Economic and Social Development Plan (1992-1996) acknowledged some of the negative effects of economic growth; for example, it noted that child prostitution was caused by children being:

...influenced by improper social values with regard to consumption and sexual relationships. Many are forced or misled to serve business interests or the [sex] entertainment industry. Law enforcement, as well as measures to protect, prevent, guard and supervise children ... are not efficient. ${ }^{80}$

Also in 1992 the NCWA outlined its program to prevent prostitution, which included a "campaign to change undesirable sexual values and create sexual morality, especially to discourage men from visiting prostitutes" and to discourage parents from selling their

${ }^{79}$ Centre for the Protection of Children's Rights (CPCR), "Case Study Report on Commercial Sexual Exploitation of Children in Thailand," (Bangkok: Centre for the Proctection of Children's Rights, October 1996) 29-30; Saisuree Chutikul, "Women and Commercial Sex in Thailand," Canadian Women Studies 15.2\&3 (1995).

${ }^{80}$ Children and Youth Development Plan During the Seventh National Economic and Social Development Plan 1992-1996, National Youth Bureau, Office of the Prime Minister, c.f. CPCR "Case Study Report on Commercial Sexual Exploitation of Children in Thailand." 
children into prostitution. ${ }^{81}$ The NCWA's campaign to stop men from visiting prostitutes included a poster competition where the captions on the winning entries read: "My father does not visit the prostitute" and "Father, please come home tonight. Please don't go to the prostitute. ${ }^{82}$ Fathers' failure to create the 'warm family' was increasingly emphasized as a cause of prostitution by the NCWA. In a 1995 article, Saisuree emphasized that prostitution was caused by a number of interrelated factors including the economic irresponsibility of fathers towards the family, as well as divorce and family violence, which led children to run away. She also blamed the "unrestricted sexual freedom" of so-called "traditional" male sexual behaviour. ${ }^{83}$

The NCWA made it clear that changing Thailand's international image would require reforming male behaviour in order to effectively address prostitution. In its 1994 report to the Beijing meeting, the NCWA pointed out that the continued operation of sex-businesses had undermined the international image of the country and in its 20 -year long term plan for women's development it declared "prostitution is seen as a part of Thai culture resulting in damages to reputation of the country and to the dignity of Thai women." ${ }^{84}$ The child sex

${ }^{81}$ NCWA, Perspective Policies and Planning, 1-33.

${ }^{82}$ Dr. Saisuree Chutikul, "Children in Commercial Sex: Demand, the Overlooked Aspect - Clients" Asia-Pacific Regional Consultation on Commercial Sexual Exploitation of Children (Bangkok, March 1996) 38-39.

${ }^{83}$ Saisuree Chutikul, "Women and Commercial Sex in Thailand, Canadian Woman Studies 15.2\&3 (1995): 118-119.

${ }^{84}$ NCWA, Perspective Policies and Planning, 11-10. 
trade was deemed to be particularly damaging. The NCWA introduced a "National Policy and Plan of Action for the Prevention and Eradication of the Commercial Sexual Exploitation of Children" in 1996 that declared:

Tolerating children in the commercial sex industry has made the country a target of attack from local and foreign media. It affects intercountry trade and plays a part in tarnishing the country's image. There has been condemnation from abroad, so much so that it has damaged the dignity of Thai women and Thailand. ${ }^{85}$

In his final article on Thailand's image, Vitit Muntarbhorn similarly stressed that the lack of effective law enforcement concerning prostitution, particularly child prostitution, had resulted in Thailand's lack of credibility in the international arena. ${ }^{86}$

The NCWA's "National Policy and Plan of Action for the Prevention and Eradication of the Commercial Sexual Exploitation of Children" called the commercial sex business a "social crime detrimental of human value and dignity ... against decent morality, tradition" and the "people-focussed" Eighth National economic plan. It outlined government policy as: the total elimination of entry into the commercial sex business by children of both sexes under 18; the prohibition of luring, threats, exploitation, and acts of violence in the prostitution business; and:

${ }^{85}$ NCWA, National Policy and Plan of Action for the Prevention and Eradication of the Commercial Sexual Exploitation of Chiidren, (National Committee for the Eradication of Commercial Sex, National Commission on Women's Affairs, Office of the Prime Minister, Thailand, 1996) 2.

${ }^{86}$ Vitit Muntarbhom, “The undoing of Thailand's image," The Nation 25 October 1996, A5. 
imposition of punishment to all persons with a part in bringing children into the commercial sex industry and punishment to officials negligent in, or choosing to ignore, their duty to enforce compliance with relevant policies, laws, rules and regulations. ${ }^{87}$

The plan was introduced at the 1996 World Congress against Commercial Sexual Exploitation of Children as evidence of Thailand's commitment to ending the child sextrade.

Accordingly, under both Chuan's and his successor's Cabinet, new legislation to combat prostitution was introduced that would include punishment for clients of children in prostitution. Chuan was widely viewed as a clean politician and 'new man' for a new age of democracy in Thailand, and he was widely trusted by the urban middle class and progressive elites. Complaints from the UN and the US Congress over Thailand's failure to address child labour and child prostitution pushed Chuan's announcement (in November 1992) of a crackdown on child prostitution. Provincial governors were told that they must "take responsibility and give special attention to child prostitution and child labour abuse." That same day a woman who had escaped a brothel in Songkhla and sought protection from the police was found murdered in the town hall. Initial reports that the woman was actually under 18 were used to support the government's anti-child prostitution campaign. ${ }^{88}$ Very soon, however, it became clear that not only was the 'girl a 'woman' but that the negligence or

\footnotetext{
${ }^{87}$ NCWA, National Policy and Plan of Action, 2.

${ }^{88}$ Wathinee and Guest, 24.
} 
direct involvement welfare officials and police led to the woman's murder ${ }^{89}$ In an attempt to restore the government's credibility, Chuan's Minister of the Interior - and future Prime Minister - General Chavalit Yongchaiyudh announced that he wanted all brothels closed down in the next two months. ${ }^{90}$ The campaign, however, was not nearly as successful as promised and the government came under heavy fire for its failure to live up to its promises. The central weakness of the Chuan administration was often cited as Chuan's being "too slow" in bringing about the reforms demanded by the middle class. As one prominent scholar noted, the Chuan Cabinet failed to "develop their reputation as efficient administrators." The importance of such a reputation was becoming clear both in national and international circles.

Chuan's government was brought down in 1995 after a scandal erupted over a land reform scheme in Phuket - the resort town and key prostitution venue - which was designed to divide land resources more equitably. It was soon discovered, however, that the wealthy husband of the local Democrat MP, and secretary to the minister in charge of land reform, was the recipient of some of the land under the scheme. ${ }^{92}$ The scandal merely built on

${ }^{89}$ Two provincial officers, two police officers, the son-in-law of the brothel owners and a pimp were eventually charged. This was one of the very rare occasions in which a police officer was actually charged, Asia Watch, 80-81; CPCR, "Case Study Report," 17.

${ }^{90}$ Asia Watch, 33-34.

${ }^{91}$ Suchit Bunbongkarn, Thailand: State of the Nation, (Singapore: Institute of Southeast Asian Studies, 1996) 33.

${ }^{92}$ Suchit, 103. 
previous disappointments, including Chuan's own Deputy Finance Minister, Boonchu Trithong, being caught hosting an "end of Parliamentary session" party that included the provision of prostitutes to fellow MPs. ${ }^{93}$ Chuan's efforts to establish an effective special task force to combat prostitution was rife with problems. In a July 1993 raid in Bangkok, the Crime Suppression Division (CSD) arrested eighty-nine girls and women holding fake Thai identity cards, and discovered account books listing protection payments to Thai government officials (including special police task units, immigration officials and the CSD policemen). ${ }^{94}$ Once again, with the proroguing of Parliament new prostitution legislation died on the order papers.

The results of the election appeared to be a disaster for middle-class aspirations. The Chat Thai party, headed by the godfather of Suphan Buri, Banharn Silpa-archa, formed a coalition government. It was believed that "much more money was used in this election than in previous ones", as well as a good deal of party switching by MPs in an attempt to garner Cabinet seats. ${ }^{95}$

While the Bangkok-based middle class was sorely disappointed with election of the Banharn government, the pressure for the reform of prostitution law, and with it, male behaviour, was strong enough that the legislation was re-introduced. Concern to present a

\footnotetext{
93 "Statement on the Call Girl Scandal," Friends of Women Newsletter 4.2 (1993): 4-5.

${ }^{94}$ Asia Watch, 76.

${ }^{95}$ Suchit, 37.
} 
modern and rational image to the rest of the world led to high support for the bill even within the Banharn Cabinet (an unstable coalition of local notables, business and former military), despite its links to the 'old ways' of governance. Some argue that in fact the bill was passed during this government's tenure because this Cabinet above all needed to prove itself in light of the "credibility crisis" of a government rife with corruption and facing divisions within its own ranks. ${ }^{96}$ Indeed, the Banharn government was the first to consider legislation which would have allowed a woman to obtain a divorce if her husband had committed adultery and to file suit to seek compensation from unfaithful fiancés and adulterous husbands. ${ }^{97}$ It clearly sought to show its commitment to fairer gender relations.

Nonetheless, debate over the prostitution bill was extensive, most importantly because for the first time the bill provided for the punishment of clients of prostitutes under the age of eighteen. The debate pitted the 'old guard' of masculine privilege against the reformists. Shepherding the bill through the House in 1996 took the concerted effort of female parliamentarians and advisors. Female MPs (who numbered only twenty-four in the 391 seat House) from Palang Dharma (Sansanee Nakpong) and the Democrat Party (Laddawan Wongsriwong) initiated drafts of the bill in the House. Khunying Chandanee,

96 Teena Gill, "Prostitution law misses the target say Activists," Gemini News Service, News-Scan International Limited, 1995 (World Sex Guide). Indeed the Banharn government was brought down very shortly after passing the new bill after several scandals including the involvement of Cabinet members in bilking the Bangkok Bank of millions of baht which eventually led to the financial 'meltdown' that occurred in 1997.

97 "Marriage bills aim to provide women with equal rights," The Nation, 10 April 1996. 
who chaired the Joint Parliamentary Committee on the bill, also emphasized the importance of passing the bill to new female Parliamentarians at a reception at the NCWT. MPs such as Kanchana Silpa-archa, daughter of then PM Banharn Silpa-archa, promised her support. ${ }^{98}$ The focus on the protection of children gave elite women within the House an unassailable ground from which to defend the bill. The protection of children is an important basis of legitimacy for female politicians - one that Kanchana made frequent reference to when she was dismissed as being in politics merely to support her father. Nonetheless, supporters of the bill faced recalcitrance from some members of the House. Commenting on the length of time that it took to get the bill through Saisuree pointed out that it was:

\begin{abstract}
... not only the opposition, but the procedure, we change the government so often, also the delay in process of getting from the Office to the Parliament to the King, that takes a long time. Then there are substantive issues, particularly, do you want to arrest the customers? Because most men will say, some said to me, you'll have to build all sorts of prisons because there might be 1.6 million men who are being arrested. But we're saying that eighteen below, sometimes people don't understand that, that our priority group is eighteen below. ${ }^{99}$
\end{abstract}

The bill was delayed for some time in the joint committee as MPs argued for lowering the penalties on clients. ${ }^{100}$ One male MP, who was an executive on the Committee,

${ }^{98}$ Interview with Khunying Chandanee Santaputra, Bangkok, 12 Nov. 1996.

${ }^{99}$ Interview with Saisuree Chutikul, Bangkok, 27 Nov., 1996.

${ }^{100}$ The penalties were set for two to twenty years and a fine of 40,000 to 400,000 baht for visiting prostitutes under the age of fifteen, with lesser penalties for using prostitutes 
said: "A lot of male MPs were shocked to learn of the harsher punishment to be imposed."101 Other proponents, like Thongbai Thongpao, a well-known human rights lawyer and media commentator, appealed to the character of the men in the House to defend the bill. He assured his audience in his weekly column that the bill would surely be passed despite the delays over the section penalizing clients and despite the domination of the House by men, because "after all, these male MPs have morals and education. Most of them are Buddhist who also fear Aids." ${ }^{02}$ Thongbai argued further that: "for the sake of righteousness, virtues, humanity, principles and the pride of the nation the new prostitution suppression draft ought to be passed" because Thai people are "notorious for prostitution all over the world."103

Khunying Chandhanee argued strenuously for the higher penalties, pointing out that the bill targeted activities inside brothels only (although the definition of brothel or "place for prostitution" has been expanded to include any places or establishments "used for contact between prostitutes and clients"). ${ }^{104}$ She was warned, however, that she would face veto in

between the ages of fifteen and eighteen. Thongbai Thongpao, "Anti-prostitution bill must be passed," Bangkok Post 7 April 1996.

${ }^{101}$ Danairit Watcharaporn, executive member of the Parliamentary Committee, in BP, $29 \mathrm{Jan}$. 1996. In the original version of the bill proposed under Chuan the fine was raised from 1,000 to 10,000 baht. Victoria Combe, "Child sex trade forced underground", The Nation 30 Jan. 1993, CI. 1996.

${ }^{102}$ Thongbai Thongpao, “Anti-prostitution bill must be passed," Bangkok Post 7 April

${ }^{103}$ Thongbai.

${ }^{104}$ CPCR, "Case Study Report on Commercial Sexual Exploitation of Children in Thailand" (Bangkok: Centre for the Proctection of Children's Rights, October 1996); 
the House if the punishments were considered "too stern." ${ }^{105}$ Although, as some MPs pointed out, harsher penalties already existed in the Criminal Code, Khunying Chandhanee insisted that real change in attitudes would only come with changes to the prostitution bill to bring it into line with the Criminal Code. In the Senate, proponents of the bill faced male Senators who argued that "sex was like food" for men - a basic requirement. Khunying Chandhanee answered quickly 'Don't you think we are hungry too? You should respect your wife and daughter ... also the women of Thailand likewise."106 Nonetheless, the penalties were eventually lowered in order to win wider support, to two to six years plus a 40,000 to 120,000 baht fine for under fifteen. ${ }^{107}$ The penalty thus remains lighter than the prison penalty for statutory rape under the Criminal Code. ${ }^{108}$ Yet, for the first time clients were to be punished for their role in prostitution.

Interview with Khunying Chandhanee.

${ }^{105}$ Supawadee Susanpoolthong, "Key hurdle for tough bill on child prostitution," Bangkok Post 29 Jan. 1996.

${ }^{106}$ Interview with Khunying Chandhanee.

${ }^{107}$ Section 8, The prostitution Prevention and Suppression Act B.E. 2539, Draft, November 1996; "Prostitution bill seen clearing second reading," Bangkok Post 29 March 1996.

${ }^{108}$ The penalty for statutory rape in the Penal Code is four to twenty years and a fine of 8,000 to 40,000 for girls under fifteen and life imprisonment or seven to twenty years with a fine of 14,000 to 40,000 baht for girls under thirteen. Section 277, Penal Code Amendment Act No. 8, BE 2530. The lower age of marriageability and the lack of a marital rape provision in Thai law led to the inclusion of the rider "if the commission of the offence as specified in the first paragraph is against the marriage partner of the offender, and is not committed for sexual gratification of the third person, the offender is not guilty" to Section 8 of the new act. 


\section{Conclusion}

The debate over what to do about the 'prostitution problem' was part of a much larger debate about the shape of Thai society and statehood. By linking the question of prostitution to the failure of the state - and the men who ran it - to modernize, to become efficient as well as protective of women and children, proponents of changes to prostitution legislation were able to garner considerable support. In particular, the growth of a middle class that saw its interest in being a modernized, globalized nation lent support to the campaign to reform masculine behaviour. Prostitution became increasingly recognized as the result of 'old style' Thai politics that frustrated the aspirations of the middle class. The middle class demanded a new kind of state and a new kind of man to run it in order to lead Thailand into a new era of prosperity and international respectability. The discourse of the new manhood, however, clearly operated to establish middle-class authority - both against the 'old-style' military politicians and 'local notables' and against peasant and poor men, who were not considered capable of adopting this new form of rational, modern masculinity. And, while middle-class women stand to benefit from the new model of masculinity that insists on monogamy for men, they find themselves continuing to be responsible for the maintenance of tradition and morality. And, as we shall see in the next chapter, for prostitute women this has meant continued pressure to conform to particular standards of 'traditional' female behaviour. 


\section{Chapter 8: The Middle Class and the Material Girl}

The achievement of the new legislation on prostitution was widely celebrated by its champions as a sign of the commitment of the Thai state to addressing the prostitution problem and reforming social attitudes, particularly male attitudes, towards women and children. The price of this new measure to discipline men into proper modern, masculine behaviour was increased control and discipline over the peasant population and prostitute women themselves. The disciplinary measures laid out by the new legislation would have their greatest impact on lower-class men and on prostitute women, who continued to be penalized for engaging in prostitution under the new legislation.

In this chapter we see how it was the peasantry, and prostitute peasant women in particular, who were viewed as the ones in need of state discipline. While the new middle class championed the values of modernity it also sought to maintain traditional Thai identity. The role of maintaining traditional identity fell, once again, to the peasantry and to women. Prostitution was viewed as the result of the failure of these groups to maintain this 'true' identity. In particular, they had adopted the values of consumerism in opposition to the ideals of Buddhism and bucolic village life. At the same time, women's groups began to recognize the importance of addressing the conditions of work of prostitution instead of seeking to abolish prostitution itself. The media and middle class, however, presented prostitute women as undeserving and greedy consumers rather than women working to support their families. The legislation's penalization of prostitute women reflected this belief. 


\section{Peasant Parents and the 1996 Bill}

As we saw in the previous chapter, the model of the new man had gained increasing acceptance among the middle class as the proper form of masculinity for Thai men. The new prostitution legislation was championed by those who sought to ensure the adoption of this model and the strength of its international and middle-class appeal eventually led to the acceptance of punishment for clients of children in prostitution. However, the adoption of the bill was seen, in effect, to be proof that middle-class Thai men already were modernized new men and that the bill's disciplinary measures would be directed against other men foreigners, old-style men, local notable types and lower-class men. Thongbai Thongpao defended the bill on the grounds that: "Above all, the law will protect our children who are usually abused by tourists, some [of] whom fly in solely for such a purpose at the expense of the welfare of Thai children and the country's honour."' Others argued that it was 'Chinese' men who were the problem, arguing that the belief that sex with a child is rejuvenating comes from Chinese tradition and has led to a demand among Sino-Thai business men. ${ }^{2}$

Experts on child prostitution, however, note that a large percentage of customers of child prostitutes are Thai rather than foreign. Importantly though, it is poor men rather than

\footnotetext{
' Thongbai Thongpao, "Anti-prostitution bill must be passed," Bangkok Post 7 April 1996.

${ }^{2}$ Victoria Coombe, "Child sex trade forced underground," The Nation 30 Jan. 1993, $\mathrm{C} 1$
} 
rich men who appear to frequent children in prostitution. According to Dr. Sappasith Koompraphandh, while "the rich will go to member clubs where women with university degrees are for sale, while the low-income Thai will go to the back-street brothel and buy a child. These men are not paedophiles.... They would prefer sex with a woman but they cannot afford it'."3 The decrease in prison time and increase in fines suggests that the bill is indeed slanted in favour of the wealthier classes. Certainly, rural and working class men are seen as less inclined to adopt the 'new man' attitude. ${ }^{4}$ Less educated men are failing to adopt the new standards of behaviour, according to newspaper reports on, for instance, AIDS prevention. According to a 1995 report in The Nation, men with lower levels of education are "still visiting brothels frequently although the HIV infection rate among prostitutes is as high as twenty per cent." The emphasis on brothel and child prostitution in the new legislation, therefore, will be most likely to catch poor men within its ambit. The new law acts as a disciplinary mechanism to force lower-class men into the 'new man' model of the middle class.

${ }^{3}$ c.f. Coombe, $\mathrm{C} 1$.

${ }^{4}$ See for example, Marissa Chatamas, "Old attitudes still difficult to eradicate," The Nation 17 Nov.1996, B3.

5 “Thais' woes on AIDS: Ignorance, old habits, and sex taboo," Thai Development Newsletter 27-28 (1995): 17. However, it is not simply 'uneducated' men that continue to take risks vis-à-vis HIV. Bamber et. al. relate a 1992 social meeting with officials from the Ministry of Public Health to discuss AIDS, after which "three young women were brought for the selection and use of the senior official." Kevin Bamber et. al., "A history of sexually transmitted diseases in Thailand: policy and politics," Genitourinary Medicine 69 (1993): 154. 
Poor men are also a target of the disciplinary ideology of the 'new man' as fathers. Elites have pointed to the failure of proper fatherhood among rural, lower-class men as a cause of prostitution. Mattani Rutnin has argued that, according to her research, girls sold into prostitution "usually have fathers who are not strong financial supporters of the family." The lack of "love and warmth" in the family is a result of the changes wrought by modernization in the rural family according to a $1992 \mathrm{NCWA}$ report on prostitution. It is this lack of 'warmth' that leads children to leave home and leaves them open to being pressured or deceived into the sex business, according to the report. ${ }^{7}$ And, as we saw in the previous chapter, the rural peasantry is viewed as having sold out to materialist values and in need of re-disciplining into 'traditional' values.

Hence, the bill also provided, for the first time, punishment for parents who knowingly sold their children into prostitution - again assumed to be the rural poor.

Originally, the bill provided for punishment of parents whether they sold their children "knowingly" or not. NGOs argued that it would be unfair to punish parents who often are unaware of what their children will be going into - having been told they will be working as

${ }^{6}$ Saisuree Chutikul, Children in Especially Difficult Situations; I. Thailand, report to UNICEF (National Youth Bureau, Office of the Prime Minister, June 1986) 43.

${ }^{7}$ National Commission on Women's Affairs (NCWA) Perspective Policies and Planning for the Development of Women (1992-2011) (Bangkok: National Commission on Women's Affairs, Office of the Prime Minister, 1995) 11-8. 
maids or waitresses in Bangkok. ${ }^{8}$ Even with the change to "knowingly", human rights organizations are concerned that the "burden of proof will be on the parents." As one analyst pointed out:

Most of the parents have been facing serious social and economic changes and are not fully aware of the working conditions their children may encounter and of the abuses they may undergo. In fact the main cause for child trafficking into prostitution remains on the demand side: procurers and customers who are responsible for the violent abuses and exploitation of prostituted children. Furthermore, human rights groups believe that it would be very difficult to prove whether a child's parents sold their children into sex trade rather than the labour market. If this section is passed under these terms, one may fear that it could later lead to many legal blunders where parents, some of them victims themselves, are systematically arrested and charged. If such a section is included, it should take into account the hardship that drives many people into committing this serious crime.

However, elite proponents of the bill viewed the issue as a problem of the 'backwards' attitude and morals of rural peasants, rather than poverty. MP Laddawong Wongsriwong, one of the chief proponents of the bill, argued that parents in the North simply do not regard selling sex as immoral: "they just think that their children can make money by going into the profession." She claimed that parents often asked "what's wrong with prostitution?" Laddawan argued that the news media needed to teach parents to be more aware of negative

\footnotetext{
${ }^{8}$ Teena Gill, "Prostitution Law Misses the Target say Activists," Gemini News Service, News-Scan International Ltd., 1995. World Sex Guide, Prostitution by Country, Thailand.

${ }^{9}$ Jasmine Caye, "Preliminary Survey on Regional Child Trafficking for Prostitution in Thailand," (Bangkok: CPCR, 1995) 10.
} 
effects of selling girls into sex industry. ${ }^{10}$ Once again, the peasantry were characterized as the backward 'other' who needed instruction from the morally superior middle class.

Indeed, the middle-class opponents of prostitution were seen as better interpreters of 'true tradition' than the peasants who embodied it. For example, while some members of the House worried that the bill's provisions would damage the 'Thai tradition' of gratitude to parents, commentators like Thongbai replied, "no Thai tradition has ever stipulate[d] that daughters sacrifice by committing an immoral deed which runs opposite to humanity and human rights. It is simply a hypocritical claim to exploit one's own children without moral support." 'Real' Thai tradition, therefore, was not that practiced by the peasants, but what was defined as 'real Thai tradition' by the educated classes.

So seriously was the issue of reforming rural parents' behaviour taken that the punishments to parents are higher than those faced by procurers and clients (parents can be imprisoned $4-20$ years and fined 80,000 to 400,000 baht). ${ }^{12}$ Parents who sell their children or who conspire with others to allow their children to enter prostitution can also have their guardianship of those children revoked. ${ }^{13}$ Commentators point out that it will certainly be easier to penalize parents - especially those from marginalized hill-tribes who do not speak

10 "Sex trade agents face tough action," The Nation 23 March 1994 reprinted in Voices of Thai Women 11 (1994): 3.

"Thongbai Thongpao, “Anti-prostitution bill must be passed," Bangkok Post 7 April 1996.

${ }^{12}$ Section 12, The Prostitution Prevention and Suppression Act. BE 2539.

${ }^{13}$ Section 13, The Prostitution Prevention and Suppression Act, BE 2539. 
Thai - than the operators who know how to "work the system." ${ }^{4}$ Others are sceptical that the provision will be helpful to the children:

It's very difficult to prove the age of the girls. And the part ... that empowers authorities or NGOs to arrest the parents of the girls, in my opinion, will work negatively, it won't help the girls. The girls will be even more abused, more paralyzed. There were some disagreements among some feminist groups and social workers who are working on women's issues and some NGOs who want to have some authority to do something with the parents because some parents are quite terrible. But, in my opinion, they may be targeting the wrong target, the weakest people. It's very easy to target parents instead of procurers. The girls will be more paralyzed because the procurers or the owners of brothels will threaten them that if they run away or what not their parents will be arrested. ${ }^{\text {is }}$

Others also worry that the bill increases the disciplinary power of the state over children and their parents:

Actually we agree with their idea that the child should be protected from their parents selling them or allowing them [into prostitution] because we think it is exploitation of children. But to have a national committee to be responsible ... we were not sure whether this will work or not, I feel it's like, not only me but the NGOs working with children, it's like, if the ... children are taken out from brothels and the parents can not [be] involved, [and] if the court proved that they [were] sold, [then] the child has to be placed somewhere, in a home, that the national committee [has] sent them to. In

${ }^{14}$ Interview with Jasmine Caye, Bangkok 12 December 1996.

${ }^{15}$ Interview with Jasmine Caye, Bangkok, 12 December 1996. 
our language we call it 'forced welfare,' you cannot choose, you must be in this place. ${ }^{16}$

Further, the state is ill-equipped to play the role of foster parent:

And we worry about the institution that will come to take care of the children. Because so far in our law and in our practice we don't have yet that kind of structure or skills to take care of the young people to replace their parents. It will be government and NGOs shelters who are registered by the government so it will be more controlled in a way, by the government. ${ }^{17}$

The new act greatly expanded the powers of the state and police vis-à-vis prostitution related offences, despite the problematic involvement of police and other officials in the trade. In an attempt to counter corruption among officials the Senate did add a clause to Section 12 which levied a heavier penalty on administrative officials who committed the act outlawed in the new legislation. ${ }^{18}$ In all, the new act greatly increased the penalties on pimps, procurers and brothel owners in line with the government's concern to 'crackdown' on child prostitution and to appear to be taking strong measures against the perpetrators. ${ }^{19}$ Section 9 provided for the punishment of "whoever procures, deceives, or traffics the other person to commit the prostitution activity, with or without consent of the other person" with one to ten

${ }^{16}$ Interview with Rangsima Limpisawas, Bangkok, 26 Nov. 1996.

${ }^{17}$ Interview with Rangsima Limpisawas, Bangkok, 26 Nov. 1996.

${ }^{18}$ Section 7, The Prostitution Prevention and Suppression Act, BE 2539.

${ }^{19}$ Brothel owners appeared to be singularly unconcerned with the new provisions however, citing 'loopholes', 'needy parents' and the fact that many young children are coming in from Burma and China rather than Thailand. See "Brothel owners indifferent to prostitution bill," Bangkok Post 1 April 1996, 6. 
years imprisonment and a fine of twenty thousands to two hundred thousand baht, and even stiffer penalties for trafficking in children under eighteen. And, for the first time, the advertising of sex services is punished.

The act also attacked the use of force in adult prostitution by penalizing procurers for using deceit, threat, physical assault, "immoral influence" or "mental coercion by any other means". The highest penalties specified in the act are for detention and assault in order to force someone into prostitution. The death penalty or life imprisonment is the specified punishment if the victim is killed in the attempt to force her into prostitution. ${ }^{20}$ This provision gave pause to some members of the House who argued that the inclusion of the death penalty would be damaging to Thailand's image given that it had been abolished in many countries on humanitarian grounds. Debate over the provision caused a second delay in the bill's passage. ${ }^{21}$

Other passages that would have increased the search and seizure powers of officials were scaled back. In the second reading in April, passages considered key by children's rights activists concerning search and entry were dropped from the bill. The provisions allowed officials without a warrant to "enter any place, night or day, if there is good reason to believe that there is confinement or forced prostitution, in order to assist the victims" and "search any vehicle and persons in the vehicle, in cases where it is suspected that the vehicle

${ }^{20}$ Section 12 paragraph 2, The Prostitution Prevention and Suppression Act BE 2539.

21 "Bill on child prostitution stalls again," The Nation 11 April 1996, A3. 
is transporting persons to commit offenses under this act, in order to help the victims of such offenses." The new provision read simply: "The official shall have authority and duties as follows: (1) to enter into the entertainment place according to the law on entertainment places, both day and night, for inspection and monitoring the commission of the offenses in this Act."22 Children's rights organizations were concerned that this greatly reduced the abilities of officials to act against procurers and owners. ${ }^{23}$ Such sweeping powers for officials, as proposed in the original bill, would, however, have been open to abuse.

The tendency to support dangerously expanded police powers in order to counter child prostitution and trafficking was also reflected in the proposed anti-trafficking bill put forward by the NCWA under Chuan. This bill would have empowered officials "to question and inspect women and children who travel abroad, at any time and without warrants" and to detain them up to 7 days before obtaining a court order. ${ }^{24}$ Such provisions contravened women's right to travel freely, as per the United Nations' Convention for the Elimination of

${ }^{22}$ Section 39, The Prostitution Prevention and Suppression Act, BE 2539.

${ }^{23}$ Centre for the Protection of Children's Rights (CPCR), "Case Study Report on Commercial Sexual Exploitation of Children in Thailand," (Bangkok: Centre for the Proctection of Children's Rights, October 1996) 20.

${ }^{24}$ CPCR, 21. Police powers were expanded in response to complaints that their hands are tied in legal terms, in particular, because women often travel alone for prostitution purposes but police are unable to stop them at the border. Kobkul Rayanakorn. Special Study on Laws Relating to Prostitution and Traffic in Women (Bangkok: Foundation for Women, 1995) 19. The new Anti-trafficking act was passed on Nov. 17, 1997 which reduced custody to no longer than half an hour but extendable to 10 days. Friends of Women Newsletter 8 (Jan-Dec. 1997): 9. 
Discrimination against Women , and were dropped before the bill's passage under the 19961997 Chavalit government. ${ }^{25}$ In all, however, the new legislation ushered in several measures that will in all likelihood be used against rural parents and working class men without respect to their weaker economic and political position in society.

\section{The Continued Criminalization of Prostitution}

The price of these new measures to protect children and to discipline parents and clients was the continued disciplining of women. A number of women's groups withheld support for the bill because it continued to penalize prostitutes rather than remove all criminal sanction as women's groups had requested. While the NCWA's development plan argued that "the way of dealing with the sex trade must be in the form of assistance/aid instead of arrest and punishment,"26 according to Khunying Chandhanee, the continued penalization of prostitute women was part of the price of getting the bill through, as male MPs were unwilling to accept penalisation of the customers if prostitutes themselves were to go unpunished. ${ }^{27}$ Some elite women also felt that punishment of prostitutes was needed. MP Sansanee Nakpong (Palang Dharma), who initiated the bill, argued that if prostitutes -

${ }^{25}$ CPCR, 23.

${ }^{26}$ National Commission on Women's Affairs (NCWA), Perspective Policies and Planning for the Development of Women (Bangkok: Office of the Prime Minister, 1995) 11-1.

${ }^{27}$ Interview with Khunying Chandhanee, Bangkok, 12 Nov. 1996. 
including child prostitutes - were not punished, they would return to the sex industry and that, in any case, the punishment was light. ${ }^{28}$ However, the chief author of the NCWA plan for prostitution was also unhappy with the penalization of women, pointing out that men are punished only if the prostitute is under eighteen:

I'm still not really happy about it, it still punishes the prostitute, and they didn't punish the man, they punish if [the men] use the young prostitute, eighteen down. But if [the women are] nineteen up, if they are caught in the sex industry, the sex workers will be punished. But what about the men? If they want to punish the prostitute they should punish the man, but if they don't want to punish the man they should not punish the prostitute, because it takes two. ${ }^{29}$

Section 4 of the new bill defines prostitution as "the acceptance of sexual intercourse, the acceptance of any other act, or the commission of any act for sexual gratification of another person in a promiscuous manner, in order to gain financial or other benefit, no matter whether the person who commits such act and the other person are of the same or opposite sex." The promiscuity of the act presumably differentiates it from acting as a minor wife. Prostitute women face a fine of up to 1,000 baht and/or one month's imprisonment for "benefitting from the prostitution activity." These punishments are lighter than in the 1960 act but not as light as originally intended. The NCWA had originally agreed to drop all prison

28 “Prostitution bill seen clearing second reading," Bangkok Post 29 March 1996.

${ }^{29}$ Interview with Maechii Khunying Kanitta Wicharoen, Bangkok, 25 Oct. 1996. 
terms and settled on a 500 baht fine. The new act, however, provided punishment for solicitation "overtly or shamelessly committed" at 1,000 baht fine. ${ }^{30}$

Unlike the 1960 Act, Section 6 recognized that if the prostitute is "forced" or "under an influence in which that person cannot avoid or resist, the offender is not guilty" thus recognizing women's groups arguments that women can be forced into the trade and held against their will and should not be punished. On the other hand, recognition that women may choose to work as prostitutes or enter into prostitution through a third party willingly was not made clear in the bill either. While women are punished for their activities, all procuring activities are also punished "with or without consent of the other person."31 The provision was in line with the UN Convention on Trafficking in Persons and met the objections of anti-trafficking organizations that women could be forced to consent. The section was also clearly part of the government's goal to stem the flow of women into the trade, which throughout the act was deemed to be unacceptable.

Critics also pointed out that:

${ }^{30}$ Drafters in the NCWA and the Department of Public Welfare had originally tried to reduce the fine for solicitation to 500 baht but the Senate dropped the section, derived from the original act, which would have made it an offense to loiter in a public place "overtly inducing prostitution." The Senate considered the clause would pose a danger to the liberty of women waiting for buses or otherwise on the street for "legitimate" reasons. "Cracking down on prostitution," Bangkok Post 3 Feb. 1993, reprinted in Voices of Thai Women, 9 (June 1993) 36; Marut Bunnag, "New laws planned to govern sex trade," Bangkok Post 10 August 1996, 11.

${ }^{31}$ Section 9, The Prostitution Prevention and Suppression Act, BE 2539. 
several sections .... refer to the protection, education and care of offenders convicted under sections 5-6, but the wording of the sections only thinly disguise the corrections mentality from which most of the work to 'reform' prostitutes in Thailand has so far been undertaken. ${ }^{32}$

Those convicted under sections 5 and 6 (and section 8 which provides for traffickers) could be remanded to a rehabilitation shelter under the newly created Committee for Protection and Vocational Development which included both government and non-government organizations. If the offender is eighteen years of age or less, the court can decide "after having examined the biography, behaviour, intelligence, education, physical health, mental health, profession and environmental surrounding of the offender" to send them to such a shelter. If the offender is over eighteen they can ask to go to a shelter if it is "appropriate in the opinion of the court". Presumably, the court will determine the 'recalcitrance' of the character of the convicted person - whether or not they can benefit from vocational training and rehabilitation - which means either they express a desire to leave the trade or claim victimhood. Section 38 of the act empowers officials, with the assistance of the police, to pursue and to return those who escape from the shelter. ${ }^{33}$ The bulk of the act deals with setting up and overseeing the reform institutions, reflecting the main thrust of the act to discipline the women involved into correct behaviour.

${ }^{32}$ CPCR, 20.

${ }^{33}$ Section 38, The Prostitution Prevention and Suppression Act, BE 2539. 
For elite women who supported the bill, it was a necessary measure to reform society. Government officials such as Ajaan Saisuree feel that Thai society is not yet ready for such a step as decriminalization. For her, laws are meant to be changed and this bill is what Thai society will accept at the moment although she personally feels that one should be able to make an informed decision to enter prostitution. As she argues, change is always possible in the future: "twenty years down the road things may be different." With this bill Saisuree hopes that in its implementation the illegal status of prostitutes over eighteen will be "soft pedalled":

\begin{abstract}
My thinking is that if you're eighteen, you're adult enough, you can vote, you can do anything, so that's a signal of being [the age of] maturity, you're on your own, decide what you want, you know the pros and cons. We have to give education to them so they know AIDS, HIV, STDS so on ... but [if] you know that, and know [that] this profession is very short - at 45 no-one wants to sleep with you - if you know that and you still want [to become a prostitute], go ahead ... if [you're] over 18. As long as there is no exploitation - just so they are not coerced to do it, not exploited in terms of wages or abuse. ${ }^{34}$
\end{abstract}

However, it seems likely that having this new act in place decreases the possibility of decriminalization in the future since arguments for it in terms of protection of prostitute women will be undermined by arguments that sufficient protection is already provided in the new act.

According to Saisuree, prostitution should not be removed from the books as suggested by some decriminalization proponents, because the issue at stake is more than an

${ }^{34}$ Interview with Ajaan Saisuree Chutikul, Bangkok, 27 Nov. 1996. 
issue of rape - which could be charged under the penal code - but of "dishonesty" and true social reform:

The moral question in prostitution is not only sexual values, also talking about honesty vs. corruption, honesty and being hypocritical, talking about the facade of presenting self in public in one way and turning around and the very action you do is opposite to your way of presenting yourself. And there seems to be no internal conflict within that person... those coexist together. The culture is based on shame not guilt. You won't let the public know because you are ashamed, but the guilt, which is more in terms of changing your values, the guilt will change more of your values is something that people don't like.

... We're talking about how do you absorb religious values, religious teaching is very superficial. Like some priest would come out and say "if you are offered the money to buy your vote, you can accept it its okay, but you don't have to vote" it's a double wrong-doing, one, accepting the money, two, not keeping your promise. ${ }^{35}$

The focus of anti-prostitution efforts therefore, according to Saisuree, must be on achieving two major changes:

Number one, it's options, you have to have more options, and those options are not only in paper, it's a real option that a woman can choose for her own career. With that kind of option you have to have knowledge and skill. You don't have option 'up there' and you cannot reach it. The option becomes a real option to you when you can reach it. Number two, conscience, men's conscience, women's conscience, parental conscience. ${ }^{36}$

${ }^{35}$ Interview with Ajaan Saisuree, Bangkok, 27 Nov. 1996.

${ }^{36}$ Interview with Ajaan Saisuree, Bangkok, 27 Nov. 1996. 
For Saisuree, a new bill specifically on prostitution put the issue into the spotlight and forced a focus on changing social attitudes. For proponents of the bill, then, the need to reform society's, particularly men's, attitudes towards women and children and to prevent further growth of the prostitution industry and abuse, overrode concerns about individual women's freedoms within prostitution.

A number of feminist organizers, however, felt that the continued criminalization of prostitution defeated what many now considered the only practical solution for women in the industry - organizing among themselves. As a Foundation for Women representative expressed it: "I think [for] the women themselves in [the] sex business, it's important to be organized, but under this bill that says prostitution is illegal how can they speak out that I am a prostitute and I want this and this?"37 Thus, prostitute women's voices are silenced by the new legislation.

\section{NGOs and Prostitution in the 1990s: Towards a Politics of Work}

While in the earlier part of the 1980s feminist activists emphasized that the women were unaware that they were going into the prostitution trade when they accepted offers from agents for work in the city or overseas, by the later 1980 s it became increasingly clear that many women did know - although, activists argued, they may not have known the conditions under which they would have to work. By the 1990s, tens of thousands of Thai women were

\footnotetext{
${ }^{37}$ Interview with Rangsima Limpisawas, Bangkok, 26 Nov. 1996.
} 
believed to be working in prostitution overseas, a growing number in Japan. The chair of the Foundation for Women remembers that as feminists did more work with women who had been deported from foreign countries, the groups discovered that rather than being relieved to be back home, many women wanted to return overseas as quickly as possible to try and make back the money it had cost them to go overseas in the first place. As she points out "... the reason [they try to go back] is that they want to find money to cover their debt and [because of] the experience of some kind of job that can make money, a lot of money - if they are not controlled by anybody - so they try to go back." 38 Increasingly, organizations like Foundation for Women had to admit that many women entered the trade because it was the best option available for making relatively large amounts of money.

For Sukanya addressing the prostitution issue would require addressing sexual control over women, particularly parental control of their daughters' sexuality and the insistence on girls becoming "dutiful daughters". ${ }^{39}$ Prostitute women, Sukanya contended, had rebelled against the control of the state in, for example, trying to escape from the reform institutions and dared to throw off the moral restraints imposed on 'good' women. ${ }^{40}$

Women like Sukanya wanted to break the "good girl/bad girl" barrier and sought out prostitute women themselves in order to understand their situation better. When several bar

\footnotetext{
${ }^{38}$ Interview with Rangsima Limpisawas, Bangkok, 26 Nov. 1996.

${ }^{39}$ Sukanya, "Prostitution," (1983) 330-34.

${ }^{40}$ Sukanya, "Prostitution," (1983) 35.
} 
girls asked to be given English lessons, Sukanya and others agreed to teach them. Sukanya had come to respect the women working as prostitutes whom she had met, seeing them not just as economic agents but as women who resisted the disciplinary gender structure and morality of Thai society. She recalled that:

Personally, I very much valued the spirit of struggle and the relatively independent and defying attitudes of the prostitutes I know which I rarely found in women who are not of their kind. They are women who have the spirit of a fighter - in sexual relations and others. While their middle-class sisters are being repressed by conservative values and the sexual double standards, they seem to have more autonomy in their personal and sexual lives.... Having marked themselves as whores, they have come out of their place - having broken so many repressive rules of good women, and developed the spirit of a fighter for survival and better living. ${ }^{41}$

Sukanya was particularly concerned to respect prostitute women's agency by, for instance, offering English lessons for sale ("money was one thing prostitutes had plenty of") rather than as a "social welfare" service. ${ }^{42}$ Sukanya argued that the majority of activities aimed at prostitutes - repression, rehabilitation, registration - were aimed at disciplining women into "proper sexual behaviour," to "make the prostitute recognise her crime of being promiscous and repent"; "to control women's sexuality, to perpetuate women's sex roles" and to restrict women's independence.

${ }^{4 l}$ Sukanya, "Prostitution," (1983) 25-26.

${ }^{42}$ Conversation with Sukanya Hantrakul, Bangkok, October 1996. 
Sukanya's approach was very much in opposition to those who sought to turn prostitute women back into 'good women' - either through reform or punishment. It also diverged from the approach of most women's groups, which, while gradually accepting prostitution as a form of work for survival had greater difficulty celebrating it as a form of rebellion. Some established elite women's organizations reacted with hostility to the idea of giving English lessons to prostitute women. ${ }^{43}$ It was felt that such activities encouraged rather than discouraged prostitution and it was the abolition of prostitution that these organizations sought to achieve.

Nonetheless the English lessons gradually developed into an organization called EMPOWER. Current director Chantawipa Apisook remembers that, while at first she too saw prostitutes as "bad women" who could be helped by "good women," she soon came to realize that these women were "all women" and that to view prostitute women simply as victims would mean they would not be able to help themselves. ${ }^{44}$ For Chantawipa the problem with the legal approach to prostitution was that it provided benefits for women only after they were arrested, not while they were still at work in providing safe working conditions. ${ }^{45}$ EMPOWER continues today to provide English classes, health education, career workshops, publishing a newspaper and producing dramas with and for women

\footnotetext{
${ }^{43}$ Sukanya Hantrakul, "Prostitutes and Human Rights in Thailand," (n.p. 1982) 25.

${ }^{44}$ Interview with Chantawipa Apisook, Bangkok, 21 Nov. 1996.

${ }^{45}$ Interview with Chantawipa Apisook, Bangkok, 21 Nov. 1996.
} 
working in the sex-trade. The organization aims to "protect bar girls' rights; to rebuild their sense of dignity and self-pride by finding ways to regain control of their lives; to encourage them to build a base for their next step in life; to provide information on health care and legal rights. ${ }^{, 46}$ Chantawipa does not view the organization as a prostitutes' rights organization "as in the West" because the women are "economically forced" to take up the occupation, otherwise most "would not want to be prostitutes. ${ }^{, 47}$ Nonetheless, she argues that the most effective and empowering way to work for women in prostitution is to address their concerns while they are still working in prostitution, rather than focussing on rescuing or removing them from the trade.

Siriporn herself found her understanding of prostitutes changing the more she met and worked with the women involved in prostitution. She recalls:

I think at the beginning I also had this position like the abolitionists ... you would like to do something good for the women in prostitution but you cannot recognize this as a form of work yet. You think that it is part of patriarchy etc. etc.... But then later on, after working more with women who are in the trade, and exchanging information with people working on this issue, I gradually changed my position. Right now I think that they should recognize it, whether we like it or not, but it is really a form of work. When we talk with women who are prostitutes they say they go to work. So I think we have to take that in to consideration also and when you said that you would believe in this feminist patriarchal approach I think you should listen to them and then not just impose

${ }^{46}$ Darunee Tantiwiramanond and Shashi Ranjan Pandey, By Women. For Women: A Study of Women's Organizations in Thailand (Singapore: ISEAS, 1991) 131.

${ }^{47}$ Interview with Chantawipa Apisook, Bangkok, 21 Nov. 1996. 
your ideas on what should be done.... And we should become more realistic and take it as work for certain women who do not have equal opportunities like others so they have to take up this form of work. And then we should concentrate more on the conditions of their work. ${ }^{48}$

Siriporn emphasized, instead, that the women were not mere "passive victims" but fought back where possible. She considered prostitute women as a "new type of wage earners." 49

The importance of drawing attention to the economic aspects of prostitution and women's agency in prostitution was made very clear in the international context as feminist campaigns against prostitution took shape. American radical feminist Kathleen Barry had begun a campaign in 1979 to have the abolition of prostitution put back on the international agenda. Barry viewed prostitution as yet one more example of male sexual violence against women - along with rape, veiling and female genital surgery. ${ }^{50}$ Thai activists soon came to resent the reduction of all Thai women's lives to victimhood in Barry's approach. They also

${ }^{48}$ Interview with Siriporn Skrobanek, Bangkok, 4 Nov. 1996.

${ }^{49}$ Siriporn, "In Pursuit of an Illusion: Thai Women in Europe," Southeast Asia Chronicle 96 (1985): 11.

${ }^{50}$ See Barry's 1979 and 1995 books, Female Sexual Slavery (New York: New York University Press, 1979) and The Prostitution of Sexuality (New York: New York University Press, 1995). For an account of the beginnings of Barry's international campaign (of which Siriporn was initially a part before breaking away to form the Global Alliance Against Trafficking in Women which respects the right of women to choose to enter prostitution) see: Kathleen Barry, Charlotte Bunch and Shirley Castley, eds., International Feminism: Networking against Female Sexual Slavery: Report of the Global Feminist Workshop to Organize against Traffic in Women Rotterdam, The Netherlands, April 6-15, 1983 (New York: International Women's Tribune Centre, 1984). 
resented the failure of Western activists to recognize the role of the global economy in shaping - but not determining - the lives of women in Thailand. The echoes of colonialism in the way that Thailand appeared to be singled out as 'mistreating its women', and Thai women portrayed as passive victims, were heard clearly by Thai activists. They countered these representations with an insistence that Thai women in prostitution acted within difficult circumstances. Most importantly, Thai activists emphasized that the women still acted. As Siriporn has pointed out, in a way, organizations like the Coalition put together by Kathleen Barry:

....argue from the 'third world' point of view - if you are in economic hardship then you have no other choice. You are forced to do that even though you get a certain income but somehow the reason behind that is force. I think that many kinds of work that we do not like to do but we do not have any other choice - we have to do that. So I think that in that sense it [prostitution] is not different from other occupations. $^{\text {s1 }}$

Siriporn also argued that focussing on the economics of prostitution and sex-tourism was the only way to forge solidarity with prostitute women themselves:

...previous actions against sex-tourism conducted by women in the center of capitalism and in the periphery constituted a strategy from above and were directed only against one side of the coin, the exploitation of sexuality. This is more subtle, more complicated and less easily accepted by prostitutes than actions against economic exploitation. In order to avoid a hierarchical and patronizing approach, such actions should include Thai prostitutes, because they know more about their

${ }^{51}$ Interview with Siriporn Skrobanek, Bangkok, 4 Nov. 1996. 
own problems and have already started to fight in their own way. ${ }^{52}$

In 1989 Friends of Women, Foundation for Women, EMPOWER, APSW and the YWCA among others had issued a joint letter to the government attacking its use of women to boost tourism and calling for the abolition of the 1960 act, which "treats prostitutes as criminals." The groups had also sought new anti-prostitution measures which focussed on youth, including a strictly enforced law not permitting girls under eighteen work in sex-business; punishment for customers and operators where girls are under eighteen; non-formal occupational training for rural young people to prevent them from entering the trade and for re-skilling prostitutes seeking alternatives; and a public campaign warning rural villagers that they could be heavily punished for selling their children into prostitution. ${ }^{53}$ While many of these concerns were addressed in the legislation, which was produced in consultation with the groups, Siriporn and others refused to support the bill and the consultation process when it was discovered that prostitute women would continue to face penalties.

At the April 1996 meeting of women's and children's NGOs to discuss the bill all participants agreed that the new bill opened the way for further exploitation through arbitrary enforcement and demands for protection money and that the trade will go underground, making it more difficult for NGOs to investigate sex-establishments. Participating sex-

${ }^{52}$ Siriporn, “In Pursuit of an Illusion,” 12.

${ }^{53}$ Chatsumarn Kabilsingh, Thai Women in Buddhism (Berkeley: Parallax Press, 1991) 80-81. 
workers also argued that what they wanted was protection under the labour law, legitimate work contracts specifying work hours and ensuring access to welfare, benefits and medical check-ups; reduction of working hours; minimum wage guarantees and access to education. Arrests and closures from stricter enforcement has often meant greater difficulties for sexworkers because they are often required by bar owners to compensate for lost revenues. ${ }^{54}$ Thaanavadee Thajeen, chair of Friends of Women, called for the bill to be scrapped arguing that better law enforcement, rather than a new law, was needed..$^{55}$

Even some children's rights activists such as Vitit have come to see the importance of decriminalization of adult prostitution. ${ }^{56}$ For others, such as Sanpasit Kumprapan, the chair of the Centre for Protection of Children's Rights, who does not support the liberalisation of prostitution, the bill's harsh measures posed problems for victims or others involved in coming forward to complain. ${ }^{57}$ Sanpasit was also less sanguine about the bill's potential enforceability: "who will enforce the law when almost every man was once a client including the judge, the police officer, the public prosecutor? The problem should be solved

${ }^{54}$ Mukdawan Sakboon, "Prostitution bill is not the answer to the problem," The Nation 9 April 1996, A5.

55 “Anti-prostitution bill slammed by women's groups," Voices of Thai Women 13 (April 1996): 6.

${ }^{56}$ Vitit Munthaborn, "The undoing of Thailand's image," The Nation 25 Oct. 1996, A5. A5.

${ }^{57}$ Interview with Jasmine Caye, CPCR, Bangkok, Dec. 1996; “Anti-prostitution bill slammed by women's groups", Voices of Thai Women 13 (April 1996) 6. 
with social not legal measures." 58 Chantawipa, director of EMPOWER, asked a similar question, pointing out that during raids on brothels under the old law the men were never to be found, so that it was unlikely things would be any different under the new law. In addition, punishing the parents will do little for underage prostitutes who "just wanted to help the family ... how can they be happy?"59

Above all the law failed to provide what prostitute women are asking for - safe conditions of work. As Chantawipa points out "This law does not allow support to women while they are still working, they must wait until they are arrested. [As well] this law doesn't give these things [safe working conditions, education, health and legal rights] to women - it doesn't give them a salary so they can gain pride and dignity and decide for themselves when they will leave voluntarily." ${ }^{60}$ Further, "trying to negotiate with government to help people they call victims, will [only result in their] being re-victimized."

\section{The Middle Class and the Material Girl}

While activists had begun to accept that prostitution needed to be viewed as a form of work and prostitute women's demands for better working conditions should be met, there was little support for this position among the expanding middle class. Just as women's

\footnotetext{
${ }^{58}$ c.f. Coombe, C1.
}

${ }^{59}$ Interview with Chantawipa Apisook, Bangkok, 21 Nov. 1996.

${ }^{60}$ Interview with Chantawipa Apisook, Bangkok, 21 Nov. 1996.

${ }^{61}$ Interview with Chantawipa Apisook, Bangkok, 21 Nov. 1996. 
groups were re-aligning themselves around a politics of labour in prostitution, society at large, particularly the rapidly growing middle class, was seeing prostitute women in a very different light. The association of prostitution with foreigners arriving or women going overseas reinforced the notion held by elites, that prostitution was a sign of the loss of traditional culture. In particular, in booming 1980 s Thailand, it was linked to the growth of materialism in what had been established in the wake of the 1970 s as the very heartland of Thai culture, the rural areas.

The growing distance between the middle and elite class on the one hand and the peasant class on the other was marked by a growing anxiety over the 'degradation' of rural culture (as defined by elites) and the peasants' presumed lack of ability to maintain that culture. Although peasants had become icons of 'true Thai-ness' they were also viewed as the ones "most at risk of losing their culture and need[ing] to be policed to ensure that they not become Westernized." ${ }^{62}$ This seeming contradiction reflects the dominant classes' belief that only they - with their education and insight - could correctly interpret national culture. For elite women, for instance, that culture included a strict sense of moral decency as encoded in Buddhism for both men and women and a commitment to family as espoused by the middle class. For the growing non-governmental movement, the 'real Thai culture' of the rural areas was sharply opposed to the capitalist culture of the urban centres. Similarly, the

\footnotetext{
${ }^{62}$ Heather Montgomery, "Pattaya and Child Prostitution as a Form of Cultural Crisis," paper presented at the Sixth International Thai Studies Conference, Chiang Mai, Thailand, 1996, CD-ROM.
} 
reformist Buddhist school argued that the villages were the source of true religion, resisting the greed fostered by capitalism. ${ }^{63}$ Indeed, 'consumerism' goes against the central tenets of Buddhism - to free oneself from desire/greed in order to free oneself from suffering. The growth of 'materialistic values' in the rural areas - particularly among those deemed most responsible for maintaining cultural purity, women - was viewed with growing anxiety by a middle class that was itself increasingly removed from the values embodied in the rural areas.

While reports on Thai women in prostitution overseas had become increasingly empathetic to the conditions they faced - particularly within the middle-class press - the women themselves were often characterized as "gold diggers." 64 The popular Daily News carried a front page story in 1983 which declared that Thai girls were "cashing in on the "sex business' and two prostitutes told them they had made 200,000 baht each in three months, reporting further than "Thai prostitutes have been pouring into [Japan] to 'dig for gold'."65 As Marjorie Muecke has pointed out "materialism is widely cited in the media as the primary

${ }^{63}$ Pasuk Phongpaichit and Chris Baker, Thailand: Economy and Politics (New York: Oxford University Press, 1995) 386-389.

${ }^{64}$ See for example, "Voice of the Press: Flown to Japan," Nation Review 21 September 1983, reprinted in Ecumenical Coalition On Third-World Tourism (ECTWT), Tourism, Prostitution, Development: Documentation (Bangkok, ECTWT, n.d.) 72; Pichai Chuensuksawadi, "Thai Girls in Hongkong: A Case of Paradise Lost," Bangkok Sunday, 17 July, 1983 reprinted in ECTWT, 48.

65 "Flown to Japan" from "Voice of the Press," Nation Review 21 Sept. 1983, reprinted in ECTWT, 72 
incentive for their choosing prostitution as a career, just as it is for parents selling their daughters." It also accounted for middle-class women becoming prostitutes as reports of government workers and college giris entering the trade grew over the years. ${ }^{66}$ The governor of Phayao province, speaking of the town of Dok Kam Tai - a town infamous for sending women and girls into prostitution - reasoned that young girls were susceptible because: "When they saw their neighbours and friends coming back from Bangkok with money to maintain a more comfortable living, they could not resist that somehow they must reach that economic status as well [sic]." ${ }^{167}$ A flesh-trade seminar held after the fire in Phuket emphasized that "the media - with its heavy consumerism - had raised the aspirations of rural people, whose hopes simply could not be met. These aspirations were exploited by unscrupulous agents and operators." It recommended "greater emphasis on morality to fight materialism". ${ }^{68}$ Such characterizations, however, emphasized the need for elite guidance. According to the governor of Phayao, "we have to hold frequent seminars to inject into their way of thinking that prostitution is not the only solution. They have to be taught that such a profession is a degradation of the social value of women." While the "consumerism critique' clearly underwrote elite intervention and power it was taken up by the new middle

${ }^{66}$ Marjorie Muecke, "Mother Sells Food, Daughter Sells her Body: The Cultural Continuity of Prostitution," Social Science and Medicine 35.7 (1992): 895. 84.

67 "Migration and Prostitution," The Nation 5 February 1984, reprinted in ECTWT,

\footnotetext{
68 "Flesh Trade Seminar," Thai Development Newsletter 2.3 (1984): 25.

69 "Migration and Prostitution," 83.
} 
class which sought to similarly distinguish itself from, and seek power over, the rural peasant.

The Growth of the Middle Class

The growth of a 'modern middle class' has occurred quickly in Thailand. In Bangkok, this class numbered nearly two million by 1986 , up from 200,000 in $1960 .{ }^{70}$ In the boom period beginning in 1986 their numbers increased even more rapidly. Pasuk estimates that the 'middle class' accounted for over five million people by the end of the 1980 s. $^{71}$ According to Sukhumbhand Paribatra, the new Thai middle class are:

... mostly young (ages 25-35); well educated (bachelor degrees or equivalent); exposed to 'modern,' Westerninfluenced culture; and employed in the professions in executive, managerial, administrative, or technical positions. A typical member of this class has a small family, a working spouse, and a two-bedroom house in a housing estate paid for with a long-term loan. He or she is predisposed to shop for food in modern supermarkets, travel, read newspapers and magazines, listen to radio and television, and if not already owning one, planning to own a car and credit card. ${ }^{72}$

${ }^{70}$ Sukhumbhand Paribatra, "State and Society in Thailand: How Fragile the Democracy?" Asian Survey 33.9 (Sept. 1993): 884.

"I Pasuk Phongpaichit, "The Thai Middle Class and the Military: Social Perspectives in the Aftermath of May 1992," The May 1992 Crisis in Thailand: Background and Aftermath, ed. Peter A. Jackson (Canberra: Australia National University, 1993) 30.

${ }^{72}$ Sukhumbhand, 885. 
By 1993, Thailand's was the seventeenth largest car market in the world. ${ }^{73}$ Shopping centres, department stores, convenience and fast-food outlets dominated Bangkok. Shopping centres and department stores have become:

...the parks of Bangkok, with fast-food outlets, mini-movie theatres, fashion stores and discount merchandisers providing much entertainment for the population. As air-conditioned pleasure-domes, evening and weekends see them filled to overflowing with family groups and young people, dressed in the latest youth fashions, who meet in the fast-food shops. A recent survey has shown that 48 per cent of 21-30-year-olds prefer shopping in department stores rather than small shops or open markets. ${ }^{74}$

Older members of the middle class who remember the days of nationalist student protests over the influx of Japanese products are worried by young people's attraction to foreign goods and the decline of 'mom and pop' shops and open markets.

${ }^{73}$ Kevin Hewison, "Emerging Social Forces in Thailand: New Political and Economic Roles," The New Rich in Asia: Mobile Phones, McDonald's and Middle-Class Revolution, eds. Richard Robinson and David S.G. Goodman (New York: Routledge, 1996) 151.

${ }^{74}$ Hewison, 151.

${ }^{75}$ In 1996 the death knell was sounded for the little stores of Siam Square - the major shopping district in downtown Bangkok - as yet another massive shopping centre - Siam Centre - was constructed kitty corner to the biggest shopping centre in Thailand "Maaboonkrong." Members of the 70s generation lamented the decline of their favourite 'hangout' in their student days, not so subtly juxtaposing their nationalist support of local merchandise and merchandisers with the cosmopolitan buying habits of the younger generation. 
This consumption of foreign goods produces a great deal of middle-class anxiety over national culture and identity. Articles on the loss of Thai culture and the increase in cosmopolitan consumerism appear regularly in middle-class newspapers. One group of newspaper analysts produced this anxiety-increasing summary in 1989:

The era of mass consumerism is upon us.... The globalization of consumerism transcends cultural differences and leaves the value of restraint as expounded by Buddhism a relic of the past. Consumerism puts the whole show on stage. ${ }^{76}$

Buddhism is one of the three pillars of Thai national identity - nation, religion and king. If Buddhism is a "relic of the past" then perhaps "nation" and "king" are as well. Such dire predictions heightened middle-class fears over the decline of national culture and identity in the onslaught of globalization.

'Consumerism' has become one of the watch-words of urban society - linked to the decline of Buddhist values and cultural identity. Kasian Tejapira argues that, unlike in the student era where nationalism was linked to national commodity consumption, Thai-ness has now been "liberated" from any "specific national or ethnic commodity-referents." $\mathrm{He}$ writes:

Thainess has become unanchored, uprooted, liberated or freed from the regime of reference to national or ethnic Thai commodities. Thainess is now able, as it were, to roam freely around the commodified globe, to coexist and copulate with

${ }^{76}$ Nation Publishing, “A Year of Drama and Disaster," 1989, c.f. Hewison, 149.

${ }^{77}$ Kasian Tejapira, "The Postmodernization of Thai-ness," paper presented at the Thai Studies Sixth International Conference, Chiang Mai, 1996. 
Italian earrings, American fragrance, English wool [etc] or any other un-Thai commodities and sundries and still refer as such to the consumer of these products. Its referential essence is limited to mere spectral, amorphous, uncorporeal, intangible, hollowed-out and undefined Thai-Thai feelings in the spirit. Once liberated Thainess takes wing and turns into a free-wheeling, free-floating signifier. ${ }^{78}$

The anxiety over this development can only be assuaged for the middle class if there is a population that remains linked to national culture. The peasantry, already established as the "backbone of Thai identity" through the machinations of Premocracy, became increasingly important in grounding what has become a "free-floating" identity for the middle class.

Contributing to this anxiety, a large part of the new middle class is Sino-Thai in background. Although most Sino-Thai families have actually been in Thailand and intermarried with Thais for several generations, the group 'Sino-Thai' is often delineated for political purposes - making their claim to 'Thai-ness' always uncertain. In the 1970 s many tried to hide their Chinese background, but in the 1980s a 'new Chinese modernity' emerged - a modernity that is less bounded to 'Thai-ness' and more cosmopolitan. Christine SzantonBlanc argues that:

The new modernity is both distinctively Sino-Thai and generally more cosmopolitan than ever before. Being socially mobile means increasingly behaving like a successful SinoThai rather than like a Thai aristocrat. It is this cosmopolitan modernity that Thailand's film industry is presenting to its rural populations when it portrays the modern homes and lifestyles of urban professionals and that both the Thai and the lower-class or petty bourgeois Sino-Thai are now increasingly

${ }^{78}$ Kasian Tejapira, n.p.. 
striving to imitate, even though not everybody partakes of it equally, and some may even resent it. ${ }^{79}$

Proving one's modernity (than samaay) is a matter of consuming the right goods, renting "modern condo apartments not wooden houses," eating in Suki houses, wearing international fashions and playing golf with foreign counterparts. ${ }^{80}$

Even within the elite and middle classes, however, there are gender differences in the acceptability of this 'modern identity.' While women were certainly among those benefitting from the rapid modernization of urban Thai society - and the legal restrictions on their abilities were gradually lifted between 1989 and 1998 - the 'model Thai woman'continued to be 'modern yet traditional.' Business women, like the recipient of the 1995 "Outstanding Business Woman Award" were profiled for their charitable behaviour, in particular their religious, merit-making activities. The Bangkok Post profile opens:

Sriporn Suthipongse does not like to waste her time doing the rounds of parties in Bangkok. Instead, the executive chairman of Pergrine Nithi Finance and Securities prefers to spend her free time making merit through Thod Kathin - offering robes to monks during the 30 days following the Buddhist Lent, and through Thod Phapa - the off-season offering of robes and other needs to monks. ${ }^{81}$

${ }^{79}$ Christine Szanton-Blanc, "The Thoroughly Modern 'Asian'," Ungrounded Empires, eds. Aihwa Ong and Donald Nonini (New York: Routledge, 1997) 271.

${ }^{80}$ Szanton-Blanc, $270-271$.

81 "Brokerage high-flyer finds relaxation in merit-making," Bangkok Post, Business, 7 Dec. 1996, 10. 
Women's role in the day to day maintenance of the Buddhist religion has remained strong, even in the urban areas. The strength of this role marks their continued importance in the maintenance of this key area of national identity.

Despite the increasingly cosmopolitan character of the new middle class, however, the "thoroughly modern Asian" is still "primarily concerned with maintaining control over the large indigenous populations of his or her country." ${ }^{82}$ One of the most powerful weapons of control is the manipulation of national identity. The middle class still needs to lay claim to that identity in order to legitimize its claim to political power. To anchor this identity, it turns to the peasant population to act as the bearers (but not the interpreters) of national culture.

The continuing flow of women into prostitution was seen by the urban population as a betrayal of this cultural role. As one Bangkok Post editorial read: "Art, tradition and culture are the root of society. Once the root is severed, people lose their knowledge of their own roots and rapidly accept a new culture, usually from the West, aggravating social problems such as prostitution. ${ }^{183}$ Consumerism was seen as symptomatic of the influence of western, capitalist, and 'un-Thai' culture. The problem of consumerism, however, was mainly attached to the rural population, and in particular to prostitute women themselves. It was not, however, blamed on the increasingly lavish lifestyles of urban men who could afford to buy

\footnotetext{
${ }^{82}$ Szanton-Blanc, 280.

${ }^{83}$ Sunday Post 3 Oct. 1993, c.f. Montgomery, n.p.
} 
ever higher priced services. Nor was it attached to the owners and procurers who were enriched through prostitution.

Even sympathetic chroniclers like Chitraporn Vanaspong in covering the traffic of Thai women to Japan each year - where they can make some three million baht in a year concluded "many women still flock to Japan as gold diggers. The potential for saving makes them overlook the negative side of the venture. Harsh treatment by pimps, mamasans and agents and the risk of AIDS mean nothing compared with the prospect of wealth." ${ }^{84}$

This kind of understanding also appeared in forms other than journalistic writing. A study of prostitution and trafficking by the FFW in the late 1980 s showed that "in the North, money earned through prostitution is normally used to build new and spacious houses for the families. A lump sum is commonly spent on consumer goods. ${ }^{.85}$ The report went on to say "the villagers are preoccupied by materialism." ${ }^{86}$ Being "preoccupied" gives the sense of "obsession" and a sense that something, "traditional culture" most likely, has been pushed aside and neglected. Similarly, the 1992-2011 women's development plan produced by the NCWA stressed the:

${ }^{84}$ Chitraporn Vanaspong, "A multi-million baht business," Bangkok Post, Perspective, 18 Aug. 1996, 4. Chitraporn points out, however, that only a third of the money made goes to the woman herself, the rest going to the agents and mamasan.

${ }^{85}$ Mayuree Rattanawannatip, "Prostitution: necessity or naked greed?" The Nation 29 June, 1990, 25.

${ }^{86}$ c.f. Mayuree Rattanawannatip, “Prostitution: necessity or naked greed?" The Nation 29 June, 1990, 25. Emphasis added. 
impact of the growing materialism and consumerism of the past two decades. People have become more money conscious as a means to gain respect into the society. New values based on amounts of possessions has taken roots [sic] and have enticed poor women to look for ways to earn easy money. Prostitution offered such an opportunity.... Parents who were willing to sell their own children wanted money. ${ }^{87}$

Children's representatives argued that even children were "victims of luxury" since "many teenagers agreed to sell themselves for as little as a fashionable outfit." While many accepted that children were generally victims of the trade, their parents could be blamed for similarly materialistic sentiments. Prapote Sritet of the Northern People's Relations Groups estimated that 80 percent of prostitutes were sold by their parents who wanted to "cut out the middlemen. ${ }^{188}$ For Mattani Rutnin, who prepared an investigatory video on child prostitution in preparation for the conference, the parents who sold their children into prostitution were not victims of poverty but "calculating and business minded and reserved in their feeling of love and care for their children." Activists like Mattani insisted that discussions at the conference should focus on the "materialistic values of parents who followed the example of their neighbours and were willing to sacrifice their daughters." While the film's narrator, Sanitsuda Ekachai, among others, emphasized that the parents were driven by economic necessity and argued that putting the blame on rural parents would lead to legal measures

\footnotetext{
${ }^{87}$ NCWA, 11-1.
}

88 "Flesh Trade Seminar," Thai Development Newsletter 2.3 (1984): 25. 
which sought to punish the parents not the procurers, Mattani maintained that this failed to come to terms with parental responsibilities. ${ }^{89}$

This perspective on rural parents emphasized that they required training in 'proper parenthood' from elites, not that the economic and political structure was stacked against them. The perspective therefore underwrites elite and middle-class authority. This becomes clear in Mattani's own later work in her scripting of a drama as part of a community development project to prevent prostitution. In her reasoning for the project she argued:

Human values have changed, and today's youth lack knowledge and understanding of traditional culture, a heritage handed down through many generations. To reach the young generation of today in an attempt to reinstate the age-old traditional values, beliefs and culture, there is no better medium than the performing arts, which can be entertaining as well as educational. ${ }^{90}$

Mattani's approach clearly reflected a concern to instill 'traditional values' - presumably better understood by elites than rural peasantry and youth. The play depicts how village life is disrupted by the temptations for an easier life, leading to indebtedness. A mother is forced to sell her daughters into prostitution. The play's hero is the village leader who goes to

${ }^{89}$ Mattani Rutnin, "The Role of Thai Women in Dramatic Arts and Social Development, Problems Concerning Child Prostitution in Thailand: A Case Study Accompanied by a Video-tape on the Lives of Child Prostitutes," Customs and Tradition, The Role of Thai Women, International Conference on Thai Studies, Aug. 22-24, Bangkok, Thai Studies Program, Chulalongkorn University, 1984, 3-4, 11-12.

${ }^{90}$ Mattani in Ernst Gohlert, Power and Culture: The Struggle against Poverty in Thailand (Bangkok: White Lotus, 1991) 48. Emphasis added. 
Bangkok in search of the daughters, and fetches them back to their mother. ${ }^{91}$ The play suggests that it is the role of leaders to protect the women and girls of the villages, returning them to their 'proper' place within the family and the village.

The consumerism critique echoed the middle class' belief that the poor are in part responsible for their own poverty through lax spending habits or lack of moral fibre. The construction of "new and spacious homes" with returns from an offspring's prostitution became the focus of considerable concern. In the eyes of the middle class, homes represented "little of productive value" as did refrigerators, televisions and furniture. ${ }^{92}$ Of course, there was little point to investing in agricultural production - given the declining value and increasing costs of agricultural production. In the 1990s agriculture accounted for less than twenty percent of GDP. ${ }^{93}$ Government development plans clearly aimed at encouraging the rural population to join the industrial labour force, not to undertake subsistence farming. ${ }^{94}$ It is more profitable to sell one's labour to local agribusiness or to migrate to the cities as a labourer and daughters are increasingly valued, particularly in the North, as high income

${ }^{91}$ Gohlert, 49.

${ }^{92}$ Walter F.Meyer, Beyond the Mask: Toward a Transdisciplinary Approach of Selected Social Problems related to the Evolution and Context of International Tourism in Thailand PhD Thesis, University of Geneva, 1987, 318; Pasuk Phongpaichit, From Peasant Girls to Bangkok Masseuses (Geneva: ILO, 1982) 69.

${ }^{93}$ Pasuk Phongpaichit, "The Middle-class and the Military," 33.

${ }^{94}$ Hewison, 148. 
generating labourers in prostitution. ${ }^{95}$ The income from prostitution is also dedicated to the education of siblings and children as an investment in future labourers. Meyer argues that the "conspicuous consumption" of the villagers with the money earned from daughters in prostitution is a way of accumulating prestige while handling the stigma of prostitution. ${ }^{96}$ Indeed, the more shunned prostitute women feel by society the more pressure they feel to "hurry home with their money to show off their wealth by renovating their houses or buying electrical appliances." 97 More importantly, perhaps, the rural areas were, like their urban compatriots, trying to take part in the processes of modernization and economic growth from which the urban areas seemed to benefit so effortlessly.

Reinforcing this sense of 'undeserved gain' was the frequent reference to 'easy money' as one of the reasons for entering the prostitution trade. The phrase suggests that the work of prostitution was illegitimate because it did not appear to require any training or application of effort, rather it was seen as women being paid simply for 'having a good time.' Not only does such a suggestion belittle the extraordinary amount of physical and emotional labour prostitute women must put into their work. Rather it suggests that the poor should be 'honest labourers' in the rice paddies of rural Thailand - hard work for little pay. Indeed, a

${ }^{95}$ See Pasuk and Baker, Chapter 2, for a discussion of the changing economy of the rural areas.

${ }^{96}$ Meyer, 318; also Foundation for Women, Final Report on the Research and Action Project on Traffic in Women (Thailand) (Bangkok: FFW, 1996) 58.

${ }^{97}$ Foundation for Women, 34. 
number of prostitute women comment on the 'back-breaking' labour of rice farming as much less desirable than work in the bars. ${ }^{98}$ Certainly the moral condemnation of prostitutes as making 'easy money' gives a sense of pride and superiority to lower paid women, such as female construction workers and urban labourers, who have not taken that route. Kanchana Tangchonlatip and Nicholas Ford's research showed that while female construction workers often were sympathetic for the reasons behind becoming a prostitute, particularly poverty, they viewed prostitution

...more negatively in terms of gaining a relatively high income without having to engage in hard work. The female construction workers (who derive from the same social strata as most sex workers in Thailand) were very clear in their minds that 'prostitutes preferred to be sex workers than construction workers' like themselves who earn little money in return for extremely arduous and often dangerous work. ${ }^{99}$

A 1996 study on prostitution conducted by the Foundation for Women discovered that the increased earning power of women in prostitution is, in fact, changing their status within the village community. The researchers pointed out that "women's increasingly obvious contribution to the improvement in the family's economic status tinrough labour migration has changed [the decision-making power of senior males] somewhat. In some

${ }^{98}$ See for example, Foundation for Women, 22-23.

${ }^{99}$ Kanchana Tangchonlatip and Nicholas Ford, "Husband's and Wives' Attitudes towards Husbands' Use of Prostitutes in Thailand," UK/Thai Collaborative Research Development in Reproductive and Sexual Health. Proceedings of the Symposium on the Mahidol-Exeter British Council Link, Institute of Population Studies Research, Mahidol University, Bangkok, November 1993, 125. 
families, women are now considered the head of the household and women have a greater share of the decision-making power. Even parents have come to respect their daughters." 100 On the other hand, the more aggressive and self-confident attitude of returning women can be resented - there is a belief that local men will not marry them because they are too independent. $^{101}$

Indeed the independence of many women working in the prostitution industry, particularly those involved in the tourist-oriented trade, may be precisely what is being targeted by the consumerism critique. This 'brazenness' contradicts the dictates of middleclass and elite society, that peasant women should be guided by their betters. Prostitute women have refused to stay within their proper roles, consorting with both the modern and the foreign outside the control of the elites that seek to guide them. By interpreting the agency of prostitute women merely as consumerism or greed, the consumerism critique effectively silences the complex realities of prostitutes' lives - either women are innocent victims or they are greedy consumers. The consumerism explanation of prostitution silences the structural issue of poverty by turning those who try to survive from prostitution into the 'undeserving poor', suggesting that their suffering stems from their greed and improper attitudes rather than the poor economic conditions in the countryside.

\footnotetext{
${ }^{100}$ Foundation for Women, 58.

${ }^{101}$ Fcandation for Women, 61.
} 
That women would engage in prostitution simply for 'consumer goods' erases the fact that even though prostitution can provide a better income than factory or domestic work, the greatest percentage of the money generated from each transaction does not end up in the pocket of the prostitute, rather it goes to owners and middle-men - as well as the officials who have to be paid off because of the illegality of prostitution. Prostitute women themselves, particularly those from the North, often send the largest portion of their income back to their villages to support their families - fulfilling their roles as 'dutiful daughters'. Indeed, rural women's consumption is more easily condemned than men's because of women's traditional responsibility to the support of the family. Men, on the other hand, are expected to be 'irresponsible' and given a great deal more latitude in their discretionary spending. ${ }^{102}$ At the same time the consumerism critique repeats a stereotype of women from the North (who predominate in the prostitution industry) as "jai oon" (soft-hearted/headed) and in love with beautiful things. This characterization of Northern Thai women erases the underlying sense of duty that Northern women feel to provide for their families. In fact, this stereotype is precisely what lies behind the demand for Northern women by Thai customers.

Further, characterizing prostitute women as consumer driven undermines attempts to recognize the agency of young women in entering the prostitution industry by translating that agency as misguided and selfish - a betrayal of her cultural heritage and her role in preserving it. As Aiwha Ong has noted in the case of women factory workers in Malaysia:

\footnotetext{
${ }^{102}$ See Mary Beth Mills, "Rural Women Working in Bangkok: The Rocky Road of Social Change," Final report to the Research Council of Thailand, n.d., 8.
} 
"By rivetting public attention on the female workers' consumption, the press trivialized women's work and helped divert discontent over their weak market position into the manageable channels of a 'youth culture' ." ${ }^{103}$ Further by viewing what consumption women did engage in as a youth culture, such a reading erased the deliberate challenge to traditional definitions of identity and sexuality. ${ }^{104}$ Young women in prostitution, similarly, continue to be read as in need of guidance and/or punishment rather than as self-interpreting agents. Thus, despite growing openness to the idea of decriminalization of prostitution among some elite and middle-class women and the growing evidence that such a move would benefit prostitute women by enabling them to get out from under the hold of procurers, owners and corrupt officials, most feel that Thai society is not yet ready for such a step. Hence, current legislation designed to address the 'prostitution problem' reflects this approach - punishing both prostitutes and parents who sell their children into prostitution - rather than focussing on the broader causes of prostitution and listening to the demands of prostitutes themselves for the decriminalization of prostitution and better working conditions.

While a number of organizations and commentators are now calling for the decriminalization of prostitution and the formation of self-help groups or unions, as the only practical solution, the new act forecloses this possibility for the foreseeable future. Prostitute women's own voices were drowned out by the campaign to reform male behaviour and

\footnotetext{
${ }^{103}$ Aiwha Ong, Spirits of Resistance and Capitalist Discipline: Factory Women in Malaysia (New York: State University of New York, 1987) 181. ${ }^{104}$ Ong, 199.
} 
change Thailand's image to a paternal, protective and effective state. For elite and middle class women, however, the campaign has provided considerable benefits as, for example, the various exemptions to CEDAW have been removed over the course of the 1990s as government's attempt to mend Thailand's image - starting with the removal of barriers to employment in government in 1990 and finally with attempts to address the only remaining substantive reservation on Article 16, equality in family life and marriage. ${ }^{105}$ At the same time, however, there is continuing pressure on women to act as defenders of tradition, particularly as male roles become increasingly 'modernized.' Women's sexual behaviour remains an object of control, as in the new prostitution law, but now men are to be disciplined to adhere to the same standard. Prostitute women, therefore, remain in a precarious position in regards to the law, and young women face increased disciplinary measures - through education and training programs - to ensure 'proper' moral and sexual behaviour. Most recently the Deputy Education Minister has instructed universities and colleges to step up their instruction on women's chastity in response to reports that university students were engaging in casual sex. The Minister argued: "The traditional Thai way of life is girls must protect their virginity before marriage. Every [education] department must work

${ }^{105}$ National Commission on Women's Affairs, Thailand's Combined Second and Third Report to the Committee for the Elimination of Discrimination against Women (Bangkok: Office of the Prime Minister, 1996) Thailand's Combined Second and Third Reports, 6-7. 
towards restoring this original way of life." 106 In a similar vein, women at Chulalongkorn University were instructed to lengthen their skirts or face grade penalties. University officials argued that "short skirts go against Thailand's customs" and "damage Chula's dignity" as well as tempting men to commit sexual attacks. ${ }^{107}$ Women remain responsible for ensuring that men adhere to moral restraints. Thus, women's political power may also remain limited by this restriction as long as politics are considered a "dirty game" unfit for "proper women." ${ }^{108}$ In accordance with this continued vigilance over women's moral and sexual behaviour, prostitute women remain targets of reform and rehabilitation.

\section{Conclusion}

The condemnation of prostitute women as driven by consumerism is a reflection of the anxiety over the apparent loss of traditional culture and national identity in the current era. Women often have a symbolic role as bearers of national culture that can result in the

${ }^{106}$ c.f. Pam Simmons, "Facing the truth about teenage sex," The Nation 19 August 1997 reprinted in Voices of Thai Women 16 (October 1997): 11.

107 "Chula women skirt disaster," "Bangkok Post Week in Review (on-line) 25-31 January 1998.

${ }^{108}$ See, for example, the complaints made by female politicians in the wake of the 1996 election about the limitations they face because of the concern about their sexual propriety. Female politicians face constant accusations of infidelity and sexual misconduct while on the campaign trail and outside the protective confines of their home territory. As one female politician pointed out this greatly limits not only their ability to campaign effectively but their ability to investigate the conditions of, for example, sexworkers since entering a sex-entertainment place would mar a female politician's image indelibly. "Deadly serious soap opera," Bangkok Post Outlook, 27 Nov. 1996, 1. 
close circumscription of their activities. Prostitution is particularly threatening because it signals women's failure to stay within their prescribed roles thereby endangering the 'reproduction of the nation' both physically and socially. The 'discovery' of prostitution as a social issue in Thailand occurred in the context of the American military presence, making the issue one of an attack on 'traditional culture' as embodied in women.

While women are traditionally considered bearers of national culture, peasants have taken on an increasing importance in the Thai national imaginary with the globalization of the middle class. The sudden expansion of the middle class in an age of globalized consumption has gone hand in hand with a growing sense of loss of Thai national culture and identity. As the middle class enjoys the fruits of the 'cosmopolitan' and the 'modern' it seeks to anchor Thai identity in the rural peasantry. Following the upheavals of the 1970 s the government had established the peasantry as central to the maintenance of Thai identity. Nonetheless, the peasants are not trusted to have the education or intelligence to maintain traditional culture, or to engage with modernity, without the guidance of their betters. The middle class found ample evidence of this as it saw its political and social goals frustrated by the rural areas. If there were men who need to be made 'modern,' it was lower-class and peasant men who refused to conform to middle-class standards. Further, if men were to be made modern, then women would need to be made more traditional, in order to maintain national culture and identity.

As peasant women, therefore, prostitute women are doubly marked as bearers of national culture. Their clear refusal to play their 'proper roles' and to follow the direction of 
the middle and elite classes, provokes anger and anxiety among these same classes, who feel the women should be disciplined into their 'proper roles.' The accusation of consumerism legitimizes such discipline by silencing the complex realities of prostitutes lives and their demands for control over their own lives. 


\section{Conclusion}

In this thesis I have explored the development of prostitution policy in Thailand as shaped by concerns over national identity and gender. The prostitute is a symbol that powerfully evokes the limitations of acceptable female behaviour. It is a powerful tool, therefore, in disciplining female identity. Rather than assuming that there is ' $a$ ' reality to prostitute women's lives, therefore, this thesis asks how prostitutes are constructed and understood in particular historical locations; and how particular interpretations come to shape state policy on prostitution. It is these policies - criminalization, reform, re-education -that have been among the most immediate problems for prostitute women and have increased state power over women in prostitution rather than empowering them as political actors.

Rather than assuming that the prostitute is by definition a powerless actor, therefore, in this thesis I have examined how she is rendered powerless as a political actor by particular interpretations of prostitution. In particular, we have seen how the discourses of gender and national identity intersect to construct the prostitute and determine policy by rendering the prostitute as an object of re-enculturation rather than a political actor. Women's bodies have become powerfully connected to the reproduction of the nation - both literally and symbolically - particularly since the colonial era. The Western powers made it clear that gender identity and sexual behaviour grounded a national identity. Particular forms of gender

and sexuality grounded claims to civilization and modernity so that therefore, national independence. In Thailand, therefore, women's identity and proper behaviour were in many ways linked to women's role in the maintenance of national identity and tradition. This 
linkage, however, was differently constructed in different periods and was subject to manipulation by political actors.

The International and the National: Global Politics of Representation.

The historical discussion of prostitution policy illustrated how gender and sexual standards have always been a part of international relations. Western gender identities were used to establish the 'essential' differences between civilized and uncivilized. The seeming failure of Siamese masculinity and femininity to meet up with Western gender norms was given as evidence of Siamese inability to govern themselves properly. In the semi-imperial era reforming women's behaviour to meet international gender standards - particularly in the form of the abolishment of the harem and the institutionalization of anti-prostitution legislation - was a key part of establishing Thailand's 'civilized' status. At the same time, however, gender roles were a site of resistance to Western demands. The practice of polygamy became, for a number of male elites, a matter of cultural identity rather than a state practice. Women's sexual service to men was institutionalized further in legalized prostitution. State leaders, particularly Chulalongkorn, were concerned to establish lowerclass male incorporation into the modernizing state through the military-once the traditional bonds of slavery were undone. A militarized masculinity, whose sexual prowess indicated political power, remained a central, if contested, model of elite Thai manhood well into the present day. Many elite men, therefore, resisted efforts to abolish prostitution in line with Western demands. Despite this resistance, both polygamy and prostitution were, eventually, 
officially banned as required to meet Western standards of civilization and modernity and Thailand could gain full international status.

This historical discussion clearly shows the importance of gender, and with it, sexuality, in international relations in anchoring the establishment of self/other identities and relations of power. In this light we begin to understand the modern day concern with 'international image' in Thailand. While such concern has tended to be dismissed as 'smoke and mirrors,' such dismissal fails to recognize the power of representation in international affairs. As was made clear in the semi-imperial era, the constructions of Thai gender identities and sexual behaviour were key in establishing Siam/Thailand as 'other,' as 'lesser,' and, therefore, as a site for Western intervention and dominance. These same constructions were activated in the criticisms of Thailand in the modern era for its failure to appropriately address the issue of prostitution. Such representations, once again, invoked and enabled relations of dominance between the West and Thailand, underwriting possible boycotts and sanctions as well as threatening Thailand's status in the world market as its governments are judged 'weak' and 'inefficient.' The Thai middle class was able to use these constructions to push for changes in modes of governance and male behaviour. By championing a new ideology of modernized masculinity as the appropriate basis of governance, in line with Western ideals, new middle-class actors were able to legitimize their claims to authority and power. The modern debate over international image, therefore, reflected the central role of representation in international relations of power. As in the colonial era, the construction of the 'other' as backwards, or traditional, underwrote the imposition of relations of dominance and has real political effect in countries such as Thailand. 
As masculinity became increasingly modernized, however, femininity became increasingly traditional. In a reflection of women's importance to the nation, men's rescripted role as modern leaders of a modern state demanded women's closer adherence to tradition. Thus the international pressure to reform Thai masculinity to conform with Western standards has, ironically, meant increased restrictions on women and greater control over prostitute women specifically. That is, Western criticism of Thailand's 'failure' to deal with prostitution has undermined prostitute women's chances for political self-determination. Thus, Western reluctance to interrogate the operation of power in representations of identity has blinded us to how power works. It is for this reason that Thai feminist groups, for example, have sought to draw attention to this aspect of international power. As Sanitsuda Ekachai argues:

One thing that's troubling me is the reporting of prostitution in Thailand overseas as a moral problem. That Thailand is a land of immoral people, a land of parents who seil their children - it's very sensationalist stories. But it's only part ố the story, and a big part of it is the income gap around the world that enables people to buy sex and all that, which goes unreported. It stresses [the] superiority of the rulers and that's troubling. ${ }^{1}$

Activists like Sanitsuda seek an international relations in which the West is critically aware of its own power. Such activists are very well aware of the inequality of the sexual and economic relations between the North and the South, and they resent the continued assumption of power implicit in international views of the sex-trade in Thailand. As one

\footnotetext{
${ }^{1}$ Interview with Sanitsuda Ekachai, Bangkok, 15 Nov. 1996.
} 
representative of Friends of Women made clear, the focus on Thailand, and Thai women, as 'the problem' means that:

When I went to Germany that time I said why do you talk about Thai women problem because Thai women don't have any problem, it's very clear, we don't have money - bad economics - and we came here. So why do you say it's Thai women's problem? It's a German men's problem. Because we can't explain why they marry with Thai women - they don't marry with German women, what happened in their society? What about the power relationship between men and women in their society?... And men exploited some who are disadvantaged. This is a very complicated problem so in Thai women it's very clear, we want money.... It's their society's problem. So now it turns back to me, now there are many prostitutes from Burma, from China from Laos, so what about Thai men? ${ }^{2}$

International solidarity among women as well as other groups clearly requires a reflexivity concerning the West's discursive as well as economic power.

\section{Sex and Borders: Gender and the Nation}

Throughout the historical period under discussion here, the understanding of the prostitute and prostitution was constructed in terms of this linkage between feminine sexual behaviour and the nation. While at first construed as a necessary service to the male citizensoldier, prostitution was gradually reconfigured as a sign of national decline. This reconstruction reflected the changing role of the state between 1850 and 1980 as it moved from a monarchical sphere of influence to a modern nation-state. The nation was at first elite based, constructed through the official nationalisms that interpolated elite women's bodies

\footnotetext{
${ }^{2}$ Ranee Hassarungsee (GROWNET -- FOW), Bangkok, 29 Nov. 1996.
} 
as symbols of the modernity and civilization of the nation. While elite women's purity and marital fidelity were closely guarded - in law and practice - from the era of absolute monarchy on, the sexual behaviour of lower-class women was only gradually brought within the ambit of the state. As the state broadened its reach under Chulalongkorn, lower-class women were made available to sexually-service male citizenry and elites. After the fall of the absolute monarchy, leaders such as Phibun and Sarit sought to extend the disciplinary mechanisms of the state to lower-class women through the reversal of previous practices and the criminalization of prostitution. Such attempts, however, lacked legitimacy and depth. The 1960 law that extended the sexual discipline of the elite to all classes of women was viewed as a response to international pressure. It was nearly immediately reversed by the 1966 law which continued to regulate certain forms of prostitution.

It was only with the middle-class nationalism of the 1960 s that the nation expanded to incorporate peasant women's bodies as the key locus of national identity. The middle class, both in the form of the student revolution and the later pro-democracy push, sought the institutionalization of a disciplinary rather than an authoritarian state. Subjects were to become citizens, integrated into the state's ambit through the inculcation of national identity and loyalty rather than force. The student movement was the first sign that the middle class 'imagined' a larger nation. For the reformist state, it became clear that the peasantry, in particular, had to be educated into this national identity, as had been made clear by peasant unrest. The post-revolutionary reformist state interpolated the peasantry as the 'backbone of the nation.' Through this process, peasant women's bodies were established as icons of national identity. For the middle class, which sought the benefits of globalization and 
modernity, national identity was anchored in the peasantry. Prostitute women, who were importantly also peasant women, came to symbolize the threat to national identity and culture posed by the American presence and growing Westernization. As symbols of cultural decline, prostitute women were denied voice and agency. The importance of national identity construction and maintenance drowned out the voices of prostitute women's own interpretations of their lives and their political demands, for example, for better working conditions. Instead, the response to prostitution was determined by the concern to restore proper cultural identity among peasant women. This discursive construction of peasant and prostitute women, as with the peasantry more generally, erased the agency and resistance of the women themselves and established the disciplinary authority of elite and middle-class women.

The predominance of national identity, and women's embodiment of it, in the 'universe of political discourse' in Thailand, however, did not predetermine women's political weakness. Rather, various women sought to engage in the political process, in interpreting and re-interpreting political reality to further women's interests and promote women's equality. Elite women, in particular, were able to draw on their position as guarantors of national identity to make claims for women's equality. In doing so, however, they strengthened the disciplinary hold of national identity over other women, particularly prostitute women. Elite women gained political voice through their role in disciplining other women, i.e. peasant, prostitute women, into the 'correct cultural role.' By shifting the burden of 'tradition' onto peasant women, elite, and then middle-class, women were able to move out of more restrictive roles. Thus, while women's role in national identity maintenance is 
clearly a double-edged sword - giving women a political voice but just as surely restricting (other) women's behaviour - it is also a role that is cathected by class, allowing the burden of restrictive behaviour to be carried by one class while freeing up another. It is the peasants who are now viewed as both the embodiment of national identity and the ones most at risk of losing that identity. The authority and legitimacy of the elites and the middle class depended on the construction of an 'other' in the form of the peasantry, who required elite/middle-class guidance to maintain national identity. Just as masculine modernity has required feminine traditionality; so middle-class modernity has required peasant cultural purity. Prostitute women - as women who defy the norms of female behaviour and as peasants who engage with the modern - are at the centre of concerns over the loss of traditional identity and culture and are the object of disciplinary measures.

The attitude of much of the new middle class in Thailand toward the peasantry and the lower-class, as indicated in their attitudes toward prostitute women, does not bode well for the development of a full democracy that incorporates the poor on their own terms. Nonetheless, it is also clear that these class barriers can be, and have been, broken. Along with the growing numbers of NGOs championing peasant causes, a number of the women's groups that formed in the 1980s have taken up the argument for decriminalization of prostitution and defended prostitute women's political and social agency. These feminist organizers have taken the time and effort to meet with and listen to prostitute women. They have recognized the process of discursive domination in the characterization of prostitute women as 'victims' in much the same way that Thai women more generally are positioned as 'victims' by Western feminist discourse. They have therefore taken up a two-pronged 
critique that demands both that the global economic exploitation of women in prostitution be recognized and addressed, and that prostitute women's right to work in prostitution under safe conditions be recognized. They, too, however, have found their appeals drowned out by middle-class anxiety over the decline of national culture as symbolized in prostitute bodies. The construction of the prostitute as 'consumer' delegitimizes claims to prostitution as a form of work for survival.

Looking at politics as a struggle over meaning, and at prostitution as a contested category of identity construction, has allowed us to see the political struggle over prostitution policy - the attempts to 'do something about it' rather than assuming an a priori capitalist or patriarchal interest in the maintenance of prostitution. Prostitution is a constructed category that reflects social concerns to police female behaviour. To understand prostitution policy, therefore, we need to understand how prostitution is understood and how prostitute women are constructed. In Thailand, where the construction and maintenance of national identity has been of primary importance to state survival since the era of colonialism, female identity has been most importantly viewed in terms of cultural and national identity. Prostitute women, as women who do not conform to proper modes of behaviour, have come to symbolize cultural decline. They are therefore viewed as requiring state intervention and discipline, rather than as capable and self-determining political actors. Prostitute women's own interpretations of their lives as, for example, wage earners and family supporters, are silenced by dominant interpretations that focus on their cultural symbolism. Prostitution policy, even as written by a progressive, pro-democratic middle class, therefore, continues to penalize prostitute women rather than adhere to their demands for decriminalization. In the end, such 
an approach only works to further undermine the position of women and of prostitute women in particular. If the mistreatment of women in prostitution and elsewhere lies in constructions of gender that position women as objects rather than subjects, then the continued treatment of prostitute women as incapable of voicing their own demands only reinforces the gendered imbalance of power. Thus, it is only by giving prostitute women a political voice and the respect to make their own political demands that the class-based, gendered power that underlies the institutionalization of prostitution will be addressed. By uncovering the ways in which 'The Prostitute' and prostitution are constructed in particular historical locations and in relation to particular structures of power i.e. gender and national identity, this dissertation helps us to understand, and hopefully to change, the relations of power that impose particular interpretations of prostitution while silencing others. 


\section{Bibliography}

(Thai names appear under given names first according to Thai usage.)

Abhinya Rathanamongkolmas. Developmental Stances of Thai Women Elites: A Study of Socialization, Social Roles and Social Policy Prescriptions. PhD Dissertation. Indiana University, 1983.

Alloula, Malek. The Colonial Harem. Minneapolis: University of Minnesota Press, 1986.

Amara Pongsapich. "Women's Social Protest in Thailand." Journal of Social Research. Chulalongkorn University Social Research Institute, Bangkok. 10 (1987): 1-12.

Andaya, Barbara Watson. "From Temporary Wife to Prostitute: Sexuality and Economic Change in Early Modern Southeast Asia." Journal of Women's History 9.4 (Winter 1998): 11-34.

Anderson, Benedict. "Withdrawal Symptoms: Social and Cultural Aspects of the October 6 Coup." Bulletin of Concerned Asian Scholars 9.3 (July -September, 1977): 13-18.

-.... Imagined Communities. Revised edition. New York: Verso, 1991.

-.... "Introduction." In the Mirror: Literature and Politics in Siam in the American Era. Eds. Benedict Anderson and Ruchira Mendiones. Bangkok: Duang Kamol, 1985.

-1.. "Murder and Progress in Modern Siam." New Left Review 181 (May-June 1990): 33-48.

-...... "Radicalism after Communism in Thailand and Indonesia.." New Left Review 202 (Nov - Dec 1993): 3-14.

- . "Studies of the Thai State: The State of Thai Studies." The Study of Thailand: Analyses of Knowledge, Approaches, and Prospects in Anthropology, Art History, Economics, History and Political Science. Ed. Elizer B. Ayal. Papers in International Studies, Southeast Asian Series, no.54. Anthens: Ohio University, 1978.

Anthias, Floya and Nira Yuval-Davis. Woman-Nation-State. New York: St. Martin's Press, 1989.

Asia Watch and the Women's Rights Project. A Modern Form of Slavery: Trafficking of Burmese Women and Girls into Brothels in Thailand. New York: Human Rights Watch, 1993.

Association for the Promotion of the Status of Women. Bangkok: Association for the Promotion of the Status of Women, 1996. 
Bamber, S.D., K.J. Hewison and P.J. Underwood. "A History of Sexually Transmitted Diseases in Thailand: Policy and Politics." Genitourinary Medicine 69 (1993): 148157.

Barmé, Scot. "Struggling for Equality: Critique of Polygamy in Siam During the 1920s." Unpublished paper. Thai Studies 6th International Conference. Chiang Mai, 14-17 October, 1996.

- Luang Wichit Wathakan and the Creation of Thai Identity. Singapore: Institute of Southeast Asian Studies, 1993.

Barry, Kathleen. The Prostitution of Sexuality: The Global Exploitation of Women. New York: New York UP, 1995.

Basham, Richard. "Democracy Means Never Having to Say You're Sorry: Notions of Freedom and Fairness in Thai Attitudes Towards Democracy." The May 1992 Crisis in Thailand: Background and Aftermath. Ed. Peter A. Jackson. Canberra: National Thai Studies Centre, Australia National University, 1993. 11-20.

Batson, Benjamin. "The First American Diplomats in Siam." Thai-American Relations in Contemporary Affairs. Singapore: Executive Publications, 1982.

Bell, Shannon. Reading, Writing and Rewriting the Prostitute Body. Bloomington: Indiana UP, 1994.

Bhassorn Limanonda. Female Commercial Sex Workers and AIDS: Perspectives from Thai Rural Communities. Paper presented at the 5th International Conference on Thai Studies - SOAS at the Centre of South East Asian Studies, School of Oriental and African Studies, University of London. July 5-10. 1993.

-The Demographic and Behavioural Study of Female Commercial Sex Workers in Thailand. Bangkok: Institute for Population Studies, Chulalongkorn University, October 1993. IPS Publication \#210/93.

Bishop, Ryan and Lillian Robinson. Night Market: Sexual Cultures and the Thai Economic Miracle. New York: Routledge, 1998.

Bowie, Katherine A. Rituals of National Loyalty: An Anthropology of the State and the Village Scout Movement in Thailand. New York: Columbia UP, 1997. 
Bowie, Katherine A. "Slavery in Nineteenth-Century Northern Thailand: Archival Anecdotes and Village Voices." State Power and Culture in Thailand. Ed. E. Paul Durrenberger. Monograph 44. New Haven: Yale Southeast Asia Studies, 1996. 100-138.

Bowring, Sir John. The Kingdom and People of Siam. Vol.s I \& II. London, John. W. Parker and Son, 1857.

Bradley, William L. Siam Then: The Foreign Colony in Bangkok Before and After Anna. Pasadena, CA: William Carey Library, 1981.

Brailey, Nigel J. Two Views of Siam on the Eve of the Chakri Reformation. Whiting Bay: Scotland: Kiscadale Publications, 1989.

-..... Thailand and the Fall of Singapore: A Frustrated Asian Revolution. Boulder: Westview Press, 1986.

Brock, Rita Nakashima and Susan Brooks Thistlethwaite. Casting Stones: Prostitution and Liberation in Asia and the United States. Minneapolis: Fortress Press, 1996.

Buell, Frederick. National Culture and the New Global System. Baltimore: Johns Hopkins UP, 1994.

Bulbeck, Chilla. Re-Orienting Western Feminisms: Women's Diversity in a Postcolonial World. Cambridge: Cambridge UP, 1998.

Callahan, William A. "The Ideology of Miss Thailand in National, Consumerist, and Transnational Space." Alternatives 23.1 (Jan.-Mar. 1998): 29-62.

Campbell, David. Writing Security: United States Foreign Policy and the Politics of Identity. Minneapolis: University of Minnesota Press, 1992.

Caye, Jasmine. "Preliminary Survey on Regional Child Trafficking for Prostitution in Thailand." Commissioned by UNICEF EAPRO. Bangkok: Centre for the Protection of Children's Rights, August-November 1995.

Centre for the Protection of Children's Rights. "Case Study Report on Commercial Sexual Exploitation of Children in Thailand." Bangkok: Centre for the Protection of Children's Rights, October 1996. 
Chai-anan Samudavanija. "Thailand: A Stable Semi-democracy." Politics in Developing Countries. Eds. Larry Diamond, Juan J. Linz and Seymour Martin Lipset. Boulder: Lynne Rienner, 1990. 271-312.

Chai-anan Samudavanija. "Economic Development and Democracy." In Thailand's Industrialization and Its Consequences. Ed. Medhi Krongkaew. New York: St Martin's Press, 1995.

Chaiyan Rajchagool. The Rise and Fall of the Thai Absolute Monarchy. Bangkok: White Lotus Press, 1994.

Chapkis, Wendy. Live Sex Acts. New York, Routledge, 1997.

Chaterjee, Partha. Nationalist Thought and the Colonial World: A Derivative Discourse? London: Zed Books, 1986.

The Nation and Its Fragments: Colonial and Postcolonial Histories. Princeton, NJ: Princeton University Press, 1993.

Chatsumarn Kabilsingh. Thai Women in Buddhism. Berkeley: Parallax Press, 1991.

Chatthip Nartsupha. "The Community Culture School of Thought." Thai Constructions of Knowledge. Eds. Manas Chitakasem and Andrew Turton. London: School of Oriental and African Studies, University of London, 1991. 118-141.

Cocks, Joan. The Oppositional Imagination: Feminism, Critique and Political Theory. London: Routledge, 1989.

Cohen, Eric. "Thai Girls and Farang Men: The Edge of Ambiguity." Annals of Tourism Research 9 (1982): 403-428.

Committee for the Promotion of Welfare for Women. National Council on Social Welfare of Thailand. Women's Development through Non-formal Education: 1971-1989. Reported by Khtsnying Dithakar Bhakdi. Bangkok: National Council on Social Welfare of Thailand, October 1989.

Connell, R.W. Gender and Power: Society, the Person and Sexual Politics. Cambridge: Polity Press, 1987.

-.... Masculinities. Berkeley: University of California Press, 1995. 
Cox, Robert. "Social Forces, States and World Orders," Neo-Realism and its Critics. Ed. Robert Keohane. New York: Columbia University Press, 1986. 204-254.

Crawfurd, John. Journal of an Embassy to the Courts of Siam and Cochin China. Kuala Lumpur: Oxford University Press, 1967.

Darling, Frank C. Thailand and the United States. Washington D.C.: Public Affairs Press, 1965.

Darunee Tantiwiramanond and Shashi Ranjan Pandey. By Women, For Women: A Study of Women's Organizations in Thailand. Singapore: ISEAS, 1991.

-.-.-. "The Status and Role of Thai Women in the Pre-Modern Period: A Historical and Cultural Perspective." Sojourn 2(1):125-149.

de la Loubere, Simon. The Kingdom of Siam. 1697. Oxford in Asia Historical Reprints. New York: Oxford UP, 1969.

Dixon, Chris. "Thailand's Rapid Economic Growth: Causes, Sustainability and Lessons." Uneven Development in Thailand. Ed. Michael J.G. Parnwell. Brookfield: Avebury, 1996.

Durrenberger, E. Paul. "The Power of Culture and the Culture of States in Thailand." State Power and Culture in Thailand. Ed. E. Paul Durrenberger. Monograph 44. Yale Southeast Asia Studies. New Haven: Yale Southeast Asia Studies, 1996. 1-21.

Eberhardt, Nancy. Ed. Gender. Power, and the Construction of the Moral Order: Studies from the Thai Periphery. University of Wisconsin-Madison Center for Southeast Asian Studies Monograph 4. Madison: University of Wisconsin-Madison, 1988.

Ecumenical Coalition On Third-World Tourism. Tourism. Prostitution, Development: Documentation. Bangkok, Ecumenical Coalition on Third World Tourism, n.d.

Eley, Geoff and Ronald Girgor Suny, Eds. "Introduction." Becoming National: A Reader. New York: Oxford UP, 1996.

Embree, John F. Loosely-structured Social Systems: Thailand in Comparative Perspective. New Haven: Yale University Southeast Asia Studies, 1969.

Enloe, Cynthia. Bananas, Beaches and Bases: Making Feminist Sense of International Politics. Berkeley: University of California Press, 1990. 
Fane, Carole, Francoise Joaquin and Wendy Madrigal. "Mixed Fortunes." Asia Magazine. 2-4 August 1996. 10-14.

Ferguson, Kathy E. "Male-Ordered Politics: Feminism and Political Science." Idioms of Inquiry. Ed. Terence Ball. New York: State University of New York Press, 1987.

Finlayson, George. The Mission to Siam and Hue: 1821-1822. Bangkok: The Siam Society, 1988.

Fordham, Graham. "The Construction of HIV/AIDS as a Disease Threat in the Northern Thai (Print) Media." Paper presented at the Sixth International Thai Studies Conference. Chiang Mai, Thailand, October 1996.

Foucault, Michel. The History of Sexuality: An Introduction. Vol. I. New York: Vintage, 1990.

Foundation for Women. Final Report of the Research and Action Project on Traffic in Women (Thailand). Bangkok: Foundation for Women, 1996.

Fox, Morris G. "Problem of Prostitution in Thailand." Social Service in Thailand. Bangkok: Dept. of Public Welfare, Ministry of the Interior, 1960.

Garber, Marjorie. "The Occidental Tourist: M. Butterfly and the Scandal of Transvestism." In Nationalisms and Sexualities. Eds. Andrew Parker, et. al. New York: Routledge, 1992. 121-146.

Gawin Chutima, "Thai NGOs and Civil Society." Thai NGOs: The Continuing Struggle for Democracy. Bangkok: Thai NGO Support Project, 1995. 135-144.

Girling, John L.S. Thailand: Society and Politics. Ithaca: Cornell UP, 1981.

-_._. "Thailand in Gramscian Perspective." Pacific Affairs. 57.3 (Fall 1984): 385-403.

Glasser, Jeffrey D. The Secret Vietnam War: The United States Air Force in Thailand, 19611975. Jefferson, N.C.: McFarland, 1995.

Gohlert, Ernst. Power and Culture: The Struggle against Poverty in Thailand. Bangkok: White Lotus, 1991.

Gong, Gerrit W. The Standard of "Civilization" in International Society. Oxford: Clarendon Press, 1984. 
Gorham, Deborah. 'The 'Maiden Tribute of Modern Babylon' Re-Examined: Child Prostitution and the Idea of Childhood in Late-Victorian England." Victorian Studies 21.3 (Spring 1978): 353-380.

Gould, James W. "American Imperialism in Southeast Asia Before 1898." Journal of Southeast Asian Studies 3.2 (Sept. 1972): 306-314.

Harrison, Rachel. 'The 'Good' the 'Bad' and the Pregnant: Why the Thai Prostitute as Literary Heroine Can't be Seen to Given Birth." Proceedings of the 6th International Conference on Thai Studies: Theme V: Women, Gender Relations and Development in Thai Society. Chiang Mai: 14-17 October, 1996. 31-48.

-.... "The Writer, the Horshoe Crab, his "Golden Blossom" and her Clients: Tales of Prostitution in Contemporary Thai Short Stories." Southeast Asia Research 3 (Sept. 1995): 125-152.

Hauser, Sjorn. "The Body Beautiful: Part II: Charming Chimes - Changing Times." Guidelines Chiang Mai (Sept. 1996): 42-44.

Hekman, Susan. Gender and Knowledge: Elements of a Postmodern Feminism. Boston: Northeastern University Press, 1990.

Hershatter, Gail. "Courtesans and Streetwalkers: The Changing Discourses on Shanghai Prostitution, 1890-1949." Journal of the History of Sexuality 3.2 (1992): 245-269.

Hevia, James L. "Sovereignty and Subject: Constituting Relations of Power in Qing Guest Ritual." Body, Subject and Power in China. Eds. Angela Zito and Tani Barlow. Chicago: University of Chicago Press, 1994. 181-200.

Hewison, Kevin. Bankers and Bureaucrats: Capital and the Role of the State in Thailand. Monograph Series 34. Yale University Southeast Asia Studies. New Haven: Yale Center for International and Area Studies, 1989.

-_... "Of Regimes, State and Pluralities: Thai Politics Enters the 1990s." Southeast Asia in the 1990s: Authoritarianism. Democracy and Capitalism. Eds. Kevin Hewison, Richard Robinson and Garry Rodan. Sydney: Allen and Unwin, 1993. 161-189.

."Emerging Social Forces in Thailand: New Political and Economic Roles." The New Rich in Asia: Mobile Phones, McDonald's and Middle-Class Revolution. Eds. Richard Robinson and David S.G. Goodman. New York: Routledge, 1996. 137-160. 
Hicks, George. The Comfort Women: Sex Slaves of the Japanese Imperial Forces. Chiang Mai, Thailand: Silkworm Press, 1995.

Hill, Catherine. "Planning for Prostitution: An Analysis of Thailand's Sex Industry." Women's Lives and Public Policy: The International Experience. Eds. Meredeth Turshen and Braivel Holcomb. Westport: Praeger, 1993. 133-144.

Hirsch, Philip. "What is the Thai Village?" National Identity and Its Defenders. Ed. Craig J. Reynolds. Chiang Mai: Silkworm Books, 1991.

Hobsbawm, E.J. Nations and Nationalism since 1780. London: Cambridge UP, 1992.

Hong, Lysa. "Warasan Setthasat Kanmu'ang: Critical Scholarhsip in Post-1976 Thailand." Thai Constructions of Knowledge. Eds. Manas Chitakasem and Andrew Turton. London: School of Oriental and African Studies, University of London, 1991. 99117.

Human Rights in Thailand Report. 9.2 - 10.1. April/July 1985 - Jan/March 1986.

Huntington, Samuel. "The Clash of Civilizations?" Foreign Affairs (Summer 1993): 22-49.

Hutchinson, E.W. Adventurers in Siam in the Seventeenth Century. London: Royal Asiatic Society, 1940.

ISIS International Bulletin 13 (1979).

Jackson, Peter. Buddhism. Legitimation and Conflict: The Political Functions of Urban Thai Buddhism. Singapore, Institute of Southeast Asia Studies, 1989.

-2. "Thai-Buddhist Identity: Debates of the Traiphuum Phra Ruang." In National Identity and Its Defenders. Ed. Craig J. Reynolds. Chiang Mai: Silkworm Books, 1991.

Jackson, Peter, ed. The May 1992 Crisis in Thailand: Background and Aftermath. Selected Papers from the Thailand Update Conference. University of Sydney, 16 October 1992. Canberra: National Thai Studies Centre, Australia National University, 1993.

Jenson, Jane. "Gender and Reproduction: Or, Babies and the State." Studies in Political Economy 20 (Summer 1986). 
Jonsson, Hjorleifur R. "Rhetorics and Relations; Tai states, Forests, and Upland Groups." State Power and Culture in Thailand. Ed. E. Paul Durrenberger. Yale Southeast Asia Studies Monography 44. New Haven: Yale Southeast Asia Studies, 1996. 166-200.

Kanchana Tangchonlatip and Nicholas Ford. "Husbands; and Wives' Attitudes towards Husbands' Use of Prostitutes in Thailand." UK/Thai Collaborative Research Development in Reproductive and Sexual Health. Proceedings of the Symposium on the Mahidol-Exeter British Council Link. Bangkok: IPSR, Mahidol University, November 1993. 117-134.

Kanitta Meesook. "The Economic Role of Thai Women." Aspects of Thai Women Today. Presented as a background document to the World Conference of The United Nations Decade for Women, Copenhagen, 14-30 july 1980 by the Delegation of Thailand. Bangkok: Thailand National Commission on Women's Affairs, 1980. 7-28.

Kasian Tejapira. "The Postmodernization of Thai-ness." Paper presented at the Thai Studies Sixth International Conference, Chiang Mai, 1996. CD-ROM.

Kandiyoti, Deniz. "Identity and its Discontents: Women and the Nation." Colonial Discourse and Post-Colonial Theory: A Reader. Eds. Patrick Williams and Laura Chrisman. New York: Columbia UP, 1994. 376-391.

Kattiya Karnasuta. "Education and Development Programs for Thai Women." Aspects of Thai Women Today. Presented as a background document to the World Conference of The United Nations Decade for Women, Copenhagen, 14-30 July 1980 by the Delegation of Thailand. Bangkok, Thailand National Commission on Women's Affairs, 1980. 29-46.

Keyes, Charles F. Thailand: Buddhist Kingdom as Modern Nation State. London: Westview Press, 1987.

-1--. "Hegemony and Resistance in Northeastern Thailand." Regions and National Integration in Thailand: 1892-1992. Ed. Volker Grabowsky. Wiesbaden: Harrossowitz Verlag, 1995. 154-182.

-2.- "Mother or Mistress but never a Monk, Buddhist Notions of Female Gender in Rural Thailand." American Ethnologist 11.2 (1984): 223-241.

Kirk, Donald. Wider War: The Struggle for Cambodia. Thailand and Laos. New York: Praeger, 1971. 
Kirsch, Thomas. "Text and Context: Buddhist Sex Roles/Culture of Gender Revisited" American Ethnologist 12.2 (1985): 302-320

Kobkua Suwannatha-Piat. Thailand's Durable Premier: Phibun through Three Decades, 1932-1957. New York: Oxford UP, 1995.

Kobkul Rayanakorn. Women and the Law in Thailand and Canada. Paper Number 6, Working Paper Series, Thai Studies Project, Women in Development Consortium in Thailand. Toronto: York Ưniversity, 1990.

- Special Study on Laws Relating to Prostitution and Traffic in Women. Bangkok: Foundation for Women, 1995.

Krannich, Caryl Rae and Ronald L. Krannich. "The Emerging Leadership Role of Women in Urban Thailand." International Journal of Women's Studies. 3.4 (1980): 358-372.

Kukrit Pramoj. Many Lives. 1954. Trans. Meredith Borthwick. Chiang Mai: Silkworm, 1995.

Laclau, Ernesto and Chantale Mouffe. Hegemony and Socialist Strategy. New York: Verso, 1985.

Laiad Pibulsonggram. "Thai Women." Aspects and Facets of Thailand. Ed. Witt Siwasariyanon. Bangkok: Public Relations Dept., 1958. 45-47.

Landon, Kenneth Perry. The Chinese in Thailand. 1941. New York: Russell and Russell, 1977.

Lapid, Yosef and Friedrich Kratochwil, Eds. The Return of Culture and Identity in IR Theory. Boulder: Lynne Riener, 1996.

League of Nations. Commission of Enquiry into Traffic in Women and Children in the Far East. "Siam: Internal Conditions Relating to Traffic." Report to the Council. 1933.

Lenze, Ise. "Tourism Prostitution in Asia." ISIS International Bulletin. 13 (1979): 6-8.

Leonowens, Anna. The Romance of the Harem. Charlottesville: University Press of Virginia, 1991.

Likhit Dhiravegin. Political Attitudes of the Bureaucratic Elite and Modernization in Thailand. Bangkok: Thai Watana Panich Co., 1973. 
Lim, Lin Lean, ed. The Sex Sector: The Economic and Social Bases of Prostitution in Southeast Asia. Geneva: International Labour Office, 1998.

Ling, L.H.M. "The Other Side of Globalization: Hypermasculine Developmentalism in East Asia." Paper presented at the International Studies Association Meeting. 18-22 March 1997, Toronto.

Lingat, Robert. Le statut de la femme au Siam. n.p. 1959.

London, Bruce. Metropolis and Nation in Thailand: The Political Economy of Uneven Development. Boulder: Westview Press, 1980.

Lomax, Louis E. Thailand: The War that is the War that will be. New York: Random House, 1967.

Lyttleton, Chris. "The Good People of Isan: Commercial Sex in Northeast Thailand." The Australian Journal of Anthropology 5.3 (1994): 257-279.

Lyttleton, Chris. "Knowledge and Meaning: The AIDS Education Campaign in Rural Northeast Thailand." Social Science and Medicine 38.1 (1994): 135-146.

McClintock, Ann. "Family feuds: gender, nationalism and the family." Feminist Review 44 (1993).

Malee Pluksponsawalee. "Women and the Law." Women in Development: Implications for Population Dynamics. Eds. Suchart Prasith-rathsint and Suwanlee Piampiti. Bangkok: National Institute of Development Administration, 1982.

Malek, Alloula. The Colonial Harem. Minneapolis: University of Minnesota Press, 1986.

Manderson, Lenore. "Public Sex Performances in Patpong and Exploration of the Edges of Imagination." Journal of Sex Research 29.4 (1992): 451-475.

-1.-. "The Pursuit of Pleasure and the Sale of Sex." Sexual Nature, Sexual Culture. Eds. Paul R. Abramson and Steven D. Pinkerton. Chicago: University of Chicago Press, 1995. 305-329.

---n. "Parables of Imperialism and Fantasies of the Exotic: Western Representations of Thailand - Place and Sex." Sites of Desire/Economies of Pleasure in Asia and the Pacific. Eds. Lenore Manderson and Margaret Jolly. Chicago: Chicago UP, 1997. 
Mattani Mojdara Rutnin. Modern Thai Literature: The Process of Modernization and the Transformation of Values. Bangkok: Thammasat UP, 1988.

Mattani Rutnin. "The Role of Thai Women in Dramatic Arts and Social Development, Problems Concerning Child Prostitution in Thailand: A Case Study Accompanied by a Video-tape on the Lives of Child Prostitutes." Customs and Tradition. The Role of Thai Women. International Conference on Thai Studies, Aug. 22-24, Bangkok, Thai Studies Program, Chulalongkorn University, 1984.

Merrick, Jeffrey. "Sexual Politics and Public Order in Late Eighteenth-Century France: the Memoires secretes and the Correspondance secrete." Forbidden History: The State. Society and the Regulation of Sexuality in Modern History. Ed. John C. Fout. Chicago: University of Chicago Press, 1992.

Meyer, Walter F. Beyond the Mask: Toward a Transdisciplinary Approach of Selected Social Problems Relation to the Evolution and Context of International Tourism in Thailand. PhD Dissertation. Geneva: University of Geneva, 1987.

Mills, Mary Beth. "Rural Women Working in Bangkok: The Rocky Road of Social Change." Final Report to the National Research Council of Thailand, n.d.

Ministry of Foreign Affairs. Statements by Chairmen of the Delegations of Thailand at the Second to Fourtieth Sessions of the UNGA (1947-1985). Bangkok: Ministry of Foreign Affairs, International Organizations Department, 1986.

Moffat, Abbot Low. Mongkut, The King of Siam. Ithaca: Cornell University Press, 1961.

Mohanty, Chandra. "Under Western Eyes: Feminist Scholarship and Colonial Discourses." In Third World Women and the Politics of Feminism. Eds. Chandra Mohanty, Ann Russo, Lourdes Torres. Bloomington: Indiana University Press, 1991.

Montgomery, Heather. "Pattaya and Child Prostitution as a Form of Cultural Crisis." Paper presented at the Sixth International Thai Studies Conference. Chiang Mai, 1996. CDROM.

Moon, Katherine H.S. "East meets West: Sex Industries in East Asia." Paper presented at the Annual Meeting of the International Studies Association, Toronto, March 18-22, 1997. 
-2.2. Sex Among Allies: Military Prostitution in U.S. - Korea Relations. New York: Columbia UP, 1997.

Morell, David and Chai-anan Samudavinjia. Political Conflict in Thailand: Reform, Reaction, Revolution. Cambridge, Mass: Oelgeschlager, Gunn and Hain, 1981.

Mosse, George. Nationalism and Sexuality. New York: Howard Ferrig, 1985.

Muecke, Majorie. "Mother Sells Food, Daughter Sells Her Body: The Cultural Continuity of Prostitution." Social Science and Medicine 35.7 (1992): 891-901.

Muntarbhorn, Vitit et. al. Status of Women: Thailand. Social and Human Sciences in Asia and the Pacific RUSHSAP Series on Monographs and Occasional Papers \#26. Bangkok: UNESCO Principal Regional Office for Asia and the Pacific, 1990.

Muscat, Robert J. Thailand and the United States: Development, Security and Foreign Aid. New York: Columbia UP, 1990.

Nader, Laura. "Orientalism, Occidentalism and the Control of Women." Cultural Dynamics 2.3 (1989): 324-355.

National Commission on Women's Affairs. Women's Development in Thailand. Bangkok: National Committee for International Cooperation, National Commission on Women's Affairs, 1985.

National Commission on Women's Affairs. Thailand's Combined Second and Third Report to the Committee for the Elimination of Discrimination against Women. Bangkok: Committee for Thailand's Second Report on the Implementation of the Convention on the Elimination of Discrimination against Women, NCWA, Office of the Prime Minister, 1996.

National Commission on Women's Affairs. Perspective Policies and Planning for the Development of Women (1992-2011) National Committee on the Perspective Plan and Policies for Women's Development, National Commission on Women's Affairs, Office of the Prime Minister, 1995.

National Commission on Women's Affairs. Thailand's Report on the Status of Women and Platform for Action 1994. For the Fourth World Conference on Women, Beijing, The People's Republic of China, 4-15 September, 1995. National Commission on Women's Affairs, Office of the Prime Minister, 1994. 
National Commission on Women's Affairs. National Policy and Plan of Action for the Prevention and Eradication of the Commercial Sexual Exploitation of Children. National Committee for the Eradication of Commercial Sex, National Commission on Women's Affairs, Office of the Prime Minister, 1996.

National Identity Board. Thai Life: Thai Women. Bangkok: National Identity Board, Prime Minister's Office, 1983.

Neale, F.A. Residence in Siam at the Capital of the Kingdom of Siam (1850). London: Office of the National Illustrated Library, 1852. Reprinted, Bangkok: White Lotus, n.d.

Neufeld, Mark. The Restructuring of International Relations Theory. Cambridge: Cambridge University Press, 1995.

O'Connell Davidson, Julia and Jacqueline Sanchez Taylor. Sex Tourism: Thailand. Bangkok: ECPAT, 1996.

Odzer, Cleo. "Patpong Prostitution: Its Relationship to, and Effect on, the Position of Women in Thai Society." Diss. New School for Social Research, 1990.

-.-Patpong Sisters: An American Woman's view of the Bangkok Sex-trade. New York: Blue Moon Books, 1994.

Oldenburg, Veena Talwar. "Lifestyle as Resistance: The Case of the Courtesans of Lucknow, India." Feminist Studies 16.2 (Summer 1990): 259-287.

Omvedt, Gail. Women in Popular Movements: India and Thailand during the Decade of Women. Geneva: UNRISD, 1986.

Ong, Aiwha. "Colonialism and Modernity: Feminist Re-presentations of Women in NonWestern Societies." Inscriptions 3/4 (1988): 79-83.

Spirits of Resistance and Capitalist Discipline: Factory Women in Malaysia. Albany: SUNY Press, 1987.

Ong, Aiwha and Michael Peletz. "Introduction." Bewitching Women, Pious Men: Gender and Body Politics in Southeast Asia. Eds. Aiwha Ong and Michael G. Peletz. Berkeley: University of California Press, 1995. 
Pasuk Phongpaichit. "The Thai Middle Class and the Military: Social Perspectives in the Aftermath of May 1992." The May 1992 Crisis in Thailand: Background and Aftermath. Selected Papers from the Thailand Update Conference. University of Sydney, 16 October 1992. Ed. Peter A. Jackson. Canberra: National Thai Studies Centre, Australia National University, 1993. 29-35.

- From Peasant Girls to Bangkok Masseuses. Geneva: International Labour Office, 1982.

."From Peasant Girls to Bangkok Masseuses." Tourism, Prostitution, Development. Ecumenical Coalition on Third World Tourism. Bangkok: ECTWT, 1983.

Pasuk Phongpaichit and Chris Baker. Thailand: Economy and Politics. New York: Oxford University Press, 1995.

Pawadee Tonguthai. "Women and Work in Thailand and the Philippines." Women's Economic Participation in Asia and the Pacific. Bangkok: United Nations Economic and Social Committee for Asia Pacific, 1987. 191 -219. ST/ESCAP/510.

Pettman, Jan Jindy. Worlding Women: A Feminist International Politics. New York: Routledge, 1996.

Pheterson, Gail. Ed. A Vindication of the Rights of Whores. Seattle: Seal Press, 1989.

Pringle, Rosemary and Sophie Watson. "Women's Interests' and the Post-Structuralist State." Destabilizing Theory: Contemporary Feminist Debates. Eds. Michele Barrett and Anne Phillips. Stanford: Stanford University Press, 1992. 53-73.

Prizzia, Ross. Thailand in Transition. Honolulu: University of Hawaii Press, 1985.

"Prostitution in Selected Countries of Asia and the Far East." International Review of Criminal Policy. 13 (Oct 1958): 44-55.

Purcell, Victor. The Chinese in Southeast Asia. 2nd edition. Kuala Lampur: Oxford University Press, 1965.

Rangson Prasertsri. Women in the Parliament of Thailand: Their Characteristics and Actitudes. PhD Diss. University of Mississippi, 1982. 
Reid, Anthony. "Introduction: Slavery and Bondage in Southeast Asian History." Slavery, Bondage and Dependency. Ed. Anthony Reid. St Lucia: University of Queensland Press, 1983.

-.-. Southeast Asia in the Age of Commerce: Volume I: The Land below the Winds. New Haven: Yale University Press, 1988.

Reid, Anthony. Southeast Asia in the Age of Commerce: Volume II: Expansion and Crisis. New Haven: Yale University Press, 1993.

Reynolds, Bruce. "American Missionaries in Nineteenth-Century Thailand." Thai-American Relations in Contemporary Affairs. Ed. Hans H. Indorf. Singapore: Executive Publications, 1982.

Reynolds, Craig. "A Nineteenth Century Thai Buddhist Defense of Polygamy and some Remarks on the Social History of Women in Thailand." A Paper Prepared for the Seventh Conference of the International Association of Historians of Asia, Bangkok, 22-26 August 1977.

-.-. "Introduction: National Identity and Its Defenders." National Identity and Its Defenders. Ed. Craig J. Reynolds. Chiang Mai: Silkworm Books, 1991.

- Thai Radical Discourse: The Real Face of Thai Feudalism Today. Ithaca: Cornell University Press, 1987.

Rhodes, Richard. "Death in the Candy Store." Rolling Stone. 28 Nov. 1991. 62-70, 105, 113 114.

Riley, Denise. "Am I That Name?" Feminism and the Category of "Woman" in History. Minneapolis: University of Minnesota, 1988.

Royal Thai Government. Thailand National Commission on Women's Affairs. Summary of Long Term Women's Development Plan (1982-2001). Prepared by the Task Force on Long term Women's Development Plan, with the Cooperation of USAID Thailand and the Department of Technical and Economic Cooperation, 1981.

Royal Thai Government. "Act for the Abatement of Prostitution, B.E. 2503 (1960)." Royal Thai Government Gazette. Vol.2, No. CCXII. November 28, 1960. 
Rueng Suksawat. "Behind the Thai NGOs." Thai NGOs: The Continuing Struggle for Democracy. Eds. Jaturong Boonyarathanasoontorn and Gawin Chutima. Bangkok: Thai NGO Support Project, 1995.

Said, Edward. Culture and Imperialism. New York: Alfred A. Knopf, 1993.

Saisuree Chutikul. "Children in Commercial Sex: Demand, the Overlooked Aspect Clients." Asia-Pacific Regional Consultation on Commercial Sexual Exploitation of Children. Bangkok, March 1996.

Saisuree Chutikul. Children in Especially Difficult Situations; I. Thailand Report to UNICEF. National Youth Bureau, Office of the Prime Minister. June 1986.

Scott, Joan W. "'Experience'." Feminists Theorize the Political. Eds. Judith Butler and Joan W. Scott. New York: Routledge, 1992.

"Sex Tourism to Thailand." ISIS International Bulletin 13 (1979): 9-12.

Sharpe, Joanne P. “A Feminist Engagement with National Identity.” Body Space. Ed. Nancy Duncan. New York: Routledge, 1996.

Siffin, William J. The Thai Bureaucracy: Institutional Change and Development. Honolulu: East-West Centre, 1965.

Sinn, Elizabeth. Chinese Patriarchalism and the Protection of Women in 19th Century Hong Kong. n.p. n.d.

Silcock, T.H. "Outline of Economic Development 1945 - 65." Thailand: Social and Economic Studies in Development. Queensland: Austraiia National University Press, 1967.

Siriporn Skrobanek. The Transnational Sex-Exploitation of Thai Women. Master's research paper. The Hague: Institute of Social Studies, 1983.

Spector, Ronald. "The American Image of Southeast Asia, 1790-1865." Journal of Southeast Asia Studies 3.2 (Sept. 1972): 299-305.

Srisurang Poolthupya. "The Changing Role of Thai Women." Seventh Conference of the International Association of Historians of Asia, Bangkok, August 1977. 
Steinstra, Deborah. "Madonna/Whore, Pimp/Protector: Prostitution and International Law and Organization." Studies in Political Economy 51 (Fall, 1996): 183-217.

Stivens, Maila. "Why Gender Matters in Southeast Asian Politics." Why Gender Matters in Southeast Asian Politics. Ed. Maila Stivens. Monash Papers on Southeast Asia, No. 23. Clayton, Victoria: Monash University, Centre for Southeast Asian Studies, 1991. 9-24.

Stowe, Judith. Siam becomes Thailand: A Story of Intrigue. London: Hurst \& Co., 1991.

Strobel, Margaret. Gender, Sex and Empire. Essays on Global and Comparative History. Washington DC: American Historical Association, 1993.

Suchit Bunbongkarn. Thailand: State of the Nation. Singapore: Institute of Southeast Asian Studies, 1996.

Sukanya Hantrakul. "Prostitutes and Human Rights in Thailand." n.p. 1982.

-2. "Prostitution in Thailand." Paper proposed to the Women in Asia Workshop. Monash University, Melbourne, July 22-24, 1983.

-.-... "Prostitution in Thailand." Development and Displacement: Women in Southeast Asia. Eds. Glen Chandler, Norma Sullivan and Jan Branson. Clayton, Australia: Centre of Southeast Asian Studies, Monash University, 1988.

-.- "The Spirit of a Fighter: Women and Prostitution in Thailand." Manushi. 18. OctNov. 1983.

Sukhumbhand Paribatra. "State and Society in Thailand: How Fragile the Democracy?" Asian Survev 33.9 (Sept. 1993): 879-893.

Sulak Sivaraksa. Siam in Crisis. Bangkok: Kamol Keemthong Foundation, 1980.

-2.-. "Buddhist Women: Past and Present." Siamese Resurgence. Bangkok: Asian Cultural Forum on Development, 1985.

Surin Maisrikrod. "Emerging Patterns of Political Leadership in Thailand." Contemporary Southeast Asia. 15.1 (June 1993): 80-97. 
Suteera Thomson. "Gender Issues in Thailand Development." A paper prepared for the United Nations Development Programme. Bangkok: Gender and Development Research Institute, July 1990.

Suthy Prasartset. "The Rise of NGOs As Critical Social Movement in Thailand." Thai NGOs: The Continuing Struggle for Democracy. Eds. Jaturong Boonyarattanasoontorn and Gawin Chutima. Bangkok: Thai NGO Support Project, 1995.

Suwadee T. Patana. "Thai Society's Expectations of Women 1904-1935: An Approach to Women's History." Paper Presented to 12th IAHA Conference, University of Hong Kong, 24-28 June 1991.

Swanson, Herbert R. “A New Generation: Missionary Education and Changes in Women's Roles in Traditional Northern Thai Society." Sojourn 3.1 (1988): 187-206.

Szanton Blanc, Christina. "The Thoroughly Modern 'Asian': Capital, Culture, and Nation in Thailand and the Philippines." Ungrounded Empires: The Cultural Politics of Modern Chinese Nationalism. Eds. Aihwa Ong and Donald Nonini. New York: Routledge, 1997.

Thailand National Commission on Women's Affairs. Aspects of Thai Women Today. Presented as a background document to World Conference of The United Nations Decade for Women, Copenhagen, 14-30 July 1980 by the Delegation of Thailand. Bangkok, Thailand National Commission on Women's Affairs, 1980.

Thak Chaloemtiarana. Thailand and the Politics of Despotic Paternalism. Social Science Association of Thailand. Thai Khadi Institute. Bangkok: Thammasat University, 1979.

Thamsook Numnonda. "Pibulsongkram's Thai Nation-Building Programme during the Japanese Military Presence, 1941-1945." Journal of Southeast Asian Studies 9.2 (Sept. 1978): 234-247.

Thitsa, Khin. Providence and Prostitution: Image and Reality for Women in Buddhist Thailand. London: Change International, 1980.

Thongbai Thongpao. "The State of Human Rights in Thailand in 1985." Thai Development Newsletter 3.4 (1986): 10-14. 
Thongchai Winichakul. Siam Mapped: A History of the Geo-body of a Nation. Chiang Mai: Silkworm Books, 1994.

_-_._. "The account of an eyewitness." The Nation 5 October 1996, A4.

…... "Struggle against forgetting." The Nation 6 October 1996, A5.

Toyota, Mika. "The Effects of Tourism Development on an Akha Community: A Chiang Rai Village Case Study." Uneven Development in Thailand. Ed. Michael J. Parnwell. Brookfield: Avebury, 1996.

Trumbach, Randolph. "Sex, Gender, and Sexual Identity in Modern Culture: Male Sodomy and Female Prostitution in Enlightenment London." Forbidden History: The State, Society and the Regulation of Sexuality in Modern History. Ed. John C. Fout. Chicago: University of Chicago Press, 1992.

Truong, Thahn-dam. Sex, Money and Morality: Prostitution and Tourism in Southeast Asia. London: Zed, 1990.

Tsing, Anna Lowenhaupt. "Alien Romance." Fantasizing the Feminine in Indonesia. Ed. Laurie J. Sears. Durham, NC: Duke University Press, 1996.

UNESCO. "Thailand." Identification of Issues Concerning Women and Their Consideration in Development Planning. Bangkok: UNESCO, 1987.

United Nations. "Prostitution in selected countries of Asia and the Far East." International Review of Criminal Policy 13 (1958): 44-55.

United Nations. Convention for the Suppression of the Traffic in Persons and of the Exploitation of the Prostitution of Others. 1950.

United Nations. Department of Economic and Social Affairs. Study on Traffic in Persons and Prostitution (Suppression of the Traffic in Persons and of the Exploitation of the Prostitution of Others. New York: United Nations, 1959. ST/SOA/SD/8.

United Nations Development Programme. The UN in Thailand. Bangkok: UNDP, 1986.

Vandergeest, Peter. "Constructing Thailand: Regulation, Everyday Resistance, and Citizenship." Society for Comparative Study of Society and History (1993): 133158. 
Van Esterik, Penny. "Gender and Development in Thailand: Deconstructing Development." Women, Feminism and Development. Eds. H. Dagenais and D. Piché. Montreal: McGill - Queen's University Press, 1994.

-2.- "Thai Prostitution and the Medical Gaze." Gender and Development in Southeast Asia. Eds. Penny and John Van Esterik. CCSEAS XX Vol. II. Montreal: Canadian Asian Studies Association, 1991.

-1... Women of Southeast Asia. Monograph Series on Southeast Asia. Occasional Paper \#9. DeKalb, Ill.: Northern Illinois University Center for Southeast Asian Studies, 1982.

Van Landingham, Mark, et. al. Friends, Wives and Extramarital Sex in Thailand: A Qualitative Study of Peer and Spousal Influence on Thai Male Extramarital Sexual Behavior and Attitudes. Bangkok: Institute for Population Studies, Chulalongkorn University, 1995.

Van Praagh, David. Thailand's Struggle for Democracy: The Life and Times of M.R. Seni Pramoj. New York: Holmes and Meier, 1996.

Vella, Walter F. Chaiyo! King Vijiravudh and the Development of Thai Nationalism. Honolulu: University of Hawaii Press, 1978.

- The Impact of the West on Government in Thailand. Berkeley: University of California Press, 1955.

Vibul Thamavit and Robert D. Golden. "The Family in Thailand." Aspects and Facets of Thailand. Ed. Witt Siwasariyanon. Bangkok: Public Relations Department, 1958.

Vipa Chulachart. "Introduction." Aspects of Thai Women Today. Presented as a background document to World Conference of The United Nations Decade for Women, Copenhagen, 14-30 July 1980 by the Delegation of Thailand. Bangkok: Thailand National Commission on Women's Affairs, 1980.

Vitit Muntarbhorn, Wimolsirir Jamnarnvej, Tanawadee Boonlue. Status of Women: Thailand. Social and Human Sciences in Asia and the Pacific RUSHAP Series on Monographs and Occasional Papers 26. Bangkok: UNESCO Principal Regional Office for Asia and the Pacific, 1990. 
Walker, Dave and Richard S. Ehrlich. "Hello My Big Big Honey": Love Letters to Bangkok Bar Girls and Their Revealing Interviews. Bangkok: Dragon Dance Publications, 1992.

Walker, R.B.J. "Sovereign Identities and the Politics of Forgetting." Inside/Outside: International Relations as Political Theory. New York: Cambridge University Press, 1993. 159-183.

- . "The Concept of Culture in the Theory of International Relations." Culture and International Relations. Ed. Jongsuk Chay. New York: Praeger, 1990.

Walkowitz, Judith. Prostitution and Victorian Society: Women, Class and the State. New York: Cambridge University Press, 1980.

Wathinee Boonchalaksi and Philip Guest. Prostitution in Thailand. IPSR Publication No. 171. Bangkok: Institute for Population and Social Research, Mahidol University, 1994.

Wawer, Maria J., Chai Podhisita, Uraiwan Kanungsukkasem, Anthony Pramulratana and Regina McNamara. "Origins and Working Conditions of Female Sex Workers in Urban Thailand: Consequences of Social Context for HIV Transmission." Social Science and Medicine 42.3 (1996): 453-463.

Weatherbee, Donald E. The United Front in Thailand: A Documentary Analysis. Studies in International Affairs \#8. Columbia: Institute of International Studies, University of South Carolina, 1970.

Weber, Cynthia. Faking It: US Hegemony in a Post-phallic Era. Minnesota: University of Minnesota Press, 1999.

Wilson, David A. Politics in Thailand. Ithaca: Comell University Press, 1966.

Winkler, Mary Packard. "Construction of Knowledge and Discourse in Middle Class Marriage: Implications for Coping with Sexual Risk Among Urban Thai." Paper Presented at the 6 th International Conference on Thai Studies, Chiang Mai, Thailand. October, 1996.

Women Lawyers' Association of Thailand. Status of Women in Thailand. Bangkok: Women Lawyers' Association, 1972. 
Young, Ken. "Political Science and Southeast Asia: The Neglect of Gender." Why Gender Matters in Southeast Asian Politics. Ed. Maila Stivens. Monash Papers on Southeast Asia, No. 23. Clayton, Victoria: Monash University, Centre for Southeast Asian Studies, 1991.

Yuangrat Wedel. "Current Thai Radical Ideology: The Returnees from the Jungle." Contemporary Southeast Asia 4.1 (June 1982):1-18.

Yuangrat Wedel with Paul Wedel. Radical Thought: Thai Mind: The Development of Revolutionary Ideas in Thailand. Bangkok: Assumption Business College Administration, 1987.

Yuval-Davis, Nira and Floya Anthias. Eds. Woman-Nation-State. New York: St. Martin's Press, 1989.

Yuval-Davis, Nira. Gender and Nation. London: Sage, 1997.

\section{Newspapers}

The Bangkok Post.

The Nation (Thailand).

The Globe and Mail.

Week in Review. On-line. (Bangkok Post)

\section{Newsletters}

Thai Development Newsletter. 1983-1997. Thai Development Support Committee. Bangkok.

Thailand Monitor. 1996-1999. International Understanding Program, Institute of Asian Studies, Chulalongkom University. Bangkok. 